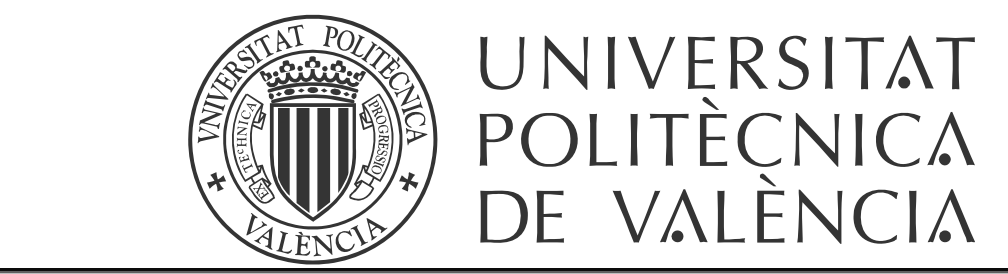

Departamento de Economía y Ciencias Sociales

\title{
MÉTODO DE VALORACIÓN DE VIVIENDAS DESDE LA PERSPECTIVA MEDIOAMBIENTAL Y ANÁLISIS DE COSTES
}

\section{Tesis Doctoral}

Presentada por:

María José Ruá Aguilar

Directores:

Dr. Dña. Natividad Guadalajara Olmeda

Dr. Dña. Belinda López Mesa

Valencia, Abril de 2011 



\section{RESUMEN}

El sector de la construcción tiene una gran importancia en el desarrollo sostenible, y la adaptación en España de recientes directivas de la Unión Europea en materia energética, obliga a definir la calificación energética de los edificios, lo cual será un factor importante en la determinación de su valor.

A este respecto, la presente Tesis Doctoral analiza la normativa y el software oficial que existe para obtener dicha calificación, en viviendas de nueva construcción y en cada zona climática de España.

Partiendo de un proyecto real de viviendas adosadas, se realiza un análisis de los materiales e instalaciones requeridos para cumplir las normativas, así como de los costes de construcción, mantenimiento y consumo energético, y la emisión de $\mathrm{CO}_{2}$, teniendo en cuenta las calificaciones energéticas y las zonas climáticas.

Viviendas más sostenibles exigen mayores costes de construcción, que deberían ser compensados con unos menores costes privados de uso. Pero en la práctica esto no ocurre y es necesario definir unos precios del $\mathrm{CO}_{2}$, o tasas medioambientales, para estimar los costes sociales que hagan rentable la elección de viviendas más eficientes energéticamente. La metodología empleada para definir estos precios son el análisis de costes y análisis de inversiones, que integran los costes económicos o privados y los costes sociales o públicos derivados de las emisiones de $\mathrm{CO}_{2}$ durante el uso de la vivienda.

Finalmente, se realiza un análisis multicriterio para obtener la composición de viviendas con distintas calificaciones en una promoción inmobiliaria, considerando los objetivos privados y públicos. 



\section{RESUM}

El sector de la construcció té una gran importància per al desenvolupament sostenible, i l'adaptació a Espanya de recents directives de la Unió Europea en matèria energètica, obliga a definir la qualificació energètica dels edificis, la qual cosa serà un factor important en la determinació del seu valor.

En aquest marc, aquesta Tesi Doctoral analitza la normativa y el software oficial que existeix per a obtenir la nomenada qualificació, en vivenda de nova construcció i en cada zona climàtica a Espanya.

Partint d'un projecte real de vivendes adossades, es realitza un anàlisi dels materials $\mathrm{i}$ instal-lacions requerits per a complir les normatives, així com dels costos de construcció, manteniment i consum energètic, i emissions de $\mathrm{CO}_{2}$, tenint en consideració les qualificacions energètiques i les zones climàtiques.

Habitatges més sostenibles requereixen majors costos de construcció, que deurien ser compensats per uns menors costos privats d'ús. Però en la pràctica això no ocorre-hi i és fa necessari definir uns preus del $\mathrm{CO}_{2}$, o taxes mig ambientals, per a estimar els costos socials que facin rentable l'elecció de habitatges més eficients energèticament. La metodologia emprada per a definir aquests preus són el anàlisi de costos i anàlisi d'inversions, que integren els costos econòmics o privats $\mathrm{i}$ els costos socials o públics derivats de les emissions de $\mathrm{CO}_{2}$ durant l'ús de l'habitatge.

Finalment, es realitza un anàlisi multi criteri per a obtenir la composició de habitatges amb distintes qualificacions en una promoció immobiliària, considerant els objectius privats i públics. 



\section{ABSTRACT}

The building industry has a major influence on sustainable development, and the application of recent European directives regarding energy policies in Spain makes energy performance certification compulsory in new residential buildings. This aspect will be considered in the evaluation of buildings.

This Doctoral Thesis examines regulations and the official software for achieving the required energy performance for newly-built dwellings in every climatic zone in Spain.

A number of aspects are analysed using information from a real property development of terraced houses. First of all, the building solutions required and facilities fulfilling the regulations are selected. Certain costs are calculated taking into account energy performance and climatic zones: the cost of the construction process, facility management, and energy consumption cost during the building's lifespan. Carbon emissions are also determined.

More sustainable dwellings require higher investment cost which should be offset by lower private costs in the use of the building. However, this does not happen. It is therefore necessary to define an environmental price or tax for $\mathrm{CO}_{2}$ in order to attach a value to the social costs which make the selection of more energy-efficient houses profitable. The methodologies implemented are analysis cost and investment cost, including private or economic cost, and social or public cost.

Finally, a multi-criteria analysis is applied in order to achieve a series of dwellings with different energy performance within a property development, taking into account both private and public cost. 



\section{AGRADECIMIENTOS}

Quiero expresar mi agradecimiento a todas aquellas personas que me han ayudado durante la realización de esta Tesis Doctoral.

En primer lugar a mis directoras de Tesis, Natividad Guadalajara y Belinda López, por su dedicación, apoyo e interés en la consecución de este trabajo, así como por sus consejos y orientación hacia la actividad investigadora.

En segundo lugar, a todos mis compañeros del Área de Construcciones Arquitectónicas de la Universidad Jaume I de Castellón, por su ayuda desinteresada en todos aquellos momentos en que la he requerido. Especial mención a José Babiloni, por su apoyo y sus valiosos consejos profesionales y a Lucía Reig por sus directrices en mi actividad investigadora.

A mis amigos por su comprensión y paciencia cuando la realización de la Tesis ha requerido todo mi tiempo. Especialmente a Juan José Pérez por sus consejos y comprensión. A Cristina, Nuria, Vicky, Sonia y Ana por estar ahí.

A mis familiares, especialmente a mis padres y hermanos por la confianza que siempre han demostrado tener en mí, y a Irún, por su afecto.

Por último, a todas aquellas personas que me han dedicado palabras sinceras de ánimo y apoyo en los momentos más duros durante la realización de esta Tesis. 



\section{ÍNDICE GENERAL}

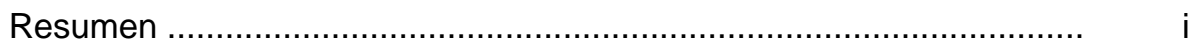

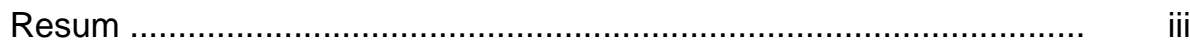

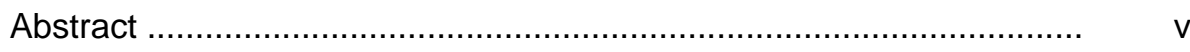

Agradecimientos ............................................................................ vii

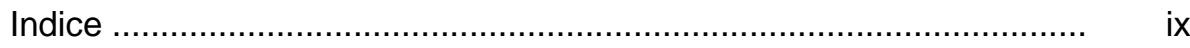

Nomenclatura .............................................................................

Capítulo l.- Introducción .................................................................... 1

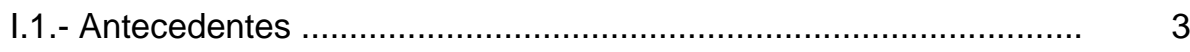

I.2.- Justificación ...................................................................................

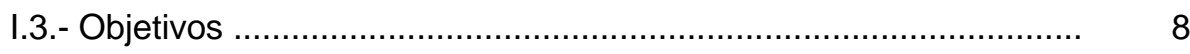

I.3.1.- Objetivo general ............................................................... 8

I.3.2.- Objetivos particulares .............................................................. 8

I.4.- Aportaciones de la tesis ................................................................. 9

I.5.- Limitaciones ........................................................................ 10

I.6.- Material utilizado ...................................................................... 11

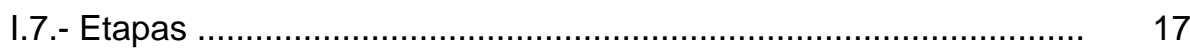

I.8.- Estructura de la tesis ............................................................... 21

Capítulo II.- Nuevo factor en la valoración de edificios: Eficiencia Energética

II.1.- Evolución de la normativa de Eficiencia Energética referida a edificios en la Unión Europea

II.2.- Evolución de la normativa de edificación en España

II.3.- Nueva variable en el valor de los inmuebles: La Eficiencia

Energética

Capítulo III.- Estudio de la Eficiencia Energética del edificio 43

III.1.- Adaptación del proyecto al Código Técnico de la Edificación ...... 45

III.1.1.- Introducción ................................................................... 45 
III.1.2.- Cálculo del cumplimiento de los mínimos de la envolvente térmica. Programa Lider

III.1.3.- Aplicación al caso de estudio .................................................... 47

III.1.3.1.- Definición geométrica del edificio ................................. 47

III.1.3.2.- Definición constructiva del edificio ............................. 48

III.2.- Calificación energética del edificio ............................................ 55

III.2.1.- Cálculo de la demanda de energía del edificio .......................... 55

III.2.2.- Calificación energética mediante Calener VYP ......................... $\quad 57$

III.3.- Parámetros que influyen en la eficiencia energética ..................... 64

III.3.1.- Estudio de los parámetros aislados .......................................... 64

III. 3.1.1.- Variación en las instalaciones ..................................... 65

III. 3.1.2.- Variación en la orientación del edificio ....................... 67

III. 3.1.3.- Variación en la envolvente ........................................ 68

III. 3.1.4.- Variación en los voladizos ........................................ 71

III. 3.1.5.- Variación en los huecos ............................................. $\quad 71$

III. 3.1.6.- Resultado de parámetros aislados ............................ $\quad 72$

III.4.- Estudio de la combinación de parámetros ......................... 78

III.4.1.- Procedimiento para la combinación de parámetros .................. 78

III.4.2.- Simulación de la peor combinación ......................................... $\quad 79$

III.4.3.- Combinaciones para mejorar la calificación ............................... 83

III.5.- Resultados de todas las configuraciones en Lider y Calener ...... 89

Capítulo IV.- Estimación del valor de las viviendas y análisis de costes

IV.1.- Métodos de valoración en viviendas ......................................... 95

IV.1.1.- Elección del método .............................................................. 95

IV.1.2.- Método del coste ................................................................ $\quad 99$

IV.2.- Coste de la inversión ................................................................ 104

IV.2.1.- Presupuesto de Contrata .......................................................... 104

IV.2.2.- Estructura del presupuesto ............................................. 105

IV.2.2.1.- Estado no 1. Mediciones .......................................... 105 
IV.2.2.2.- Estado $n^{0}$ 2. Precios ...................................... 106

IV.2.2.3.- Estado no 3. Aplicación de precios .......................... 107

IV.2.3.- Aplicación al caso de estudio ...................................... 107

IV.2.3.1.- Medición ...................................................... 107

IV.2.3.2.- Precios ...................................................... 110

IV.2.3.3.- Resultados .............................................. 113

IV.3.- Coste del uso de la vivienda ....................................... 121

IV.3.1.-Tipos de costes ................................................ 121

IV.3.2.- Vida útil y costes de amortización ................................ 123

IV.3.3.- Coste de la energía ................................................... 127

IV.3.3.1.- Coste de la electricidad ................................ 130

IV.3.3.2.- Coste del gas natural ..................................... 131

IV.3.3.3.- Coste de la biomasa ..................................... 131

IV.3.4.- Coste de mantenimiento .......................................... 134

IV.3.4.1.- Antecedentes ........................................... 134

IV.3.4.2.- Aplicación al caso de estudio .............................. 137

IV.3.5.- Coste Social del Carbono ............................................... 142

IV.3.5.1.- Antecedentes ............................................... 146

IV.3.5.2.- Valoración del Coste Social del Carbono .................. 154

IV.3.5.3.- Conclusiones revisión bibliográfica SCC ................ 158

IV.3.5.4.- Valores adoptados coste medioambiental................ 164

IV.4.- Costes totales .......................................................... 166

Capítulo V.- Modelos de costes y precio umbral del $\mathbf{C O}_{2} \ldots \ldots \ldots \ldots \ldots . . . . .171$

V.1.- Modelos de costes ...................................................... 173

V.1.1.- Selección de variables ................................................ 174

V.1.2.- Definición de las variables explicativas ............................. 174

V.1.3.- Análisis de la normalidad de las variables cuantitativas ........... 176

V.1.4.- Matriz de correlaciones ........................................ 177

V.1.5.- Resultados .......................................................... 179

V.1.6.- Análisis del modelo ..................................................... 182 
V.2.- Análisis de costes. Cálculo del precio umbral del $\mathrm{CO}_{2}$

V.3.- Análisis de inversiones

V.4.- Comparación entre el análisis de costes y el análisis de inversiones. Conclusiones sobre el precio umbral del $\mathrm{CO}_{2}$

Capítulo VI.- Análisis Multicriterio 197

VI.1.- Programación multiobjetivo

VI.1.1.- Generalidades 199

VI.2.- Programación compromiso 205

VI.2.1.- Generalidades 205

VI.2.2.- Determinación de los precios como pesos sombra 210

VI.2.3.- Determinación de la solución compromiso ............................ 213

VI.3.- Aplicación

Capítulo VII.- Conclusiones y discusión

VII.1.- Conclusiones y discusión

VII.1.1.- Análisis de las medidas de mejora de la EE y su costoeficiencia

VII.1.2.- Análisis de las herramientas de certificación energética en España 234

VII.1.3.- Análisis de costes en relación a la calificación energética 237

VII.1.4.- Aplicación de técnicas multicriterio a edificación 240

VII.2.- Aportaciones 241

VII.3.- Líneas de investigación futuras

Anexos

Anexo 1.- Materiales y equipos 273

Anexo 2.- Presupuesto de Mantenimiento ................................... 279

Anexo 3.- Gráficas de los modelos de regresión ................................. 293 


\section{NOMENCLATURA}

6-12-8: vidrio de doble luna de 6 y $8 \mathrm{~cm}$, con cámara intermedia aislante $12 \mathrm{~cm}$

44-12-44: vidrio laminar doble de 4+4 cm, con cámara intermedia aislante $12 \mathrm{~cm}$

90US\$: dólares de 1990

ACS: agua caliente sanitaria

ANDIMA: Asociación Nacional de Industriales de Materiales Aislantes

ASPRIMA: patronal de constructores madrileños

BAU: Estructura económica actual (Bussiness As Usual)

BI: Beneficio Industrial

CBA: Cost-Benefit Analysis

C: carbono

$\mathrm{CFCl}_{3}:$ Clorofluorocarbonos

$\mathrm{CH}_{4}$ : metano

$\mathrm{CO}_{2}$ : dióxido de carbono

$\mathrm{CO}_{2}$ eq: dióxido de carbono equivalente

CRB: Coste de Reemplazamiento Bruto

CRN: Coste de Reemplazamiento Neto

Cv: caravista

DB: Documento Básico

DICE: Dynamic Integrated Climate Economy

EE: eficiencia energética

EMF: Energy Modelling Forum 
EPA: Environmental Protection Agency

ETS: European Trade Scheme

FR: forjado reticular

Frsi: Factor de temperatura superficial interior

FU: forjado unidireccional

FUND: Climate Framework for Uncertainty, Negotiation and Distribution

Fv: fachada ventilada

GDP: Gross Domestic Product

GEI (GHG) Gases efecto invernadero (greenhouse gases)

GG: Gastos Generales

HA: hormigón armado

HM: hormigón en masa

Hz: horizontal

IAM: Integrated Assessment Method

IDAE Instituto para la Diversificación y Ahorro Energético

IPCC: Intergovernamental Panel of Climate Change

IETCC: Instituto Eduardo Torroja de Ciencias de la Construcción

ITEC: Instituto Tecnológico de la Edificación de Cataluña

IVE: Instituto Valenciano de la Edificación

Lhd: ladrillo hueco doble

Lhs: ladrillo hueco sencillo

Lm: ladrillo macizo

LM: lana mineral 
LOE: Ley de Ordenación de la Edificación

LP: ladrillo panal

$\mathrm{m}^{2}$ : metro cuadrado construido

$\mathrm{m}_{\mathrm{u}}^{2}$ : metro cuadrado útil

mc: mortero de cemento

MC: Marginal Cost

MV: Ministerio de Vivienda

NBE: Normas Básicas de la Edificación

NTE: Normas Tecnológicas de la Edificación

NO: Óxidos de Nitrógeno

$\mathrm{O}_{3}$ : Ozono

OMM: Organización Mundial Meteorología

P1: Panta Primera

PAGE: Policy Analysis of the Greenhouse Effect

PB: Planta Baja

PEC: Presupuesto de Ejecución de Contrata

PEM: Presupuesto de Ejecución Material

PMB (GWP): Producto Mundial Bruto (Gross World Product)

PNA: Plan Nacional de Asignacion de Derechos de Emision (NAP National Allocation Plan)

PNGRDC: Plan Nacional de Gestión de Residuos de Demolición y Construcción

PRTP: Pure rate of time preference

PS: Planta Sótano 
PT: Puente térmico

PUR: poliuretano

qvt: caudal de aire en el tramo del conducto $\left(\mathrm{cm}^{3} / \mathrm{cm}\right)$

RCD: Resíduo de la Construcción y Demolición

RPT: Rotura de Puente Térmico

SCC: Coste Social del Carbono (Social Cost of Carbon)

SOx: óxidos de sulfuro

SRES: Special Report Emission Scenarios

SRTP: Social rate of time preference

$\mathrm{U}:$ transmitancia térmica $\left(\mathrm{W} / \mathrm{m}^{2} \mathrm{~K}\right)$

UN: United Nations

Vt: vertical

Xps: Poliestireno extruido

$\lambda$ : conductancia térmica $(\mathrm{W} / \mathrm{mK})$ 


\section{CAPÍTULO I INTRODUCCIÓN}





\section{I.1.- ANTECEDENTES}

En la valoración de edificios existe multitud de parámetros a considerar que influyen en el valor. Tradicionalmente, la superficie del inmueble, la localización, características y calidades constructivas y la antigüedad del mismo, han sido decisivos en la adopción del valor.

Dentro de las características y calidades constructivas, y dado el reciente desarrollo de la normativa en el sector de la construcción, en esta Tesis se va a estudiar con detalle el parámetro "eficiencia energética" (en adelante $\mathrm{EE})$. Intuitivamente, el hecho de que una vivienda más eficiente adquiera cualitativamente una mayor valoración parece lógico, pero resulta difícil de cuantificar. Las valoraciones de edificios realizadas hasta la fecha no han tenido en cuenta este parámetro de una manera explícita, si bien podía estar contenido dentro de otros como "calidad de acabados", "instalaciones", etc.

Por otro lado, hasta hace poco tiempo, la EE no ha sido considerada por los agentes de la construcción o los usuarios de los edificios como factor de calidad, y pese a que, en la mayor parte de los casos, todavía no es prioritario en la construcción de promociones, se prevé un mayor peso de este factor en el valor de los inmuebles en un futuro próximo. Las nuevas circunstancias, con la creación de una escala de valoración de este parámetro por parte de las administraciones públicas, hacen prever la influencia de este factor en el valor de los inmuebles [Popescu et al., 2009].

Las nuevas regulaciones españolas en el sector de edificios, tienen como una de sus consecuencias, la posibilidad de calificar los edificios en función de su eficiencia en el uso de la energía. Así se establece una escala de valor según la cual, el edificio "mejor" desde el punto de vista energético adquirirá una calificación $A$ y el "peor" una calificación $E$, cuando se refiere a nuevas construcciones. La normativa para certificación energética en 


\section{CAPÍTULO I.- INTRODUCCIÓN}

viviendas existentes está todavía en fase de desarrollo. La asignación de esta letra está relacionada con la cantidad de $\mathrm{CO}_{2}$ que dicho edificio va a emitir durante su uso [R.D. 47/2007, de 19 de enero, por el que se aprueba el Procedimiento básico para la certificación de eficiencia energética de edificios de nueva construcción].

Prueba de la importancia que va a tener este aspecto en la valoración, son las subvenciones que ya existen, en el ámbito de la vivienda protegida, para viviendas de mejor clase energética, $A, B$ y $C$, tanto en planes de vivienda estatales como autonómicas. En el caso de las estatales, y en virtud del Plan de vivienda 2009-2012, se establece, respectivamente, para las calificaciones mencionadas en viviendas de nueva construcción: 3.500, 2.800 y $2.000 €$. Dependiendo de la CCAA, la ayuda autonómica varía. Así por ejemplo, son de 1.500, 1.000, $700 €$ respectivamente en Extremadura, de $3.500,2.800$ y $2.000 €$ en Canarias, de 40,30 y $20 € / \mathrm{m}^{2}$ útil en Navarra.

El origen de estas medidas está relacionado con el compromiso de la disminución de las emisiones de $\mathrm{CO}_{2}$ por parte de los países firmantes del Protocolo de Kioto de 1997. Aunque distintos sectores son responsables de las emisiones, industria, transporte y edificación fundamentalmente, todos ellos trabajan en su reducción. En lo que se refiere a edificación, los gobiernos de los países, en el caso de países desarrollados como son los pertenecientes a la Unión Europea, combinan distintas estrategias para tratar de reducir sus emisiones, al ser conscientes de que será un sector clave para lograr la reducción de las mismas. Distintas fuentes hablan de alrededor de un tercio de las emisiones de $\mathrm{CO}_{2}$ consecuencia de los edificios en Europa [Balaras et al, 2005; Pérez-Lombarda et al., 2008; Hamdy, M. et al, 2011]. La reducción de estas emisiones requiere la aplicación de políticas, entre las que se encuentran los mecanismos de regulación y control como son los códigos de la edificación [Ürge-Vorsatz et al., 2007]. 
En Europa este objetivo se materializa en la Directiva 2002/91/EC, actualizada recientemente, en la Directiva 2010/31/UE relativa a la eficiencia energética de los edificios, junto con la Concerted Action Energy Performance of Buildings (EPBD) que involucra a los Ministerios e instituciones encargadas de preparar los aspectos técnicos, legales y administrativos en cada uno de los Estados Miembros para el cumplimiento de las mencionadas directivas.

Uno de los objetivos es la modificación de las normativas de edificación, con el fin de construir edificios más eficientes energéticamente.

La presente Tesis se desarrolla sobre la base de las acciones que se han llevado a cabo en España, como país miembro de la UE. La transposición de las directivas europeas mencionadas se materializa con la puesta en marcha del Código Técnico de la Edificación, en adelante CTE, [RD 314/2006, de 19 de octubre], principalmente en sus documentos de Ahorro de Energía y de salubridad (CTE-HE y CTE-HS, respectivamente), así como del Reglamento de Instalaciones Térmicas de los edificios (RITE) [R.D. 1027/2007, de 20 de julio]. Por último, el R.D. 47/2007, de 19 de enero, por el que se aprueba el Procedimiento básico para la certificación de eficiencia energética de edificios de nueva construcción, permite asignar a los edificios una determinada clase energética en función de su EE.

Los cambios en la normativa van a tener consecuencias a nivel de la valoración de los edificios y, previsiblemente el factor EE tendrá influencia en el valor de los inmuebles. Es necesario, por tanto, conocer y cuantificar los costes y los ahorros derivados de la aplicación de diseños, materiales, sistemas y procesos constructivos que, a priori, son más adecuados desde un punto de vista medioambiental. No sólo se debe tener en cuenta el coste de la inversión en la construcción de los edificios, sino también los costes incurridos durante el uso del inmueble (sobre todo de ahorro de energía) y 


\section{CAPÍTULO I.- INTRODUCCIÓN}

mantenimiento del edificio durante su vida útil. Por otro lado, la mayor eficiencia supondrá una reducción de las emisiones de $\mathrm{CO}_{2}$.

Los requerimientos energéticos de los edificios varían según su uso, sea residencial, comercial, industrial, etc. Este trabajo se centra exclusivamente en los usos residenciales. Dentro de las tipologías residenciales los requerimientos también difieren, según se trate de viviendas en edificios plurifamiliares o unifamiliares, y en este último caso según sean viviendas aisladas, adosadas, pareadas, etc. [IDAE, 2009]. En esta Tesis se trata el caso concreto de uso residencial, viviendas unifamiliares adosadas, por tener acceso a documentación de estas tipologías constructivas. Concretamente se trabaja sobre una promoción real de viviendas de nueva construcción, proporcionada por Iberdrola Inmobiliaria S.A.U.

Como se ha comentado anteriormente, en España, las viviendas de nueva construcción adquieren una calificación energética $A, B, C, D \circ E$, desde las más a las menos eficientes, respectivamente, desde el punto de vista energético. Además los requerimientos varían según la zona climática que se considere dentro de la geografía española. EI CTE establece 12 posibles [CTE-HE, apéndice D]. El proyecto de partida se adaptará a cada uno de los casos posibles, resultando 60 combinaciones (5 calificaciones x 12 zonas climáticas), para realizar un estudio de costes en cada una de las situaciones.

En definitiva, la presente Tesis combina el estudio de la eficiencia energética de los edificios desde dos vertientes, por un lado el punto de vista arquitectónico-constructivo y por otro, el económico. Desde la perspectiva arquitectónica se analiza un proyecto real, con soluciones constructivas y de instalaciones aplicables a la realidad y en un determinado marco normativo de reciente desarrollo en España, para alcanzar una determinada calificación energética. Posteriormente se abordará el análisis 6 
de las soluciones arquitectónicas contempladas con sus costes económicos, incluyendo la inversión inicial, mantenimiento y el consumo de energía durante la vida útil del edificio y, por último, el coste social derivado de las emisiones de gases efecto invernadero durante el uso de la vivienda.

\section{I.2. JUSTIFICACIÓN.}

La eficiencia energética de los inmuebles, no es un factor que se haya considerado hasta la fecha en la valoración de inmuebles y, efectivamente, no es tenido en cuenta explícitamente en las normativas de valoración vigentes. Sin embargo, las nuevas circunstancias, en las que surge una escala de valoración de este parámetro [RD 47/2007], hacen prever la influencia que va a tener este factor en el valor de los inmuebles [Popescu et al., 2009].

En el momento actual es posible conocer cuánto influye la eficiencia energética en el precio de las viviendas, puesto que las nuevas viviendas pueden ya ostentar una determinada calificación según su eficiencia, atendiendo a recientes normas aplicables al sector de la construcción. Sin embargo, debido a la reciente entrada en vigor de la normativa, y por otro lado, a la crisis económica, no ha tenido lugar el desarrollo y venta de nuevas promociones como se daría en un momento más estable del mercado inmobiliario. Por tanto, aunque a las nuevas viviendas ya es posible asignarles una determinada calificación energética, no existe todavía un mercado suficientemente representativo que permita estimar el valor de mercado de los inmuebles por comparación, en función de su eficiencia energética.

Al no poder utilizar valores de mercado, en este trabajo se relaciona la eficiencia energética de los edificios con su coste. Se trata, por tanto, de un punto de partida para analizar cómo afecta un factor que previsiblemente 
tendrá cada vez una mayor importancia en la oferta y demanda de viviendas, a falta de que el mercado se desarrolle en este sentido.

\section{I.3. OBJETIVOS}

\section{I.3.1. OBJETIVO GENERAL}

Determinar los factores que influyen en los costes de viviendas con diferentes calificaciones energéticas, según las posibles combinaciones que se pueden encontrar en España.

\section{I.3.2. OBJETIVOS PARTICULARES}

A continuación se enumeran los objetivos particulares:

1. Analizar la metodología de certificación energética oficialmente reconocida en España en la actualidad, utilizando un proyecto de una promoción de viviendas adosadas adaptado al CTE.

2. Estudiar medidas constructivas e instalaciones que puedan influir en la EE del edificio. Se considerará la cuantía de la reducción de emisiones de $\mathrm{CO}_{2}$, así como el coste económico de cada medida implementada para obtener un ratio de costo-eficiencia de las mismas.

3. Obtener combinaciones de medidas que permitan alcanzar todas las calificaciones energéticas, al menor coste posible.

4. Elaborar los costes de construcción o inversión de las viviendas, según zonas climáticas y calificaciones energéticas. También se calculan los costes de amortización, mantenimiento y consumo de energía durante la vida útil del edificio.

5. Obtener modelos de costes a partir de los datos obtenidos, que permitan prever el valor de un inmueble a partir de su calificación energética y la zona climática donde se sitúe. 
6. Recoger información sobre los precios de los $\mathrm{Kg}$ de $\mathrm{CO}_{2}$ emitidos, propuestos en la literatura.

7. Establecer un precio umbral del $\mathrm{CO}_{2}$, a partir del cual, en las condiciones actuales, fuera rentable optar por calificaciones energéticas mejores.

8. Alcanzar una solución compromiso entre costes económicos y medioambientales por medio de la valoración multicriterio.

\section{I.4. APORTACIONES DE LA TESIS.}

La principal aportación de esta Tesis es analizar cómo influye la calificación energética en la valoración de las viviendas. La novedad de este trabajo radica en el estudio de costes, bajo las circunstancias actuales, teniendo en consideración todas las zonas climáticas españolas.

Los estudios sobre la calificación energética de viviendas han ido aumentando desde la entrada en vigor del CTE. Sin embargo, se desconoce cómo afectará sobre el valor de las viviendas el factor EE, que con toda seguridad será un parámetro a considerar en las valoraciones que se realicen en adelante.

Existen multitud de estudios de diferentes casas comerciales sobre los ahorros en energía de determinadas soluciones: calderas más eficientes, soluciones de carpinterías más aislantes, etc. La tendencia del mercado hace que las empresas dirijan sus esfuerzos al desarrollo de energías renovables, equipos más eficientes y materiales más ecológicos.

Diversos organismos recogen también datos y elaboran guías técnicas al respecto; es el caso de la base de datos de calderas y la de aparatos de aire acondicionado que recoge el Instituto para la Diversificación y Ahorro Energético (IDAE), utilizada en este trabajo. También existen distintas guías técnicas con recomendaciones sobre materiales, como la de la Asociación 


\section{CAPÍTULO I.- INTRODUCCIÓN}

Nacional de Industriales de Materiales Aislantes (ANDIMA), junto con el IDAE. Las guías publicadas por el Instituto Tecnológico de la Edificación de Cataluña (ITEC). Catálogos de elementos constructivos como el del Instituto Eduardo Torroja de Ciencias de la Construcción (ITECC) o del Instituto Valenciano de la Edificación (IVE). Y así un largo etcétera de organismos y asociaciones que dirigen sus esfuerzos hacia una construcción más eficiente en el uso de la energía. Sin embargo, no se conoce ningún estudio que integre las soluciones constructivas con las soluciones comerciales disponibles, para cada una de las zonas climáticas españolas, teniendo además en consideración los costes económicos de implementar dichas soluciones.

Todas estas medidas son útiles en la fase de diseño del edificio y deben tenerse en cuenta; pero los estudios realizados hasta la fecha tampoco han considerado otros factores importantes, como son los costes derivados del uso de las viviendas, y los derivados de sus emisiones de carbono a la atmósfera (Coste Social del Carbono).

\section{I.5. LIMITACIONES}

El presente trabajo se centra en una promoción de viviendas unifamiliares adosadas. La elevada variabilidad de tipologías de edificios, hace inabarcable estudiar toda la casuística posible. Por tanto, será necesario en un futuro analizar otras tipologías, como las viviendas en bloque, que ya aparece diferenciada en la normativa, frente a la vivienda unifamiliar, y los edificios de usos no residenciales, como comercios, oficinas, etc.

En cuanto al método de valoración, aún no existe mercado representativo de viviendas que ostenten una determinada calificación energética y no es un factor que hasta la fecha se haya tenido en cuenta en la valoración. Por ello, no existe un valor de mercado que relacione EE con el valor del inmueble. Se adopta por tanto, el método del coste (ver capítulo IV). 
El programa utilizado para el estudio del cumplimiento de los mínimos requeridos por el CTE, por parte de la envolvente térmica del edificio es el Lider v1.0. Esta herramienta es la preceptiva en estos momentos y está patrocinada por el Ministerio de Vivienda y por el Instituto para la Diversificación y Ahorro de la Energía (IDAE).

El programa utilizado para la obtención de la calificación energética del edificio, Calener VYP v1.0 (versión actualizada 01/07/09), es proporcionado por el Ministerio de Turismo, Industria y Comercio. Gran parte de las limitaciones encontradas en este estudio se derivan de los programas, incapaces de modelizar determinadas soluciones eficientes energéticamente, entre otros motivos, pero son las escogidas en el trabajo por ser las únicas herramientas oficiales que se pueden utilizar en este momento en España, para obtener todo el abanico de calificaciones energéticas posible.

\section{I.6. MATERIAL UTILIZADO}

\section{Caso de estudio:}

El estudio del caso en esta Tesis se centra en la documentación de un proyecto real. Se trata de una promoción de 13 adosados, originalmente emplazado en Móstoles (Madrid). Si bien dicho proyecto se diseñó conforme a las normas de construcción derogadas en la actualidad, las antiguas Normas Básicas de la Edificación (NBE), la primera parte de esta Tesis se basa en el estudio del proyecto y su adaptación a la nueva normativa contenida en el CTE.

El estudio de este proyecto es el resultado de un convenio entre la Universidad Jaume I, Iberdrola Inmobiliaria S.A.U. y Miyabi, "Proyecto de investigación sobre costes de la Eficiencia Energética en Edificios (CEEEd)" y que forma parte de algunos aspectos estudiados en esta Tesis (Capítulo III). 


\section{CAPÍTULO I.- INTRODUCCIÓN}

Iberdrola Inmobiliaria S.A.U. es una inmobiliaria de implantación nacional, producto de la unión de las sociedades inmobiliarias de Iberdrola en 1993. Entre los productos que ofrece, apuesta por la promoción de edificios sostenibles, participando en congresos, foros, concursos y grupos de trabajo relacionados con la sostenibilidad. En este marco firmó el convenio con la Universidad Jaume I, anteriormente referenciado, aportando como material de partida una de sus promociones y asesorando en algunos de los aspectos relacionados con el diseño del edificio.

MIYABI es una sociedad pública del Gobierno de Navarra, fundada en el año 2001. Tiene como objeto social la promoción de eficiencia energética, uso racional de la energía, e integración de renovables, en viviendas y espacios urbanos. Entre sus servicios, actúa como consultora y asesora en materia de eficiencia energética y sostenibilidad, labor que llevó a cabo en algunos aspectos del presente trabajo.

\section{Características de la promoción:}

La promoción se sitúa sobre parcela de $2332 \mathrm{~m}^{2}$. La superficie de terreno por vivienda es de $154-157 \mathrm{~m}^{2}$. Las viviendas cuentan con $120 \mathrm{~m}^{2}$ construidos computables, $123,75 \mathrm{~m}^{2}$ si se tienen en cuenta los tendederos. Se distribuyen en planta baja y primera. El programa se desarrolla en planta sótano, garaje, con acceso a la vivienda desde este nivel; en planta baja se sitúa el estar comedor, cocina con tendedero, vestíbulo y aseo; en planta primera, dos dormitorios, un baño, y dormitorio principal con baño incorporado.

En cuanto a las dimensiones, difieren sensiblemente según sean viviendas intermedias (A2, A3, A4, A7, A8, A11 y A12), con 66,75 $\mathrm{m}^{2}$ en planta baja y $57 \mathrm{~m}^{2}$ en planta primera; o viviendas en los extremos ( $\mathrm{A} 1, \mathrm{~A} 5, \mathrm{~A} 6, \mathrm{~A} 9, \mathrm{~A} 10 \mathrm{Y}$ A13), con $68,10 \mathrm{~m}^{2}$ en planta baja y $58,88 \mathrm{~m}^{2}$ en planta primera. 
El total construido es de $1628,13 \mathrm{~m}^{2}$ para viviendas, aunque si se tienen en cuenta que no computan tendederos y huecos instalaciones $\left(68,25 \mathrm{~m}^{2}\right)$, el total de viviendas computable es de $1559,88 \mathrm{~m}^{2}$.

En planta sótano hay un garaje mancomunado, perteneciendo a cada vivienda de esta planta, un cuarto para instalaciones, dos plazas para coche grande y una para coche pequeño, además de disponer de acceso independiente a la vivienda. La superficie de aparcamiento es de 1884,61 $\mathrm{m}^{2}$ y la superficie total de viviendas más aparcamiento de $3512,74 \mathrm{~m}^{2}$, correspondiéndole a cada vivienda, incluyendo garaje y zonas comunes: $270,21 \mathrm{~m}^{2}$.

Como aspectos constructivos más destacables, las viviendas cuentan con cimentación a base de zapatas HA35, acero B500S y muros de contención en sótano garajes. La Estructura son pórticos HA35, con acero B500S en pórticos y forjados y B500T en losas. El cerramiento es fachada ventilada y la cubierta plana transitable. Carpinterías exteriores de aluminio anodizado y vidrios aislantes de doble luna con cámara intermedia, de varios espesores, algunos de ellos laminados.

La documentación de partida es el Proyecto Básico y de Ejecución, con fecha de visado 02-10-2006 en el Colegio Oficial de Arquitectos de Madrid. El proyecto fue diseñado en el estudio Anaya Arquitectos de Madrid. Se dispone de la versión en formato pdf del proyecto, y de los planos en autocad. Se muestra a continuación, algunos de los planos más relevantes: 


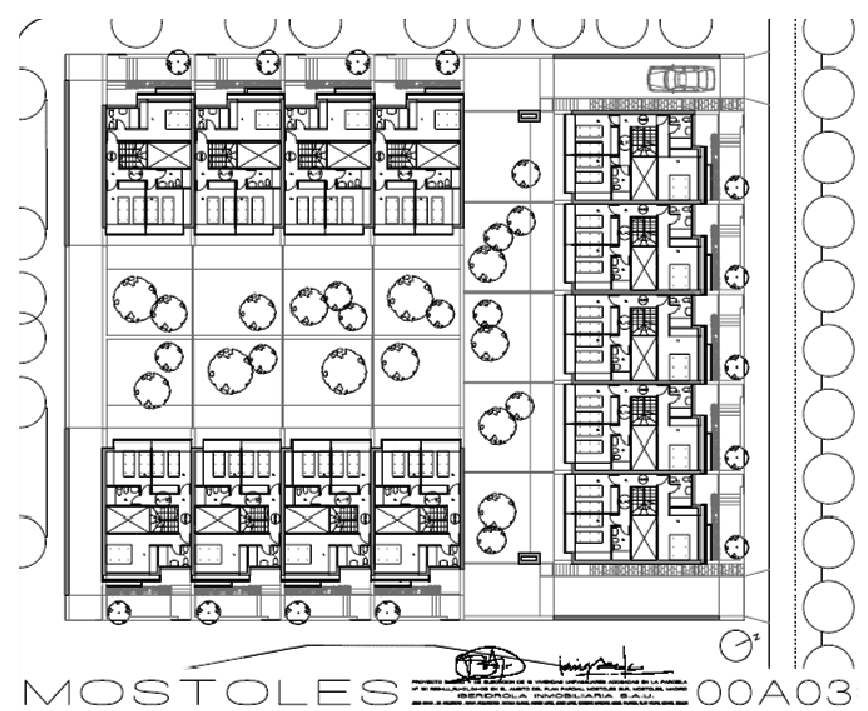

Imagen 1.1.- Vista general promoción; distribución Planta Primera. (Proyecto de Anaya Arquitectos, facilitada por Iberdrola Inmobiliaria S.A.U.)

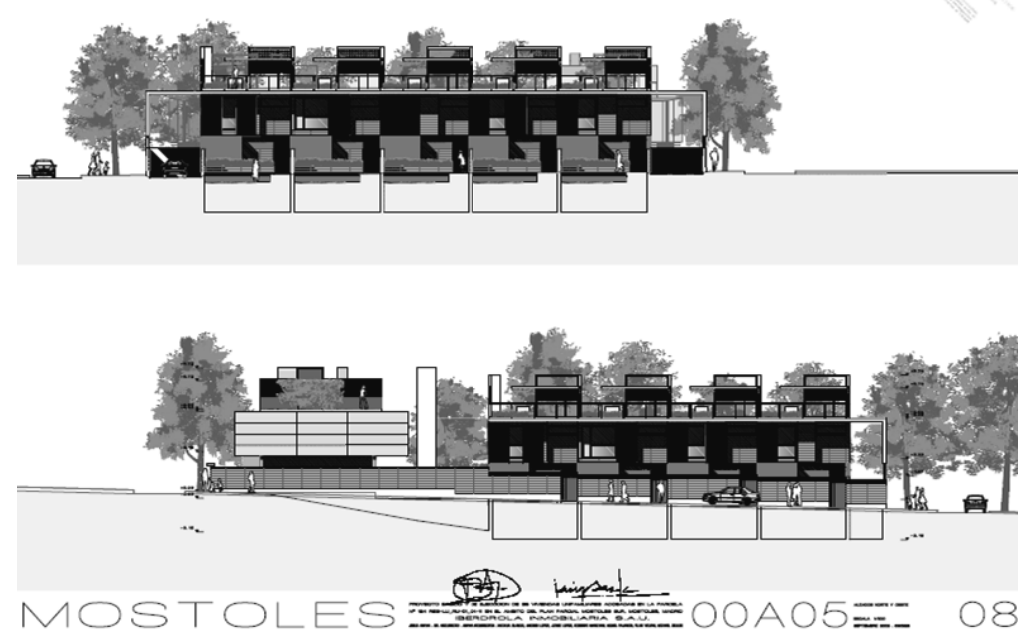

Imagen 1.2.- Alzados. (Proyecto de Anaya Arquitectos, facilitada por Iberdrola Inmobiliaria S.A.U.) 


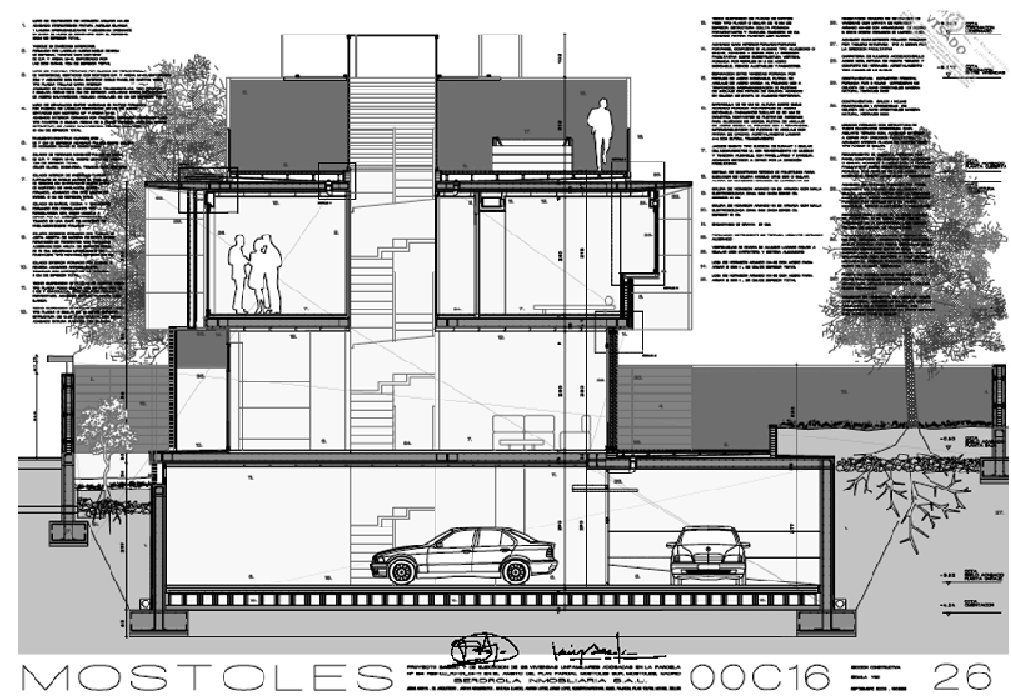

Imagen 1.3.- Sección. (Proyecto de Anaya Arquitectos, facilitada por Iberdrola Inmobiliaria S.A.U.)

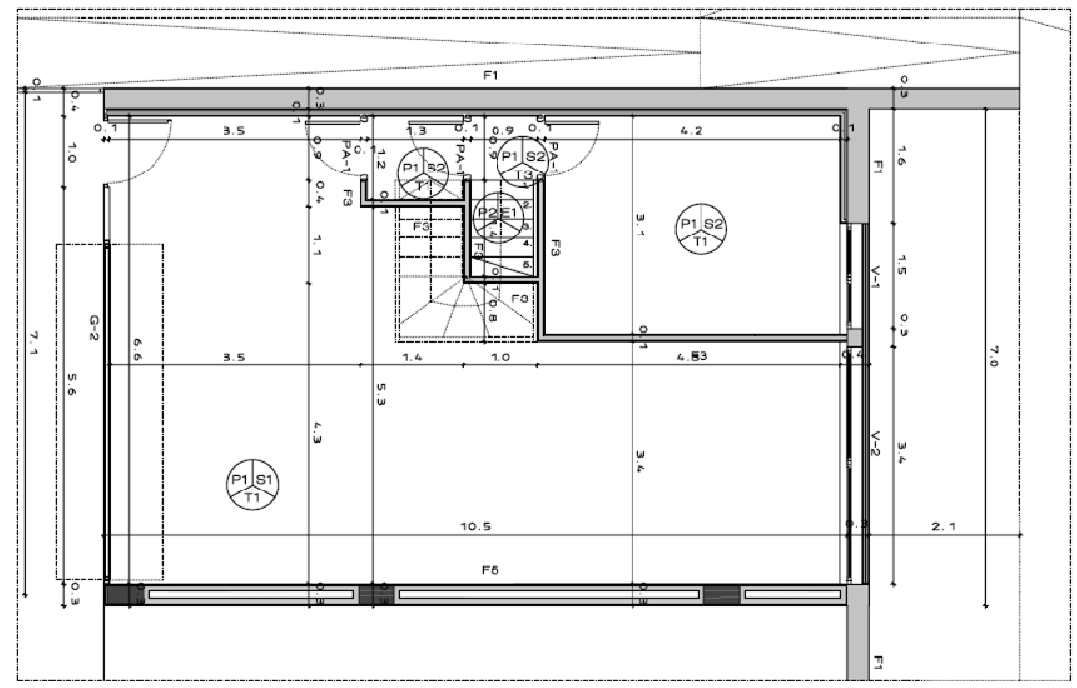

Imagen 1.4.- Plano de cotas y distribución planta sótano (Proyecto de Anaya Arquitectos, facilitada por Iberdrola Inmobiliaria S.A.U.) 


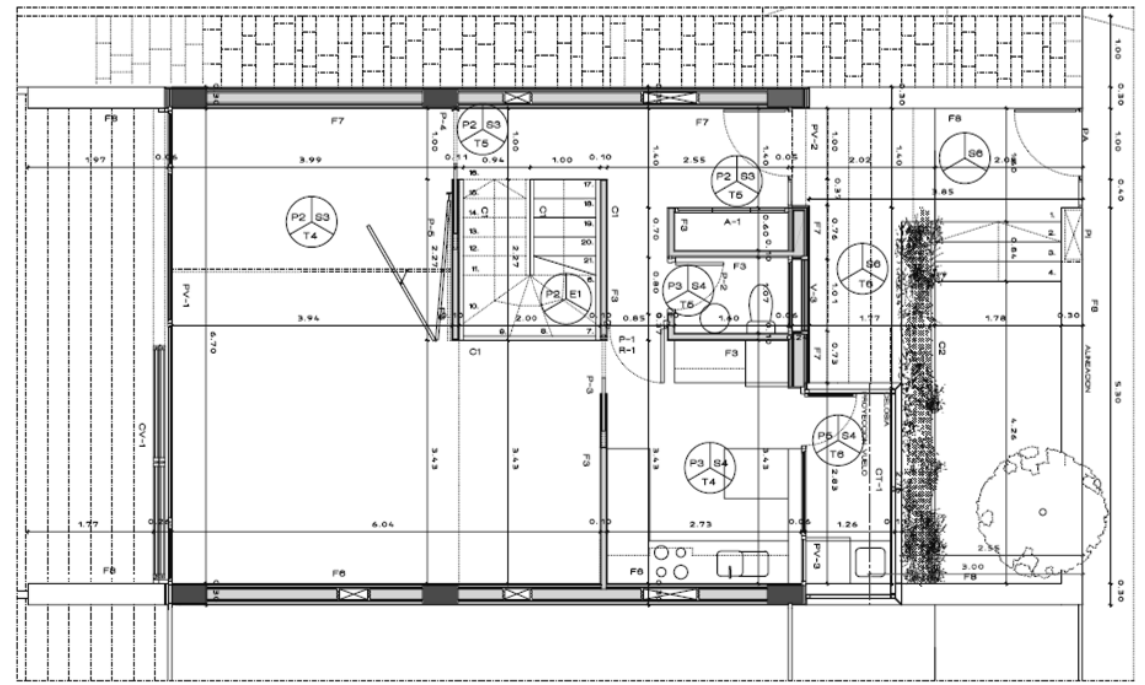

Imagen 1.5.- Plano de cotas y distribución planta baja (Proyecto de Anaya Arquitectos, facilitada por Iberdrola Inmobiliaria S.A.U.)

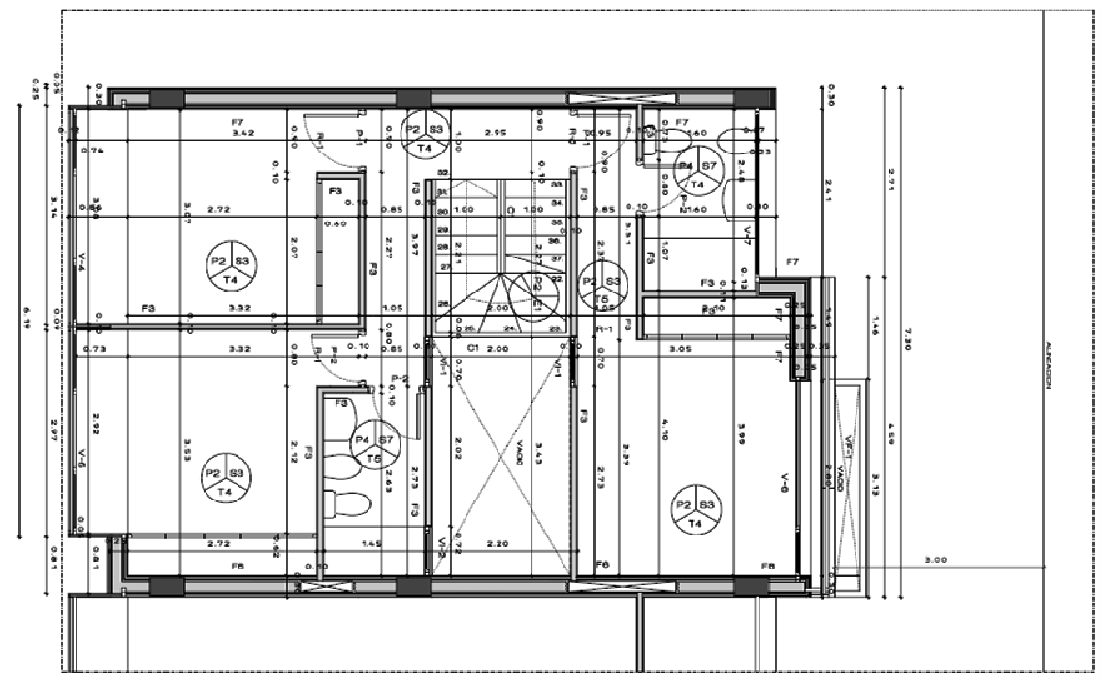

Imagen 1.6.- Plano de cotas y distribución planta primera (Proyecto de Anaya Arquitectos, facilitada por Iberdrola Inmobiliaria S.A.U.) 


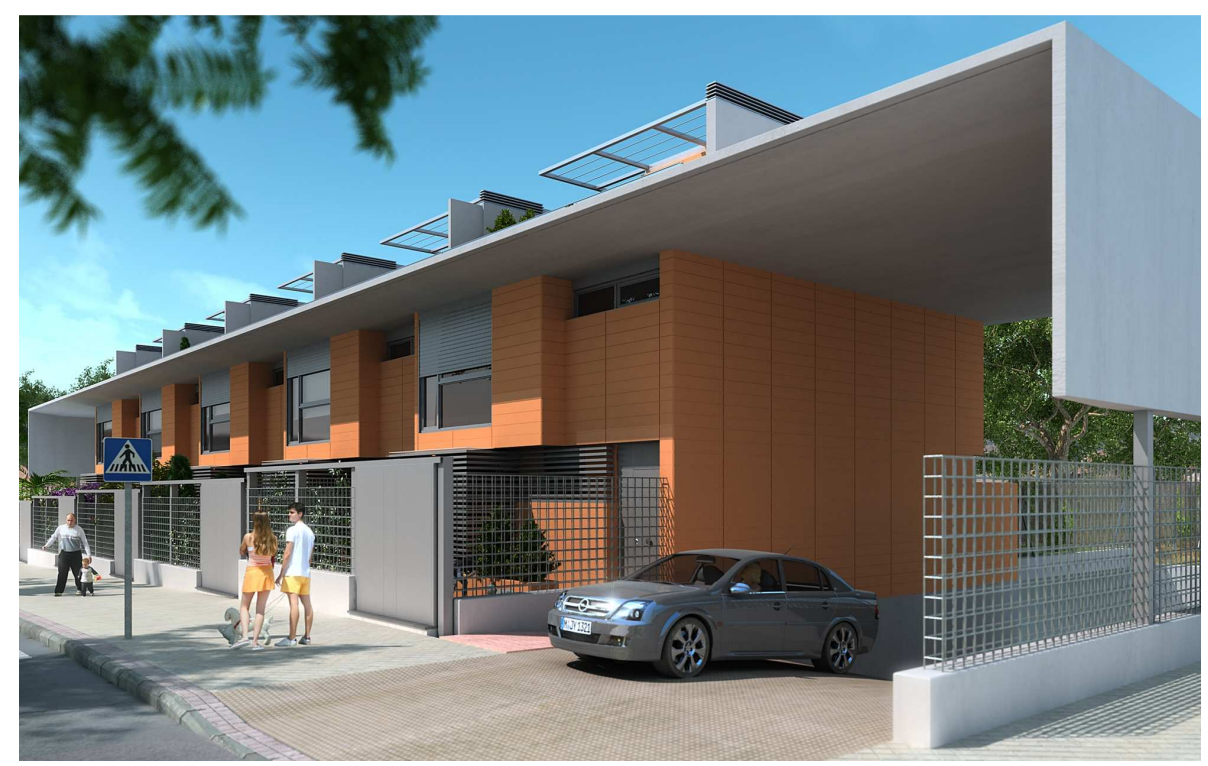

Imagen 1.7.- Imagen 3D de la promoción (Proyecto de Anaya Arquitectos, facilitada por Iberdrola Inmobiliaria S.A.U.)

\section{Programas utilizados:}

Se utilizan diferentes herramientas informáticas para llevar a cabo los cálculos necesarios, durante todas las fases del trabajo de investigación:

- Lider v1.0, para el cálculo del cumplimiento de los mínimos de la envolvente térmica.

- Calumen, para el cálculo de transmitancia y factor solar en vidrios.

- dpCLima, para el cálculo de las potencias necesarias de los equipos de las viviendas.

- Calener VYP v1.0 para obtener la calificación energética.

- Cype generador de precios, para la búsqueda de precios de las soluciones constructivas y de instalaciones.

- Cálculo de las placas solares mediante programa HSolGas v1.0 de Gas Natural.

- Lingo 6: Programa de optimización.

- SPSS 16: Herramienta para análisis estadístico de datos 


\section{I.7. ETAPAS}

La metodología para la realización de la Tesis se resume a continuación:

1. Analizar el proyecto que se utiliza como caso de estudio.

2. Adaptar el mismo a los requerimientos del CTE. Para ello se utiliza la herramienta Lider. Ello implica la búsqueda de nuevos materiales y la investigación de cómo adaptar las soluciones constructivas utilizadas originalmente, para su adecuación al CTE. Esto debe, además, adecuarse al caso de cada zona climática considerada, ya que los requerimientos lógicamente difieren entre ellas.

3. Calcular las necesidades de calefacción, aire acondicionado y agua caliente sanitaria, en cada zona climática, por medio del programa dpclima.

4. Calificar energéticamente el edificio, mediante la herramienta oficial en España, Calener VYP v1.0.

5. Estudiar aisladamente diversos parámetros que influyen en la EE, para ver su influencia en la calificación energética del edificio. Estudiar costes del cambio de parámetros.

6. Buscar la combinación de medidas que permitan obtener las distintas calificaciones energéticas, al menor coste de inversión posible.

7. Obtener los costes de inversión y amortización en cada una de las combinaciones analizadas en el capítulo precedente. Se realizan los presupuestos de ejecución material y de contrata para cada una de las configuraciones obtenidas (zona climática-clase energética). Para ello se llevan a cabo el análisis detallado de costes, incluyendo las mediciones, los precios y los presupuestos (estados 1, 2 y 3 de los documentos que conforman el presupuesto del proyecto). Se tienen en cuenta nuevos capítulos derivados de la nueva normativa, que no constaban en el proyecto original, por ejemplo, el capítulo referente a la gestión de residuos. 
8. Calcular el consumo de energía, a partir de las cifras obtenidas por simulación de cada configuración en Calener y teniendo en cuenta las tarifas vigentes, según el tipo de combustible empleado.

9. Calcular los costes de mantenimiento durante la vida útil del inmueble. Los presupuestos de cada configuración en este caso, tendrán en cuenta la vida útil del edificio y de sus componentes, así como la periodicidad requerida para cada operación de mantenimiento.

10. Estudiar los costes de las emisiones de $\mathrm{CO}_{2}$ durante la vida útil la vivienda. Este tipo de coste se calcula utilizando los valores de $\mathrm{Kg}$ emitidos de $\mathrm{CO}_{2}$, que se obtienen en las simulaciones con Calener VYP. Para determinar los precios del $\mathrm{Kg}$ de $\mathrm{CO}_{2}$ se realiza una revisión bibliográfica sobre los valores existentes en la literatura sobre el coste social del carbono (SCC).

11. Obtener modelos de costes, por regresión mínimo cuadrático ordinaria, que permitan relacionar los costes de las viviendas con su calificación energética. Realizar análisis de los costes y análisis de inversiones a partir de los resultados obtenidos. Con ello se establecerá un precio umbral del $\mathrm{CO}_{2}$ a partir del cual sea rentable optar por una mejor calificación energética.

12. Proponer un posible reparto de distintas calificaciones energéticas en una promoción de viviendas, utilizando programación lineal. Se utilizará programación multicriterio al tener que optimizar objetivos que no pueden ser satisfechos simultáneamente; por un lado, el criterio ambiental que implica la disminución de emisiones, y por otro, el criterio económico que supone la disminución del resto de costes considerados.

El siguiente esquema resume gráficamente las etapas: 


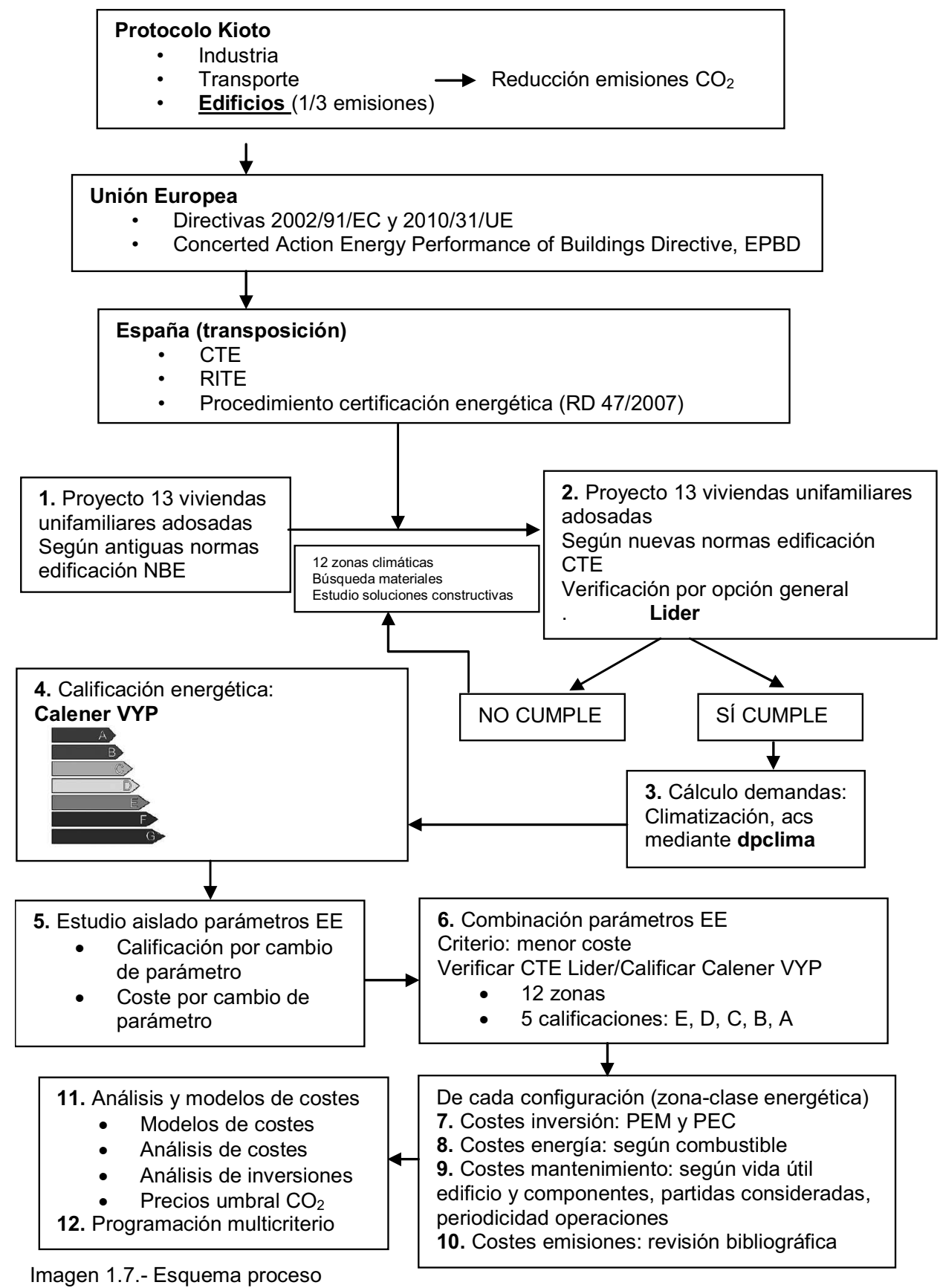

Imagen 1.7.- Esquema proceso 


\section{I.8. ESTRUCTURA DE LA TESIS}

La presente Tesis Doctoral, se estructura en dos partes claramente diferenciadas. La primera relacionada con las áreas de la arquitectura y la construcción, y la segunda con los aspectos económicos y su valoración. A su vez, ambas vertientes se relacionan con aspectos medioambientales.

El trabajo se estructura por capítulos, siguiendo el orden cronológico de su realización.

\section{Capítulo I: Introducción}

Capítulo II: Nuevo factor en la valoración de edificios: Eficiencia Energética. Análisis de la situación actual en España con respecto a la certificación energética de edificios.

Capítulo III: Está relacionado con aspectos arquitectónicos y constructivos. En este capítulo pueden diferenciarse varias partes:

1. Analizar el proyecto que se utiliza como caso de estudio

2. Adaptar el mismo a los requerimientos del CTE

3. Calificar energéticamente el edificio

4. Estudiar aisladamente parámetros que influyen en la EE

5. Estudiar costes del cambio de parámetros

6. Buscar la combinación de medidas que permitan obtener las distintas calificaciones energéticas, al menor coste de inversión posible

Capítulo IV: Análisis de costes para cada combinación de las posibles calificaciones energéticas con las zonas climáticas existentes. Se tiene en cuenta:

1. Costes de inversión obtenidos de las combinaciones analizadas en el capítulo precedente

2. Costes de amortización, de acuerdo a las distintas vidas útiles de los elementos que conforman el edificio 
3. Consumo de energía

4. Costes de mantenimiento durante la vida útil del inmueble

5. Emisiones de $\mathrm{CO}_{2}$ durante la vida útil la vivienda

Capítulo V: Se realiza, a partir de los resultados obtenidos en los capítulos precedentes:

1. Modelos de costes en función de la calificación energética

2. Análisis de costes

3. Análisis de inversiones

4. Precio umbral del $\mathrm{CO}_{2}$ que hace rentable una mejor calificación

Capítulo VI: Se propone un posible reparto del presupuesto de acuerdo a las distintas calificaciones energéticas, aplicando métodos de programación multicriterio, con dos objetivos, por un lado el ambiental al minimizar las emisiones, por otro, el económico al disminuir los costes.

Capítulo VII: Se resumen las principales conclusiones y se explican cuáles han sido las aportaciones del presente trabajo. Como consecuencia de los resultados se reflexiona acerca de las herramientas disponibles en la actualidad, y se proponen recomendaciones de mejora. Por último se indican las líneas de investigación futuras que quedan abiertas, al concluir la Tesis. 


\section{CAPÍTULO II NUEVO FACTOR EN LA VALORACIÓN DE EDIFICIOS: EFICIENCIA ENERGÉTICA}





\section{II.1.- Evolución de la Normativa de Eficiencia Energética referida a edificios en la Unión Europea}

Hasta 1973 las políticas en materia de energía en la UE tenían como objetivo fundamental garantizar el suministro para la creciente demanda, siendo señal de prosperidad el aumento del consumo energético. No obstante, la crisis del petróleo de 1973, supone un punto de inflexión y desde este momento comienza a fomentarse el uso de fuentes de energía renovables y la eficiencia energética. Varios programas en materia de energía se dan en la década de los 80 , si bien no es hasta los 90 que el binomio consumo energía-medioambiente es tenido en cuenta en las políticas energéticas comunitarias [Rodríguez et al., 2011].

En la actualidad, en la Política Energética de la Unión Europea, hay diversos objetivos: por un lado, el intentar evitar en la medida de lo posible la dependencia de fuentes externas de energía y por otro, incrementar la protección del medio ambiente por medio del desarrollo tecnológico y de las fuentes de energía renovables, así como el favorecer la eficiencia energética. Sólo este último factor supone unas pérdidas del $20 \%$ de energía en Europa [Martínez de Alegría et al., 2009].

En lo que se refiere al sector de la construcción, los edificios consumen entre un 20 y $40 \%$ de energía en los países desarrollados [Pérez-Lombarda et al., 2008]. Teniendo en cuenta, que gran parte del sector industrial está relacionado con la edificación, el porcentaje estaría más cercano al límite superior de $40 \%$ [Diakaki, C. et al, 2008].

De entre los edificios de la UE, aproximadamente el $77 \%$ son residenciales, correspondiendo un $60 \%$ a viviendas unifamiliares [Hamdy, M. et al, 2011]. Datos del Instituto de Diversificación y Ahorro Energético (IDAE), indican un $22,8 \%$ en España y un $36,7 \%$ de consumo de energía en los edificios en Europa para el sector residencial. 
Los países firmantes del protocolo de Kioto, entre los que se encuentran los países integrantes de la Unión Europea (UE), ponen en marcha políticas encaminadas a la disminución de emisiones de carbono, al ser éstas responsables en gran medida del cambio climático (véase capítulo IV). La UE presenta unos objetivos más ambiciosos que otros países, debiendo alcanzarse una reducción del $20 \%$ de las emisiones de $\mathrm{CO}_{2}$, respecto a los niveles de 1990, en el año 2020.

Por ello, entre otras cosas, se promueve la EE en edificios. A este respecto se actúa a nivel de la Directiva 2002/91/EC (Energy Performance of Buildings Directive, EPBD), actualizada recientemente, en la Directiva 2010/31/UE de 19 de mayo, publicada en el Diario Oficial del Parlamento Europeo, de 18 de junio, (aumentando algo más las exigencias en cuanto a $\mathrm{EE}$, que la directiva precedente). Esta Directiva considera, entre otras cosas, las necesidades de calefacción, refrigeración y agua caliente en los edificios residenciales, principales consumidores de energía. Cada Estado miembro debe transponer la Directiva, adecuándola a sus circunstancias particulares, tanto a nivel de clima como de métodos constructivos, normativas reguladoras propias, etc. [Rey et al., 2007; Andaloro et al., 2010].

Los objetivos de la Directiva EPBD son entre otros:

- Desarrollar un método de cálculo para la eficiencia energética en edificios. Se indica la necesidad de diferenciar los edificios residenciales del resto, y dentro de estos, las viviendas unifamiliares de las viviendas en bloque (Artículo 4).

- Aplicar los requerimientos mínimos para la eficiencia energética en edificios (Artículo 4). 
- Desarrollar el procedimiento para la certificación energética de los edificios (Artículo 7).

- Definir inspecciones regulares de calderas y sistemas de aire acondicionado de los edificios.

Para apoyar a los países de la UE en esta tarea, la Comisión Europea, promovió la llamada Concerted Action Energy Performance of Buildings Directive (CA EPBD), con el fin de promover el diálogo y el intercambio de información entre los países. Entre otras cosas, se realizan periódicamente informes que recogen las conclusiones y recomendaciones, a partir de la acción de cada uno de los Países.

A este respecto se recogió la situación de cada Estado miembro en 2008 por medio del Informe de los países "Implementation of the Energy Performance of Buildings Directive. Country Reports 2008". En dicho informe se recoge información de los 27 países de la UE, más Noruega y Croacia, acerca de distintos aspectos: marco legal, estado de la transposición y también se indican aspectos tales como qué planifica hacer cada país en un futuro respecto a los temas tratados en la Directiva y qué campañas de concienciación han llevado a cabo cada Estado Miembro a nivel nacional.

En lo que respecta al marco legal, el EPBD Country Reports recoge qué normativas nacionales son las responsables de la transposición de la Directiva EPBD (incluso, en ocasiones, considera diferencias regionales, caso de Bélgica que distingue tres regiones o Reino Unido que considera Inglaterra y Gales por un lado e Irlanda del Norte por otro).

En España la EPBD fue parcialmente transpuesta por medio de tres reales decretos. Hasta el momento está en proceso de aprobación el método de 
certificación de Eficiencia Energética en edificios existentes, habiéndose desarrollado solamente para edificios de nueva construcción. Los tres reales decretos mencionados son:

- RD 314/2006, que aprueba el Código Técnico de la Edificación (CTE), en Consejo de Ministros de 17 de Marzo de 2006 y publicado en el BOE de 28 de Marzo de 2006.

- RD 47/2007, aprobado en Consejo de Ministros de 17 de Enero de 2007 y publicado en el BOE de 31 de Enero de 2007. Se aprueba el procedimiento básico para la certificación de la EE en edificios de nueva construcción.

- RD, que aprueba el Reglamento Técnico de Instalaciones Térmicas en Edificios, aprobado en Consejo de Ministros de 20 de julio de 2007 y publicación en el BOE de 29 de Agosto de 2007, entrando en vigor el 1 de Marzo de 2008.

En cuanto al estado de la implementación en cada Estado Miembro, del análisis del informe de 2008, se puede concluir que la situación es desigual entre los países, en cuanto al grado y forma de implantación de la directiva. Además, no es posible hacer todavía una comparación entre países, puesto que en muchos de ellos los procedimientos no están del todo implantados. A ello se une el hecho de las lógicas diferencias entre países, a causa del clima, por ejemplo, en países fríos como Austria, el indicador que se utiliza para medir la eficiencia energética es la demanda anual de calefacción, mientras que en otros, como España o Portugal introducen también las demandas de refrigeración. En la mayoría de países el indicador para calificar energéticamente los viviendas es la demanda de energía $\left(\mathrm{kW} . \mathrm{h} / \mathrm{m}^{2}\right.$, o $\mathrm{MJ} / \mathrm{m}^{2}$ en Países Bajos), algunos incorporan además el indicador 
emisiones $\mathrm{KgCO}_{2} / \mathrm{m}^{2}$.año. En la mayor parte de casos, la escala para calificar se divide en letras de mejor calificación energética a peor, conteniendo las letras de la $\mathrm{A}$ a la $\mathrm{G}$. Algunos países subdividen en más clases su escala:

- Escala A, B, C, D, E, F, G: Bulgaria, Chipre, República Checa, Dinamarca, España, Estonia, Finlandia, Italia, Francia, Malta, Rumanía, República Eslovaca, Lituania.

- Otros países, además de las clases A-G, presentan subclases en su escala de calificación: Austria $\left(A^{++}, A^{+}\right)$, Grecia $\left(A^{+}, A^{-}, B^{+}, B^{-}\right)$, Hungría y Reino Unido $\left(A^{+}\right)$, Países Bajos $\left(A^{+}, A^{-}\right)$, Portugal $\left(A^{+}, B^{-}\right)$, Eslovenia (indica que hay dos subclases para $A$ y $B$ ).

- En el caso de Irlanda, se distinguen las clases A1, A2, A3, B1, B2, B3, C1, C2, C3, D1, D2, E1, E2, F, G.

- Bélgica, Alemania y Polonia dan una escala numérica en la que se mide la energía consumida en $\mathrm{kwh} / \mathrm{m}^{2}$.año en calefacción y agua caliente sanitaria (ACS).

- Otros amplían la escala, caso de Luxemburgo, con clases de la A hasta la I o Latvia, con clases de la A hasta la N.

La reciente Directiva 2010/31/UE es más estricta en cuanto a requerimientos de EE que la precedente, Directiva 2002/91/EC. Su transposición debe estar resuelta por medio de los Estados miembros en 2012 y 2013 (según artículos). En ella se indica que para 2020 los edificios deben ser de consumo casi nulo, lo cual hace prever que las escalas con las letras $A-G$, evolucionarán y se hará necesario incluir nuevas calificaciones como $\mathrm{A++}, \mathrm{A}+$, en respuesta a las nuevas demandas.

En el apartado II.2 se tratará más detenidamente la escala en el caso de España, en el momento actual. En el apartado II.3, se analizará resumidamente cómo se han establecido los valores numéricos para determinar la escala, a partir de las emisiones de $\mathrm{CO}_{2}$ del edificio. 


\section{II.2.- Evolución de la Normativa de Edificación en España}

Dado que el trabajo realizado en la presente Tesis se basa en la normativa actual en el sector de la construcción, básicamente el CTE, y más concretamente, sus documentos HE y HS, veremos a continuación, cuál ha sido desarrollo de estas regulaciones. Esta normativa tiene su base en normas previas que se resumen brevemente a continuación.

La Dirección General de Arquitectura del Ministerio de Gobernación (institución creada en 1937), desarrolló las normas técnicas que regulaban el sector de la edificación, conocidas como normas MV o del Ministerio de Vivienda. Entraron en vigor en 1957 y eran competencia del Ministerio de la Vivienda.

En 1977, estas reglas se transformaron en las Normas Básicas de la Edificación (NBE). El Gobierno decidió crear un marco unificado para toda la normativa relacionada con la edificación. Su aplicación era de obligado cumplimiento para los agentes del sector. A las NBE se le añadieron las Normas Tecnológicas de la Edificación (NTE) para completar el marco regulatorio. Estas especificaciones servían como el desarrollo operativo de las NBE, aunque no tenían carácter obligatorio.

En 1999 se publicó la Ley 38/1999 de 5 de noviembre de Ordenación de la Edificación cuyo principal objetivo es regular el sector de la edificación. En materia de reglamentación era preciso actualizar una reglamentación que había quedado obsoleta. En este momento la ley instó y autorizó al Gobierno para la aprobación de un código técnico de la edificación mediante Real Decreto que estableciera las exigencias que deben cumplir los edificios en relación con los requisitos básicos de seguridad y habitabilidad. Las nuevas normas debían responder a las demandas de la sociedad española y de la Unión Europea, cada vez más preocupada por la calidad en los 
edificios, la seguridad, el bienestar, la energía y la protección del medio ambiente [Directiva 2002/91/EC].

EI CTE recoge los objetivos de la LOE y traduce al lenguaje técnico estas aspiraciones.

Consta de varios documentos que derogan a las antiguas NBE, recogiéndose en la tabla 2.1 la correspondencia entre las antiguas normas y las actuales:

\begin{tabular}{|c|c|c|c|}
\hline NBE-AE & Acciones edificación & DB-SE-AE & $\begin{array}{l}\text { Seguridad estructural. } \\
\text { Acciones edificación }\end{array}$ \\
\hline NBE-EA & Estructuras de acero & DB-SE-A & $\begin{array}{l}\text { Seguridad estructural. } \\
\text { Estructuras de acero }\end{array}$ \\
\hline NBE-FL & Fábricas de ladrillo & DB-SE-F & $\begin{array}{l}\text { Seguridad estructural. } \\
\text { Fábricas de ladrillo }\end{array}$ \\
\hline NBE-CPI & Protección contra incendios & DB-SI & $\begin{array}{l}\text { Seguridad en caso de } \\
\text { incendios }\end{array}$ \\
\hline NBE-QB & Cubiertas bituminosas & DB-HS & $\begin{array}{llll}\text { Protección frente } & \text { a la } \\
\text { humedad } & & & \end{array}$ \\
\hline NBE-ISA & Suministro de agua & DB-HS & $\begin{array}{l}\text { Salubridad: Suministro de } \\
\text { agua }\end{array}$ \\
\hline NBE-CT & Condiciones Térmicas & DB-HE & Ahorro de energía \\
\hline NBE-CA & Condiciones Acústicas & DB-HR & Protección contra el ruido \\
\hline
\end{tabular}

Tabla 2.1.- Comparación antiguas NBE frente a documentos CTE. Fuente: elaboración propia

Con la reciente incorporación del documento SUA: Seguridad de utilización y accesibilidad [RD 173/2010, de 19 de febrero, por el que se modifica el CTE, en materia de accesibilidad y no discriminación de las personas con discapacidad; publicado en el BOE de 11 de marzo de 2010].

Los objetivos que se persiguen con la puesta en marcha del CTE son: 
- Reducir la demanda energética de edificios (HE1)

- Producir un uso real de energías renovables (HE4 y 5 )

- Aumentar la calidad del aire en los edificios (HS3), realizar estimaciones de consumo energético e implementar inspecciones.

El documento HE-1 del CTE aporta dos opciones para el cálculo de la envolvente térmica de un edificio, la opción simplificada y la opción general.

La opción simplificada consiste en comprobar que no se traspasan unos determinados límites de transmitancia térmica $\left(\mathrm{W} / \mathrm{m}^{2} \mathrm{~K}\right)$ en la envolvente del edificio. Con el cumplimiento a través de la opción simplificada se puede optar a calificación energética D O E. Clases energéticas superiores requerirán el utilizar la opción general.

En la opción general se realiza una comparación con un edificio de referencia que es aquel que cumple los mínimos que especifica el CTE en cuanto a limitación de demanda energética y que tiene unas características geométricas similares, está situado en el mismo lugar y posee la misma orientación que el edificio que se pretende comprobar. Las características geométricas son las mismas en cuanto a forma, pero no necesariamente en cuanto al número de huecos en los paños de fachada.

La opción simplificada tiene algunos límites para su aplicación. Por ejemplo, no es de aplicación para soluciones de fachada diferentes a las convencionales como fachadas ventiladas, muros Trombé o invernaderos adosados, etc. Además sólo es de aplicación si se cumple simultáneamente que en cada fachada el porcentaje de huecos sea inferior al $60 \%$ y que la superficie de los lucernarios sea inferior al $5 \%$ de la superficie de cubierta. En la promoción estudiada, no se cumple esta última condición, por lo que para este proyecto es de aplicación la opción general, que se verifica mediante el programa Lider. 
Lider es la aplicación informática que permite cumplir con la opción general de verificación de la exigencia de Limitación de Demanda Energética establecida el CTE-HE1 y está patrocinada por el Ministerio de Vivienda y por el IDAE. Con esta herramienta es posible describir el edificio con sus características geométricas y constructivas, realizar los cálculos que se establecen en el HE1 e imprimir toda la documentación necesaria desde el punto de vista administrativo. Esta implementación informática fue desarrollada por el Grupo de Termotecnia de Ingenieros Industriales de la Universidad de Sevilla y la Asociación de Investigación y Cooperación Industrial de Andalucía (AICIA), con la colaboración del Instituto Eduardo Torroja de Ciencias de la Construcción (IETCC).

Son tres puntos principales los que deben de darse para que el edificio cumpla según la opción general (Lider):

- Las demandas de calefacción y refrigeración del edificio objeto (aquel que se pretende comprobar), deben ser inferiores a las del edificio de referencia.

- Para evitar descompensaciones entre la calidad térmica de diferentes espacios, cada uno de los cerramientos y particiones interiores de la envolvente térmica debe tener además una transmitancia no superior a los valores indicados en la tabla 2.1 del CTE en función de la zona climática en la que se ubique el edificio.

- La humedad relativa interior no debe superar el $80 \%$ con el fin de controlar las condensaciones. La humedad en cada capa del cerramiento se debe secar a lo largo de un año. La máxima condensación en un mes debe ser inferior al valor admisible para cada material aislante.

- Además deben cumplirse unas limitaciones de permeabilidad al aire de las carpinterías, de manera que en las zonas A y B se cumple la normativa con carpinterías clase $1\left(50 \leq \mathrm{m}^{3} / \mathrm{h} \cdot \mathrm{m}^{2}\right)$, 
mientras que para las zonas $\mathrm{C}, \mathrm{D}$ y E, el mínimo a utilizar son las carpinterías clase $2\left(27 \leq \mathrm{m}^{3} / \mathrm{h} \cdot \mathrm{m}^{2}\right)$ [UNE-EN 1026; UNE-EN 12207].

Una vez las viviendas cumplan con esos requerimientos mínimos, se podrá llevar a cabo su certificación energética. El procedimiento básico de certificación energética se recoge en el RD 47/2007, de 19 de enero. Se pretende de esta manera establecer criterios para la consecución de la denominada "etiqueta de eficiencia energética". La etiqueta se consigue al simular el edificio por medio del programa Calener y presenta el aspecto que se muestra en la imagen 2.1. Se puede observar la escala de calificación desde la letra $A$ a la $G$, tal y como se ha mencionado en el apartado II.1 y la utilización en este caso del indicador $\mathrm{KgCO}_{2} / \mathrm{m}^{2}$. Además permite distinguir las emisiones debidas a calefacción, refrigeración y ACS:

\begin{tabular}{|c|c|c|c|c|c|c|}
\hline $\begin{array}{l}\text { Certificación Energética de Edificios } \\
\text { Indicador } \mathrm{kgCO} / \mathrm{m}^{2}\end{array}$ & \multicolumn{3}{|c|}{$\begin{array}{c}\text { Edificio } \\
\text { Objeto }\end{array}$} & \multicolumn{3}{|c|}{$\begin{array}{c}\text { Edificio } \\
\text { Referencia }\end{array}$} \\
\hline \multicolumn{7}{|l|}{$<4.6 \quad A$} \\
\hline \multicolumn{7}{|l|}{ 4.6-8.9 B } \\
\hline & \multicolumn{3}{|c|}{$14.6 \mathrm{C}$} & & & \\
\hline \multicolumn{7}{|l|}{$14.9-24.0$} \\
\hline \multicolumn{7}{|l|}{$>24.0$} \\
\hline & Clase & $\mathrm{kWh} / \mathrm{m}^{2}$ & kWh/año & Clase & $\mathrm{kWh} / \mathrm{m}^{2}$ & kWh/año \\
\hline Demanda calefacción & $\mathrm{D}$ & 26.0 & 2763.0 & $E$ & 42.2 & 4484.5 \\
\hline \multirow[t]{2}{*}{ Demanda refrigeración } & $E$ & 32.7 & 3475.0 & $E$ & 37.8 & 4016.9 \\
\hline & Clase & $\mathrm{kgCO} 2 / \mathrm{m}^{2}$ & kgCO2/año & Clase & \multicolumn{2}{|c|}{\begin{tabular}{|l|l}
$\mathrm{kgCO} 2 / \mathrm{m}^{2}$ & $\mathrm{kgCO} 2 /$ año \\
\end{tabular}} \\
\hline Emisiones CO2 calefacción & c & 5,0 & 531.3 & $\mathrm{E}$ & 13.5 & 1434,6 \\
\hline Emisiones CO2 refrigeración & $\mathrm{D}$ & 7.0 & 743.9 & $E$ & 14.4 & 1530.3 \\
\hline Emisiones $\mathrm{CO} 2 \mathrm{ACS}$ & $\mathrm{D}$ & 2.6 & 276.3 & D & 2.6 & 276,3 \\
\hline Emisiones $\mathrm{CO} 2$ totales & & & 1551.5 & & & 3241.2 \\
\hline
\end{tabular}

Imagen 2.1.- Etiqueta de eficiencia energética que Calener-VYP v1.0 genera con la simulación

El Programa informático Calener es una herramienta promovida por el Ministerio de Industria, Turismo y Comercio, a través del IDAE, y por el Ministerio de Vivienda, que permite determinar el nivel de EE 
correspondiente a un edificio. El programa consta de dos herramientas informáticas, Calener GT que se utiliza para grandes edificios del sector terciario y Calener VYP, utilizado en usos residenciales y en edificios terciarios pequeños y medianos. Se compone del programa Lider, explicado con anterioridad y el motor de cálculo Esto2, para simular las instalaciones de climatización y ACS, y en el caso de uso no residencial, también iluminación.

Calener-VYP v1.0 es de momento la única herramienta oficial que permite determinar la clase energética de viviendas de nueva construcción en España, para aplicación del método general. En el caso del método simplificado sí existen diversas herramientas reconocidas (CERMA, CE2, CES).

De momento estas normas sólo son aplicables a edificios de nueva construcción y no existe aún normativa respecto a procedimientos aplicables a edificios existentes, al estar en fase de aprobación administrativa.

La legislación Española deja en manos de las distintas Comunidades Autónomas aspectos más concretos como son el establecimiento del alcance de los órganos de control externo.

El procedimiento de certificación se basa en tres premisas:

$1^{\circ}$ - Requiere de unos indicadores energéticos que permitan comparar edificios. En el caso de España son dos: por un lado, las emisiones anuales de $\mathrm{CO}_{2}$ para servicios principales del edificio y por otro, la energía primaria anual en $\mathrm{Kwh} / \mathrm{m}^{2}$, [IDAE, 2009. Escala de Calificación Energética para edificios de nueva construcción] 
$2^{\circ}$ - Debe existir un cierto grado de similitud. En el caso de viviendas deberán estar en la misma zona. Además el procedimiento diferencia entre viviendas en bloque y viviendas unifamiliares.

$3^{\circ}$ - Se establece una escala de calificación, caracterizada por 7 letras, desde $A$ hasta $F$, indicando el rango de mayor a menor eficiencia energética. Esta escala se establece en principio para edificios de nueva construcción, pero con la posibilidad de aplicarla en edificios existentes cuando se desarrolle la normativa en ese sentido. En el caso de nueva construcción, los edificios $\mathrm{G}$ y $\mathrm{F}$ no se ajustan a los mínimos que establece el CTE, por lo que no es posible encontrar nuevos edificios fuera de los límites A-E.

Con la obtención de la calificación el edificio tendrá que ser sometido a certificación para obtener la etiqueta de EE. El comprador de la vivienda debe disponer de la información por medio de la etiqueta de certificación que se le ha otorgado al edificio, como un parámetro más de calidad. Las actuaciones en materia de certificación de EE en edificios son establecidos desde las distintas Comunidades Autónomas (CCAA), que son responsables de la creación de un Registro de certificación de EE en edificios.

En la actualidad y según información del Ministerio de Industria, Turismo y Comercio, la situación a nivel de las CCAA es desigual. Solamente existe normativa a nivel de las siguientes:

- Navarra: Orden foral $7 / 2010$, de 21 de enero, del Consejero de Innovación, Empresa y Empleo, por la que regula el Registro administrativo de certificados de eficiencia energética de edificios de nueva construcción.

- Andalucía: Orden de 25 de junio de 2008, por la que se crea el Registro Electrónico de Certificados de eficiencia energética de 
edificios de nueva construcción y se regula su organización y funcionamiento

- Canarias: Decreto 26/2009, de 3 de marzo, por el que se regula el procedimiento de visado del Certificado de Eficiencia Energética de Edificios y se crea el correspondiente Registro en el ámbito de la Comunidad Autónoma de Canarias

- Extremadura: Decreto 136/2009, de 12 de junio, por el que se regula la certificación de eficiencia energética de edificios en la Comunidad Autónoma de Extremadura

- Galicia: Decreto 42/2009, de 21 de enero, por el que se regula la certificación energética de edificios de nueva construcción en la Comunidad Autónoma de Galicia.

- Galicia: Orden de 3 de septiembre de 2009 por la que se desarrolla el procedimiento, la organización y el funcionamiento del Registro de Certificados de Eficiencia Energética de Edificios en la Comunidad Autónoma de Galicia, modificada por la Orden de 23 de diciembre de 2010 (DOG de 11 de enero de 2011).

- Valencia: Decreto 112/2009, de 31 de julio, del Consell, por el que regula las actuaciones en materia de certificación de eficiencia energética de edificios.

Hay tres fases diferentes para la certificación:

De Proyecto: incluido en el proyecto de ejecución y suscrito por el proyectista. El promotor es el responsable de su inscripción en el Registro correspondiente.

De Edificio Terminado: se comprueba si coincide con la de proyecto. Este es suscrito por la Dirección Facultativa. Será el promotor o el propietario el que lo presente al órgano competente de la Comunidad Autónoma (CA). 
De Control Externo: las CCAA establecerán el alcance (generalmente obligatorio en edificios públicos y voluntario en el resto) y las características de los controles externos que se deban realizar sobre el edificio, a fin de garantizar la veracidad de esta certificación.

El nivel de desarrollo de los distintos decretos autonómicos es variable, siendo por ejemplo muy generalista y poco descriptivo en el caso de Canarias y bastante detallado en el caso de Galicia. En algunos casos, como los de la Comunidad Valenciana, Navarra, Andalucía y Galicia, se especifica la obligatoriedad de ostentar el certificado de EE a nivel de proyecto para la obtención de la consiguiente Licencia de Obras. A nivel de edificio terminado, según CCAA, puede ser necesario para obtener la Licencia de Primera Ocupación o de Apertura (en locales), así como su inclusión en el Libro del Edificio.

En esta Tesis se obtiene la etiqueta de certificación energética de la fase de proyecto.

\section{II.3.- Nueva variable en el valor de los inmuebles: La Eficiencia Energética}

En la Directiva 2002/91/UE se define EE como: la cantidad de energía consumida realmente o que se estima necesaria para satisfacer las distintas necesidades asociadas a un uso estándar del edificio, que podría incluir, entre otras cosas, la calefacción, el calentamiento del agua, la refrigeración, la ventilación y la iluminación. Dicha magnitud deberá quedar reflejada en uno o más indicadores cuantitativos calculados teniendo en cuenta el aislamiento, las características técnicas y de la instalación, el diseño y la orientación, en relación con los aspectos climáticos, la exposición solar y la influencia de construcciones próximas, la generación de energía propia y 
otros factores, incluidas las condiciones ambientales interiores, que influyen en la demanda de energía.

Por otro lado, el artículo 3 indica, entre otras cosas, que: ...La EE de un edificio se expresará de forma clara y podrá incluir entre otras cosas un indicador de emisiones de $\mathrm{CO}_{2}$.

El artículo 7 indica que: Los Estados miembros velarán por que, cuando los edificios sean construidos, vendidos o alquilados, se ponga a disposición del propietario o, por parte del propietario, a disposición del posible comprador o inquilino, según corresponda, un certificado de EE...

Dicho certificado es el documento que refleja la calificación energética, recogida en una etiqueta energética.

En el caso Español, para la confección de la escala en el caso de viviendas se creó un escenario de comparación que estimaba la situación probable de los edificios en 2006. Las hipótesis de este escenario de comparación eran:

- Los edificios serían similares en tipologías a los construidos en el periodo 1991-2000

- Las calidades constructivas no superarían sustancialmente las exigencias del CTE-HE1

- Los sistemas térmicos y la contribución de energías renovables, seguirían los mínimos establecidos en los documentos CTEHE2 y CTE-HE4

- Se consideraría no significativa la contribución de la iluminación artificial

El proceso en el establecimiento de la escala de calificación aplicado a edificios de viviendas tuvo tres pasos [AICIA, 2009a]: 
1.- Selección de edificios representativos: Para ello se adoptaron los datos estadísticos del Instituto Nacional de Estadística del 2001. Los criterios de representatividad fueron la superficie útil en el caso de viviendas unifamiliares y el número de plantas en el caso de viviendas en bloque. Asimismo, en ambos casos se tuvo en cuenta la compacidad y el ratio porcentaje de superficie acristalada por superficie útil. Finalmente se escogieron 14 viviendas unifamiliares y 11 bloques de viviendas como representativos para caracterizar el escenario.

2.- Obtención de indicadores para cada zona climática: Para ello se establecen las condiciones de partida en cuanto a demandas, consumos de energía final, consumos de energía primaria y emisiones de $\mathrm{CO}_{2}$ para calefacción, refrigeración y ACS.

3.- Caracterización matemática: Para cada localidad se obtuvieron dos gráficas:

La primera que representa en eje de abscisas las emisiones totales de $\mathrm{CO}_{2}$ y en eje de ordenadas el porcentaje de superficie útil de viviendas nuevas que alcanzarán dichas emisiones. El valor medio de dicha distribución se denomina $I_{\text {reglamentación, }} \mathrm{y}$ es el valor medio esperado del indicador asociado a nuevos edificios que cumplen estrictamente CTE.

La segunda representa la distribución de frecuencias acumuladas. De esta última se obtienen dos ratios:

$R_{50 / 10}$ que indica el ratio entre el valor de $I_{\text {reglamentación, }} y$ el valor de emisiones correspondiente al percentil del $10 \%$ de los edificios nuevos

$R_{90 / 10}$, ratio del percentil $90 \%$ entre el percentil $10 \%$.

Los escenarios se ajustan bastante bien a la distribución de probabilidad de Weibul, utilizada con anterioridad en aplicaciones de energética en edificios. 
Se propone que la frontera entre C y D coincida con el percentil $40 \%$, por lo que, el cumplir estrictamente CTE ( Ireglamentación $_{\text {}}$ ), supone una calificación D.

Para adoptar valores en la escala se establece el límite inferior en cero emisiones, que correspondería a la clase A. Los edificios que cumplan estrictamente el CTE serán mayoritariamente C y D (sobre un 35 y $45 \%$ respectivamente), en algún caso $B$ o $E$ ( $10 \%$ de cada calificación), pero nunca $A$. 



\section{CAPÍTULO III ESTUDIO DE LA EFICIENCIA ENERGÉTICA DEL EDIFICIO}





\section{III.1. ADAPTACIÓN DEL PROYECTO AL CÓDIGO TÉCNICO DE LA EDIFICACIÓN}

\section{III.1.1.- Introducción}

El proyecto de partida está diseñado para el cumplimiento de las antiguas Normas Básicas de la Edificación. El primer paso es modificar el proyecto, de manera que se cumpla la nueva normativa, en vigor desde 2006, el Código Técnico de la Edificación (CTE) [RD 314/2006].

El estudio del proyecto revela una serie de carencias para el cumplimiento del CTE, requisito imprescindible para poder calcular el nivel de EE del edificio. Entre otras medidas, la adaptación consiste en aumentar los espesores de aislamientos o añadirlos en algunos casos, y modificar alguno de los cerramientos que forman parte de la envolvente.

Se intenta mantener en todo momento las soluciones constructivas del proyecto original, haciendo las modificaciones mínimas para conseguir cumplir con la nueva normativa. Las soluciones constructivas varían ligeramente de unas zonas climáticas a otras. En el siguiente apartado se describen las soluciones finalmente adoptadas.

\section{III.1.2- Cálculo del cumplimiento de los mínimos de la envolvente térmica. Programa Lider}

La adaptación del proyecto al CTE-HE-1, se comprueba mediante el cumplimiento de los mínimos, utilizando en este caso la opción general, que utiliza la aplicación informática Lider. Posteriormente, el edificio modelizado en Lider puede exportarse al programa Calener, con el que, una vez conocidas las necesidades de calefacción, refrigeración y ACS y aplicados los equipos y sistemas de climatización requeridos, permite obtener la calificación energética.

El siguiente cuadro esquematiza las entradas y salidas del programa Lider: 


\begin{tabular}{|c|c|}
\hline ENTRADAS & \\
\hline Zona climática & $\begin{array}{l}\text { Seleccionar entre las } 12 \text { zonas climáticas españolas (según } \\
\text { apéndice } D \text { del documento básico de ahorro de energía HE-1 } \\
\text { del CTE).Elegir provincia y altitud localidad ubicación edificio. }\end{array}$ \\
\hline Orientación edificio & Grados respecto al norte \\
\hline Tipo de edificio & Vivienda unifamiliar, plurifamiliar o edificio terciario \\
\hline Uso & $\begin{array}{l}\text { - } \text { Residencial } \\
\text { - Comercial (Intensidad baja, media o alta, con } \\
\text { ocupación de 8, 12,16 ó } 24 \text { horas en cada caso) }\end{array}$ \\
\hline $\begin{array}{l}\text { Condiciones } \\
\text { higrometría }\end{array}$ & $\begin{array}{l}\left.\text { - Clase higrométrica } 3 \text { ó inferior (HR } 55 \% \text {, Ta } 20^{\circ} \mathrm{C}\right) \text { : } \\
\text { viviendas } \\
\text { Clase higrométrica } 4\left(\mathrm{HR} 62 \%, \mathrm{~T}^{\mathrm{a}} 20^{\circ} \mathrm{C}\right) \text { : restaurantes, } \\
\text { instalaciones deportivas } \\
\text { Clase higrométrica } 5\left(\mathrm{HR} 70 \%, \mathrm{~T}^{\mathrm{a}} 20^{\circ} \mathrm{C}\right) \text { : piscinas, } \\
\text { lavanderías } \\
\text { (según apartado } 3.1 .2 \text { del documento básico de ahorro de } \\
\text { energía HE-1 del CTE) }\end{array}$ \\
\hline $\begin{array}{l}\text { Número } \\
\text { renovaciones hora }\end{array}$ & $\begin{array}{l}\text { En } \mathrm{m}^{3} \text { /hora. (Calculado según documento básico de calidad del } \\
\text { aire interior HS-3 del CTE) }\end{array}$ \\
\hline $\begin{array}{l}\text { Soluciones } \\
\text { constructivas en } \\
\text { cerramientos } \\
\text { opacos }\end{array}$ & $\begin{array}{l}\text { Definir los tipos existentes de los siguientes, con la ayuda de la } \\
\text { base de datos que lleva Lider incorporada (Catálogo de } \\
\text { Elementos Constructivos del CTE). Cuando sea necesario } \\
\text { introducir nuevos materiales. Para ello hay que obtener la } \\
\text { información del fabricante e indicar para cada capa que } \\
\text { compone el cerramiento: espesores }(\mathrm{m}) \text {, conductividad }(\mathrm{W} / \mathrm{mk}) \text {, } \\
\left.\text { densidad }\left(\mathrm{Kg} / \mathrm{m}^{3}\right) \text {, calor específico ( } / \mathrm{KgK}\right) \text {, o bien resistencia } \\
\text { térmica }\left(\mathrm{m}^{2} \mathrm{~K} / \mathrm{W}\right) \text {, así como el factor de resistencia a la difusión } \\
\text { de vapor de agua. } \\
\text { Verticales: muros exteriores, medianeras, tabiques, muros en } \\
\text { contacto con el terreno } \\
\text { Horizontales: forjados contacto con el terreno, forjados } \\
\text { interiores, cubiertas }\end{array}$ \\
\hline $\begin{array}{l}\text { Soluciones } \\
\text { constructivas en } \\
\text { cerramientos } \\
\text { semitransparentes }\end{array}$ & $\begin{array}{l}\text { Definir los tipos existentes de los siguientes, con la ayuda de la } \\
\text { base de datos que lleva Lider incorporada (Catálogo de } \\
\text { Elementos Constructivos del CTE) o por adición de nuevos } \\
\text { materiales si fuera necesario, para lo cual habrá que obtener la } \\
\text { información del fabricante. } \\
\text { - Marcos: material, posición vertical u horizontal, } \\
\text { transmitancia térmica }\left(\mathrm{W} / \mathrm{m}^{2} \mathrm{~K}\right) \text { y absortividad (según } \\
\text { apéndice E del documento básico de ahorro de energía } \\
\text { HE-1 del CTE) } \\
\text { - Cristales: material, posición vertical u horizontal, }\end{array}$ \\
\hline
\end{tabular}




\begin{tabular}{|l|l|}
\hline Geometría edificio & $\begin{array}{l}\text { transmitancia térmica }\left(\mathrm{W} / \mathrm{m}^{2} \mathrm{~K}\right) \text { y factor solar. } \\
\text { Definir forma, dimensiones superficiales, altura entre forjados } \\
\text { compartimentación interior, situación de los huecos, espacios } \\
\text { habitables o no habitables, número de pilares por espacio, } \\
\text { puentes térmicos adecuados a las soluciones constructivas y } \\
\text { todo aquello necesario para definir geométricamente la vivienda. }\end{array}$ \\
\hline SALIDAS & $\begin{array}{l}\text { Tanto para el global del edificio, como el detalle por estancias } \\
\text { (con sus superficies), al calcular el programa se obtiene: } \\
\text { Cumplimiento o no de los mínimos según CTE en } \\
\text { relativos a transmitancias y condensaciones } \\
\text { Porcentaje de calefacción y refrigeración respecto al } \\
\text { edificio de referencia. } \\
\text { Proporción relativa de calefacción y refrigeración }\end{array}$ \\
\hline
\end{tabular}

Tabla 3.1.- Resumen entradas y salidas del programa Lider

\section{III.1.3.- Aplicación al caso de estudio \\ III.1.3.1- Definición geométrica del edificio}

Se utiliza la geometría de solamente una de las viviendas. Aunque en los estados iniciales del estudio se planteó la idea de representar la promoción entera, se desechó esta idea por diversos motivos:

En primer lugar, el estudio con el modelo de hilera del edificio, no permite apreciar las diferencias entre viviendas en esquina y medianeras.

Además, el dibujar en Lider la hilera de viviendas obliga a realizar una serie de simplificaciones necesarias para que el edificio se pueda exportar posteriormente al programa Calener.

Con la promoción entera tampoco era posible crear exactamente la fachada a patio inglés (en planta sótano, fachada posterior de la vivienda) y por otro, la planta primera del edificio se trazaría con más de 30 vértices según su forma geométrica real, lo cual imposibilitaría su exportación a Calener; según esta última limitación sólo podría dibujarse una forma aproximada, para poder utilizar luego el archivo en Calener. 
La vivienda escogida y utilizada como modelo, es aquella que posee las condiciones más desfavorables, en este caso la grafiada en planos como A1. En este caso la longitud de fachada expuesta a norte es mayor (fachada más larga a NW y más corta a NE), así como la mayor dimensión de muro de sótano en contacto con el terreno. Esta vivienda es una de las viviendas esquineras, en concreto de la hilera de cinco viviendas central, que presenta una orientación $25^{\circ}$. Como los equipos a utilizar deberían ser iguales en todas las viviendas, el dimensionamiento se realiza tomando como modelo esta vivienda. En otras orientaciones y para otros módulos, el dimensionamiento sería suficiente.

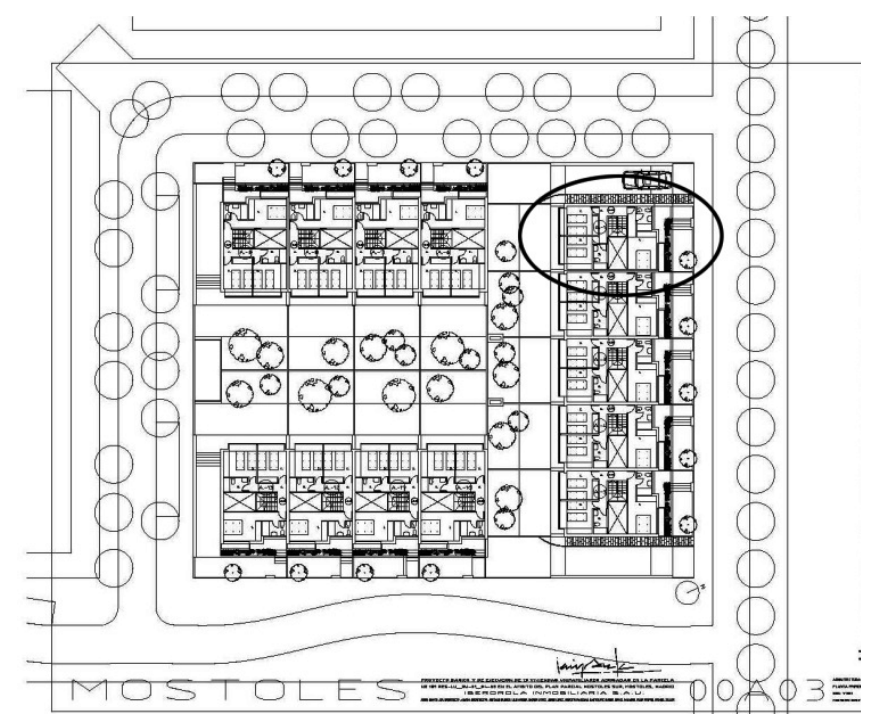

Imagen 3.1.- Vivienda seleccionada de la promoción para la simulación (Proyecto de Anaya Arquitectos, facilitada por Iberdrola Inmobiliaria S.A.U.)

\section{III.1.3.2- Definición constructiva del edificio}

El programa Lider contiene una base de datos de materiales para definir los edificios constructivamente. Esta base de datos tiene su origen en el Catálogo de Elementos Constructivos del CTE, redactado por el Instituto Eduardo Torroja de Ciencias de la Construcción. Pese a que contiene un 48 
listado soluciones bastante completo, no todos los materiales que contiene el proyecto estudiado están representados.

Una labor previa a la definición del edificio la constituye la búsqueda de materiales que estaban en el proyecto original, generalmente con nombres comerciales, para poderlos crear como nuevo material de la base de datos del programa Lider. Por ello es necesario obtener la información sobre varios materiales y soluciones constructivas, así como datos del fabricante, acerca de ciertos parámetros como la resistencia térmica $\left(m^{2} K / W\right)$, o bien espesor $(\mathrm{m})$, conductividad $(\mathrm{W} / \mathrm{mK})$, densidad $\left(\mathrm{Kg} / \mathrm{m}^{3}\right)$ y calor específico $(\mathrm{J} / \mathrm{KgK})$, en el caso de elementos opacos. Se utilizan diferentes fuentes, tanto información comercial y páginas web (ver anexo 1), como bibliografía diversa [Amarilla, 1989; Roca, 2005; Lucuik, 2006; IDAE 2008a, 2008b, 2008c; Casanovas, 2009; Mahlia, 2010].

El caso de los elementos en huecos (denominados semitransparentes según la clasificación que hace la base de datos del programa), fue necesario realizar el cálculo de los vidrios que se utilizaron en el proyecto, puesto que tampoco existían como tales en la base de datos de Lider. Para ello, se utilizó el programa Calumen desarrollado por la casa comercial Saint Gobain, que permite el cálculo de la transmitancia $\left(\mathrm{W} / \mathrm{m}^{2} \mathrm{~K}\right)$ y el factor solar de los vidrios utilizados. Con esa información se incorporan los nuevos materiales a la base de datos de Lider (ver anexo 1).

Por otro lado, como ya se ha mencionado anteriormente, zonas climáticas diferentes, requieren distintas soluciones constructivas. De acuerdo a la limitación de la demanda energética, hay 12 posibles zonas climáticas [apéndice D.1, CTE-HE1]. Cada una de las capitales de provincia está adscrita a una de estas zonas, tal y como se ve en la imagen 3.2. Esta calificación corresponde a la capital provincial, si bien, dentro de una provincia, puede haber distintas zonas climáticas cuando la altitud de la 
localidad difiera en más de $200 \mathrm{~m}$ de altitud, respecto a altura de su capital provincial.

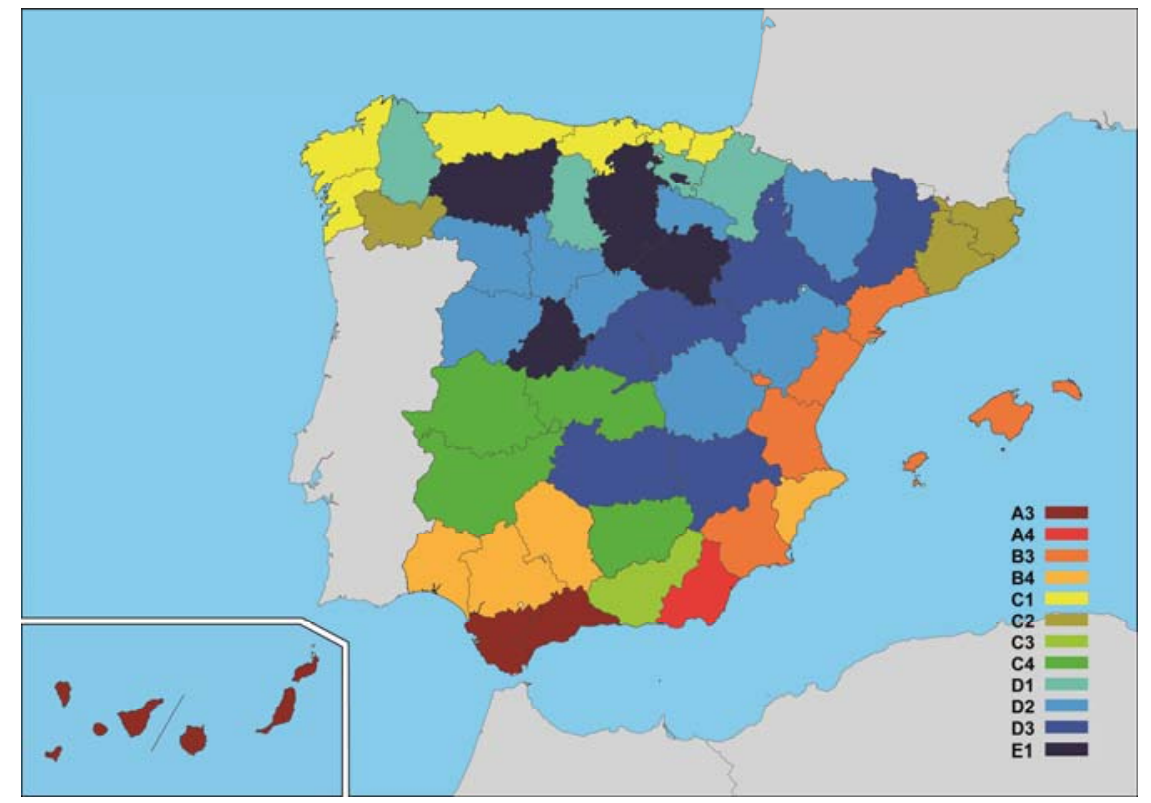

Figura 3.2.- Zonas climáticas de capitales provinciales (no toda la provincia se adscribe a la misma zona climática, al estar también condicionado por la altitud)

Para este estudio se seleccionan las siguientes capitales de provincia:

\begin{tabular}{|c|c|c|c|c|c|c|}
\hline \multicolumn{2}{|c|}{} & \multicolumn{5}{|c|}{ Calefacción } \\
\hline \multirow{4}{*}{ Refrigeración } & 1 & & B & C & D & E \\
\cline { 2 - 8 } & 2 & & & Santander & Pamplona & Burgos \\
\cline { 2 - 8 } & 3 & Málaga & Castellón & Granada & Madrid & \\
\cline { 2 - 8 } & 4 & Almería & Sevilla & Badajoz & & \\
\hline
\end{tabular}

Tabla 3.2.- Poblaciones escogidas como representación de las zonas climáticas

Esta nomenclatura, compuesta por una letra y un número indican la severidad de los veranos e inviernos respectivamente. En cuanto al invierno, la letra $A$ indica el invierno más suave (menos frío) y la letra $E$ el más severo (más frío). En cuanto al verano, el número 1 indica el verano más suave 50 
(menos calor) y el número 4 el verano más severo (más calor). Como consecuencia, de la zonas climáticas $\mathrm{A}$ a la $\mathrm{E}$ aumenta la necesidad de calefacción, y de las zonas climáticas 1 a las zonas climáticas 4 aumenta la necesidad de refrigeración. Cuanto más severo es el invierno, más exigentes son los requerimientos relativos a transmitancias y permeabilidad al aire de carpinterías.Cuanto más severo es el verano, más exigentes son los requerimientos relativos a factor solar modificado de huecos. En cuanto a la calefacción, las zonas $A$ tienen menores requerimientos que las $B$, éstas que las $C$, etc. En cuanto a refrigeración, las zonas 1 no requieren refrigeración, mientras que a mayor número, mayores necesidades. Así, por ejemplo, la zona D3, corresponde a Móstoles, ubicación del proyecto de partida. Su nomenclatura indica demandas altas, tanto en calefacción (D) como en refrigeración (3). Las combinaciones de letra y número marcadas en gris en la tabla $x$, no existen.

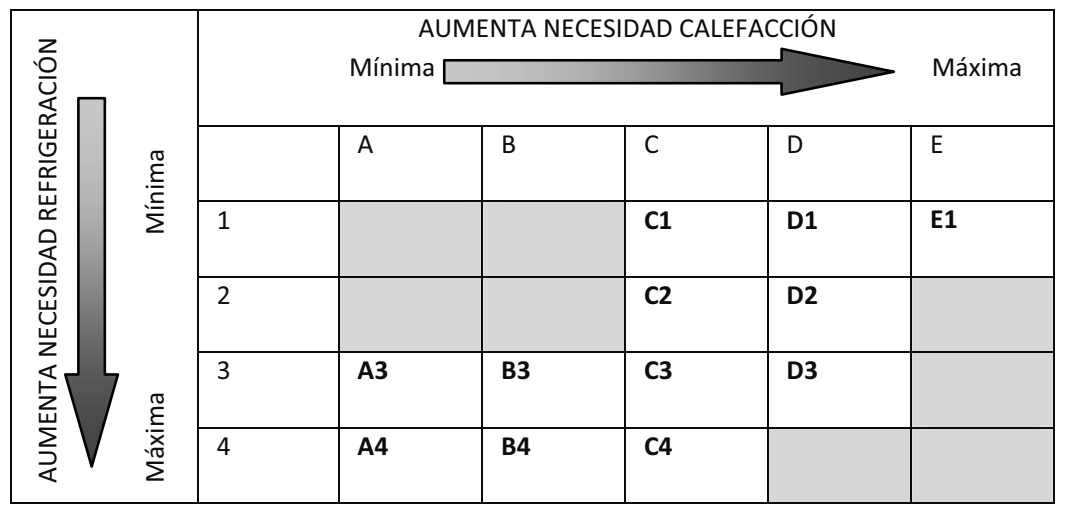

Tabla 3.3.- Esquema de nomenclatura calificación energética

Las soluciones constructivas de partida intentan ajustarse en la medida de lo posible a las originales, con los cambios estrictamente necesarios para el cumplimiento de CTE, pero usando soluciones según formatos comerciales reales, disponibles en el mercado. La composición de los cerramientos de la envolvente térmica de partida, respecto a las soluciones de origen, se esquematiza en la siguiente tabla 3.4 . 


\begin{tabular}{|c|c|c|c|}
\hline & Según NBE & \multicolumn{2}{|l|}{ Según CTE } \\
\hline Cerramiento & Sección según Proyecto & Sección A-C & Sección D-E \\
\hline $\begin{array}{l}\text { F1: Muro } \\
\text { sótano contacto } \\
\text { terreno }\end{array}$ & $\begin{array}{l}\text { HA } 30 \mathrm{~cm}+\text { cámara aire sin } \\
\text { ventilar vt } 5 \mathrm{~cm}+\mathrm{lhs} 4 \mathrm{~cm}+ \\
\mathrm{mc} 2 \mathrm{~cm}\end{array}$ & $\begin{array}{l}\text { Añadir aislamiento: } \\
\text { PUR } 3 \mathrm{~cm}\end{array}$ & $\begin{array}{l}\text { Aumentar espesor } \\
\text { aislamiento } \\
\text { respecto a zonas } \\
\text { A-C: PUR } 5 \mathrm{~cm}\end{array}$ \\
\hline $\begin{array}{l}\text { F5: Medianera } \\
\text { entre viviendas } \\
\text { en PS }\end{array}$ & $\begin{array}{l}\mathrm{mc} 1,5 \mathrm{~cm}+\mathrm{Ihd} 8 \mathrm{~cm}+ \\
\text { cámara aire sin ventilar } 10 \mathrm{~cm} \\
+ \text { Ihd } 8 \mathrm{~cm}+\mathrm{mc} 1,5 \mathrm{~cm}\end{array}$ & $\begin{array}{l}\text { Añadir aislamiento: } \\
\text { PUR } 3 \mathrm{~cm}\end{array}$ & $\begin{array}{l}\text { Aumentar espesor } \\
\text { aislamiento } \\
\text { respecto a zonas } \\
\text { A-C: PUR } 5 \mathrm{~cm}\end{array}$ \\
\hline $\begin{array}{l}\text { F6: Medianera } \\
\text { entre viviendas } \\
\text { en PB y } \mathrm{P} 1\end{array}$ & $\begin{array}{l}\text { Pladur trillaje }+\mathrm{mc} 2 \mathrm{~cm}+\mathrm{BC} \\
14 \mathrm{~cm} \text { con mortero aislante }+ \\
\mathrm{mc} 2 \mathrm{~cm}+\text { pladur trillaje }\end{array}$ & $\begin{array}{l}\text { Cumple } \\
\text { No se modifica }\end{array}$ & $\begin{array}{l}\text { Cumple } \\
\text { No se modifica }\end{array}$ \\
\hline $\begin{array}{l}\text { F7: Fachada } \\
\text { ventilada }\end{array}$ & $\begin{array}{l}\text { Efecto fv + PUR } 3 \mathrm{~cm}+\mathrm{BC} 14 \\
\mathrm{~cm} \text { con mortero aislante }+\mathrm{mc} 2 \\
\mathrm{~cm}+\text { pladur trillaje }\end{array}$ & $\begin{array}{l}\text { Modificar } \\
\text { aislamiento: Lana } \\
\text { mineral } 5 \mathrm{~cm}\end{array}$ & $\begin{array}{l}\text { Misma solución } \\
\text { que en A-C }\end{array}$ \\
\hline $\begin{array}{l}\text { Vvda-Gje: } \\
\text { Cerramiento } \\
\text { entre garaje y } \\
\text { vivienda }\end{array}$ & $\begin{array}{l}\text { No existe en proyecto inicial, } \\
\text { según proyecto, existía F3 } \\
(m c+l h d+m c), \text { que son } \\
\text { particiones interiores }\end{array}$ & $\begin{array}{l}\text { Nuevo cerramiento: } \\
\text { Lp } 1 / 2 \text { PIE }+ \text { mc } 1,5 \\
\text { cm + cámara sin } \\
\text { ventilar vt } 2 \mathrm{~cm}+ \\
\text { PUR } 3 \mathrm{~cm}+\mathrm{lhs} 4 \\
\mathrm{~cm}+\text { yeso } 1,5 \mathrm{~cm}\end{array}$ & $\begin{array}{l}\text { Nuevo } \\
\text { cerramiento y } \\
\text { mayor espesor } \\
\text { aislamiento que } \\
\text { zonas A-C: } \\
\text { Lp } 1 / 2 \text { pié + mc } \\
1,5 \mathrm{~cm}+\text { cámara } \\
\text { sin ventilar vt } 2 \\
\mathrm{~cm}+\text { PUR } 5 \mathrm{~cm}+ \\
\text { lhs } 4 \mathrm{~cm}\end{array}$ \\
\hline $\begin{array}{l}\text { PS-terreno: } \\
\text { Forjado } \\
\text { contacto } \\
\text { terreno }\end{array}$ & $\begin{array}{l}\text { Piedra artificial }+\mathrm{mc} 3 \mathrm{~cm}+ \\
\text { arena y grava }+\mathrm{HA} 10 \mathrm{~cm}+ \\
\mathrm{FR} 30 \mathrm{~cm}+\mathrm{HM} 10 \mathrm{~cm}\end{array}$ & $\begin{array}{l}\text { Añadir aislamiento: } \\
\text { xps } 5 \mathrm{~cm}\end{array}$ & $\begin{array}{l}\text { Aumentar espesor } \\
\text { aislamiento } \\
\text { respecto a zonas } \\
\text { A-C: } \\
\text { xps } 6 \mathrm{~cm}\end{array}$ \\
\hline $\begin{array}{l}\text { PS-PB. Forjado } \\
\text { entre PS Y PB }\end{array}$ & $\begin{array}{l}\text { Frondosa pesada } 2 \mathrm{~cm}+\mathrm{mc} 2 \\
\mathrm{~cm}+\mathrm{FU} 30 \mathrm{~cm}+\text { PUR } 2 \mathrm{~cm}+ \\
\text { cámara horiz ligeramnt } \\
\text { ventilada } 2 \mathrm{~cm}+\text { Pladur Foc }\end{array}$ & $\begin{array}{l}\text { Cumple } \\
\text { No se modifica }\end{array}$ & $\begin{array}{l}\text { Aumentar espesor } \\
\text { aislamiento } \\
\text { respecto a zonas } \\
\text { A-C: } \\
\text { PUR } 5 \mathrm{~cm}\end{array}$ \\
\hline $\begin{array}{l}\text { PB-P1: Forjado } \\
\text { entre PB y } \mathrm{P} 1\end{array}$ & $\begin{array}{l}\text { Frondosa pesada + mc } 2 \mathrm{~cm}+ \\
\text { FU } 30 \mathrm{~cm}+\text { cámara } \\
\text { ligeramente ventilada hz } 5 \mathrm{~cm} \\
+ \text { pladur foc }\end{array}$ & $\begin{array}{l}\text { Añadir aislamiento: } \\
\text { xps } 3 \mathrm{~cm}\end{array}$ & $\begin{array}{l}\text { Aumentar espesor } \\
\text { aislamiento } \\
\text { respecto a zonas } \\
\text { A-C: } \\
\text { xps } 5 \mathrm{~cm}\end{array}$ \\
\hline Cubierta plana & $\begin{array}{l}\text { No hay coherencia entre } \\
\text { documentos del proyecto. En } \\
\text { planos no es cubierta invertida, } \\
\text { aunque sí lo es. La descripción } \\
\text { del precio no permite saber la } \\
\text { sección exacta. Finalmente se } \\
\text { adopta: } \\
\text { Piedra artificial }+ \text { cámara } \\
\text { ligeramente ventilada hz } 10 \mathrm{~cm} \\
+ \text { HDPE } 1 \mathrm{~cm}+\text { arcilla } \\
\text { expandida } 7 \mathrm{~cm}+\mathrm{FU} 30 \mathrm{~cm}+ \\
\text { cámara ligeramente ventilada } \\
\text { hz } 5 \mathrm{~cm}+\text { pladur foc }\end{array}$ & $\begin{array}{l}\text { Añadir aislamiento: } \\
\text { xps } 3 \mathrm{~cm}\end{array}$ & $\begin{array}{l}\text { Aumentar espesor } \\
\text { aislamiento } \\
\text { respecto a zonas } \\
\text { A-C: } \\
\text { xps } 5 \mathrm{~cm}\end{array}$ \\
\hline
\end{tabular}

Tabla 3.4.- Cambios soluciones constructivas de proyecto-NBE a proyecto-CTE, según zonas climáticas 
Para definir las condiciones de partida es necesario definir además otros parámetros:

- Qué espacios se definen como habitables o como no habitables. Los espacios resultantes, con la nomenclatura que los espacios adoptan en Lider, se muestra en la siguiente tabla:

\begin{tabular}{|l|l|l|l|}
\hline $\begin{array}{l}\text { Nomenclatura } \\
\text { Lider }\end{array}$ & Tipo espacio & Planta & Estancias \\
\hline P01_E01 & No habitable & PS & Garaje \\
\hline P01_E02 & Acondicionado & PS & Acceso vivienda \\
\hline P02_E01 & Acondicionado & PB & Comedor+cocina+aseo \\
\hline P02_E02 & Acondicionado & PB & Hueco escalera \\
\hline P03_E01 & Acondicionado & P1 & Dormitorios individuales sin voladizo+baño \\
\hline P03_E02 & No habitable & P1 & Patio interior \\
\hline P03_E03 & Acondicionado & P1 & Dormitorio principal+baño \\
\hline P03_E04 & Acondicionado & P1 & *Voladizo dormitorios individuales \\
\hline P03_E05 & Acondicionado & P1 & *Voladizo dormitorio principal \\
\hline
\end{tabular}

Tabla 3.5.- Espacios resultantes en el modelo Lider. *Los voladizos se crean como espacio diferente, ya que no están en contacto por su cara interior con el exterior.

- Cuáles son las condiciones higrométricas de cada uno de esos espacios. En el caso de uso residencial, la clase higrométrica 3.

- El número de renovaciones hora necesario para cumplir con los mínimos de ventilación, basado en el cálculo según CTE-HS-3. El valor para el caso de estudio es de 0,6.

- Valor de los puentes térmicos para el caso concreto a modelizar, ya que de ellos depende el cálculo [Theodosiou, 2008]. Para cada espacio hay que definir el número de pilares, lo cual tendrá su repercusión en el cálculo. El programa Lider proporciona unos valores de partida para cada tipo de puente térmico, que hay que adaptar a cada caso concreto que se pretenda simular. Se realiza el 
cálculo de acuerdo a la promoción estudiada, utilizando los valores más adecuados [Sole, J., 2007]. Además se tiene en cuenta que se trata de una vivienda adosada, y como tal hay que adaptar los puentes térmicos, a la superficie de fachada que está expuesta al exterior y la superficie de pared medianera. Se realiza el cálculo en base a los valores promedio [Manual de Lider, apartado 5.2.2.], obteniendo en cada posible puente térmico los siguientes valores:

\begin{tabular}{|l|l|l|l|}
\hline Tipo & Fv $(\mathrm{m})$ & $\lambda$ & frsi \\
\hline Forjado-fachada & 26.25 & 0.49 & 0.65 \\
\hline Suelo exterior-fachada & 32.3 & 0.21 & 0.65 \\
\hline Cubierta-fachada & 32.73 & 0.69 & 0.59 \\
\hline Esquina saliente & 36.6 & 0.1 & 0.8 \\
\hline Hueco ventana & -- & 0.05 & 0.8 \\
\hline Esquina entrante & -- & -0.13 & 0.8 \\
\hline Pilar & -- & 0.02 & 0.89 \\
\hline Solera-Pared exterior & -- & SM1 & SM1 \\
\hline
\end{tabular}

Tabla 3.6.- Puentes térmicos adoptados para fachada ventilada en el caso de estudio. Fuente: Solé, J., 2007 (-- indica que no hay cambios)

Pese a las posibilidades que presenta Lider, ciertas soluciones constructivas no pueden ser modelizadas exactamente. En concreto, para el edificio objeto de estudio, con el fin de reflejar lo mejor posible el proyecto original, se hacen las siguientes aproximaciones:

Fachada ventilada: Los algoritmos para su simulación no están incluidos en Lider v1.0, por lo que se adopta una aproximación al comportamiento de este tipo de fachadas, basado en la norma UNE-EN-ISO 6946:1996. Según esta norma "la resistencia térmica total de un elemento de edificación que contiene una cámara de aire muy ventilada se obtendrá despreciando la resistencia térmica de la cámara de aire y las demás cámaras entre la capa de aire y el ambiente exterior, e incluyendo una resistencia superficial exterior correspondiente al aire en calma (por ejemplo, igual a la resistencia superficial interior del mismo elemento)". 
En el caso de la fachada ventilada, despreciamos la resistencia térmica a partir de la capa de aislamiento, es decir, del revestimiento cerámico y la cámara, e incluimos una resistencia superficial exterior de $0,13 \mathrm{~m}^{2} \cdot \mathrm{K} / \mathrm{W}$, en lugar de $0,04 \mathrm{~m}^{2} \cdot \mathrm{K} / \mathrm{W}$. Para hacer esto en el programa Lider v1.0, es necesario crear una un material ficticio con la resistencia térmica 0,09 $\mathrm{m}^{2} \cdot \mathrm{K} / \mathrm{W}$, que es la diferencia entre los valores anteriores de resistencia superficial (tabla E.1 del apéndice E, del CTE-DB-HE1). [Ruá, M.J. et al, 2010].

Fachada a patio inglés: Una pequeña parte de la fachada posterior, a nivel de la planta sótano, recae a un patio inglés, y en ella existen dos huecos para carpintería. El resto de la fachada está en contacto con el terreno. Es decir, requerimos dos tipos de cerramiento en un mismo paño de fachada. En este caso, para poder simular esta solución constructiva hay que eliminar el cerramiento de fachada posterior y utilizar líneas auxiliares para crear cerramientos singulares.

Plantas en voladizo: Las zonas que vuelan en planta primera, tienen el cerramiento en contacto con el exterior, mientras que el resto de la planta está en contacto con la zona acondicionada de la planta baja. Ello obliga a separar los dormitorios en dos espacios.

\section{III.2. CALIFICACIÓN ENERGÉTICA DEL EDIFICIO}

\section{II.2.1. Cálculo de la demanda de energía del edificio}

Una vez modelizado en Lider el edificio y verificado el cumplimiento de los requisitos mínimos de la envolvente, y previamente a su exportación a Calener, hay que calcular las demandas energéticas, con el fin de poder dimensionar los equipos necesarios para el servicio de la vivienda. 
Para el dimensionamiento de los equipos de climatización, se empleó el programa dpClima, desarrollado por el Departamento de Termodinámica Aplicada de la Universidad Politécnica de Valencia. Esta herramienta permite el cálculo de la carga térmica màxima (verano e invierno) de los edificios y con ello poder dimensionar la potencia de los equipos. Se realizaron los cálculos para cada una de las zonas climáticas.

La selección de equipos se hace en base a estos valores, dimensionando para cubrir al menos las necesidades calculadas. Se seleccionan modelos comerciales reales, con sus valores reales de potencia, rendimiento, etc., de acuerdo con la información que suministra el fabricante. En las soluciones de partida se utiliza, siguiendo las características del proyecto, caldera mixta estándar de gas natural, con apoyo de placas solares para agua caliente sanitaria y aire acondicionado por conductos.

Las demandas calculadas en dpclima son las reflejadas en las dos tablas siguientes, 3.7 y 3.8, para calefacción y refrigeración respectivamente:

\begin{tabular}{|c|c|c|c|c|}
\hline Zona & P02E01 & P01E02 & P03E01+P03E04 & P03E03+P03E05 \\
\hline A3 & 3,0 & 0,3 & 0,8 & 0,8 \\
\hline A4 & 2,6 & 0,3 & 0,7 & 0,7 \\
\hline B3 & 3,7 & 0,4 & 1,1 & 1,1 \\
\hline B4 & 3,6 & 0,4 & 1,0 & 1,0 \\
\hline C1 & 3,1 & 0,4 & 0,9 & 0,9 \\
\hline C2 & 3,8 & 0,4 & 1,1 & 1,1 \\
\hline C3 & 4,7 & 0,5 & 1,4 & 1,4 \\
\hline C4 & 2,7 & 0,4 & 0,8 & 0,8 \\
\hline D1 & 5,1 & 0,6 & 1,6 & 1,6 \\
\hline D2 & 4,1 & 0,5 & 1,2 & 1,2 \\
\hline D3 & 4,8 & 0,5 & 1,4 & 1,4 \\
\hline E1 & 5,3 & 0,6 & 1,6 & 1,6 \\
\hline
\end{tabular}

Tabla 3.7.- Demandas calefacción dpclima (P03E01+P03E04 constituyen una sola estancia; el modelo en Lider requiere separar en dos espacios, al tener que dar distinta solución al voladizo) 


\begin{tabular}{|c|c|c|c|c|}
\hline Zona & P02E01 & P01E02 & P03E01+P03E04 & P03E03+P03E05 \\
\hline A3 & 4,5 & 0,6 & 1,4 & 1,4 \\
\hline A4 & 5,4 & 0,6 & 1,6 & 1,6 \\
\hline B3 & 5,3 & 0,6 & 1,5 & 1,5 \\
\hline B4 & 5,8 & 0,7 & 1,8 & 1,8 \\
\hline C1 & 4,0 & 0,5 & 1,1 & 1,1 \\
\hline C2 & 5,2 & 0,6 & 1,5 & 1,5 \\
\hline C3 & 4,6 & 0,5 & 1,4 & 1,4 \\
\hline C4 & 4,2 & 0,5 & 1,3 & 1,3 \\
\hline D1 & 4,8 & 0,5 & 1,5 & 1,5 \\
\hline D2 & 4,8 & 0,5 & 1,4 & 1,4 \\
\hline D3 & 5,1 & 0,6 & 1,6 & 1,6 \\
\hline E1 & 4,0 & 0,4 & 1,6 & 1,6 \\
\hline
\end{tabular}

Tabla 3.8.- Demandas refrigeración dpclima

\section{III.2.2. Calificación energética mediante Calener VYP}

Definido el edificio para el cumplimiento del documento HE1 del CTE y calculadas las demandas de calefacción y refrigeración para cada región climática, el siguiente paso es la asignación de la clase energética mediante el programa Calener.

Partiendo de la definición geométrica y constructiva del edificio, generado con el programa Lider, debe definirse el sistema de acondicionamiento del edificio. En el caso de edificios residenciales, los sistemas a introducir serán de calefacción, refrigeración y ACS; en cada uno de éstos hay que definir qué equipos y qué unidades terminales se van a utilizar para cubrir las necesidades de confort de la vivienda. Hay que proporcionar al programa la información referente a las potencias, rendimientos nominales y a carga parcial de los equipos, caudales, temperatura de impulsión, etc., en función del tipo de equipo que se trate. En usos residenciales, por tanto, directamente se pueden importar los archivos de Lider a Calener VYP, donde, previamente a la simulación, será necesario definir los equipos y sistemas de agua caliente sanitaria, calefacción y refrigeración de la vivienda. 
El nivel de eficiencia energética que se otorga al edificio, está relacionado con las emisiones de $\mathrm{CO}_{2}$, en $\mathrm{Kg} / \mathrm{m}^{2}$.año, que son consecuencia del uso de dicho edificio y que dependerán, tanto de su envolvente térmica como del tipo de instalaciones que utilice para su servicio.

La cuantía de emisiones permite establecer la categoría o calificación que se le otorga al edificio. Hay por tanto una escala de valores, que es variable según la zona climática considerada y según el tipo de edificio sea unifamiliar o en bloque:

\begin{tabular}{|l|l|l|l|l|l|l|l|}
\hline \multirow{2}{*}{ Zona Climática } & \multirow{2}{*}{ Ciudad } & \multirow{2}{*}{$\begin{array}{l}\text { Minima solar } \\
\text { contribución }\end{array}$} & \multicolumn{5}{|l}{ Nivel Eficiencia Energética } \\
\cline { 5 - 9 } & & A & B & C & D & E \\
\hline A3 & Málaga & $60 \%$ & $<4,6$ & $4,6-8,9$ & $8,9-14,9$ & $14,9-24$ & $>24$ \\
\hline A4 & Almería & $70 \%$ & $<4,4$ & $4,4-8,3$ & $8,3-14$ & $14-22,6$ & $>22,6$ \\
\hline B3 & Castellón & $60 \%$ & $<5,4$ & $5,4-10,4$ & $10,4-17,4$ & $17,4-28$ & $>28$ \\
\hline B4 & Sevilla & $70 \%$ & $<6,3$ & $6,3-11$ & $11-17,9$ & $17,9-28,1$ & $>28,1$ \\
\hline C1 & Santander & $30 \%$ & $<7,8$ & $7,8-12,7$ & $12,7-19,8$ & $19,8-30,4$ & $>30,4$ \\
\hline C2 & Barcelona & $30 \%$ & $<7,9$ & $7,9-13$ & $13-20,2$ & $20,2-31$ & $>31$ \\
\hline C3 & Granada & $60 \%$ & $<8,2$ & $8,2-14$ & $14,4-23,2$ & $23,2-36,6$ & $>36,6$ \\
\hline C4 & Badajoz & $70 \%$ & $<7$ & $7-12,4$ & $12,4-20$ & $20-31,5$ & $>31,5$ \\
\hline D1 & Pamplona & $30 \%$ & $<13,2$ & $13,2-20,2$ & $20,2-30,2$ & $30,2-45,2$ & $>45,2$ \\
\hline D2 & Logroño & $50 \%$ & $<10,9$ & $10,9-17,8$ & $17,8-27,8$ & $27,8-42,6$ & $>42,6$ \\
\hline D3 & Madrid & $60 \%$ & $<10$ & $10-16,4$ & $16,4-25,4$ & $25,4-39,1$ & $>39,1$ \\
\hline E1 & Burgos & $30 \%$ & $<16,9$ & $16,9-25,9$ & $25,9-38,7$ & $38,7-57,9$ & $>57,9$ \\
\hline
\end{tabular}

Tabla 3.9.- Indicador $\mathrm{kg} \mathrm{CO}_{2} / \mathrm{m}^{2}$.año (para viviendas unifamiliares, según método AICIA 2009a)

En principio, la metodología que figura en el documento "Escala de calificación energética. Edificios de nueva construcción" del Instituto para la Diversificación y Ahorro de la energía, Ministerio de Industria, Turismo y Comercio. [AICIA 2009a], indica que hay dos indicadores, por un lado las emisiones de $\mathrm{CO}_{2}$ y por otro el consumo de energía primaria. Estos dos indicadores son también empleados en los métodos de otros países 
europeos [García Casals, 2006; Mínguez, 2006; Concerted Action EPBD, 2008; Martínez Alegría, 2009].

Los valores límite de consumo energético para el caso de viviendas unifamiliares en España son:

\begin{tabular}{|l|l|l|l|l|l|l|l|}
\hline \multirow{2}{*}{$\begin{array}{l}\text { Zona } \\
\text { Climática }\end{array}$} & \multirow{2}{*}{ Ciudad } & \multirow{2}{*}{$\begin{array}{l}\text { Minima } \\
\text { contribución } \\
\text { solar }\end{array}$} & \multicolumn{5}{|l|}{ Nivel Eficiencia Energética } \\
\cline { 5 - 8 } & & $\mathrm{A}$ & $\mathrm{B}$ & $\mathrm{C}$ & $\mathrm{D}$ & $\mathrm{E}$ \\
\hline A3 & Málaga & $60 \%$ & $<19,9$ & $19,9-38,2$ & $38,2-64,2$ & $64,2-103,2$ & $>103,2$ \\
\hline A4 & Almería & $70 \%$ & $<18,6$ & $18,6-35,7$ & $35,7-60,0$ & $60,0-96,4$ & $>96,4$ \\
\hline B3 & Castellón & $60 \%$ & $<23,6$ & $23,6-45,1$ & $45,1-75,9$ & $75,9-122,0$ & $>122,0$ \\
\hline B4 & Sevilla & $70 \%$ & $<26,9$ & $26,9-47,4$ & $47,4-76,6$ & $76,6-120,5$ & $>120,5$ \\
\hline C1 & Santander & $30 \%$ & $<34,5$ & $34,5-56,4$ & $56,4-87,7$ & $87,7-134,7$ & $>134,7$ \\
\hline C2 & Barcelona & $30 \%$ & $<34,6$ & $34,6-56,6$ & $56,6-88,0$ & $88,0-135,2$ & $>135,2$ \\
\hline C3 & Granada & $60 \%$ & $<35,9$ & $35,9-63,3$ & $63,3-102,4$ & $102,4-161,1$ & $>161,1$ \\
\hline C4 & Badajoz & $70 \%$ & $<31,5$ & $31,5-55,5$ & $55,5-89,8$ & $89,8-141,3$ & $>141,3$ \\
\hline D1 & Pamplona & $30 \%$ & $<59,0$ & $59,0-90,2$ & $90,2-134,8$ & $134,8-201,7$ & $>201,7$ \\
\hline D2 & Logroño & $50 \%$ & $<46,2$ & $46,2-75,6$ & $75,6-117,6$ & $117,6-180,5$ & $>180,5$ \\
\hline D3 & Madrid & $60 \%$ & $<44,2$ & $44,2-72,3$ & $72,3-112,5$ & $112,5-172,7$ & $>172,7$ \\
\hline E1 & Burgos & $30 \%$ & $<75,8$ & $75,8-115,9$ & $115,9-173,2$ & $173,2-259,2$ & $>259,2$ \\
\hline
\end{tabular}

Tabla 3.10.- Indicador $\mathrm{KWh} / \mathrm{m}^{2}$ año (para viviendas unifamiliares, según método AICIA, 2009a)

Sin embargo, el programa Calener, si bien tiene en consideración el cálculo de ambos indicadores, solamente tiene en cuenta en la calificación las emisiones de $\mathrm{CO}_{2}$, como queda de manifiesto en esta Tesis (veáse discusión capítulo VI).

La información técnica obtenida con Calener VYP se materializa en una etiqueta energética, similar a la que se utiliza en otros bienes de consumo como electrodomésticos o lámparas. Incluye valores de la $A$ a la $G$ (de mayor a menor eficiencia energética) y permite evaluar las prestaciones energéticas, aportando nuevos criterios para la adquisición de la vivienda. En nueva construcción, solamente los valores con calificación E o superior, 
superan los mínimos del CTE. Las clasificaciones $F$ y $G$ serán destinadas a viviendas existentes, cuyo proceso de certificación está en este momento todavía en vías de desarrollo administrativo.

La etiqueta de eficiencia energética debe presentar la siguiente información, tal y como se recoge en el anexo II del RD 47/2007, de 19 de enero, por el que se aprueba el Procedimiento básico para la certificación energética de edificios de nueva construcción:

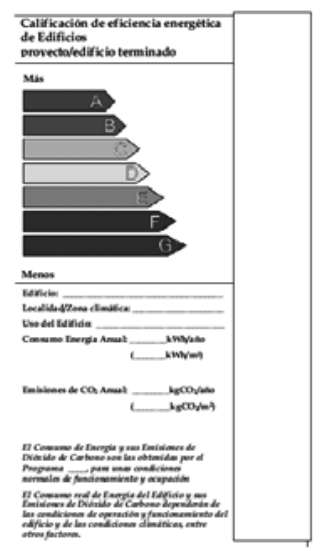

Figura 3.2.- Esquema etiqueta EE (RD 47/2007)

Las clases $D$ y $E$ son las estrictamente reglamentarias, y son las que se adoptarían en el caso de demostrar el cumplimiento del DB-HE1 con la opción simplificada. Con el uso de Lider y Calener se puede acceder a mejores calificaciones $\mathrm{C}, \mathrm{B}$ o $\mathrm{A}$. Los tipos $\mathrm{F}$ y $\mathrm{G}$ quedarían fuera de la ley, si nos referimos a viviendas de nueva construcción, al no cumplir los mínimos exigidos por el CTE.

Al realizar el dimensionamiento de los equipos, habrá que ajustar las demandas a los mínimos que cumplan los formatos comerciales, que serán los que se valorarán posteriormente.

Los datos requeridos por Calener, posteriormente a la exportación del edificio modelizado en Lider, se recogen en el siguiente cuadro:

60 


\begin{tabular}{|c|c|}
\hline ENTRADAS & \\
\hline $\begin{array}{l}\text { Demanda } \\
\text { ACS }\end{array}$ & $\begin{array}{l}\text { Conforme a lo dispuesto en el documento básico de ahorro de } \\
\text { energía HE-4 del CTE }\end{array}$ \\
\hline $\begin{array}{l}\text { Contribución } \\
\text { solar al ACS }\end{array}$ & $\begin{array}{l}\text { Mínimos conforme a lo dispuesto en el documento básico de ahorro } \\
\text { de energía HE-4 del CTE, en función de la zona climática } \\
\text { seleccionada }\end{array}$ \\
\hline $\begin{array}{l}\text { Equipos de } \\
\text { calefacción y } \\
\text { refrigeración } \\
\text { (de acuerdo al } \\
\text { cálculo de las } \\
\text { demandas } \\
\text { con dpclima) }\end{array}$ & $\begin{array}{l}\text { Seleccionar si es aire-aire con bomba de calor, caldera, de } \\
\text { acumulación, etc. En cada caso aportar los datos que demanda el } \\
\text { programa, por ejemplo combustible y rendimiento en calderas o } \\
\text { volumen y coeficiente de pérdidas en acumuladores. Cada equipo } \\
\text { lleva asociadas unas curvas de comportamiento que el programa } \\
\text { aporta por defecto, pero en su caso podrían cambiarse por otras } \\
\text { más adecuadas al mismo. }\end{array}$ \\
\hline $\begin{array}{l}\text { Unidades } \\
\text { terminales }\end{array}$ & $\begin{array}{l}\text { - De agua caliente: capacidad nominal en } \mathrm{KW} \\
\text { - De impulsión de aire: Caudal de impulsión nominal }\left(\mathrm{m}^{3} / \mathrm{h}\right) \\
\text { - De expansión directa: capacidad total de refrigeración } \\
\text { nominal, capacidad sensible de refrigeración nominal, } \\
\text { capacidad calorífica nominal, caudal de impulsión nominal }\end{array}$ \\
\hline Sistemas & Se asocian los equipos a las unidades terminales necesarias \\
\hline \multirow[t]{2}{*}{ SALIDAS } & \\
\hline & $\begin{array}{l}\text { Tanto para el edificio objeto como el de referencia, el cálculo del } \\
\text { programa proporciona los siguientes datos: } \\
\text { - Etiqueta con la calificación } \mathrm{A}, \mathrm{B}, \mathrm{C}, \mathrm{D} \text { o } \mathrm{E} \\
\text { - Demanda calefacción y refrigeración }\left(\mathrm{KWh} / \mathrm{m}^{2} \text { y } \mathrm{KWh} / \mathrm{año}\right) \\
\text { - Consumo energía final total y desglosado en calefacción, } \\
\left.\text { refrigeración y ACS ( } \mathrm{KWh} / \mathrm{m}^{2} \text { y } \mathrm{KWh} / \mathrm{año}\right) \\
\text { - Consumo energía primaria total y desglosado en } \\
\text { calefacción, refrigeración y } \mathrm{ACS}\left(\mathrm{KWh} / \mathrm{m}^{2} \text { y } \mathrm{KWh} / a n ̃ o\right) \\
\text { Emisiones } \mathrm{CO}_{2} \text { total y desglosado en calefacción, } \\
\text { refrigeración y } \mathrm{ACS}\left(\mathrm{KgCO}_{2} / \mathrm{m}^{2} \text { y } \mathrm{KgCO}_{2} / \mathrm{año}\right)\end{array}$ \\
\hline
\end{tabular}

Tabla 3.11.- Resumen entradas y salidas del programa Calener 
El cálculo en lo que se refiere a las demandas de agua caliente sanitaria (en lo sucesivo ACS) se basa en el CTE-HE-4 (apartado 3.1.1.), obteniéndose en el caso estudiado unas necesidades de $1,1 \mathrm{l} / \mathrm{m}^{2}$.día.

Por otro lado, para la generación de energía para obtener ACS, la nueva normativa, en apoyo al uso de energías renovables, establece unos valores mínimos que se deben cubrir para este fin. Las nuevas viviendas deben tener cubiertas gran porcentaje de sus necesidades de ACS, mediante energía solar, si bien es difícil conseguir el $100 \%$, ya que se trata de una fuente de energía variable y por lo tanto, deberá existir algún sistema de apoyo para cuando las aportaciones solares sean menores. Obviamente los porcentajes dependen de la zona climática de que se trate. En este sentido, en cuanto a la contribución solar mínima, se parte para el proyecto estudiado, de los mínimos que establece el CTE:

\begin{tabular}{|l|c|c|c|}
\hline Zona Lider & $\begin{array}{l}\text { Zona } \\
\text { CTE-HE4 }\end{array}$ & $\begin{array}{l}\text { Contrib. solar mínima. } \\
\text { Caso gral. Tabla 2.1. } \\
\text { Para 50-5000 l/d }\end{array}$ & $\begin{array}{l}\text { Contrib. Solar mínima. Caso } \\
\text { Efecto Joule.Tabla 2.2 } \\
\text { (Eléctrico.)Para 50-5000 l/d }\end{array}$ \\
\hline A3- Málaga & IV & 60 & 70 \\
\hline A4- Almería & V & 70 & 70 \\
\hline B3- Castellón & IV & 60 & 70 \\
\hline B4- Sevilla & V & 70 & 50 \\
\hline C1- Santander & I & 30 & 70 \\
\hline C2- Barcelona & II & 30 & 70 \\
\hline C3- Granada & IV & 60 & 70 \\
\hline C4- Badajoz & V & 70 & 70 \\
\hline D1- Pamplona & II & 30 & 60 \\
\hline D2- Logroño & III & 50 & 60 \\
\hline D3- Madrid & IV & 60 & 30 \\
\hline E1- Burgos & II & 30 & 70 \\
\hline
\end{tabular}

Tabla 3.12.- Porcentajes mínimos de contribución de energía solar, necesaria para agua caliente sanitaria, por zonas climáticas según CTE. 
En estas primeras simulaciones los equipos son similares a los que originalmente contenía el proyecto de partida. Se utilizó una caldera estándar mixta de gas natural para ACS y calefacción, en combinación con radiadores; la solución de origen ya contaba con placas solares como apoyo al acs. La refrigeración se resolvía mediante conductos. Se obvió la existencia de energía solar fotovoltaica, al no ser posible su simulación con estos programas.

En el caso de estudio, con la introducción de datos, tal y como se vio en el apartado precedente, se obtuvo una calificación $C$ ó $D$, en función de la zona climática. Hay que tener en cuenta que la vivienda fue diseñada desde un principio teniendo en cuenta criterios bioclimáticos y el cumplimiento del CTE, junto con una fase de diseño más o menos cuidada, ya permite obtener una calificación media C ó D. Obviamente esto está también condicionado por la severidad del clima de la zona seleccionada y con la adecuación mejor o peor de las soluciones constructivas al clima. En resumen, las calificaciones obtenidas fueron las que se muestran en la tabla a continuación:

\begin{tabular}{|c|c|}
\hline Zona & Calificación Calener \\
\hline A3 & $13,8 \mathrm{C}$ \\
\hline A4 & $12,9 \mathrm{C}$ \\
\hline B3 & $18,5 \mathrm{D}$ \\
\hline B4 & $17,0 \mathrm{C}$ \\
\hline C1 & $19,5 \mathrm{C}$ \\
\hline C2 & $19,6 \mathrm{C}$ \\
\hline C3 & $24,9 \mathrm{D}$ \\
\hline C4 & $21,0 \mathrm{D}$ \\
\hline D1 & $31,5 \mathrm{D}$ \\
\hline D2 & $27,1 \mathrm{C}$ \\
\hline D3 & $26,5 \mathrm{D}$ \\
\hline E1 & $43,4 \mathrm{D}$ \\
\hline
\end{tabular}

Tabla 3.13.- Resultados simulaciones para solución de adaptación del proyecto al CTE 
Partiendo de estos valores, el siguiente paso es modificar características del edificio con el fin de obtener otras calificaciones de la EE. En el apartado III.3 se estudian los parámetros a modificar, realizando en primer lugar las simulaciones con la selección de un parámetro aislado tras otro, para ver en qué orden de magnitud influye sobre las emisiones de $\mathrm{CO}_{2}$.

A partir de esta primera fase de estudio de parámetros aislados, en el apartado III.4, se analizan las posibles combinaciones de los mismos, manteniendo el criterio de obtener otra calificación energética al menor coste de inversión, es decir, intentando cambiar aquel parámetro dentro de los considerados, que suponga menor coste adicional.

\section{III.3.- PARÁMETROS QUE INFLUYEN EN LA EE}

\section{III.3.1.- Estudio de los parámetros aislados}

Una vez el proyecto ha sido adaptado al CTE, se va a trabajar en buscar viviendas con todas las calificaciones posibles. Para ello, hay que actuar sobre los factores que influyen en la EE. En esta fase del estudio se cambiarán los parámetros uno a uno para conocer, cuál es la influencia de dicha variación en la calificación energética del inmueble.

Se realiza en este apartado una clasificación de los parámetros de variación agrupados en las siguientes tipologías:

1.- Instalaciones

1.1.- Tipo de caldera

1.2.- Tipo de combustible

1.3.- Tipo de instalación

1.4.- Aumento de contribución energía solar a acs

2.- Orientación

2.1.- Norte-Sur

64 
2.2.- Este-Oeste

2.3.- Nordeste- Suroeste

2.4.- Nordoeste- Sureste

3.- Envolvente

3.1.- Inercia térmica

3.2.- Aislamientos

3.3.- Renovaciones hora

4.- Voladizos

5.- Huecos

5.1.- Dimensión del hueco

5.2.- Tipo carpintería

5.3.- Tipo vidrio

\section{III.3.1.1- Variación en las instalaciones}

\section{Tipo de caldera:}

En la configuración de origen que cumplía CTE, se utilizó una caldera de gas natural estándar (los datos de partida se muestran en negrita). A continuación se simulan de nuevo las 12 zonas climáticas utilizando Caldera de Baja Temperatura y Caldera de Condensación. En la siguiente tabla se recogen los modelos comerciales utilizados, con las características de rendimiento (recogidas de los catálogos de los modelos comerciales y corroborado con la base de datos del IDAE).

\begin{tabular}{|l|l|l|l|}
\hline Tipo caldera & Marca comercial & $\begin{array}{l}\text { Potencia } \\
(\mathrm{KW})\end{array}$ & $\begin{array}{l}\text { Rendimiento } \\
(\%)\end{array}$ \\
\hline Estándar & Immergas Hercules 27 & $\mathbf{3 1 , 4}$ & $\mathbf{9 1 , 5}$ \\
\hline Baja Temperatura & Hermann Master INox 30 SE & 32,0 & 93,7 \\
\hline Condensación & Immergas Hercules Condensing & 31,4 & 98,0 \\
\hline
\end{tabular}

Tabla 3.14.- Tipos de caldera 


\section{Tipo de combustible:}

Se utiliza de partida gas natural como combustible. Otras fuentes de energía como la electricidad o el gasóleo son energéticamente menos eficientes, al contrario que otros como la biomasa. Se simulan los distintos tipos de combustibles para conocer cómo variaría cuantitativamente la calificación, según modelos comerciales de la tabla 3.15 (ver anexo 1):

\begin{tabular}{|l|l|l|}
\hline Tipo combustible & Marca comercial & Rendimiento (\%) \\
\hline Gas natural & Immergas Hercules 27 & $\mathbf{9 1 , 5}$ \\
\hline Gasoleo & Roca Gavina 26 GTA & 88,3 \\
\hline Electricidad & Junkers HS 200 & -- \\
\hline Biomasa & PE08 Ökofen & -- \\
\hline
\end{tabular}

Tabla 3.15.- Tipo de combustible

\section{Tipo de instalación:}

El siguiente de los factores a simular esta relacionado con el tipo de instalación. De partida el proyecto tiene una caldera mixta (para agua caliente y calefacción); la distribución de calor se efectúa por medio de radiadores y la refrigeración consta de una instalación que distribuye el frío por conductos. Las configuraciones son las mostradas en la tabla 3.16:

\begin{tabular}{|l|}
\hline Acs y calefacción caldera gas natural y radiadores \\
Refrigeración por conductos \\
\hline Acs y calefacción caldera gas natural y radiadores \\
Refrigeración por splits \\
\hline Acs caldera gas natural \\
Calefacción y refrigeración con splits con bomba de calor
\end{tabular}

Tabla 3.16.- Tipo instalación 


\section{Aumento contribución solar a ACS:}

El modelo original se ajusta a los mínimos por zonas climáticas del CTE, como se vió en la tabla 3.12. En este apartado se verá la variación si se aumenta el porcentaje de contribución de energía solar, en un 15 y en un $30 \%$, según la tabla 3.17 :

\begin{tabular}{|l|}
\hline Mínimos CTE \\
\hline Mínimos CTE aumentados en un 15\% \\
\hline Mínimos CTE aumentados en un 30\% \\
\hline
\end{tabular}

Tabla 3.17.- Contribución energía solar ACS

\section{III.3.1.2.- Variación en la orientación del edificio}

El edificio objeto de simulación es aquel que, dentro de la promoción, tiene las condiciones de orientación más desfavorables, en este caso $25^{\circ} \mathrm{N}$. El parámetro orientación no se utilizará posteriormente cuando se haga la combinación de variables para obtener distintas calificaciones, ya que no es modificable en una promoción ya dada y situada sobre parcela.

Además de la orientación original de $25^{\circ}$, se tienen en cuenta las orientaciones Norte-Sur, Este-Oeste, Nordeste-Sudoeste y NoroesteSudeste, esquematizadas en la tabla 3.18:

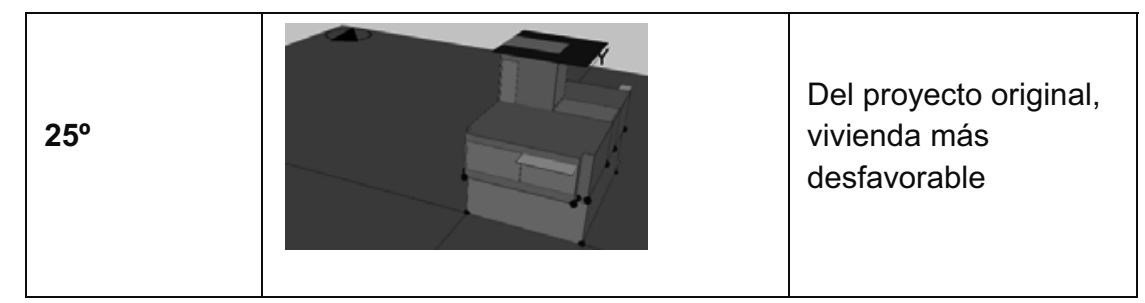




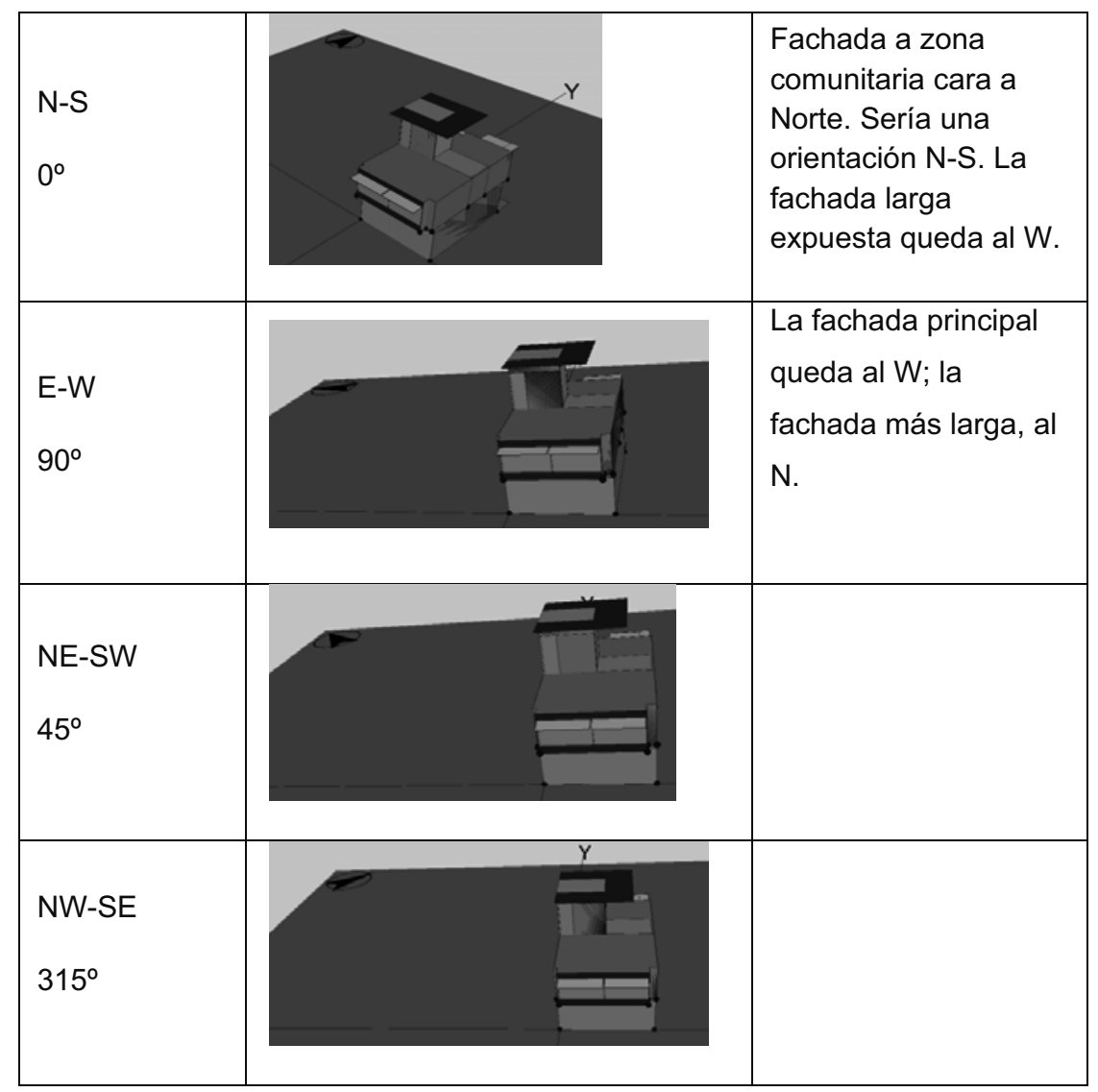

Tabla 3.18.- Orientaciones consideradas

\section{III.3.1.3.- Variación en la envolvente}

En cuanto a la influencia de envolvente se trabajó con dos parámetros, por un lado los espesores de las capas de aislamiento y por otro, cambiando el tipo de fachada, de fachada ventilada a fachada de doble hoja cara vista, con el fin de estudiar la influencia que tiene la inercia térmica sobre la EE. El tercer parámetro considerado es el número de renovaciones hora.

\section{Aislamiento:}

Hay que considerar que los espesores de aislamientos difieren en función de la zona climática. En el modelo adaptado al CTE que se utiliza de 68 
partida, hay ligeras variaciones en cuanto a las secciones constructivas y se establecen dos secciones tipo, según la vivienda se sitúe en las zonas climáticas $\mathrm{A}-\mathrm{C}$, o en zonas D-E. Se establecen por tanto, las siguientes variaciones en los aislamientos aportados en la tabla 3.19:

\begin{tabular}{|l|l|l|l|}
\hline Zona climática & Origen & Variación 1 & Variación 2 \\
\hline A-C & PUR 3 cm & PUR 5 cm & LM $8 \mathrm{~cm}$ \\
\hline D-E & PUR 5 cm & LM 8 cm & LM $10 \mathrm{~cm}$ \\
\hline
\end{tabular}

Tabla 3.19.- Variaciones de capa aislamiento en cerramiento (PUR: poliuretano; LM: lana mineral)

En este punto conviene recordar, que la elección del tipo y espesor del aislante depende de las posibilidades constructivas y de los formatos comerciales existentes. Por ejemplo, no se encontró lana mineral en formato de $10 \mathrm{~cm}$, sin embargo, se ha comprobado la utilización en situaciones reales dos capas contiguas de lana mineral de $5 \mathrm{~cm}$ de espesor, según consulta con responsable asesor Iberdrola Inmobiliaria S.A.U.

\section{Inercia térmica:}

Se simula una solución de fachada con mayor inercia térmica que la fachada ventilada de la solución de origen. Para ello, se modifica la sección del cerramiento de fachada original (denominado F7 en proyecto), por una fachada de doble hoja cerámica, con acabado exterior caravista, cámara de aire intermedia y aislamiento de lana mineral, según la sección:

1. $1 / 2$ pié $\mathrm{Im}$ métrico o catalán $40 \mathrm{~mm}<\mathrm{G}<50 \mathrm{~mm}$

2. $1,5 \mathrm{~cm}$ de mortero de cemento o cal para albañilería y para revoco/enlucido $1800<\mathrm{d}<2000$

3. Cámara de aire sin ventilar vertical $2 \mathrm{~cm}$

4. Lana Mineral $(0,04 \mathrm{~W} / \mathrm{mK}), 5 \mathrm{~cm}$ espesor

5. Tabicón lhd (60 mm $<E<90 \mathrm{~mm})$, espesor $7 \mathrm{~cm}$ 
6. Enlucido yeso $1000<\mathrm{d}<3000$, de $1,5 \mathrm{~cm}$

Esta modificación del cerramiento requiere además recalcular los puentes térmicos adecuados a esta solución constructiva:

\begin{tabular}{|l|r|r|c|}
\hline Tipo & Cv $(\mathrm{m})$ & \multicolumn{1}{|c|}{$\lambda$} & frsi \\
\hline Forjado-fachada & 9,60 & 0,49 & 0,65 \\
\hline Suelo exterior-fachada & 10,47 & 0,21 & 0,65 \\
\hline Cubierta-fachada & 9,60 & 0,69 & 0,59 \\
\hline Esquina saliente & 5,38 & 0,10 & 0,80 \\
\hline Hueco ventana & -- & 0,05 & 0,80 \\
\hline Esquina entrante & -- & $-0,13$ & 0,80 \\
\hline Pilar & -- & 0,02 & 0,89 \\
\hline Solera-Pared exterior & -- & SM1 & SM1 \\
\hline
\end{tabular}

Tabla 3.20.- Valores de puentes térmicos adoptados en fachada caravista. Fuente: Solé, J., 2007 (-- indica que no hay cambios)

\section{Número renovaciones hora verano:}

En el uso normal de las ventanas en una vivienda, lo habitual es manternerlas abiertas más frecuentemente durante el verano que durante el invierno. Las simulaciones de Lider y posteriormente Calener, no permiten hacer una distinción entre los regímenes de uso de los huecos de verano e invierno, según las condiciones climáticas, y sólo es posible dar un valor constante. Esto puede ser válido en los países del Norte de Europa, con climas fríos; sin embargo, no refleja el régimen real de uso de las ventanas en países cálidos como España.

Con este planteamiento, en esta fase del estudio, se mantienen todos los demás parámetros constantes, variando las renovaciones hora (expresadas en $\mathrm{m}^{3} / \mathrm{hora}$ ). De esa manera, se obtiene un valor medio ponderado, utilizando para los cálculos de calefacción y ACS, un valor de 0,6 renovaciones hora, (según CTE-HS-3) para invierno, tal y como qse calculó en un principio. Para refrigeración, durante el periodo estival, se adopta un 
valor de 5 renovaciones hora (cálculo según valores recomendados de velocidad del aire entre 0,2 y $0,82 \mathrm{~m} / \mathrm{s}$ de la norma UNE-EN-ISO 7730).

\section{III.3.1.4.- Variación en los voladizos}

Los voladizos son elementos de protección pasiva frente a la radiación solar y como tales conviene tener en cuenta en las fases de diseño del edificio, en combinación con la orientación del mismo. Se compara en este caso los resultados de simular el edificio con los voladizos que posee el diseño arquitectónico de origen, frente al mismo edificio sin los voladizos.

\section{III.3.1.5.- Variación en los huecos}

En este apartado se tiene en consideración zonas de la envolvente no opacas. Se puede actuar a tres niveles; el primero a tener en consideración:

\section{Dimensión del hueco:}

Se analiza la influencia en la calificación energética de reducir la dimensión de los huecos, bajo dos supuestos a partir de la orientación original del edificio. Hay por tanto tres valores recogidos en la tabla 3.21:

\begin{tabular}{|l|}
\hline Diseño de proyecto original \\
\hline Reducción $30 \%$ huecos al NE \\
\hline Reducción $30 \%$ huecos al SW \\
\hline
\end{tabular}

Tabla 3.21.- Supuestos de reducción de huecos

\section{Material del marco:}

Las carpinterías de origen son metálicas, de aluminio anodizado. Se simulan los cambios en la solución para carpinterías de dos materiales diferentes, PVC y madera. Los supuestos de carpinterías se muestran en la tabla 3.22:

\begin{tabular}{|l|}
\hline Aluminio anodizado \\
\hline PVC \\
\hline Madera \\
\hline
\end{tabular}

Tabla 3.22.- Supuestos de carpinterías 


\section{Tipo de vidrio:}

En comparación con el tipo de vidrio de proyecto, se simula un vidrio bajo la denominación "peor" y un vidrio bajo emisivo. Los vidrios laminares o de seguridad no se modifican. La situación de los vidrios cambiados, con respecto a la nomenclatura de los planos se recoge en la tablan 3.23:

\begin{tabular}{|l|l|l|l|l|}
\hline Planta & Tipo ventana & Vidrio origen & Vidrio peor & Vidrio mejor \\
\hline PS & V1-V2 & $6-12-4$ & $6-4-4$ & Mismos espesores, \\
pero bajo emisivos \\
PB & PV1-PV3-V3 & $6-12-8$ & $6-4-6$ & $6-4-6$ \\
\hline \multirow{4}{*}{ P1 } & V4-V5-V6ab-V7 & $6-12-8$ & 6 una de sus lunas \\
\cline { 2 - 4 } & VI1-VI2 & $6-12-4$ & $6-4-4$ & \\
\cline { 2 - 4 } & V6 fijo-PV2 & $44-12-6$ & $44-12-6$ & \\
\hline \multirow{4}{*}{ Casetón } & LC2 & $44-12-44$ & $44-12-44$ & \\
\cline { 2 - 4 } & LC1 & $6-12-8$ & $6-12-8$ & \\
\cline { 2 - 4 } & LC3 & $44-12-44$ & $44-12-44$ & \\
\cline { 2 - 4 } & LC4 & $1010-12-44$ & $1010-12-44$ & \\
\hline
\end{tabular}

Tabla 3.23.- Tipos de vidrios

\section{III.3.1.6.- Resultados de parámetros aislados}

A continuación se recogen resumidamente en tablas los resultados de las 25 variaciones de parámetros, que en las 12 zonas climáticas, con un total de 300 simulaciones del edificio en Calener (en negrita la solución de origen para hacer la comparación):

\section{Con respecto a las instalaciones:}

\section{Por tipo de caldera:}

Hay ligeras variaciones, obteniéndose una ligera mejora al utilizar caldera de condensación, que presenta mayor rendimiento del equipo (tabla 3.14). Las diferencias entre caldera estándar y de baja temperatura son muy pequeñas como queda reflejado en la tabla 3.24: 


\begin{tabular}{|c|c|c|c|}
\hline Zona & Estándar & Baja temperatura & Condensación \\
\hline A3 & 13,8 C & $13,8 \mathrm{C}$ & $13,6 \mathrm{C}$ \\
\hline A4 & $\mathbf{1 2 , 9} \mathbf{C}$ & $12,9 \mathrm{C}$ & $12,8 \mathrm{C}$ \\
\hline B3 & $\mathbf{1 8 , 5} \mathbf{D}$ & $18,4 \mathrm{D}$ & $18,3 \mathrm{D}$ \\
\hline B4 & $\mathbf{1 7 , 0} \mathbf{C}$ & $17,0 \mathrm{C}$ & $16,9 \mathrm{D}$ \\
\hline C1 & $\mathbf{1 9 , 5} \mathbf{C}$ & $19,4 \mathrm{C}$ & $19,2 \mathrm{C}$ \\
\hline C2 & $\mathbf{1 9 , 6} \mathbf{C}$ & $19,5 \mathrm{C}$ & $19,4 \mathrm{C}$ \\
\hline C3 & $\mathbf{2 4 , 9} \mathbf{D}$ & $24,9 \mathrm{D}$ & $24,7 \mathrm{D}$ \\
\hline C4 & $\mathbf{2 1 , 0} \mathbf{D}$ & $20,9 \mathrm{D}$ & $20,8 \mathrm{D}$ \\
\hline D1 & $\mathbf{3 1 , 5} \mathbf{D}$ & $31,4 \mathrm{D}$ & $31,2 \mathrm{D}$ \\
\hline D2 & $\mathbf{2 7 , 1} \mathbf{C}$ & $27,0 \mathrm{C}$ & $26,9 \mathrm{C}$ \\
\hline D3 & $\mathbf{2 6 , 5} \mathbf{D}$ & $26,5 \mathrm{D}$ & $26,3 \mathrm{D}$ \\
\hline E1 & 43,4 D & $43,3 \mathrm{D}$ & $43,1 \mathrm{D}$ \\
\hline
\end{tabular}

Tabla 3.24.- Resultados por tipo de caldera

\section{Por tipo de combustible:}

El uso de biomasa aporta los mejores resultados, al ser considerado como combustible neutral, es decir como que no emite $\mathrm{CO}_{2}$. En realidad sí existe cierto nivel de emisiones, pero se considera que es compensado por la cantidad de $\mathrm{CO}_{2}$, que el material absorbió durante la vida del árbol [ $\mathrm{L}$. Uzsilaityte, 2010]. Le sigue el gas natural, gasóleo y electricidad. Las emisiones por $\mathrm{KWh}$ de electricidad son de $649 \mathrm{KWh} / \mathrm{Kg} \mathrm{CO}$ y de gas natural $204 \mathrm{KWh} / \mathrm{Kg} \mathrm{CO}{ }_{2}$ [IDAE].

\begin{tabular}{|c|c|c|c|c|}
\hline Zona & Gas natural & Gasoleo & Electricidad & Biomasa \\
\hline A3 & $\mathbf{1 3 , 8} \mathbf{C}$ & $15,1 \mathrm{D}$ & $17,7 \mathrm{D}$ & $11,5 \mathrm{C}$ \\
\hline A4 & $\mathbf{1 2 , 9} \mathbf{C}$ & $14,0 \mathrm{C}$ & $17,3 \mathrm{D}$ & $11,7 \mathrm{C}$ \\
\hline B3 & $\mathbf{1 8 , 5} \mathbf{D}$ & $19,8 \mathrm{D}$ & $22,4 \mathrm{D}$ & $15,6 \mathrm{C}$ \\
\hline B4 & $\mathbf{1 7 , 0} \mathbf{C}$ & $18,1 \mathrm{D}$ & $21,4 \mathrm{D}$ & $14,7 \mathrm{C}$ \\
\hline C1 & $\mathbf{1 9 , 5} \mathbf{C}$ & $21,6 \mathrm{D}$ & $25,1 \mathrm{D}$ & $17,0 \mathrm{C}$ \\
\hline C2 & $\mathbf{1 9 , 6} \mathbf{C}$ & $21,7 \mathrm{D}$ & $23,6 \mathrm{D}$ & $15,2 \mathrm{C}$ \\
\hline C3 & $\mathbf{2 4 , 9} \mathbf{~ D}$ & $26,3 \mathrm{D}$ & $29,0 \mathrm{D}$ & $22 \mathrm{C}$ \\
\hline C4 & $\mathbf{2 1 , 0} \mathbf{D}$ & $22,1 \mathrm{D}$ & $25,5 \mathrm{D}$ & $18,6 \mathrm{C}$ \\
\hline D1 & $\mathbf{3 1 , 5} \mathbf{D}$ & $33,7 \mathrm{D}$ & $35,6 \mathrm{D}$ & $29,6 \mathrm{C}$ \\
\hline D2 & $\mathbf{2 7 , 1} \mathbf{C}$ & $28,7 \mathrm{D}$ & $30,6 \mathrm{D}$ & $23,6 \mathrm{C}$ \\
\hline D3 & $\mathbf{2 6 , 5} \mathbf{D}$ & $30,2 \mathrm{D}$ & $30,6 \mathrm{D}$ & $23,6 \mathrm{C}$ \\
\hline E1 & $\mathbf{4 3 , 4} \mathbf{D}$ & $45,6 \mathrm{D}$ & $47,6 \mathrm{D}$ & $35,0 \mathrm{C}$ \\
\hline
\end{tabular}

Tabla 3.25.- Resultados por fuente energía 


\section{Por tipo de instalación y por contribución de energía solar al ACS:}

En cuanto a tipo de instalación siempre resulta la solución más eficiente aquella con radiadores.

En cuanto a la contribución solar, lógicamente a mayor contribución de esta energía renovable, mayor EE.

\begin{tabular}{|c|c|c|c|c|}
\hline \multicolumn{3}{|c|}{ Tipo instalación } & \multicolumn{2}{l|}{ Contribución solar acs } \\
\hline $\begin{array}{c}\text { Conductos } \\
\text { Radiadores } \\
\text { Contribución solar CTE }\end{array}$ & $\begin{array}{l}\text { Splits más } \\
\text { radiadores }\end{array}$ & Splits BC & Más 15\% & Más 30\% \\
\hline 13,8 C & 12,5 C & 14,3 D & $13,1 \mathrm{C}$ & $12,4 \mathrm{C}$ \\
\hline 12,9 C & $12,5 \mathrm{C}$ & $14,4 \mathrm{D}$ & $12,2 \mathrm{C}$ & $11,5 \mathrm{C}$ \\
\hline $\mathbf{1 8 , 5}$ D & $13,8 \mathrm{C}$ & $18,9 \mathrm{D}$ & $17,7 \mathrm{D}$ & $17,0 \mathrm{C}$ \\
\hline 17,0 C & $20,2 \mathrm{D}$ & $18,6 \mathrm{D}$ & $16,3 \mathrm{C}$ & $15,6 \mathrm{C}$ \\
\hline 19,5 C & $18,0 \mathrm{C}$ & $21,5 \mathrm{D}$ & $18,7 \mathrm{C}$ & $17,9 \mathrm{C}$ \\
\hline 19,6 C & $18,6 \mathrm{C}$ & $22,1 \mathrm{D}$ & $18,9 \mathrm{C}$ & $18,1 \mathrm{C}$ \\
\hline 24,9 D & $23,0 \mathrm{C}$ & $27,4 \mathrm{D}$ & $24,2 \mathrm{D}$ & $23,4 \mathrm{D}$ \\
\hline 21,0 D & $21,9 \mathrm{D}$ & $23,0 \mathrm{D}$ & $20,2 \mathrm{D}$ & $19,5 \mathrm{C}$ \\
\hline 31,5 D & $27,9 \mathrm{C}$ & $33,2 \mathrm{D}$ & $30,7 \mathrm{D}$ & $29,9 \mathrm{C}$ \\
\hline 27,1 C & $24,4 \mathrm{C}$ & $29,2 \mathrm{D}$ & $26,3 \mathrm{C}$ & $25,5 \mathrm{C}$ \\
\hline 26,5 D & $23,6 \mathrm{C}$ & $28,7 \mathrm{D}$ & $25,8 \mathrm{D}$ & $25,0 \mathrm{C}$ \\
\hline 43,4 D & $33,4 \mathrm{C}$ & $41,6 \mathrm{D}$ & $46,2 \mathrm{D}$ & $41,8 \mathrm{D}$ \\
\hline
\end{tabular}

Tabla 3.26- Resultados por tipo de instalación y contribución solar a ACS

\section{Con respecto a la orientación:}

La orientación más eficiente es la Norte-Sur y la menos la Este-Oeste. Las diferencias obtenidas son importantes, lo cual corrobora la importancia de las decisiones que se adoptan en la fase de diseño, en este caso cómo orientar el edificio en la parcela, lo cual puede favorecer significativamente la mejor eficiencia energética del edificio. La tabla 3.27 recoge los resultados obtenidos por cambios en la orientación: 


\begin{tabular}{|c|c|c|c|c|c|}
\hline \multirow{2}{*}{ Zona } & \multicolumn{5}{|c|}{ Orientación } \\
\hline & $25^{\circ}$ & $\mathrm{NS} 0^{\circ}$ & EW $90^{\circ}$ & NwSe $315^{\circ}$ & $\mathrm{NeSw} 45^{\circ}$ \\
\hline A3 & $13,8 \mathrm{C}$ & $13,0 \mathrm{C}$ & $16,3 \mathrm{D}$ & $14,4 \mathrm{C}$ & $15,0 \mathrm{D}$ \\
\hline A4 & $12,9 \mathrm{C}$ & $12,3 \mathrm{C}$ & $14,9 \mathrm{D}$ & $13,3 \mathrm{C}$ & $13,8 \mathrm{C}$ \\
\hline B3 & $18,5 \mathrm{D}$ & $17,6 \mathrm{D}$ & $22,2 \mathrm{D}$ & $19,4 \mathrm{D}$ & $20,1 \mathrm{D}$ \\
\hline B4 & $17,0 \mathrm{C}$ & $16,2 \mathrm{C}$ & $20,0 \mathrm{D}$ & $17,7 \mathrm{C}$ & $18,5 \mathrm{D}$ \\
\hline C1 & $19,5 \mathrm{C}$ & $18,3 \mathrm{C}$ & $21,6 \mathrm{D}$ & $19,9 \mathrm{D}$ & $20,3 \mathrm{D}$ \\
\hline $\mathrm{C} 2$ & $19,6 \mathrm{C}$ & $18,8 \mathrm{C}$ & $23,1 \mathrm{D}$ & $20,6 \mathrm{D}$ & $21,0 \mathrm{D}$ \\
\hline C3 & $24,9 \mathrm{D}$ & $23,6 \mathrm{D}$ & $28,5 \mathrm{D}$ & $25,6 \mathrm{D}$ & $26,5 \mathrm{D}$ \\
\hline $\mathrm{C} 4$ & $21,0 \mathrm{D}$ & $20,0 \mathrm{C}$ & $24,0 \mathrm{D}$ & $21,7 \mathrm{D}$ & $22,4 \mathrm{D}$ \\
\hline D1 & $31,5 \mathrm{D}$ & $30,5 \mathrm{D}$ & $34,6 \mathrm{D}$ & $32,1 \mathrm{D}$ & $32,6 \mathrm{D}$ \\
\hline D2 & $27,1 \mathrm{C}$ & $25,9 \mathrm{C}$ & $30,1 \mathrm{D}$ & $27,9 \mathrm{D}$ & $28,2 \mathrm{D}$ \\
\hline D3 & 26,5 D & $25,6 \mathrm{D}$ & $29,7 \mathrm{D}$ & $27,3 \mathrm{D}$ & $27,8 \mathrm{D}$ \\
\hline E1 & 43,4 D & $38,8 \mathrm{D}$ & $42,5 \mathrm{D}$ & $40,4 \mathrm{D}$ & $40,9 \mathrm{D}$ \\
\hline
\end{tabular}

Tabla 3.27.- Resultados por orientación

\section{Respecto a la envolvente opaca:}

Los resultados de parámetros relacionados con la envolvente opaca se resumen en la tabla 3.28 , de la que se concluye que:

El aumento del aislamiento supone una mayor EE en todos los casos.

La fachada ventilada supone una mejor solución, desde el punto de vista energético, que la fachada doble hoja cerámica caravista.

El aumento de las renovaciones hora da mejores resultados en las zonas más frías $\mathrm{C} 1, \mathrm{C} 2$, D1 y E1, pero empeora en el resto de zonas. 


\begin{tabular}{|c|c|c|c|c|c|c|c|c|c|}
\hline \multirow[b]{2}{*}{ Zona } & \multirow[b]{2}{*}{ Proyec } & \multicolumn{4}{|c|}{ Aislamientos } & \multicolumn{2}{|c|}{ Inercia térmica } & \multicolumn{2}{|c|}{ Renovaciones hora } \\
\hline & & $\begin{array}{c}\text { AC PUR } \\
5\end{array}$ & AC LV 8 & DE LV 8 & DE LV 10 & FV & $\mathrm{CV}$ & 0,6 & $\begin{array}{l}\text { Aumento } \\
\text { verano }\end{array}$ \\
\hline A3 & $13,8 \mathrm{C}$ & $13,4 \mathrm{C}$ & $13,2 \mathrm{C}$ & - & - & $13,8 \mathrm{C}$ & $15,0 \mathrm{D}$ & $13,8 \mathrm{C}$ & 14,8 \\
\hline A4 & $12,9 \mathrm{C}$ & $12,6 \mathrm{C}$ & $12,4 \mathrm{C}$ & - & - & $12,9 \mathrm{C}$ & $14,0 \mathrm{C}$ & $12,9 \mathrm{C}$ & 14,0 \\
\hline B3 & $18,5 \mathrm{D}$ & $17,8 \mathrm{D}$ & $17,4 \mathrm{C}$ & - & - & $18,5 \mathrm{D}$ & $20,5 \mathrm{D}$ & $18,5 \mathrm{D}$ & 19,1 \\
\hline B4 & $17,0 \mathrm{C}$ & $16,6 \mathrm{C}$ & $16,3 \mathrm{C}$ & - & - & $17,0 \mathrm{C}$ & $18,6 \mathrm{D}$ & $17,0 \mathrm{C}$ & 19,6 \\
\hline $\mathrm{C} 1$ & $19,5 \mathrm{C}$ & $18,9 \mathrm{C}$ & $18,4 \mathrm{C}$ & - & - & $19,5 \mathrm{C}$ & $20,7 \mathrm{D}$ & $19,5 \mathrm{C}$ & 17,8 \\
\hline $\mathrm{C} 2$ & $19,6 \mathrm{C}$ & $18,9 \mathrm{C}$ & $18,5 \mathrm{C}$ & - & - & $19,6 \mathrm{C}$ & $21,7 \mathrm{D}$ & $19,6 \mathrm{C}$ & 18,9 \\
\hline C3 & 24,9 D & $24,0 \mathrm{D}$ & $23,3 \mathrm{D}$ & - & - & 24,9 D & $27,3 \mathrm{D}$ & 24,9 D & 27,1 \\
\hline $\mathrm{C} 4$ & $21,0 \mathrm{D}$ & $20,4 \mathrm{D}$ & $20,0 \mathrm{C}$ & - & - & $21,0 \mathrm{D}$ & $23,0 \mathrm{D}$ & $21,0 \mathrm{D}$ & 23,4 \\
\hline D1 & $31,5 \mathrm{D}$ & - & - & $30,9 \mathrm{D}$ & $30,5 \mathrm{D}$ & $31,5 \mathrm{D}$ & $34,2 \mathrm{D}$ & $31,5 \mathrm{D}$ & 28,1 \\
\hline $\mathrm{D} 2$ & $27,1 \mathrm{C}$ & - & - & $26,6 \mathrm{C}$ & $26,2 \mathrm{C}$ & $27,1 \mathrm{C}$ & $29,6 \mathrm{D}$ & $27,1 \mathrm{C}$ & 27,1 \\
\hline D3 & $26,5 \mathrm{D}$ & - & - & $26,0 \mathrm{D}$ & $25,5 \mathrm{D}$ & $26,5 \mathrm{D}$ & $29,1 \mathrm{D}$ & 26,5 D & 27,2 \\
\hline E1 & 43,4 D & - & - & $39,0 \mathrm{D}$ & $38,3 \mathrm{C}$ & 43,4 D & $43,6 \mathrm{D}$ & 43,4 D & 41,6 \\
\hline
\end{tabular}

Tabla 3.28.- Resultados de los parámetros de la envolvente

\section{Respecto a los voladizos:}

Las diferencias son muy pequeñas y sólo se aprecian en algunas de las zonas.

\begin{tabular}{|c|c|c|}
\hline \multirow{2}{*}{ Zona } & \multicolumn{2}{|c|}{ Voladizos } \\
\hline & Con voladizos & Sin voladizos \\
\hline A3 & $13,8 \mathrm{C}$ & $13,8 \mathrm{C}$ \\
\hline A4 & $12,9 \mathrm{C}$ & $12,8 \mathrm{C}$ \\
\hline B3 & $18,5 \mathrm{D}$ & $18,6 \mathrm{D}$ \\
\hline B4 & $17,0 \mathrm{C}$ & $17,1 \mathrm{C}$ \\
\hline $\mathrm{C} 1$ & $19,5 \mathrm{C}$ & $19,5 \mathrm{C}$ \\
\hline $\mathrm{C} 2$ & $19,6 \mathrm{C}$ & $19,6 \mathrm{C}$ \\
\hline $\mathrm{C} 3$ & 24,9 D & $24,9 \mathrm{C}$ \\
\hline C4 & $21,0 \mathrm{D}$ & $21,0 \mathrm{D}$ \\
\hline D1 & 31,5 D & $31,4 \mathrm{D}$ \\
\hline $\mathrm{D} 2$ & $27,1 \mathrm{C}$ & $27,1 \mathrm{C}$ \\
\hline D3 & 26,5 D & $26,5 \mathrm{D}$ \\
\hline E1 & 43,4 D & $39,7 \mathrm{C}$ \\
\hline
\end{tabular}

Tabla 3.29.- Resultados de eliminar voladizos 


\section{Respecto a los huecos:}

Los resultados de los cambios de los parámetros relacionados con los huecos, se muestran en la tabla 3.30.

Se puede concluir que:

EL PVC es el tipo de marco más eficiente, seguido de madera y aluminio.

Por otro lado, la menor dimensión de los huecos favorece la EE, como era de esperar, dad la mayor transmitancia térmica de los acristalamietnos frente a la envolvente opaca.

Por último, los vidrios bajo emisivos favorecen la EE.

\begin{tabular}{|c|c|c|c|c|c|c|c|c|}
\hline \multirow[b]{2}{*}{ Zona } & \multicolumn{3}{|c|}{ Material marco } & \multirow[b]{2}{*}{$\begin{array}{l}\text { Dimensión } \\
\text { proyecto }\end{array}$} & \multicolumn{2}{|c|}{ Reducción de huecos } & \multicolumn{2}{|c|}{ Tipo de vidrios } \\
\hline & Al & PVC & Madera & & $30 \% \mathrm{NE}$ & $30 \% \mathrm{SW}$ & Peor & emisivos \\
\hline A3 & $13,8 \mathrm{C}$ & $13,3 \mathrm{C}$ & $13,4 \mathrm{C}$ & $13,8 \mathrm{C}$ & $13,6 \mathrm{C}$ & $13,6 \mathrm{C}$ & $14,6 \mathrm{C}$ & $13,2 \mathrm{C}$ \\
\hline A4 & $12,9 \mathrm{C}$ & $12,5 \mathrm{C}$ & $12,5 \mathrm{C}$ & $12,9 \mathrm{C}$ & $12,6 \mathrm{C}$ & $12,7 \mathrm{C}$ & $13,6 \mathrm{C}$ & $12,4 \mathrm{C}$ \\
\hline B3 & $18,5 \mathrm{D}$ & $17,3 \mathrm{C}$ & $17,5 \mathrm{D}$ & 18,5 D & $18,3 \mathrm{D}$ & $19,0 \mathrm{D}$ & $20,1 \mathrm{D}$ & $17,0 \mathrm{C}$ \\
\hline B4 & $17,0 \mathrm{C}$ & $16,4 \mathrm{C}$ & $16,4 \mathrm{C}$ & $17,0 \mathrm{C}$ & $16,8 \mathrm{C}$ & $16,9 \mathrm{C}$ & $18,2 \mathrm{D}$ & $16,2 \mathrm{C}$ \\
\hline C1 & $19,5 \mathrm{C}$ & $18,2 \mathrm{C}$ & $18,4 \mathrm{C}$ & $19,5 \mathrm{C}$ & $19,3 \mathrm{C}$ & $18,8 \mathrm{C}$ & $20,2 \mathrm{D}$ & $18,1 \mathrm{C}$ \\
\hline $\mathrm{C} 2$ & $19,6 \mathrm{C}$ & $18,8 \mathrm{C}$ & $18,6 \mathrm{C}$ & $19,6 \mathrm{C}$ & $19,3 \mathrm{C}$ & $19,8 \mathrm{C}$ & $21,2 \mathrm{D}$ & $18,2 \mathrm{C}$ \\
\hline C3 & $24,9 \mathrm{D}$ & $23,1 \mathrm{C}$ & $23,3 \mathrm{D}$ & 24,9 D & $24,3 \mathrm{D}$ & $24,6 \mathrm{D}$ & $26,8 \mathrm{D}$ & $22,7 \mathrm{C}$ \\
\hline $\mathrm{C} 4$ & $21,0 \mathrm{D}$ & $20,4 \mathrm{D}$ & $20,1 \mathrm{D}$ & $21,0 \mathrm{D}$ & $20,7 \mathrm{D}$ & $20,7 \mathrm{D}$ & $22,3 \mathrm{D}$ & $19,8 \mathrm{C}$ \\
\hline D1 & 31,5 D & $29,4 \mathrm{C}$ & $29,7 \mathrm{C}$ & 31,5 D & $30,9 \mathrm{D}$ & $30,8 \mathrm{D}$ & $33,6 \mathrm{D}$ & $28,7 \mathrm{C}$ \\
\hline $\mathrm{D} 2$ & $27,1 \mathrm{C}$ & $25,0 \mathrm{C}$ & $25,2 \mathrm{C}$ & $27,1 \mathrm{C}$ & $26,6 \mathrm{C}$ & $26,5 \mathrm{C}$ & $28,7 \mathrm{D}$ & $24,7 \mathrm{C}$ \\
\hline D3 & $26,5 \mathrm{D}$ & $24,4 \mathrm{C}$ & $24,7 \mathrm{C}$ & $26,5 \mathrm{D}$ & $26,1 \mathrm{D}$ & $26,1 \mathrm{D}$ & $28,4 \mathrm{D}$ & $24,2 \mathrm{C}$ \\
\hline E1 & 43,4 D & $37,6 \mathrm{C}$ & $38,0 \mathrm{C}$ & 43,4 D & $39,0 \mathrm{D}$ & $38,6 \mathrm{C}$ & $42,6 \mathrm{D}$ & $36,3 \mathrm{C}$ \\
\hline
\end{tabular}

Tabla 3.30.- Resultados de variaciones en los huecos 


\section{III.4. ESTUDIO DE LA COMBINACIÓN DE PARÁMETROS}

\section{III.4.1.- Procedimiento para la combinación de parámetros}

A continuación, los resultados obtenidos en el apartado precedente se utilizan para combinar dos aspectos, la variación de los parámetros relacionados con EE, con el coste de su modificación. En un principio los cambios para cambiar la calificación energética de la vivienda, se realizan de manera que la modificación suponga el menor coste.

Los parámetros aislados dan en resumen los siguientes resultados en cuanto a la mejor y peor opción desde el punto de vista de EE (valores en apartado III.3):

\begin{tabular}{|l|l|l|}
\hline Conclusiones & Mejor calificación & Peor calificación \\
\hline Tipo caldera & $\begin{array}{l}\text { Biomasa, seguida de gas } \\
\text { natural condensación }\end{array}$ & Estándar \\
\hline Tipo combustible & Biomasa, gas natural & Electricidad \\
\hline Tipo instalación & Splits+radiadores & $\begin{array}{l}\text { Conductos en B3 y E1 Splits en el } \\
\text { resto }\end{array}$ \\
\hline $\begin{array}{l}\text { Contribución } \\
\text { solar ACS }\end{array}$ & Aumento 30\% & Mínimos CTE \\
\hline Orientación & N-S & E-W \\
\hline Aislamientos AC & LM 8 cm & PUR 3 cm \\
\hline Aislamiento DE & LM 10 com & PUR 5 cm \\
\hline Inercia térmica & Fv, cv con PT de fv & cv con PT de cv \\
\hline $\begin{array}{l}\text { Renovaciones } \\
\text { hora }\end{array}$ & Mínimo CTE & Media verano-invierno \\
\hline Voladizos & $\begin{array}{l}\text { Sensiblemente en A4, D1 } \\
\text { y E1. Poco significativo }\end{array}$ & $\begin{array}{l}\text { Sensiblemente en B3 y B4. Poco } \\
\text { significativo }\end{array}$ \\
\hline Marco & Al rotura PT & Madera o PVC según escuadría \\
\hline $\begin{array}{l}\text { Reducción } \\
\text { huecos }\end{array}$ & NE todas/SE resto & SE B3 y C2 \\
\hline Vidrios & Bajo emisivos & Peores \\
\hline
\end{tabular}

Tabla 3.31.- Conclusiones por tipos de parámetros

Hay que considerar simultáneamente dos aspectos, en primer lugar, el grado de cambio a realizar para pasar de una calificación a otra, es decir 
qué valor numérico se obtiene dentro del intervalo de calificación (más o menos cerca del límite de calificación); en segundo lugar, el coste de realizar el cambio, observando si la combinación de varias medidas puede resultar económicamente más ventajosa que una sola de ellas.

Si bien el aspecto valorativo de las soluciones se tratará con mayor detalle en el capítulo IV, es necesaria una estimación previa de precios, que oriente acerca de qué variables se deben modificar en primer lugar al menor coste. Estos precios se ajustarán después en función de la base de datos de precios que se emplee.

\section{III.4.2.- Simulación de la peor configuración}

Como se vio anteriormente, en el estudio de los parámetros aislados se han conseguido las calificaciones $C, D \circ E$. El método que se sigue en esta fase de es buscar una combinación tal que reuna los parámetros con los que se obtienen peores calificaciones $y$, desde ese punto de partida, ir introduciendo mejoras, de manera que las soluciones sean las menos costosas posible.

Cada combinación se simula en Lider y en Calener para comprobar por un lado el cumplimiento del CTE y por otro, obtener la letra correspondiente a la calificación.

Para cada zona climática, la combinación esperada como peor, que se ha denominado "Configuración de partida $(P)$ ", es la que se utiliza en primera de las simulaciones, cumpliendo el DB-HE1 y contiene las siguientes características con respecto a los parámetros que se utilizarán a continuación como influyentes en la EE, según la tabla 3.32: 


\begin{tabular}{|l|l|l|l|}
\hline & \multicolumn{1}{|c|}{ zonas A-B } & \multicolumn{1}{c|}{ zona C } & \multicolumn{1}{c|}{ zonas D-E } \\
\hline Caldera & Termo & Termo & Termo \\
\hline Combustible & Electricidad & Electricidad & Electricidad \\
\hline Tipo Instalación & Splits BC & Splits BC & Splits BC \\
\hline Contribución solar ACS & Mínimo CTE & Mínimo CTE & Mínimo CTE \\
\hline $\begin{array}{l}\text { Aislamientos } \\
\text { envolvente excepto } \\
\text { fachada }\end{array}$ & PUR 3 cm & PUR 3 cm & PUR 5 cm \\
\hline Aislamientos fachada & LM 5 cm & LM 5 cm & LM 5 cm \\
\hline $\begin{array}{l}\text { Fachada-Inercia } \\
\text { Térmica }\end{array}$ & Caravista & Caravista & $\begin{array}{l}\text { Caravista con } \\
\text { barrera de vapor }\end{array}$ \\
\hline $\begin{array}{l}\text { Renovaciones Hora } \\
\text { (S/CTE) }\end{array}$ & 0,6 & 0,6 & 0,6 \\
\hline Carpintería & Al sin rotura PT & Al con rotura PT & Al con rotura PT \\
\hline Vidrio & $\mathbf{4 - 6 - 6 ~ y ~ 4 - 6 - 4 ~}$ & $\mathbf{4 - 6 - 6 ~ y ~ 4 - 6 - 4 ~}$ & 6-12-4 y 6-12-8 \\
\hline
\end{tabular}

Tabla 3.32.- Configuración de partida P: Aquella que cumple con el menor coste a priori y con la peor calificación (en negrita medidas con cambios según zonas climáticas)

Como ocurriera con las secciones constructivas que se modelizaron para la adaptación del proyecto al CTE, hay ligeras diferencias entre las zonas climáticas. Si adoptamos las soluciones de A-C en las zonas D-E, no se cumple con la comprobación de Lider, y por tanto, con el documento DB-

HE1. Las principales diferencias se recogen en la tabla 3.32:

- En aislamientos: las zonas más severas $D$ y E, requieren mayor espesor.

- En fachada caravista: las zonas más severas $D$ y $E$, requieren incorporar una barrera de vapor para evitar condensaciones.

- En cuanto a huecos para cumplir con las transmitancias mínimas que indica el CTE:

- Carpinterías con rotura de puente térmico en las zonas C, D yE.

- Vidrios con mayores espesores, en D y E. 
En estas primeras 24 simulaciones, 12 en Lider y 12 en Calener, los resultados obtenidos otorgan una calificación entre $D$ y $E$ según zonas climáticas, quedándose en todos los casos muy cerca del límite entre ambas calificaciones. Esto indica que pequeños cambios permitirían mejorar la calificación de E a D.

Los resultados se muestran en la tabla 3.33, donde se aporta también el intervalo de calificación para mostrar la proximidad a los límites.

Para la solución de partida, se obtiene calificación $D$ en las zonas $A 3, A 4$, B3, C3, C4, D3 y E1, y calificación E en los demás casos:

\begin{tabular}{|c|c|c|c|c|c|}
\hline Zona & $\begin{array}{c}|c| \\
\text { Calefacción/Refrigeración } \\
(\% \text { respecto referencia })\end{array}$ & $\begin{array}{c}\text { Calener } \\
\left(\mathrm{KgCO}^{2} / \mathrm{m}^{2} \text {.año }\right)\end{array}$ & $\begin{array}{c}\text { Calificación } \\
\text { Calener }\end{array}$ & $\begin{array}{c}\text { Intervalo } \\
\text { clase } \\
\text { energética }\end{array}$ \\
\hline A3 & 86,0 & 77,9 & 23,3 & $\mathrm{D}$ & $14,9-24$ \\
\hline A4 & 81,9 & 91,0 & 22,5 & $\mathrm{D}$ & $14-22,6$ \\
\hline B3 & 94,1 & 74,4 & 27,5 & $\mathrm{D}$ & $17,4-28$ \\
\hline B4 & 92,1 & 90,1 & 28,2 & $\mathrm{E}$ & $>28,1$ \\
\hline C1 & 92,2 & 23,0 & 33,5 & $\mathrm{E}$ & $>30,4$ \\
\hline C2 & 87,1 & 89,2 & 32,3 & $\mathrm{E}$ & $>31,0$ \\
\hline C3 & 82,4 & 72,3 & 36,2 & $\mathrm{D}$ & $>36,6$ \\
\hline C4 & 86,1 & 89,7 & 31,1 & $\mathrm{D}$ & $>31,5$ \\
\hline D1 & 87,1 & 65,0 & 46,0 & $\mathrm{E}$ & $>45,2$ \\
\hline D2 & 90,8 & 83,3 & 43,6 & $\mathrm{E}$ & $>42,6$ \\
\hline D3 & 97,9 & 78,2 & 37,2 & $\mathrm{D}$ & $25,4-39,1$ \\
\hline E1 & 96,0 & 62,0 & 51,8 & $\mathrm{D}$ & $38,7-57,9$ \\
\hline
\end{tabular}

Tabla 3.33.- Resultados Lider y Calener primeras simulaciones configuración $\mathrm{P}$

De la tabla 3.33 se concluye que la comparación de la calificación energética para cada configuración inicial se debe considerar separadamente entre zonas climáticas, pudiendo encontrar tres grupos:

- Zonas climáticas A y B: Para las zonas A y B3 se obtiene una calificación energética $D$, mientras que para la zona climática $B 4$, dicha calificación es E. Las zonas climáticas con condiciones más benignas en invierno (A) alcanzan mejores calificaciones energéticas, así como las más zonas más benignas en verano (3). 
- Zonas climáticas C: C1 y C2 alcanzan una calificación E, mientras que C3 y C4 adoptan una calificación energética D. En este caso, pese a que las zonas $\mathrm{C} 1$ y 2 son más benignas en condiciones de verano, obtienen una peor calificación energética. El motivo es que en estos casos, a pesar de que en $\mathrm{C} 1$ y $\mathrm{C} 2$ se generan menos emisiones en $\mathrm{Kg}$ de $\mathrm{CO}_{2}$, los valores límite para la calificación son más restrictivos que en $\mathrm{C} 3$. Con respecto a la zona $\mathrm{C} 4$, a pesar de ser más dura en condiciones de verano, adquiere mejor calificación energética que en las zonas C1 y C2. La explicación en este caso tiene que ver a la reducción de consumo energético que se consigue por una mayor contribución solar en la zona $\mathrm{C} 4$, según los mínimos que establece el CTE (tabla 3.12).

- Zonas climáticas $D$ y E: Se obtiene calificación energética $E$ en las zonas D1 y D2, mientras que en las zonas D3 y E1, la calificación es D. Aunque la zona climática D1 y D2 son más suaves que la E1, en condiciones de invierno, la vivienda adquiere una peor calificación energética. La razón es que aunque el edificio en las zonas D1 y D2 genera menos emisiones que en la zona climática E1, los valores límite para otorgar la calificación son más restrictivas cuanto más suave es la zona (como ocurriera entre C1-C2 y C3). Aunque la zona climática D3 es más dura que D1 and D2, en condiciones de verano, la vivienda adosada adquiere peor eficiencia energética en D1 y D2. El motivo es que, en Madrid (zona climática D3) las emisiones totales de $\mathrm{CO}_{2}$ son menores, dado que se puede alcanzar una reducción significativa al utilizar energía solar en la producción de ACS (tabla 3.12). 


\section{III.4.3.- Combinaciones para mejorar la calificación}

En las configuraciones de partida que resultaron $D$ se buscará las calificaciones $C, B$ y $A$. En las que resultaron $E$, se buscará $D, C, B$ y A. Es decir, a priori deben obtenerse 43 nuevas simulaciones en Lider y 43 en Calener, con las que se obtengan los resultados deseados (sumadas a las 12+12 de partida). En la búsqueda de dichos resultados, las realmente realizadas fueron muchas más.

El procedimiento a partir de este momento es mucho más complejo, ya que hay que ir comprobando las combinaciones que van a ir mejorando la calificación. En la decisión de qué medida adoptar se van a conjugar varios criterios:

- Precio de la modificación

- Cuánto hay que lograr bajar las emisiones de $\mathrm{CO}_{2}$, en función de lo cerca que se esté del límite inferior de la calificación y cuánto se puede sobrepasar ese límite con cada medida.

- Considerar una sola de las posibles soluciones de mejora puede no ser suficiente para obtener el cambio de calificación deseado (¿una medida que consiga cambio en calificación es más económica que combinar dos medidas?)

El criterio de que se adoptó en un principio, de ir introduciendo soluciones desde las más económicas a las más caras, es difícil de mantener homogéneo entre zonas, debido a las diferencias climáticas y constructivas. Para aquellas que dieron E, como ya se vió muy cerca de la calificación $D$, un pequeño cambio sería suficiente para cambiar de calificación. Para aquellas otras que dieron $D$, pero próximas a $E$, se requerirán cambios que sean cuantitativamente importantes en cuanto a las emisiones, para pasar a C.

Se une además el hecho de que es difícil obtener las calificaciones B y A, ya que son muy exigentes, e incluso utilizando todas las variables 
consideradas, en ocasiones no se podrán alcanzar y habrá que introducir nuevas medidas si queremos obtener mejoras en la calificación; por ejemplo se utilizarán vidrios de control solar o se incrementarán las superficies de lamas en zonas donde las exigencias de refrigeración nos impidan mejorar.

En cada caso, habrá que estudiar el "punto débil" de la calificación. Calener permite diferenciar resultados por contribución de calefacción, refrigeración y acs de forma separada, lo cual servirá de orientación respecto a los cambios a adoptar.

Por otro lado, algunas de las medidas, tales como la caldera de biomasa o los aumentos de espesor de aislamiento, conllevan algunos problemas a nivel práctico, que se irán viendo a lo largo de la presente Tesis.

Uno de estos problemas mencionados es que la caldera de biomasa tiene la desventaja de tener unos requerimientos de espacio, que no todas las promociones o tipologías de viviendas podrían adoptar. Sin embargo, el caso de estudio, permite su uso, utilizando el espacio disponible en planta sótano.

En cuanto a los aislamientos, el problema también es de difícil cuantificación, en primer lugar por que es una material que aparece en distintas partes de la envolvente y en segundo lugar porque dependiendo del cerramiento, el tipo empleado difiere. Así, por ejemplo, utilizamos lana mineral en fachadas y xps en cubierta, porque la tipología de cubierta invertida así lo requiere. En lo sucesivo, el cambio de aislamiento tendrá que ver solamente con el espesor y se realizará a nivel de fachada.

Por todo ello, y a falta de hacer un estudio económico más profundo, se hacen una serie de simplificaciones en cuanto a la toma de medidas para pasar de calificación. En resumen, partiendo de los cinco grupos de 
medidas que se consideraron en un principio, no se considera la orientación, ya que implica cambios en el diseño del proyecto, ni los voladizos, ya que éstos además no aportan cambios significativos en este caso. La selección de los cambios a realizar se muestra en el esquema:

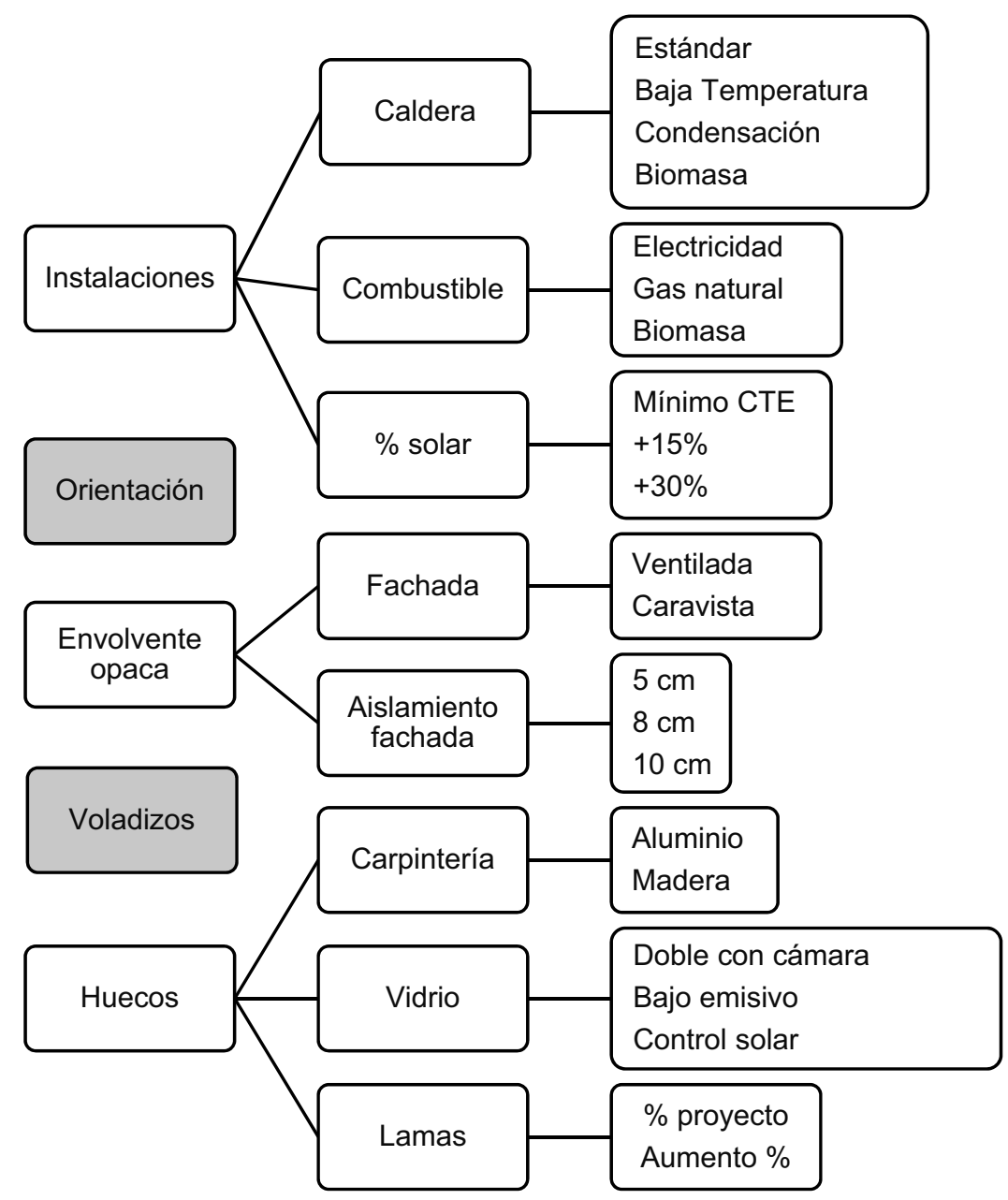

Figura 3.3.- Selección de cambios

Las variaciones sobre las que se hacen las simulaciones desde la configuración de partida $\mathrm{P}$, se recogen en la tabla 3.34: 


\begin{tabular}{|c|c|c|c|c|}
\hline Tipo & Medida & Zonas A-C & Zonas D-E & $\begin{array}{l}\text { Medidas por precios de menor } \\
\text { a mayor }\end{array}$ \\
\hline \multirow[t]{4}{*}{ Instalaciones } & Caldera & Termo & Termo & $\begin{array}{l}\text { Caldera estándar } \\
\text { Caldera baja temperatura } \\
\text { Caldera condensación } \\
\text { Caldera y silo biomasa }\end{array}$ \\
\hline & Combustible & Electricidad & Electricidad & $\begin{array}{l}\text { Gas natural } \\
\text { Biomasa }\end{array}$ \\
\hline & $\begin{array}{l}\text { Tipo } \\
\text { Instalación }\end{array}$ & $\begin{array}{l}\text { Splits } \\
\text { bomba } \\
\text { calor }\end{array}$ & $\begin{array}{l}\text { Splits } \\
\text { bomba } \\
\text { calor }\end{array}$ & $\begin{array}{l}\text { Splits refrigeración y bomba } \\
\text { calor en calefacción } \\
\text { Radiadores en calefacción }\end{array}$ \\
\hline & $\begin{array}{l}\text { Contribución } \\
\text { solar ACS }\end{array}$ & $\begin{array}{l}\text { Mínimo } \\
\text { CTE }\end{array}$ & $\begin{array}{l}\text { Mínimo } \\
\text { CTE }\end{array}$ & $\begin{array}{l}15 \% \\
30 \%\end{array}$ \\
\hline \multirow[t]{2}{*}{$\begin{array}{l}\text { Envolvente } \\
\text { opaca }\end{array}$} & $\begin{array}{l}\text { Aislamientos } \\
\text { fachada }\end{array}$ & LM $5 \mathrm{~cm}$ & LM $5 \mathrm{~cm}$ & $\begin{array}{l}\text { LM } 8 \mathrm{~cm} \\
\text { LM } 10 \mathrm{~cm}\end{array}$ \\
\hline & $\begin{array}{l}\text { Fachada- } \\
\text { Inercia } \\
\text { Térmica }\end{array}$ & Caravista & $\begin{array}{l}\text { Caravista } \\
\text { con barrera } \\
\text { de vapor }\end{array}$ & $\begin{array}{l}\text { Fachada ventilada (con } \\
\text { puentes térmicos } \\
\text { correspondientes) }\end{array}$ \\
\hline \multirow[t]{2}{*}{ Huecos } & Carpintería & $\begin{array}{l}\text { A-B: } \mathrm{Al} \sin \\
\text { rotura } \mathrm{PT} \\
\text { C: Al con } \\
\text { rotura PT } \\
\end{array}$ & $\begin{array}{l}\mathrm{Al} \text { con } \\
\text { rotura } \mathrm{PT}\end{array}$ & $\begin{array}{l}\text { Al sin RPT } \\
\text { Al con RPT- Madera }\end{array}$ \\
\hline & Vidrio & $\begin{array}{l}4-6-6 \text { y } 4-6- \\
4\end{array}$ & $\begin{array}{l}6-12-4 \text { y } 6- \\
12-8\end{array}$ & $\begin{array}{l}\text { Vidrios } 6-12-4 ; 6-12-8 \\
\text { Vidrios bajo emisivos } \\
\text { Vidrios control solar } \\
\text { Aumento superficie lamas }\end{array}$ \\
\hline
\end{tabular}

Tabla 3.34.- Cambios a realizar para cambio de calificación

El orden en que hubo que introducir los cambios para pasar de la configuración de partida, D ó E, según los casos, a calificación energéticamente más eficiente, se recoge en la tabla 3.35. Existe variación del parámetro en aquellos cuadros oscurecidos. Entre los cuadros señalados hay tres formatos: los cuadros en gris indican cambios que sí alcanzaron la calificación buscada. En la calificación $B$, encontramos cuadros en gris oscuro indican cambios que sí alcanzaron la calificación buscada, pero la solución resultaba más costosa que la solución A. Esta última se lograba directamente aplicando caldera de biomasa a las soluciones adoptadas en C. Los cuadros con un aspa indican que se realizó las modificaciones señaladas pero no se alcanzó la calificación buscada con el uso de todas las variables disponibles. 


\begin{tabular}{|c|c|c|c|c|c|c|c|c|c|c|c|c|c|}
\hline Clase & Cambios & A3 & A4 & B3 & B4 & $\mathrm{C} 1$ & $\mathrm{C} 2$ & C3 & $\mathrm{C} 4$ & D1 & $\mathrm{D} 2$ & D3 & $\mathrm{E} 1$ \\
\hline \multirow{11}{*}{ D } & Carpintería madera & & & & & & & & & & & & \\
\hline & Gas natural y radiadores & & & & & & & & & & & & \\
\hline & Vidrios $6-12-4 ; 6-12-8$ & & & & & & & & & & & & \\
\hline & Vidrios control solar & & & & & & & & & & & & \\
\hline & Vidrios bajo emisivos & & & & & & & & & & & & \\
\hline & Incremento \% lamas & & & & & & & & & & & & \\
\hline & Lana mineral $8 \mathrm{~cm}$ & & & & & & & & & & & & \\
\hline & Lana mineral $10 \mathrm{~cm}$ & & & & & & & & & & & & \\
\hline & Fachada ventilada & & & & & & & & & & & & \\
\hline & Incremento \% solar ACS & & & & & & & & & & & & \\
\hline & Caldera biomasa+silo & & & & & & & & & & & & \\
\hline \multirow{11}{*}{ C } & Carpintería madera & & & & & & & & & & & & \\
\hline & Gas natural y radiadores & & & & & & & & & & & & \\
\hline & Vidrios $6-12-4 ; 6-12-8$ & & & & & & & & & & & & \\
\hline & Vidrios control solar & & & & & & & & & & & & \\
\hline & Vidrios bajo emisivos & & & & & & & & & & & & \\
\hline & Incremento \% lamas & & & & & & & & & & & & \\
\hline & Lana mineral $8 \mathrm{~cm}$ & & & & & & & & & & & & \\
\hline & Lana mineral $10 \mathrm{~cm}$ & & & & & & & & & & & & \\
\hline & Fachada ventilada & & & & & & & & & & & & \\
\hline & Incremento \% solar ACS & & & & & & & & & & & & \\
\hline & Caldera biomasa+silo & & & & & & & & & & & & \\
\hline \multirow{11}{*}{ B } & Carpintería madera & & & & & & & & & & & & \\
\hline & Gas natural y radiadores & & & & & & & & & & & & \\
\hline & Vidrios $6-12-4 ; 6-12-8$ & & & & & & & & & & & & \\
\hline & Vidrios control solar & & & & & & & & & & & & \\
\hline & Vidrios bajo emisivos & & & & & & & & & & & 8 & \\
\hline & Incremento \% lamas & & & & & & & $\times$ & & & & & \\
\hline & Lana mineral $8 \mathrm{~cm}$ & & & & & & & & & & & & \\
\hline & Lana mineral $10 \mathrm{~cm}$ & & & & & & & & & & & 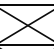 & \\
\hline & Fachada ventilada & & & & & & & & & & & $\sum$ & \\
\hline & Incremento \% solar ACS & & & & & & & 7 & & & & $\sum$ & \\
\hline & Caldera biomasa+silo & & & & & & & & & & & & \\
\hline \multirow{11}{*}{ A } & Carpintería madera & & & & & & & & & & & & \\
\hline & Gas natural y radiadores & & & & & & & & & & & & \\
\hline & Vidrios $6-12-4 ; 6-12-8$ & & & & & & & & & & & & \\
\hline & Vidrios control solar & & & & & & & & & & & & \\
\hline & Vidrios bajo emisivos & & & & & & & & & & & & \\
\hline & Incremento \% lamas & & & & & & & & & & & & \\
\hline & Lana mineral $8 \mathrm{~cm}$ & & & & & & & & & & & & \\
\hline & Lana mineral $10 \mathrm{~cm}$ & & & & & & & & & & & & \\
\hline & Fachada ventilada & & & & & & & & & & & & \\
\hline & Incremento \% solar ACS & & & & & & & & & & & & \\
\hline & Caldera biomasa+silo & & & & & & & & & & & & \\
\hline
\end{tabular}

Tabla 3.35.- Cambios por calificaciones 
La configuración de partida es D en las zonas A3, A4, B3, C3, C4, D3 y E1, por lo que no se consideran las combinaciones de esas zonas con la calificación E. No se logra alcanzar la calificación B en las zonas C3, C4 ni D3. Finalmente de las 60 combinaciones esperadas a priori, se han obtenido 50.

Los cambios necesarios para mejorar la calificación, según la tabla 3.35 se explican a continuación:

- Cambio de calificación energética E a D: Las zonas climáticas en las que con la solución inicial alcanza la calificación E son A4, C1, C2, D1, D3. Incrementar la capa de aislamiento en espesor es suficiente para alcanzar la calificación D en las zonas climáticas B4, $\mathrm{D} 1$ and D2, pero no en $\mathrm{C} 1$ y C2. En estos dos últimos casos, el uso de caldera de gas natural con radiadores resulta la solución más económica que consegue alcanzar la calificación deseada.

- Cambio de calificación energética D a C: En todas las zonas climáticas se requiere el cambio a caldera de gas natural. También el incremento del espesor de los vidrios donde inicialmente se utilizaban vidrios 6-4-6 and 6-4-4. El uso de carpintería de madera es necesario excepto en las zonas climáticas C3, C4, D1, D2. A pesar de que los perfiles de madera son soluciones costosas, es la única solución que permite alcanzar la calificación $\mathrm{C}$ en la mayor parte de zonas climáticas.

- Cambio de calificación energética C a B: Esta calificación sólo se puede alcanzar utilizando caldera de biomasa en las zonas climáticas A3, A4, B3 and B4. En el resto de zonas, donde los requerimientos de refrigeración no son tan elevados, el uso de calderas de biomasa implica directamente una calificación A. Para obtener la calificación B en las zonas climáticas C1, C2, D1, D2 and E1 es necesario emplear la combinación de otras soluciones, aunque en algunos casos llegamos a la situación de obtener costes 
de inversión más elevados en B que en A. En las zonas C3, C4 y D3 no fue posible alcanzar la calificación $B$ con las soluciones consideradas en este estudio.

- Cambio de calificación energética B a A: En todos los casos, la calificación A sólo se obtiene mediante el uso de caldera de biomasa, ya que se considera como un combustible neutral. Además en las zonas más cálidas, A3, A4, B3 and B4, se hace necesario introducir otras medidas, no consideradas en un principio. Por un lado, se utiliza vidrio de control solar para controlar las altas demandas de refrigeración de estas zonas. Además las zonas A3, A4 and B4 requieren incrementar el porcentaje de las lamas en ventanas como elemento de sombreamiento.

\section{III.5.- RESULTADOS DE TODAS LAS CONFIGURACIONES EN LIDER Y CALENER}

Al realizar las simulaciones de las 50 combinaciones en Lider y posteriormente en Calener, los resultados obtenidos para cada una de las zonas climáticas, aparecen en la tabla 3.36 , para cada zona climática se muestran 4 filas, con resultados que corresponden a:

- Resultado de simulación en Lider, porcentaje respecto al edificio de referencia en cuanto a calefacción y refrigeración

- Intervalo de calificación para la letra asignada

- Resultado de simulación en Calener

- Resultados parciales obtenidos en Calener para calefacción, refrigeración y agua caliente sanitaria

- Aparecen entre paréntesis valores de calificación de las simulaciones que se intentaron sin conseguir la calificación perseguida 


\begin{tabular}{|c|c|c|c|c|c|c|}
\hline & & E & D & C & B & A \\
\hline \multirow[t]{4}{*}{ A3 } & Lider Cal-Ref & & $86,0-77,9$ & $61,6-86,4$ & $30,8-86,0$ & $54,8-42,2$ \\
\hline & Intervalo Calener & & $14,9-24,0$ & $8,9-14,9$ & $4,6-8,9$ & $<4,6$ \\
\hline & Valor Calener & & 23,3 & 14,6 & $(9,5) / 7,0$ & 4,0 \\
\hline & Cal/Ref/acs & & $10,0 / 6,6 / 6,7$ & $5,0 / 7,0 / 2,6$ & $3,3 / 4,9 / 1,3$ & $0,0 / 4,0 / 0,0$ \\
\hline \multirow[t]{4}{*}{ A4 } & Lider Cal-Ref & & $81,9-91,0$ & $48,2-99,8$ & $48,2-99,8$ & $93,5-38,9$ \\
\hline & Intervalo Calener & & $14,0-22,6$ & $8,3-14,0$ & $4,4-8,3$ & $<4,4$ \\
\hline & Valor Calener & & 22,5 & 13,9 & 7,8 & 4,3 \\
\hline & Cal/Ref/acs & & $8,4 / 7,4 / 6,7$ & $3,9 / 7,8 / 2,2$ & $0,0 / 7,8 / 0,0$ & $0,0 / 4,3 / 0,0$ \\
\hline \multirow[t]{4}{*}{ B3 } & Lider Cal-Ref & & $94,1-74,4$ & $65,3-87,6$ & $65,3-87,6$ & $65,6-74,7$ \\
\hline & Intervalo Calener & & $17,4-28,0$ & $10,4-17,4$ & $5,4-10,4$ & $<5,4$ \\
\hline & Valor Calener & & 27,5 & 16,7 & 6,0 & 5,4 \\
\hline & Cal/Ref/acs & & $15,3 / 5,4 / 6,8$ & $8,0 / 6,0 / 2,7$ & $0,0 / 6,0 / 0,0$ & $0,0 / 5,4 / 0$ \\
\hline \multirow[t]{4}{*}{ B4 } & Lider Cal-Ref & $92,1-90,1$ & $69,3-95,2$ & $53,2-95,4$ & $53,2-95,4$ & $97,1-54,1$ \\
\hline & Intervalo Calener & $>28,1$ & $17,9-28,1$ & $11,0-17,9$ & $6,3-11,0$ & $<6,3$ \\
\hline & Valor Calener & 28,2 & 27,7 & 17,5 & 10,0 & 6,2 \\
\hline & Cal/Ref/acs & $11,9 / 9,6 / 6,7$ & $11,4 / 9,6 / 6,7$ & $5,3 / 10,0 / 2,2$ & $0,0 / 10,0 / 0,0$ & $0,0 / 6,2 / 0,0$ \\
\hline \multirow[t]{4}{*}{ C1 } & Lider Cal-Ref & $99,2-23,0$ & $86,7-30,6$ & $92,8-24,0$ & $45,3-97,5$ & $48,0-68,2$ \\
\hline & Intervalo Calener & $>30,4$ & $19,8-30,4$ & $12,7-19,8$ & $7,8-12,7$ & $<7,8$ \\
\hline & Valor Calener & 33,5 & 22,2 & 19,5 & 12,7 & 1,4 \\
\hline & Cal/Ref/acs & $22,8 /--/ 10,1$ & $17,0 /--/ 4,3$ & $15,8 /--/ 2,8$ & $7,6 /--/ 2,7$ & $0,00 /--/ 0,00$ \\
\hline \multirow[t]{4}{*}{$\mathrm{C} 2$} & Lider Cal-Ref & $87,1-89,2$ & $96,4-64,6$ & $80,4-76,8$ & $53,3-64,2$ & $80,4-76,8$ \\
\hline & Intervalo Calener & $>31,0$ & $20,2-31,0$ & $13,0-20,2$ & $7,9-13,0$ & $<13,0$ \\
\hline & Valor Calener & 32,3 & 21,9 & 20,1 & 12,7 & 4,5 \\
\hline & Cal/Ref/acs & $20,1 / 3,8 / 8,4$ & $13,6 / 4,1 / 4,2$ & $11,4 / 4,5 / 4,2$ & $5,1 / 4,9 / 2,7$ & $0 / 4,5 / 0$ \\
\hline \multirow[t]{4}{*}{ C3 } & Lider Cal-Ref & & $82,4-78,3$ & $82,4-78,3$ & $65,3-78$ & $78,5-79,4$ \\
\hline & Intervalo Calener & & $23,2-36,6$ & $14,4-23,2$ & $8,2-14,4$ & $<8,2$ \\
\hline & Valor Calener & & 36,2 & 22,9 & $(18)$ & 7 \\
\hline & Cal/Ref/acs & & $22,6 / 6,6 / 7$ & $14,1 / 6,8 / 2,0$ & $10,5 / 6,2 / 1,3$ & $0 / 7 / 0$ \\
\hline \multirow[t]{4}{*}{$\mathrm{C} 4$} & Lider Cal-Ref & & $86,1-89,7$ & $76,7-94$ & $55,3-90,9$ & $55,3-90,9$ \\
\hline & Intervalo Calener & & $20-31,5$ & $12,4-20$ & $7-12,4$ & $<7$ \\
\hline & Valor Calener & & 31,1 & 20 & (16) & 6,5 \\
\hline & Cal/Ref/acs & & $16,5 / 7,7 / 6,9$ & $10,7 / 7,8 / 1,5$ & $6,8 / 2,5 / 2,2$ & $0,0 / 6,5 / 0,0$ \\
\hline \multirow[t]{4}{*}{ D1 } & Lider Cal-Ref & $87,1-65$ & $82,1-66,9$ & $82,4-66,7$ & $57,9-50$ & $82,6-74,1$ \\
\hline & Intervalo Calener & $>45,2$ & $30,2-45,2$ & $20,2-30,2$ & $13,2-20,2$ & $<13,2$ \\
\hline & Valor Calener & 46,0 & 44,9 & 28,6 & 19,4 & 3,1 \\
\hline & Cal/Ref/acs & $29,6 /--/ 13,5$ & $28,5 /--/ 13,5$ & $21,3 /--/ 4,4$ & $14,2 /--/ 2,8$ & 0,0/--/0,0 \\
\hline
\end{tabular}

90 


\begin{tabular}{|l|c|c|c|c|c|c|}
\hline & & $\mathrm{E}$ & $\mathrm{D}$ & $\mathrm{C}$ & $\mathrm{B}$ & $\mathrm{A}$ \\
\hline \multirow{4}{*}{ 2 } & Lider Cal-Ref & $90,8-83,3$ & $85,8-84,9$ & $85,8-84,9$ & $56,7-68,2$ & $83,3-89,7$ \\
\cline { 2 - 7 } & Intervalo Calener & $>\mathbf{4 2 , 6}$ & $27,8-42,6$ & $17,8-27,8$ & $10,9-17,8$ & $<10,9$ \\
\cline { 2 - 7 } & Valor Calener & $\mathbf{4 3 , 6}$ & $\mathbf{4 2 , 6}$ & $\mathbf{2 7 , 7}$ & $\mathbf{1 7 , 8}$ & $\mathbf{4 , 5}$ \\
\cline { 2 - 7 } & Cal/Ref/acs & $\mathbf{2 7 , 2 / 4 , 1 / 1 3 ,}$ & $\mathbf{2 5 / 4 , 3 / 1 3 , 3}$ & $19,1 / 4,3 / 4,3$ & $11,3 / 3,7 / 2,8$ & $0,0 / 4,5 / 0,0$ \\
\hline \multirow{4}{*}{ D3 } & Lider Cal-Ref & & $97,9-78,2$ & $90,8-81,5$ & $60,1-68,8$ & $60,1-68,8$ \\
\cline { 2 - 7 } & Intervalo Calener & & $25,4-39,1$ & $16,4-25,4$ & $10,0-16,4$ & $<10,0$ \\
\cline { 2 - 7 } & Valor Calener & & $\mathbf{3 7 , 2}$ & $\mathbf{2 5 , 2}$ & $(17,3)$ & $\mathbf{5 , 9}$ \\
\cline { 2 - 7 } & Cal/Ref/acs & & $24,9 / 5,7 / 7$ & $16,6 / 5,9 / 2,7$ & $10,5 / 6,2 / 1,3$ & $0,0 / 5,9 / 0,0$ \\
\hline \multirow{4}{*}{ E1 } & Lider Cal-Ref & & $96,0-62,0$ & $90,2-67,9$ & $63,2-43$ & $90,2-67,9$ \\
\cline { 2 - 7 } & Intervalo Calener & & $38,7-57,9$ & $25,9-38,7$ & $16,9-25,9$ & $<16,9$ \\
\cline { 2 - 7 } & Valor Calener & & $\mathbf{5 1 , 8}$ & $\mathbf{3 2 , 1}$ & $\mathbf{2 5 , 5}$ & $\mathbf{1 , 5}$ \\
\cline { 2 - 7 } & Cal/Ref/acs & & $41,0 /--/ 8,9$ & $\mathbf{2 5 , 7 / - - / 4 , 4}$ & $18,7 /--/ 4,4$ & 1,5 \\
\hline
\end{tabular}

Tabla 3.36.- Resultados simulaciones (-- indica que no hay emisiones)

Las principales conclusiones de acuerdo a los valores de las emisiones obtenidas al simular con Calener permiten extraer las siguientes conclusiones:

En general: conforme va mejorando la EE, subir de calificación en la escala se va haciendo más difícil, es decir, requiere implementar muchas más medidas de mejora. Es decir, es más difícil pasar de una clase $C$ a una $B$ que de una $\mathrm{D}$ a una $\mathrm{C}$.

Sobre la calificación E: no en todas las zonas se obtiene esta calificación, a pesar de utilizar las medidas menos eficientes energéticamente. Además los casos en que sí se obtiene, se observa que se obtienen valores próximos al límite superior de la calificación $\mathrm{D}$.

Sobre la calificación D: Generalmente es la calificación de partida. En los casos en que se partía de $\mathrm{E}$, al estar muy cerca del límite es suficiente con cambios que permitan ligeras mejoras en la EE, excepto las zonas C1 y C2 que ya requieren cambio en el tipo de combustible. 
Sobre la calificación C y B: en ambos casos se encuentran cerca del límite superior de clase en la escala. Como consecuencia será necesario implementar la combinación de varias medidas para poder mejorar la calificación.

Sobre la calificación A: los valores de Kg anuales de emisiones por unidad de superficie son significativamente menores en las zonas de veranos más benignos, con el número 1 y 2 en su designación. Como se ha visto todos los casos $\mathrm{A}$ han requerido de la utilización de calderas de biomasa, que solucionan, a nivel de obtención de mejores clases energéticas, los problemas en zonas frías. Los valores son más altos en zonas en cuya denominación aparecen los números 3 y 4 , ya que en estas, las demandas de refrigeración, no resueltas con la caldera de biomasa, hacen aumentar la cuantía de emisiones. 


\section{CAPÍTULO IV \\ ESTIMACIÓN DEL VALOR DE LAS VIVIENDAS Y ANÁLISIS DE COSTES}





\section{IV.1.- MÉTODOS DE VALORACIÓN EN VIVIENDAS}

\section{IV.1.1.- Elección del método}

En valoración de bienes inmuebles de uso residencial, el Método de Comparación es el más usado en la práctica, y parte de la premisa que "no existe más valor que el de mercado".

La base de este método lo constituye la obtención del valor de un inmueble por comparación con los valores conocidos de compraventas reales de otros inmuebles de las mismas características, dependiendo su fiabilidad del número de muestras válidas o representativas obtenidas. [García Palacios, 1999; Silvan Martínez, 2006].

Según la normativa vigente para valoración de bienes inmuebles, cuya finalidad sea la garantía hipotecaria, Orden ECO/805/2003, este método está basado en el principio de sustitución -el valor de un inmueble es equivalente al de otros activos de similares características sustitutivos de aquel- y parte de la premisa de la existencia de un mercado libre - sin influencias ni presiones externas- de compraventa de inmuebles de las características del bien a tasar.

Si bien esta norma no es la única existente en temas de valoración de bienes inmuebles, al existir otras tales como la normativa Catastral (RDL 1/2004) o la Ley de Suelo (RD2/2008), en ella constan directrices básicas referentes a la aplicabilidad del método de comparación, que pueden servir de guía para valoraciones con finalidades diferentes. En cualquier caso, se puede concluir del estudio de esta norma que, el método de comparación no es adecuado para el caso de estudio. En los artículos 20 y 21, se indica lo siguiente respecto a la aplicabilidad del método: 
Artículo 20.- 1. El Método de comparación será aplicable a la valoración de toda clase de inmuebles, siempre que se cumplan los requisitos que se establecen en el artículo siguiente ...

Artículo 21. Requisitos para la utilización del método de comparación.

1. Para la utilización del Método de comparación a efectos de esta Orden será necesario que se cumplan los siguientes requisitos:

a. La existencia de un mercado representativo de los inmuebles comparables.

b. Disponer de suficientes datos sobre transacciones $u$ ofertas que permitan, en la zona de que se trate, identificar parámetros adecuados para realizar la homogeneización de comparables.

c. Disponer de información suficiente sobre al menos seis transacciones $u$ ofertas de comparables, que reflejen adecuadamente la situación actual de dicho mercado...

En definitiva, el método no se puede aplicar si no existe mercado y este es el caso; en la actualidad no hay mercado de viviendas representativo de las que se conozca su calificación energética

Debido a la reciente entrada en vigor de la normativa CTE, y a la crisis económica en los últimos años, el desarrollo y venta de nuevas promociones no ha ocurrido, tal y como sería normal en un momento más estable del mercado inmobiliario. Por tanto, aunque a las nuevas viviendas ya es posible asignarles una determinada calificación energética, de acuerdo a la normativa vigente en el sector de la construcción, no existe todavía un mercado suficientemente representativo, que permita estimar el valor de los inmuebles por comparación en función de su eficiencia energética. 
Como se puede observar en la figura 4.1, el número de proyectos de viviendas unifamiliares visados en España, alcanza su valor máximo en 2006, coincidiendo con el momento previo a la entrada en vigor de la CTE. La tendencia a partir de ese momento es decreciente, hasta alcanzar cotas muy bajas en los últimos años 2009 y 2010. Por tanto, resulta difícil el cumplimiento de las premisas $(a, b, c)$ indicadas en el artículo 21.

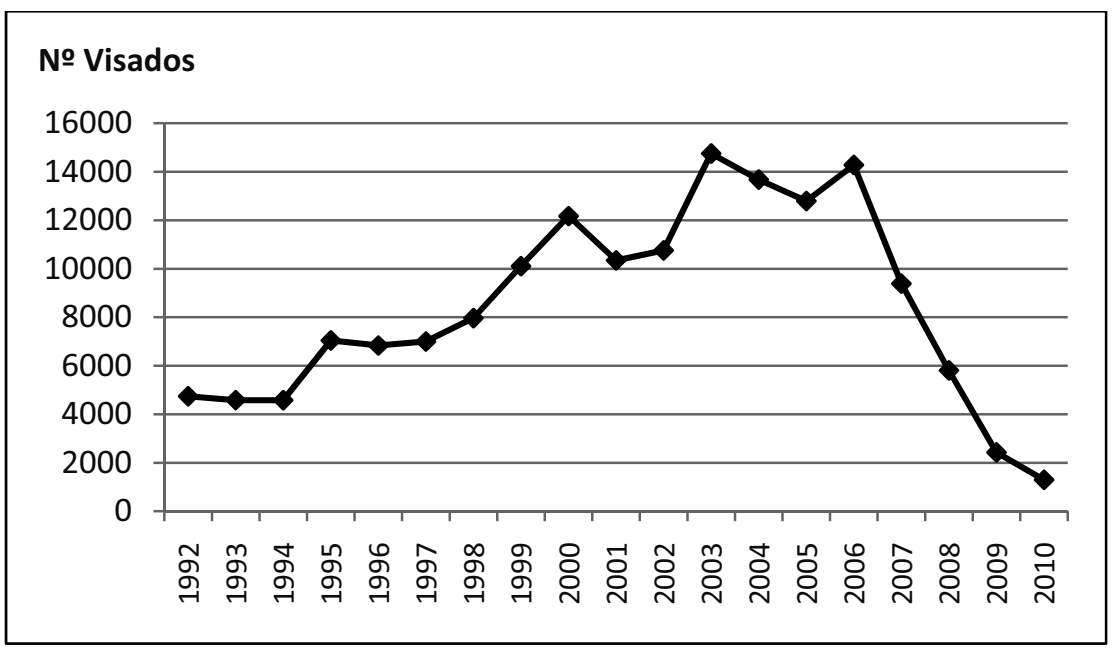

Figura 4.1.- Evolución del número de visados de viviendas unifamiliares en España, según Colegios de Arquitectos. Fuente: Elaboración propia a partir de INE, censo viviendas 2001

Otro método que podría aplicarse en la valoración de bienes inmuebles sería el Método de Actualización de Rentas. Este método permite obtener el valor del bien inmueble a partir de las rentas que puede originar a lo largo de su vida útil. En el caso de viviendas, se emplea cuando se dispone de un contrato de arrendamiento o de un mercado representativo de alquileres.

Tampoco es adecuado este método en este caso, por no disponer de datos de rentas de inmuebles que tengan una calificación energética. La 
normativa hipotecaria hace también referencia a su aplicabilidad (Artículos 24 y 25 , Orden ECO 805/2003)

Artículo 24. Aplicabilidad del método de actualización.

1. El método de actualización de rentas será aplicable, siempre que se cumplan los requisitos establecidos en el artículo siguiente, a la valoración de toda clase de inmuebles susceptibles de producir rentas...

2. Mediante este método se calculará un valor técnico que se denominará valor por actualización, que permite determinar tanto el valor de mercado de un determinado bien como su valor hipotecario.

Artículo 25. Requisitos para la utilización del método de actualización.

1. Para la utilización del método de actualización a efectos de esta Orden será necesario que se cumpla al menos uno de los siguientes requisitos:

a. La existencia de un mercado de alquileres representativo de los comparables. Para presumir tal existencia, será necesario disponer, como mínimo, de seis datos de rentas de alquiler sobre comparables que reflejen adecuadamente la situación actual de este mercado y disponer de suficientes datos sobre transacciones en alquiler $u$ ofertas, que permitan identificar parámetros adecuados para realizar la homogeneización de rentas en comparables.

b. La existencia de un contrato de arrendamiento sobre el inmueble objeto de valoración.

c. Que el inmueble valorado esté produciendo o pueda producir ingresos como inmueble ligado a una actividad económica, y que además existan suficientes datos contables de la explotación o información adecuada sobre ratios estructurales medios de la rama de actividad correspondiente... 
Se adopta, por tanto, como método de valoración de las viviendas, el Método del Coste. La forma de valorar con esta metodología se desarrolla en el siguiente apartado y básicamente consiste en obtener el valor de un bien considerando solamente sus costes de producción.

\section{IV.1.2.- Método del Coste}

La finalidad inicial del método es obtener el valor del coste de reposición de un edificio o construcción, si es posible, para un edificio exactamente de las mismas características que el que se valora [Roca Cladera, 1989]. En edificios de cierta antigüedad esto no suele ser factible, ya que generalmente los materiales y técnicas constructivas utilizadas en la actualidad difieren de las empleadas en épocas anteriores. Por ello, es más correcto hablar de coste de reemplazamiento, que consiste en obtener el coste de un edificio considerando los materiales y técnicas de construcción actuales, pero que tenga la misma utilidad física y funcional que el edificio que se quiere a valorar.

Para obtener la similitud entre dos edificios, hay que basarse principalmente en tres premisas:

- Tipología constructiva.

- Calidad de la construcción.

- La utilidad del edificio.

Se consideran dos valores, el coste de reemplazamiento bruto (CRB) y coste de reemplazamiento neto (CRN). En el primer caso se considera el valor estimado como "a nuevo", mientras que en el segundo hay que deducir la depreciación producida en el edificio. Tradicionalmente se han considerado tres tipos de depreciación: física, funcional o económica. Es conveniente en este punto hacer referencia, dada la naturaleza del estudio, a una depreciación tecnológica, que pudiera quizás englobarse dentro de la 
depreciación funcional, al considerar aspectos de pronta obsolescencia de las instalaciones o de los materiales, teniendo en cuenta la larga vida útil de los edificios. Debería asimismo tenerse en consideración una depreciación ecológica, puesto que se está planteando en la presente Tesis una valoración en base a criterios medioambientales.

En definitiva, depreciar es disminuir el valor o el precio de una cosa, es decir, determinar la pérdida de valor que experimenta un bien desde el momento de su constitución hasta la fecha de valoración. En el caso considerado, al tratarse de una promoción de nuevo edificio, no ha sufrido depreciación. Por tanto, coincidirán los valores de reemplazamiento bruto y neto.

Para la obtención del valor de la construcción, en nuestro caso de estudio se puede hablar de dos procedimientos:

1. Sintético

2. Analítico

1.- Sintético: Se obtiene un valor por $\mathrm{m}^{2}$ construido de la tipología constructiva que se valora.

Entre las diferentes formas de conseguir dicho valor tenemos:

a) Comparación con obras semejantes: debe utilizarse cuando exista un número significativo de construcciones con tipologías, superficies, calidades y acabados semejantes en la misma zona que el inmueble valorado. En definitiva, se trataría de aplicar el método de comparación a nuevas promociones similares a la que se valora.

b) Utilización de presupuestos experimentados de tipologías edificatorias. 
c) Utilización de módulos por tipología constructiva: Se aplica unos módulos $\left(€ / \mathrm{m}_{\mathrm{c}}{ }^{2}\right)$ que se multiplican por unos coeficientes en función de la tipología constructiva (caso de la valoración catastral).

d) Utilización disposiciones del colegio de arquitectos: Se aplican las disposiciones del colegio de arquitectos para la obtención del presupuesto de ejecución material (PEM) que figura en los proyectos.

2.- Analítico: Mediante presupuesto de obra. Es el método que se ajusta más a la realidad, puesto que se adapta al caso particular a valorar, pero es el más costoso y además es difícil de obtener en obras ya realizadas.

En este estudio se sigue el procedimiento analítico, por lo que se realizarán los Presupuestos de Ejecución por Contrata (PEC) de cada una de las configuraciones simuladas, teniendo en cuenta las diferencias constructivas entre zonas climáticas y entre distintas calificaciones. EI PEC, a efectos de este estudio, no va a tener en consideración el Impuesto sobre el Valor Añadido (IVA), ya que, posteriormente, este valor se sumará a otros tipos de valores que no consideran este impuesto.

Para obtener el PEC, se parte del Valor de Reemplazamiento Bruto (en este caso, igual al neto), entendiéndose como tal, la suma de las inversiones que serían necesarias para construir, en la fecha de la valoración, otro inmueble de las mismas características pero utilizando tecnología y materiales de construcción actuales [Orden ECO 805/2003].

En el VRB se consideran los siguientes componentes [Alcázar Molina, 2003; Bertrán Moreno, 2005]:

$$
\mathrm{VRB}=\mathrm{V}_{\mathrm{s}}+\mathrm{CRB}
$$

siendo, $V_{\mathrm{s}}=$ Valor del Suelo 
$\mathrm{CRB}=$ Coste de reemplazamiento bruto

Nótese que la diferencia entre VRB y CRB, radica en la consideración, o no, del suelo. En el cálculo que se va a realizar no se considera el término suelo de la expresión [1], pues su estimación requeriría otro método de valoración, como el método de comparación o el residual. Además, el suelo va a tener el mismo valor para cualquier calidad o calificación energética de la vivienda.

El segundo término en la expresión [1] está relacionado con los costes de la construcción y en este caso, sí es de aplicación el método del coste. A su vez, el CRB tiene varios componentes a considerar, expresados por la siguiente fórmula [2]:

$$
C R B=P E C+G p+B p
$$

donde,

PEC $=$ Presupuesto de Ejecución por Contrata

$\mathrm{G}=$ Gastos de la Promoción (financieros, impuestos, licencias, comercialización)

$\mathrm{Bp}=$ Beneficio del Promotor

Los componentes de gastos y beneficios de la promoción, no están relacionados con los costes de construcción propiamente dichos. Su consideración tiene sentido cuando se obtienen valores de suelo partiendo de valores de mercado. Por tanto, sólo se va a analizar en adelante el PEC.

A su vez, el PEC, tiene tres componentes y se incrementa con el IVA. En este estudio no se tiene en cuenta el IVA y por lo tanto, se utiliza la expresión [3]: 


$$
P E C=P E M+G G+B I
$$

siendo,

$\mathrm{PEM}=$ Presupuesto de Ejecución Material

$\mathrm{GG}=$ Gastos Generales de la construcción

$\mathrm{Bl}=$ Beneficio Industrial (de la construcción)

El Presupuesto de Ejecución Material (PEM) se obtiene como consecuencia de los materiales, maquinaria y mano de obra necesarios para llevar a cabo la construcción.

Los Gastos Generales (GG) serían los necesarios para el funcionamiento de la empresa constructora, pero no están relacionados directamente con la construcción del edificio considerado. Por ejemplo incluirían, entre otros, sueldos del personal directivo, administrativo y técnico, alquileres y/o amortización de oficinas y/o almacenes, electricidad, agua y otras instalaciones no relacionadas con la obra, etc. Suele calcularse como un porcentaje del PEM, y es variable según la dimensión y volumen de obra de la empresa constructora. En obras para la Administración, este porcentaje se cifra en el $13 \%$.

El Beneficio Industrial (BI) es el necesario para compensar el capital invertido, el tiempo empleado y el riesgo, y también se calcula como un porcentaje sobre el PEM. Este es libre para cada empresa constructora. En obras para la Administración es del $6 \%$.

La forma de realizar dichos presupuestos se detalla en el apartado IV.2.3 y las cantidades obtenidas se muestran en las tablas 4.4 y 4.5 de este capítulo. 


\section{IV.2.- COSTE DE LA INVERSIÓN ( $\mathrm{C}_{\mathrm{INV}}$ ) \\ IV.2.1.- Presupuesto de Contrata}

Para estimar el coste de la inversión se utiliza eIPEC. El presupuesto resultará de la aplicación de unos precios a unas mediciones.

$$
\text { Presupuesto }=\text { Precio } \times \text { Medición }
$$

En la determinación de los precios hay que analizar dos componentes:

- Costes directos

- Costes indirectos

La base del presupuesto lo constituyen los costes directos; y son aquellos que inciden directamente en el proceso constructivo y son imputables directamente a las diferentes unidades de obra. Están compuestos por la mano de obra directa, maquinaria directa y materiales. Se obtiene aplicando al coste unitario de cada componente el rendimiento o cantidad en que interviene en el mismo. La suma de los valores obtenidos de todos los elementos que lo componen, dará su precio de coste directo.

Los costes indirectos lo forman aquellos, que siendo necesarios para la obra, no se imputan directamente a las unidades de obra, sino que se repercuten en forma de porcentaje a cada una de ellas. El porcentaje es variable en función del tipo de empresa que lleve a cabo la obra y del tipo de promoción y, por tanto, debe de adecuarse a cada caso concreto. Sin embargo, lo habitual en la fase de proyecto es asignar un porcentaje estimativo sobre los costes directos, en función de la experiencia acumulada de obras anteriores. Los gastos que debemos incluir en este apartado son: mano de obra indirecta, medios auxiliares y gastos generales de obra.

El precio de ejecución material se calcula aplicando al coste directo el porcentaje de costes indirectos. Si a estos precios resultantes les aplicamos 
la correspondiente medición conseguiremos el Presupuesto de Ejecución Material (PEM).

El último cálculo es la obtención del PEC (en este caso igual al presupuesto de empresa, ya que no estamos incluyendo ni gastos de contrato ni impuestos). Se calcula sumando al PEM el porcentaje de aplicación de los gastos generales (GG) y del beneficio industrial (BI). [Bertrán Moreno, 2005; Ramírez de Arellano Agudo, 2004; Rodrigo Morant et al, 2001].

\title{
IV.2.2.- Estructura del presupuesto
}

Se realiza un presupuesto valorativo detallado, que se estructura en los siguientes apartados:

\author{
Estado $\mathrm{n}^{\circ} 1$ - Mediciones \\ Estado $n^{\circ} 2$ - Precios \\ Cuadro $\mathrm{n}^{0} 1$ - Precios unitarios y complejos \\ Cuadro $n^{\circ} 2$ - Descomposición precios unitarios y complejos \\ Cuadro $n^{\circ} 3$ - Precios de los materiales \\ Cuadro $n^{\circ} 4$ - Precios de la mano de obra \\ Cuadro $n^{\circ} 5$ - Precios de la maquinaria \\ Estado $n^{\circ} 3$ - Aplicación de precios \\ Cuadro $n^{0} 1$ - Aplicación precios a la medición \\ Cuadro $n^{\circ} 2$ - Resumen general por capítulos
}

\section{IV.2.2.1.- Estado $\mathrm{n}^{\circ}$ 1. Mediciones}

Es la medición completa y detallada de la obra. Cada unidad de obra debe estar totalmente definida, tanto en su aspecto descriptivo como en sus características geométricas. Toda medición debe estar clasificada, normalmente de forma jerárquica, ordenada por capítulos, que agrupe las partidas, que coinciden normalmente con los distintos oficios de la obra y su orden de actuación en la misma. 
En los impresos correspondientes a la medición aparecen los siguientes conceptos:

- $\quad \mathrm{N}^{\circ}$ de orden: Número de capítulo y partida. Normalmente consta de dos números, el primero indica el capitulo y el segundo el $n^{\circ}$ de orden de la unidad de obra. Sirve para numerar y ordenar las partidas dentro del capítulo y presupuesto, y mantiene la numeración en los distintos estados del presupuesto.

- Código. Está generalizado desde que existen programas informáticos. Es el código particular de la unidad de obra dentro de la base de datos general.

- Unidades: Unidad de medida utilizada en la medición de la unidad de obra.

- Designación de la unidad de obra: descripción de la partida

- $\quad N^{0}$ de unidades iguales: para agrupar todas las medidas que tienen las mismas medidas dentro de cada partida.

- Longitud o largo

- Latitud o ancho

- Altura

- Medición parcial: producto de las tres mediciones anteriores.

- Medición total: suma de todas las mediciones parciales

\section{IV.2.2.2.- Estado ${ }^{\circ}{ }^{2}$. Precios}

Recoge todos los precios de los distintos elementos que van a conformar la obra. Se subdivide en cuadros:

- Cuadro $n^{\circ} 1-$ Precios unitarios y complejos de las unidades de obra. Este cuadro refleja los precios de todas las unidades de obra del proyecto. 
- Cuadro $\mathrm{n}^{\circ}$ 2- Precios unitarios y complejos descompuestos de las unidades de obra. Se refleja la descomposición de cada uno de los precios de las unidades de obra.

- Cuadro $n^{\circ} 3$ - Precios de los materiales. En este cuadro deben figurar todos los materiales que se necesitan para la ejecución de la obra, deben venir numerados, referenciados de forma individual, con su descripción y su precio a pie de obra.

- Cuadro $n^{\circ}$ 4- Precios de la mano de obra. En este cuadro se detallan los precios de coste de la mano de obra directa. Todos los elementos deben ir referenciados y codificados, no debiendo figurar los datos de la mano de obra indirecta -capataces, etc.-

- Cuadro no 5- Precios de la maquinaria. En este cuadro se dispondrá toda la maquinaria que tengamos que utilizar para la ejecución de la obra.

\section{IV.2.2.3.- Estado n ${ }^{\circ}$ 3. Aplicación de precios}

- Cuadro $n^{\circ}$ 1- Aplicación de precios: Se aplican a las partidas del estado 1 , los precios recogidos en el estado 2 .

- Cuadro $n^{\circ} 2-$ Resumen. En este cuadro figurará el resumen de los capítulos, lo que nos dará el Presupuesto de Ejecución Material. En este mismo cuadro podemos incluir los gastos generales de empresa, el beneficio industrial, lo que nos dará el Presupuesto de Contrata.

\section{IV.2.3.- Aplicación al caso de estudio}

\section{IV.2.3.1.- Medición}

Se ha realizado tomando como base el proyecto de partida. Sin embargo, las configuraciones adoptadas para distintas calificaciones obliga a hacer modificaciones puntuales de unos presupuestos a otros, es decir, no existe un presupuesto exactamente igual a otro. Por ejemplo, entre otras 
variaciones, si consideramos el capítulo de carpintería, una calificación E recogerá las partidas y los precios correspondientes a las carpinterías de alumnio anodizado; sin embargo, este capítulo, en la calificación A, debe variar sus partidas al tener carpinterías de madera.

Asimismo, se han considerado nuevos capítulos de obra que no aparecían en el proyecto original o recalcular algunas partidas existentes, como consecuencia de la adaptación al CTE. Estos son:

1. Capítulo 7: Energía solar. De acuerdo a CTE-HE1

Recalculado de acuerdo a los mínimos del CTE y a los aumentos de porcentaje estipulados en la mejora de la calificación.

Se dimensionan el número de placas solares necesarias en cada caso, según el porcentaje que deban suponer de aportación de energía; el cálculo es función de diversos parámetros como: localidad, superficie del captador, factor de rendimiento, pérdidas térmicas (de acuerdo a características del modelo comercial seleccionado por Cype), inclinación, latitud y altura.

2. Capítulo 8: Instalación Ventilación. De acuerdo a CTE-HS3 Abertura de admisión (sólo habrán desde la zona C1 en adelante) Salón comedor: $12 \mathrm{l} / \mathrm{s}=2$ aberturas de $125 \mathrm{~mm}$ (10 l/s cada una) Dormitorio principal: $10 \mathrm{l} / \mathrm{s}=1$ abertura de $125 \mathrm{~mm}(10 \mathrm{l} / \mathrm{s})$

Dormitorio 1 = Dormitorio 2: $5 \mathrm{l} / \mathrm{s}=2$ de $100 \mathrm{~mm}$ (5l/s cada una)

En total: 3 de $125 \mathrm{~mm}$ y 2 de $100 \mathrm{~mm}$

Aberturas de paso: Rejillas de 200×100 mm. 11 unidades según plano Aspirador extracción: en cubierta. $S \geq 1,5 q v t=1,5 * 61,57=92,36 \mathrm{~cm}^{2}$ Modelo ISM031 (base de datos Cype) para todas las zonas Conductos: para 0,6 renovaciones hora $=221,65 \mathrm{~m}^{3} / \mathrm{h}: 2$ de 110 Medición $18 \mathrm{~m}$ 
3. Capítulo 20: Se dimensiona para 10 operarios [RD 604/2006]

4. Capítulo 21 Gestión de Residuos [RD 105/2008].

Se realiza la medición de acuerdo al transporte de tierras de excavación, residuos a transportar, clasificación a pié de obra y contenedores necesarios (véase tabla 4.1).

\begin{tabular}{|c|c|c|}
\hline RCD & $\begin{array}{l}\% \text { En } \\
\text { peso }\end{array}$ & $\begin{array}{l}\mathrm{Tde} \\
\mathrm{RCD} \\
\end{array}$ \\
\hline \multicolumn{3}{|l|}{ Naturaleza pétrea } \\
\hline $\begin{array}{l}\text { Ladrillos, azulejos y } \\
\text { otros cerámicos }\end{array}$ & 54,00 & 143,21 \\
\hline $\begin{array}{l}\text { Arenas, gravas y } \\
\text { otros }\end{array}$ & 4,00 & 10,61 \\
\hline Hormigón & 12,00 & 31,82 \\
\hline Piedra & 5,00 & 13,26 \\
\hline \multicolumn{3}{|l|}{ Naturaleza no pétrea } \\
\hline Madera & 4,00 & 10,61 \\
\hline Vidrio & 0,50 & 1,33 \\
\hline Plástico & 1,50 & 3,98 \\
\hline Metales & 2,50 & 6,63 \\
\hline Asfalto & 5,00 & 13,26 \\
\hline Yeso & 0,20 & 0,53 \\
\hline Papel & 0,30 & 0,80 \\
\hline $\begin{array}{l}\text { Potencialmente } \\
\text { peligrosos y otros }\end{array}$ & 4,00 & 10,61 \\
\hline Basura & 7,00 & 18,56 \\
\hline
\end{tabular}

\begin{tabular}{|c|c|c|c|}
\hline $\mathrm{RCD}$ & $\begin{array}{l}\mathrm{Tde} \\
\mathrm{RCD}\end{array}$ & $\begin{array}{l}\text { Densidad } \\
\text { tipo } t / \mathrm{m}^{3}\end{array}$ & \begin{tabular}{|l} 
Volumen \\
RCD $\mathrm{m}^{3}$ \\
\end{tabular} \\
\hline \multicolumn{4}{|l|}{ Naturaleza pétrea } \\
\hline $\begin{array}{l}\text { Ladrillos, azulejos y } \\
\text { otros cerámicos }\end{array}$ & 143,21 & 1,60 & 229,13 \\
\hline Arenas, gravas y otros & 10,61 & 1,60 & 16,97 \\
\hline Hormigón & 31,82 & 2,50 & 79,56 \\
\hline Piedra & 13,26 & 2,70 & 35,80 \\
\hline \multicolumn{4}{|l|}{ Naturaleza no pétrea } \\
\hline Madera & 10,61 & 0,60 & 6,36 \\
\hline Vidrio & 1,33 & 2,60 & 3,45 \\
\hline Plástico & 3,98 & 2,10 & 8,35 \\
\hline Metales & 6,63 & 7,50 & 49,73 \\
\hline Asfalto & 13,26 & 1,30 & 17,24 \\
\hline Yeso & 0,53 & 1,25 & 0,66 \\
\hline Papel & 0,80 & 1,10 & 0,88 \\
\hline \begin{tabular}{|l|} 
Potencialmente \\
peligrosos y otros \\
\end{tabular} & 10,61 & 1,50 & 15,91 \\
\hline Basura & 18,56 & 1,20 & 22,28 \\
\hline
\end{tabular}

Tabla 4.1.- Cálculo gestión de residuos. Fuente: Elaboración propia a partir de PNGRDC 2001-2006

Se utiliza el método estadístico, que se basa en estudios realizados en la Comunidad de Madrid [Plan Nacional de Gestión de Residuos de Demolición y Construcción, PNGRDC 2001-2006] y en la normativa europea Orden MAM/304/2002. 
También se consultan las publicaciones al respecto del Instituto Tecnológico de Cataluña [ITEC 2000a, b, c]

\section{IV.2.3.2.- Precios}

Es necesario tener en cuenta la variación de precios entre provincias. Generalmente las poblaciones de Madrid y Barcelona van a tener precios algo más altos que otras, como Badajoz o Almería.

Existe multitud de bases de datos de precios de la construcción. De entre las más utilizadas, cabe destacar las bases de datos de dlstintos organismos y empresas relacionadas con el sector de la construcción:

- Instituto Valenciano de la Edificación (IVE), adecuada a precios de Levante, Baleares y Madrid

- Colegio de Aparejadores, Arquitectos Técnicos e Ingenieros de la Edificación de Guadalajara, adecuada a precios del centro de la península

- Base de precios de la construcción de la Comunidad de Madrid

- Base de datos de la Consejeria de Fomento de la Junta de Extremadura

- Base de datos de la Construcción de Andalucía (BCCA) Consejeria de Obras Públicas y Transporte

- Base de Precios de Gobierno Vasco

- Base de datos BEDEC del Instituto Tecnologico de la Edificación y Construcción de Cataluña

- PREOC: Precios de edificación y obra civil en España

- Cype: Generador de Precios de la Construcción

- etc.

No es objetivo de la presente Tesis valorar la calidad de las distintas bases de datos. En cualquier caso, la misma base de datos se va a aplicar a todos 
los presupuestos y es la comparación entre ellos lo que interesa en este estudio.

Para la selección de una de las bases de datos de precios, se tiene en cuenta el hecho de que muchas de ellas son adecuadas para unas zonas de la península, pero no para otras. Por otro lado, no todas disponen de versiones gratuitas actualizadas a los años 2009-2010.

La base de datos de Cype reune las características que se precisan en este estudio. Por un lado, la posibilidad de adecuar el precio a la provincia. Por otro lado, permite adaptar el precio al tipo de obra considerado, puesto que permite adaptarse a la tipología constructiva. Obviamente el precio no va a ser el mismo si se presupuesta una promoción de 13 que de 300 viviendas. También influirá si se trata de un edificio plurifamiliar de viviendas con varias plantas sobre rasante, o si se trata de viviendas unifamiliares.

En este caso los precios de partida, están adaptados a viviendas unifamiliares adosadas, para una promoción con unos $2.300 \mathrm{~m}^{2}$ construidos, planta $780 \mathrm{~m}^{2}, 1$ planta bajo rasante y 2 sobre rasante, que se corresponderían con los precios adecuados a las características de la promoción. Con ellos se obtendrá el presupuesto de la vivienda simulada.

En cuanto a las condiciones de partida de topografía del terreno, accesibilidad, etc., se adoptan las medias que permite el generador de precios, manteniendo estas características constantes en todos los presupuestos.

El número de precios buscados en las 12 zonas asciende a 3.120. Véase como ejemplo la tabla 4.2: 


\begin{tabular}{|c|c|c|c|c|c|c|c|c|c|c|c|}
\hline \multicolumn{1}{|c|}{$\mathrm{m}^{2}$ Barniz sintético sobre superficie de carpintería exterior de madera... } \\
\hline A3 & A4 & B3 & B4 & C1 & C2 & C3 & C4 & D1 & D2 & D3 & E1 \\
\hline 16,26 & 15,58 & 16,36 & 16,27 & 17,33 & 19,61 & 13,91 & 13,1 & 17,24 & 17,05 & 19,54 & 13,75 \\
\hline
\end{tabular}

Tabla 4.2.- Ejemplo de precio unitario por zonas climáticas. Fuente: Elaboración propia a partir de Generador precios Cype Ingenieros S.A.

Muchos de los precios unitarios y complejos que conforman las partidas, tal y como son necesarios en la composición del proyecto, requieren su cálculo por medio de los precios descompuestos. Se calculan con precios básicos, auxiliares y/o unitarios, recogidos de la base de datos. Cada precio se adecua a la sección constructiva de la zona climática, y en su caso a las variaciones para cambios de calificación energética, por ejemplo, un aumento de espesor en el aislamiento de fachada, requiere cambiar el nuevo tipo de aislamiento en el descompuesto del precio, con su aumento precio correspondiente. La tabla 4.3 muestra la estructura de un precio complejo, que no existe como tal en la base de datos.

\begin{tabular}{|c|c|c|c|c|c|c|c|c|}
\hline \multirow[t]{2}{*}{1.1} & \multirow[t]{2}{*}{ CP. 1} & \multicolumn{6}{|c|}{$\begin{array}{l}\mathrm{m}^{2} . \mathrm{F} 1 \text { : Cerramiento en contacto con el terreno en PS compuesto de muro } \\
\text { de HA de } 30 \mathrm{~cm} \text { de espesor (no incluido en este precio, partida 2.3), cámara } \\
\text { de aire de } 2 \mathrm{~cm} \text {, aislamiento de PUR ... }\end{array}$} & \multirow[t]{2}{*}{33,90} \\
\hline & & Código & Uds & Componentes unidad de obra & Ren. & Precio & $\begin{array}{l}\text { Importe } \\
\text { parcial }\end{array}$ & \\
\hline & & RPE010 & $\mathrm{m}^{2}$ & $\begin{array}{l}\text { Enfoscado de cemento de espesor } \\
2 \mathrm{~cm} \text {, a buena vista, aplicado sobre } \\
\text { un paramento vertical exterior, } \\
\text { acabado superficial rugoso, con } \\
\text { mortero de cemento M-5. }\end{array}$ & 1,20 & 10,45 & 12,54 & \\
\hline & & NAF040 & $\mathrm{m}^{2}$ & $\begin{array}{l}\text { Aislamiento por el interior en } \\
\text { fachada de doble hoja de fábrica } \\
\text { para revestir formado por espuma } \\
\text { rígida de poliuretano proyectado de } \\
20 \mathrm{~mm} \text { de espesor mínimo, } 30 \\
\mathrm{~kg} / \mathrm{m}^{3} \text { de densidad mínima, } \\
\text { colocado por proyección mecánica. }\end{array}$ & 1,05 & 5,30 & 5,56 & \\
\hline & & FFR010 & $\mathrm{m}^{2}$ & $\begin{array}{l}\text { Hoja interior de cerramiento de } \\
\text { fachada de } 4 \mathrm{~cm} \text { de espesor de } \\
\text { fábrica, de ladrillo cerámico hueco } \\
\text { doble, para revestir, } 24 \times 11 \times 4 \mathrm{~cm} \text {, } \\
\text { recibida con mortero de cemento } \\
\text { M-5. }\end{array}$ & 1 & 15,8 & 15,8 & \\
\hline
\end{tabular}

Tabla 4.3.- Ejemplo de precio complejo descompuesto adaptado al proyecto. Fuente: Elaboración propia a partir de Generador precios Cype Ingenieros S.A. 
La tabla 4.3 se confeccionó a partir de tres precios unitarios, que sí contiene la base de datos. La descomposición del precio permite observar qué elementos lo componen. Si se precisara aumentar la capa de aislamiento, se trataría de modificar los conceptos señalados en las celdas en gris, que corresponde a la descripción del precio y a su precio unitario.

\section{IV.2.3.3.- Resultados}

Los costes de inversión para cada zona climática van a depender de la naturaleza y calidad de los materiales que se utilicen, así como de las instalaciones empleadas, lo cual dará lugar a una mayor o menor emisión del $\mathrm{CO}_{2}$ a la atmósfera.

Una de las primeras etapas en esta Tesis fue el estudio de medidas que influían en la EE (apartado III.3), considerando cómo afectaban en la reducción de emisiones de $\mathrm{CO}_{2}$ el implementar dichas medidas. Estos parámetros se estudiaron aisladamente para ver en qué medida repercutían en la disminución de emisiones. Existen estudios en otros países al respecto, por ejemplo, el estudio de viviendas aisladas y adosadas en el Reino Unido, donde se tienen en cuenta medidas como los aislamientos, cambio de los vidrios, mejora de las calderas, etc. [Jenkins, 2010]. Posteriormente se combinarían dichas medidas para alcanzar las distintas calificaciones energéticas en las zonas climáticas españolas.

El criterio para combinar las medidas de mejora de EE, tal y como se vió en el apartado III.4, fue un criterio económico, es decir, adoptar preferiblemente las medidas más económicas.

El desarrollo de los presupuestos detallados, permite conocer los costes de las medidas de mejora de la EE, analizando qué partidas son las que recogen estos parámetros y su coste. Por ello, antes de proceder a la combinación de las medidas, se puede deducir a partir de los PEM y de los 
costes individuales de cada parámetro, cuál de ellos es mejor desde el punto de vista de su costo-efectividad, es decir, se puede determinar qué medidas son más eficientes para la reducción de emisiones desde el punto de vista económico. Este aspecto es de interés para proyectistas, con el fin de adoptar las medidas más adecuadas, teniendo en consideración el criterio ambiental y el económico.

La tabla 4.4 muestra la reducción de emisiones en porcentaje respecto a la solución de partida para cada zona climática de las configuraciones que inicialmente se simularon, como resultado de adaptar la vivienda de proyecto al CTE en cada zona climática. Se observa también una tabla de valores medios de las zonas $A-B, C$ y $D-E$, ya que existen ligeras diferencias constructivas entre ellas, para poder adaptar la vivienda a los mínimos requerimientos del CTE, como se vio en el capítulo III.

La medida más efectiva desde el punto de vista de la reducción de las emisiones es la caldera de biomasa, ya que Calener-VYP v1.0 considera que las calderas de biomasa emiten $0 \mathrm{~kg} \mathrm{CO}_{2}$ al ser considerada la biomasa combustible $\mathrm{CO}_{2}$ neutral.

La siguiente medida para reducir las emisiones es la sustitución de termo eléctrico por caldera de gas natural. También el tipo de caldera tiene influencia, siendo de la que menos a la que más emite: condensación boiler, baja temperatura y estándar. Algunas medidas son más o menos eficientes en función de la zona climática. Por ejemplo, los vidrios bajo emisivos y el uso de radiadores presentan importantes reducciones en zonas de inviernos más duros, mientras que el uso de calderas de gasóleo parece más interesante en zonas de inviernos templados. El resto de medidas producen menores reducciones en emisiones.

La tabla 4.5 recoge el PEM de cada configuración, así como el de cada una de las medidas estudiadas como influyentes en la EE. 


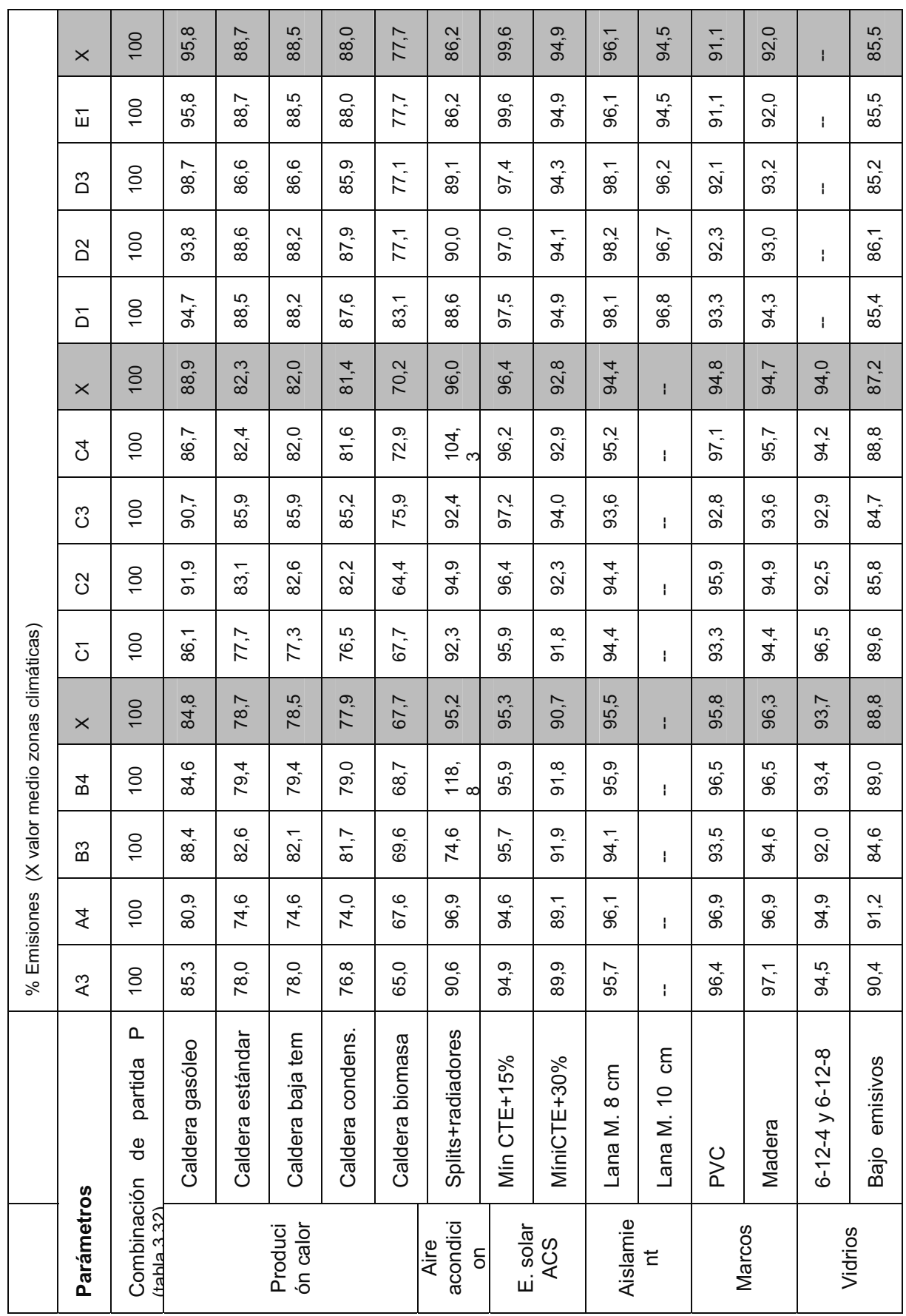

Tabla 4.4.- Reducción de emisiones alcanzada con los cambios parámetro a parámetro de la configuración inicial 


\begin{tabular}{|c|c|c|c|c|c|c|c|c|c|c|c|c|c|c|}
\hline $\bar{w}$ & 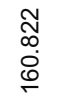 & 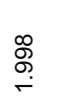 & 옹 & $\begin{array}{l}\stackrel{8}{\circ} \\
\stackrel{\leftrightarrow}{r}\end{array}$ & 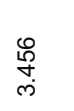 & $\begin{array}{l}\overline{1} \\
\stackrel{0}{0} \\
\stackrel{0}{0}\end{array}$ & $\stackrel{\Gamma}{\stackrel{\Gamma}{r}}$ & 0 & 0 & 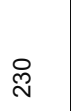 & 趈 & 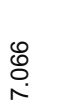 & i & 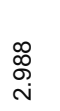 \\
\hline ฉ̊ & 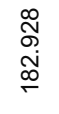 & 犬ั & $\stackrel{\stackrel{\leftrightarrow}{\leftrightarrow}}{\stackrel{\leftrightarrow}{N}}$ & 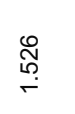 & 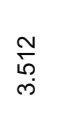 & $\begin{array}{l}\tilde{\tilde{O}} \\
\stackrel{\circ}{\circ}\end{array}$ & $\stackrel{\stackrel{\leftrightarrow}{\circ}}{\stackrel{\leftrightarrow}{\leftarrow}}$ & 0 & 0 & $\stackrel{\circ}{\sim}$ & $\frac{m}{6}$ & 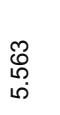 & i & $\begin{array}{l}\stackrel{\infty}{\infty} \\
\stackrel{\sim}{N}\end{array}$ \\
\hline ธิ & 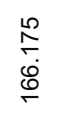 & 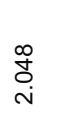 & $\begin{array}{l}\mathbb{D} \\
\stackrel{N}{N}\end{array}$ & $\stackrel{0}{\stackrel{0}{10}}$ & 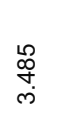 & $\begin{array}{l}\hat{N} \\
\stackrel{0}{\circ} \\
\stackrel{0}{0}\end{array}$ & 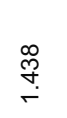 & 0 & 0 & $\stackrel{\mathscr{L}}{\sim}$ & $\stackrel{\infty}{i}$ & 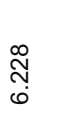 & 1 & 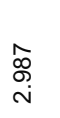 \\
\hline $\bar{\Delta}$ & $\begin{array}{l}\circ \\
0 \\
0 \\
0 \\
0\end{array}$ & 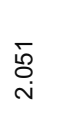 & $\begin{array}{l}\stackrel{\leftrightarrow}{\Omega} \\
\stackrel{\sim}{N}\end{array}$ & $\stackrel{\hat{n}}{\stackrel{\hat{n}}{r}}$ & $\begin{array}{l}\stackrel{\infty}{\infty} \\
\stackrel{\infty}{\infty}\end{array}$ & $\begin{array}{l}\text { o } \\
\stackrel{0}{0} \\
\stackrel{0}{0}\end{array}$ & $\underset{\stackrel{N}{\stackrel{N}{r}}}{.}$ & 0 & 0 & $\stackrel{\text { \& }}{\sim}$ & 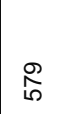 & 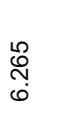 & i & $\begin{array}{l}\infty \\
\stackrel{\infty}{\infty} \underset{\sim}{\sim}\end{array}$ \\
\hline J & 孞 & 离 & 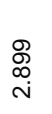 & 宮 & $\underset{n}{\stackrel{N}{f}}$ & $\begin{array}{l}\text { ڤ્o } \\
\stackrel{0}{\circ}\end{array}$ & $\stackrel{\Gamma}{\stackrel{\Gamma}{\operatorname{s}}}$ & $\circ$ & 0 & N & $\stackrel{\sim}{\sim}$ & 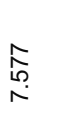 & $\underset{\stackrel{\circ}{\circ}}{\stackrel{\circ}{+}}$ & 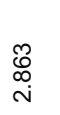 \\
\hline$\tilde{O}$ & 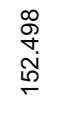 & 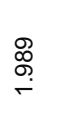 & $\begin{array}{l}\stackrel{8}{\circ} \\
\text { ì }\end{array}$ & 总 & 点 & $\begin{array}{l}\hat{\hat{O}} \\
\stackrel{0}{\circ}\end{array}$ & $\underset{\stackrel{\Gamma}{\circ}}{\stackrel{\Gamma}{r}}$ & 0 & 0 & $\widehat{N}$ & 只 & 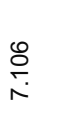 & $\underset{\stackrel{f}{f}}{\stackrel{f}{r}}$ & 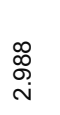 \\
\hline $\mathcal{O}$ & 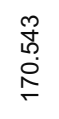 & $\begin{array}{l}\stackrel{\circ}{\circ} \\
\stackrel{\sim}{*}\end{array}$ & 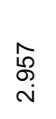 & ִָ & $\sum_{m}^{m}$ & $\begin{array}{l}\infty \\
\stackrel{\infty}{0} \\
\stackrel{0}{\circ}\end{array}$ & 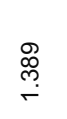 & 0 & 0 & $\stackrel{\circ}{\sim}$ & $\frac{N}{6}$ & స్త్ర & $\stackrel{\hat{f}}{\stackrel{\hat{f}}{r}}$ & $\begin{array}{l}\stackrel{\infty}{\infty} \\
\stackrel{\leftrightarrow}{N}\end{array}$ \\
\hline$\overline{0}$ & $\begin{array}{l}\stackrel{\infty}{N} \\
\stackrel{+}{\sigma}\end{array}$ & 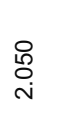 & $\stackrel{\widehat{్}}{\stackrel{N}{N}}$ & $\stackrel{\infty}{\stackrel{\infty}{\leftarrow}}$ & $\begin{array}{l}\infty \\
\stackrel{\infty}{\infty} \\
\stackrel{\infty}{\infty}\end{array}$ & $\begin{array}{l}\text { o } \\
\stackrel{\leftrightarrow}{\circ} \\
\stackrel{0}{0}\end{array}$ & $\stackrel{\mathcal{f}}{\stackrel{ }{r}}$ & 0 & 0 & I & $\underset{\substack{\infty \\
\infty}}{\infty}$ & 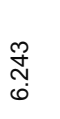 & $\begin{array}{l}\stackrel{0}{f} \\
\stackrel{+}{-}\end{array}$ & 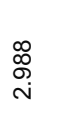 \\
\hline 足 & $\begin{array}{l}\stackrel{\circ}{\circ} \\
\stackrel{\circ}{\circ} \\
\stackrel{\circ}{\circ}\end{array}$ & 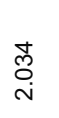 & $\stackrel{\widehat{్}}{\text { N }}$ & $\stackrel{\text { ț }}{\stackrel{t}{\circ}}$ & $\begin{array}{l}\hat{f} \\
\text { j }\end{array}$ & $\begin{array}{l}\infty \\
\stackrel{8}{0} \\
\stackrel{0}{\circ}\end{array}$ & 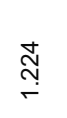 & 0 & 0 & $\stackrel{0}{N}$ & \begin{tabular}{l}
$\infty$ \\
\hdashline \\
\hdashline
\end{tabular} & 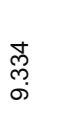 & $\begin{array}{l}\stackrel{0}{f} \\
\stackrel{+}{\leftarrow}\end{array}$ & $\underset{\substack{\mathcal{D} \\
\text { N }}}{ }$ \\
\hline లె & $\begin{array}{l}8 \\
0 \\
0 \\
\infty 0 \\
0 \\
0\end{array}$ & $\begin{array}{l}\stackrel{\leftrightarrow}{0} \\
\stackrel{\sim}{N}\end{array}$ & 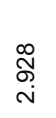 & $\stackrel{\text { ț }}{\stackrel{t}{i}}$ & $\begin{array}{l}\stackrel{\infty}{f} \\
\stackrel{\infty}{\infty}\end{array}$ & $\begin{array}{l}\text { 䓀 } \\
\stackrel{0}{0}\end{array}$ & 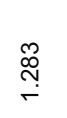 & 0 & 0 & $\stackrel{O}{N}$ & $\hat{\circ}$ & $\begin{array}{l}\hat{\sigma} \\
\text { ò }\end{array}$ & 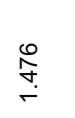 & 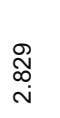 \\
\hline 妾 & $\begin{array}{l}\infty \\
\circ \\
0 \\
0 \\
\end{array}$ & 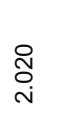 & ָั & $\stackrel{\circ}{\stackrel{\circ}{\operatorname{so}}}$ & 总 & $\begin{array}{l}\mathbb{O} \\
\stackrel{0}{\circ}\end{array}$ & $\stackrel{\text { S̊ }}{\leftarrow}$ & 0 & 0 & $\stackrel{\sim}{\sim}$ & 怘 & 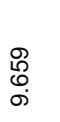 & $\underset{\stackrel{f}{+}}{\stackrel{N}{r}}$ & 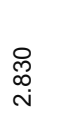 \\
\hline జ̛ & $\begin{array}{l}\bar{\sigma} \\
\stackrel{\sigma}{0} \\
\stackrel{0}{\sigma}\end{array}$ & 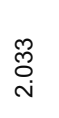 & $\underset{\sim}{\stackrel{N}{N}}$ & $\stackrel{m}{\stackrel{m}{\leftarrow}}$ & \begin{tabular}{l}
$\stackrel{0}{2}$ \\
\multirow{\infty}{\infty}{}
\end{tabular} & $\begin{array}{l}\bar{o} \\
\stackrel{\circ}{\circ}\end{array}$ & $\stackrel{+}{\stackrel{\Delta}{\circ}}$ & 0 & 0 & $\underset{\sim}{-}$ & $\stackrel{\Omega}{\hat{b}}$ & 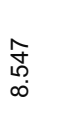 & $\stackrel{\hat{f}}{\leftarrow}$ & 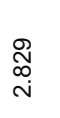 \\
\hline 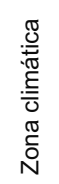 & $\begin{array}{l}\mathbb{\Psi} \\
\frac{\pi}{c} \\
\frac{0}{\omega} \\
\stackrel{\sum}{>}\end{array}$ & 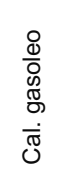 & $\begin{array}{l}\dot{y} \\
z_{0} \\
\overline{0} \\
\dot{\bar{\delta}} \\
0\end{array}$ & 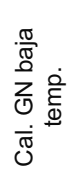 & 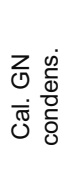 & 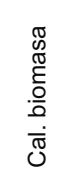 & 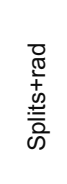 & 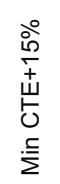 & $\begin{array}{l}\stackrel{\circ}{0} \\
\stackrel{+}{4} \\
\stackrel{+}{U} \\
\stackrel{5}{\Sigma}\end{array}$ & 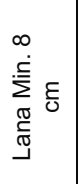 & 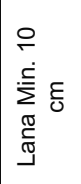 & 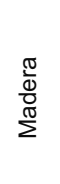 & 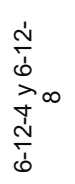 & 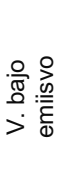 \\
\hline
\end{tabular}

Tabla 4.5.- Coste de inversión de la vivienda adosada y coste de inversión de cada cambio señalado en la tabla 4.4 
Las medidas más económicas son las alcanzadas por el cambio en el material aislante, seguida del uso de radiadores, espesor de los vidrios y el uso de diferentes tipos de caldera (siendo la de gas natural de baja temperatura la más económica). El cambio de marcos y el uso de caldera de biomasa son soluciones significativamente más caras que otras medidas. El coste de incrementar la contribución solar de acs es en la mayoría de los casos cero, ya que los formatos comerciales existentes ya alcanzaban un porcentaje por encima del mínimo que establecía el CTE, incluso superando el $15 \%$ y el $30 \%$ (excepto en la zona $\mathrm{C} 1$ ).

Finalmente la tabla 4.6 muestra el ratio porcentaje de reducción de emisiones por euro de coste de inversión.

El mayor ratio se obtiene por incremento de espesor de la capa de aislamiento en la envolvente del edificio. La diferencia con el resto de medidas es significativa, fundamentalmente por el bajo coste de inversión que suponer frente a otras medidas.

Las dos siguientes medidas son el uso de radiadores y la mejora de los vidrio. A estas medidas le siguen el uso de calderas, destacando como mejor el uso de caldera de baja temperatura, y de vidrios bajo emisivos.

Las soluciones con menor ratio, debido al alto coste de inversión, son los marcos de madera y la caldera de biomasa. 
CAPÍTULO IV.- ESTIMACIÓN DEL VALOR DE LAS VIVIENDAS Y ANÁLISIS DE COSTES

\begin{tabular}{|c|c|c|c|c|c|c|c|c|c|c|c|c|}
\hline $\begin{array}{c}\text { Zona } \\
\text { climática }\end{array}$ & A3 & A4 & B3 & B4 & C1 & $\mathrm{C} 2$ & C3 & $\mathrm{C} 4$ & D1 & D2 & D3 & $\mathrm{E} 1$ \\
\hline $\begin{array}{c}\text { Caldera } \\
\text { gasoil }\end{array}$ & 0,042 & 0,040 & 0,043 & 0,042 & 0,042 & 0,044 & 0,046 & 0,044 & 0,046 & 0,046 & 0,047 & 0,048 \\
\hline Caldera & & & & & & & & & & & & \\
\hline $\begin{array}{c}\text { GN } \\
\text { estándar }\end{array}$ & 0,027 & 0,026 & 0,028 & 0,027 & 0,026 & 0,028 & 0,030 & 0,028 & 0,030 & 0,030 & 0,029 & 0,030 \\
\hline Caldera & & & & & & & & & & & & \\
\hline $\begin{array}{c}\text { GN } \\
\text { baja t. }\end{array}$ & 0,052 & 0,049 & 0,054 & 0,052 & 0,051 & 0,054 & 0,057 & 0,055 & 0,058 & 0,058 & 0,057 & 0,059 \\
\hline Caldera & & & & & & & & & & & & \\
\hline $\begin{array}{c}\text { GN } \\
\text { condens. }\end{array}$ & 0,022 & 0,021 & 0,023 & 0,023 & 0,022 & 0,023 & 0,025 & 0,024 & 0,025 & 0,025 & 0,024 & 0,025 \\
\hline $\begin{array}{c}\text { Caldera } \\
\text { biomasa }\end{array}$ & 0,006 & 0,007 & 0,007 & 0,007 & 0,007 & 0,006 & 0,008 & 0,007 & 0,008 & 0,008 & 0,008 & 0,008 \\
\hline $\begin{array}{c}\text { Splits + } \\
\text { radiador } \\
\text { es }\end{array}$ & 0,084 & 0,078 & 0,058 & 0,097 & 0,081 & 0,068 & 0,061 & 0,069 & 0,050 & 0,063 & 0,056 & 0,085 \\
\hline $\begin{array}{c}\text { Lana } \\
\text { mineral } \\
8 \mathrm{~cm}\end{array}$ & 0,396 & 0,412 & 0,393 & 0,443 & 0,381 & 0,363 & 0,412 & 0,428 & 0,399 & 0,400 & 0,377 & 0,417 \\
\hline $\begin{array}{c}\text { Lana } \\
\text { mineral } \\
10 \mathrm{~cm}\end{array}$ & - & - & - & - & - & - & - & - & 0,167 & 0,167 & 0,157 & 0,174 \\
\hline $\begin{array}{c}\text { Marco } \\
\text { madera }\end{array}$ & 0,011 & 0,010 & 0,010 & 0,010 & 0,015 & 0,017 & 0,013 & 0,013 & 0,015 & 0,015 & 0,017 & 0,013 \\
\hline $\begin{array}{c}\text { Vidrio } \\
6-12-4 \text { y } \\
6-12-8\end{array}$ & 0,064 & 0,064 & 0,062 & 0,063 & 0,065 & 0,063 & 0,063 & 0,059 & - & - & - & - \\
\hline $\begin{array}{l}\text { Vidrio } \\
\text { bajo } \\
\text { emisivo }\end{array}$ & 0,032 & 0,032 & 0,030 & 0,031 & 0,030 & 0,029 & 0,028 & 0,031 & 0,029 & 0,029 & 0,029 & 0,029 \\
\hline
\end{tabular}

Tabla 4.6.- Porcentaje de reducción de emisiones por euro de coste de inversión para cada cambio señalado en la tabla 8.1 
La siguiente etapa en esta Tesis consistió en la combinación de parámetros para obtener, en cada zona climática, las posibles calificaciones energéticas que se pueden obtener en obra nueva. Así, teniendo en cuenta que pueden darse en España 5 posibles calificaciones y 12 zonas climáticas, se podría hablar de 60 presupuestos; sin embargo, se obtendrá en total 50 , ya que no se alcanzan las calificaciones E, en las zonas A3, A4, B3, C3, C4, D3, E1, ni B en las zonas C3, C4, D3.

La forma de combinar los parámetros de vio en el apartado III.4. De cada una de las nuevas configuraciones simuladas, se obtienen los presupuestos detallados, recogiéndose los resultados en las tablas 4.7 y 4.8 :

Los valores de los Presupuestos de Ejecución Material (PEM) para la vivienda simulada (señalada como A1 en proyecto de partida, ver imagen 3.1, capítulo III) son los mostrados en la tabla 4.7 :

\begin{tabular}{|l|l|c|c|c|c|c|}
\hline \multirow{2}{*}{ PEMVIVIENDA } & \multicolumn{5}{|c|}{ CALIFICACIÓN } \\
\cline { 3 - 7 } & $\mathrm{E}$ & $\mathrm{D}$ & $\mathrm{C}$ & $\mathrm{B}$ & $\mathrm{A}$ \\
\hline A3 & Málaga & & 151.205 & 165.161 & 169.849 & 183.561 \\
\hline A4 & Almería & & 155.846 & 166.918 & 171.300 & 185.288 \\
\hline B3 & Castellón & & 153.927 & 168.509 & 173.147 & 182.420 \\
\hline B4 & Sevilla & 154.142 & 154.315 & 169.155 & 173.806 & 183.749 \\
\hline C1 & Santander & 161.128 & 166.401 & 174.215 & 181.258 & 176.541 \\
\hline C2 & Barcelona & 170.543 & 174.700 & 181.906 & 188.149 & 186.466 \\
\hline C3 & Granada & & 146.959 & 152.498 & & 164.461 \\
\hline C4 & Badajoz & & 142.953 & 151.487 & & 174.225 \\
\hline D1 & Pamplona & 162.038 & 162.203 & 166.610 & 176.314 & 177.604 \\
\hline D2 & Logroño & 161.814 & 162.046 & 166.175 & 176.308 & 177.128 \\
\hline D3 & Madrid & & 172.445 & 182.928 & & 188.160 \\
\hline E1 & Burgos & & 149.382 & 160.822 & 172.526 & 165.970 \\
\hline
\end{tabular}

Tabla 4.7.- PEM en $€$ de la vivienda simulada por zona climática y calificación energética Fuente: Elaboración propia 
Para la obtención del PEC, se adoptan unos porcentajes de Gastos Generales y de Beneficio Industrial del $13 \%$ y $6 \%$ respectivamente. Se utilizan estos valores por ser los porcentajes que se aplican en las obras de la Administración [L.30/2007]. En obra privada los porcentajes no están fijados, pero habitualmente, son próximos a los valores que se estipulan en la obra pública.

El cálculo del PEC permite obtener el valor de la vivienda por el método del coste. La tabla 4.8 muestra el PEC para cada configuración para la vivienda estudiada:

\begin{tabular}{|l|l|c|c|c|c|c|}
\hline \multirow{2}{*}{ PEC VIVIENDA } & \multicolumn{5}{|c|}{ CALIFICACIÓN } \\
\cline { 3 - 7 } & & E & D & C & B & A \\
\hline A3 & Málaga & & 179.935 & 196.541 & 202.120 & 218.437 \\
\hline A4 & Almería & & 185.456 & 198.633 & 203.848 & 220.493 \\
\hline B3 & Castellón & & 183.173 & 200.525 & 206.045 & 217.080 \\
\hline B4 & Sevilla & 183.429 & 183.635 & 201.295 & 206.829 & 218.661 \\
\hline C1 & Santander & 191.742 & 198.017 & 207.316 & 215.697 & 210.084 \\
\hline C2 & Barcelona & 202.946 & 207.893 & 216.468 & 223.898 & 221.895 \\
\hline C3 & Granada & & 174.882 & 181.473 & & 195.708 \\
\hline C4 & Badajoz & & 170.114 & 180.269 & & 207.327 \\
\hline D1 & Pamplona & 192.825 & 193.022 & 198.266 & 209.814 & 211.349 \\
\hline D2 & Logroño & 192.559 & 192.835 & 197.748 & 209.806 & 210.783 \\
\hline D3 & Madrid & & 205.209 & 217.684 & & 223.910 \\
\hline E1 & Burgos & & 177.765 & 191.379 & 205.306 & 197.504 \\
\hline
\end{tabular}

Tabla 4.8.- PEC en € de la vivienda simulada. Fuente: elaboración propia

Generalmente el coste de la vivienda es mayor según mejora la clase energética. Sin embargo, de la tabla 4.8, en las cifras en cursiva, se observa que este patrón de comportamiento no se cumple en algunos casos en los que se pasa de una calificación $B$ a una calificación $A$.

La explicación, tal y como se comentó en la tabla 3.36 del capítulo III, es que en estas zonas frías $\mathrm{C} 1, \mathrm{C} 2$ y E1, con muy bajos requerimientos de 
refrigeración, con el uso de una caldera de biomasa a partir de la configuración C, resulta directamente una calificación A. El alcanzar la calificación $B$, sólo es posible utilizando la combinación de todas las medidas de mejora de la EE utilizadas en este estudio, que en conjunto, resultan más costosas que la caldera de biomasa por si sola.

Teniendo en cuenta los resultados de la tabla 4.8 , se concluye que, un coste de la inversión mayor, implica una mejor calificación energética $y$, por consiguiente, una menor emisión de $\mathrm{CO}_{2}$.

\section{IV.3.- COSTES DE USO DE LA VIVIENDA}

\section{IV.3.1.- Tipos de costes}

En el apartado anterior se han obtenido los costes de construcción de la vivienda, y que constituyen una parte del pago ${ }^{1}$ realizado por el propietario de la vivienda en el momento de la compra. Dicho pago se repercutirá a lo largo de la vida la vivienda a través de los costes de amortización. Sin embargo, existen otros costes en los que también se incurrirá por el uso normal del inmueble durante su vida útil.

Según Rudbeck (2002), se puede hablar de 5 tipos de valores o costes a considerar:

- Valor de la inversión: es el coste de la adquisición de la vivienda. Se correspondería con el valor de reemplazamiento neto mencionado en el apartado anterior. Tiene lugar únicamente en el año 0 o año de compra de vivienda y supone un pago. Dicho valor se repercutirá como coste de amortización anual.

- Valor de operación: considera los costes o pagos anuales en los que incurre el usuario como consecuencia del normal uso de la vivienda. En

${ }^{1}$ Otros pagos adicionales que forman parte del precio de la vivienda serían: el suelo, el beneficio del promotor, etc. 
este estudio se va a considerar únicamente la energía necesaria para el funcionamiento de los servicios de la vivienda (calefacción, refrigeración, agua caliente sanitaria). Otros costes como los de iluminación, no son tenidos en cuenta al no ser integrados en el caso de viviendas en el programa para certificación energética Calener VYP v.01.

- Valor de mantenimiento: se refiere a los costes o pagos como consecuencia de las operaciones periódicas necesarias para el correcto funcionamiento de cada uno de los elementos que conforman el edificio, como por ejemplo: labores de limpieza de fachadas, revisión de calderas, pintura, etc.

- Valor de reemplazamiento: se debe a que los elementos que conforman un edificio tienen distintas vidas útiles, generalmente menores en el caso de las instalaciones que de los elementos constructivos. Cuando estos elementos han agotado su vida útil, pero no así el edificio en su globalidad, es necesario sustituirlos por nuevas unidades. Este valor supondrá un pago cada año que tenga lugar la renovación y, al igual que el coste de construcción de la vivienda, se repercutirá anualmente a través de los costes de amortización

- Valor de reversión: se refiere a la recuperación de parte de la inversión inicial, en el caso de que no se haya agotado su vida útil. En este análisis no se considera ya que se supone agotada la vida útil del edificio.

En definitiva, se consideran 4 tipos de costes, que coinciden con 3 de los señalados anteriormente (costes de operación, amortización y mantenimiento), a los que se añade un coste adicional, el coste medioambiental o coste social del carbono, derivado de las emisiones de $\mathrm{CO}_{2}$ que realiza el inmueble durante su uso. La inclusión de este coste se justifica por el hecho de que el objetivo del presente estudio es relacionar el valor del inmueble con su EE, y el indicador para estimar dicha EE, en la herramienta utilizada Calener VYP, es precisamente la cantidad de emisiones de $\mathrm{CO}_{2}$ a la atmósfera. 
Por otro lado, hay que considerar el número de años en que el edificio se encuentre en servicio, ya que la simulación realizada con Calener VYP proporciona los resultados del emisiones del $\mathrm{CO} 2$ anuales por uso de la vivienda.Todos los valores de costes se van a estimar por metro cuadrado y año, en valores constantes o precios referidos al año 0 , y son:

1. $\mathrm{C}_{\text {AM }}$ : Coste de amortización del edificio y de los elementos que se renuevan periódicamente. Es el único coste que no supone un pago.

2. C $C_{\text {ENER }}$ : Coste del consumo de energía necesaria para el funcionamiento de los servicios de la vivienda durante su uso, también denominado coste de operación.

3. $\mathrm{C}_{\text {MAN }}$ : Costes de mantenimiento.

4. $\mathrm{C}_{\mathrm{CO} 2}$ : Coste de las emisiones de $\mathrm{CO}_{2}$ durante la vida útil o el periodo de uso de la vivienda.

El Coste total, en $€ / \mathrm{m}^{2}$.año, se obtiene como suma de los cuatro componentes anteriores:

$$
C_{T}=C_{A M}+C_{E N E R}+C_{M A N}+C_{C O 2}
$$

\section{IV.3.2.- Vida útil y costes de amortización}

Se considera vida útil de un inmueble aquella durante la cual se mantienen las condiciones para poder utilizarse según el uso previsto [ISO 15686-1]. Varía en función de la calidad de la edificación, del uso y del mantenimiento que se realice al inmueble.

Es importante definir la vida útil por varios motivos:

- Para conocer cuál será la amortización anual de la vivienda.

- Para conocer los costes de consumo de la energía necesaria para el normal uso de la vivienda, durante los años en que esté siendo utilizada, así como las emisiones de $\mathrm{CO}_{2}$ a la atmósfera. 
- Para establecer las labores de mantenimiento durante su uso, en función de la vida útil de cada uno de sus componentes. Aquí hay que diferenciar la vida útil de distintos elementos que conforman la vivienda, por ejemplo de una determinada instalación, elemento constructivo, etc. y relacionarlo con el periodo en el que el inmueble estará en uso.

- Los periodos de vida útil en viviendas varían según las fuentes consultadas: Según el RD 1777/2003, de 30 de julio, por el que se aprueba el Reglamento de Impuesto sobre Sociedades, en la "Tabla de coeficientes de amortización", que aparece como anexo, se consideran 50 años.

- En la Resolución $N^{\circ} 43$, de 26-12-2002, según la tabla de vida útil fijada por el Servicio de Impuestos Internos para bienes físicos del activo inmovilizado, se fija en 80 años.

- En la literatura consultada se pueden ver cifras de 60 años [Rudbeck, 2002], y 90 años [Johnstone, 2001ª; 2001b].

- Del estudio del parque de viviendas europeo, se constata que alrededor del $35 \%$ de viviendas en Europa superan los 50 años, encontrándose hasta viviendas de 154 años en servicio [Davies and Wyatt, 2004].

- A nivel nacional, consultas sobre las antigüedades del parque edificatorio residencial, demuestran que un gran porcentaje de edificios superan los 50 años, todo ello, sin haber sido sometidas al nivel de mantenimiento que se debería realizar en este edificio. Otras fuentes han sido asimismo consultadas [García Olmos, 1997; Bradley and Kohler, 2007; Durán Redondo, 2009], dando distintas cifras.

- El censo de viviendas español, según datos del Instituto Nacional de Estadística, pone de manifiesto las edades de los edificios a vivel nacional, como se muestra en la tabla 4.9: 


\begin{tabular}{|l|l|r|}
\hline Periodo & $\begin{array}{l}\text { Edificios } \\
\text { de viviendas }\end{array}$ & $\%$ \\
\hline Antes de 1900 & 901.299 & 10,45 \\
\hline $1900-1920$ & 426.872 & 4,95 \\
\hline $1921-1940$ & 497.039 & 5,76 \\
\hline $1941-1950$ & 539.425 & 6,26 \\
\hline $1951-1960$ & 886.544 & 10,05 \\
\hline $1961-1970$ & 1.090 .319 & 12,64 \\
\hline $1971-1980$ & 1.504 .984 & 17,45 \\
\hline $1981-1990$ & 1.360 .191 & 15,77 \\
\hline $1991-2001$ & 1.417 .202 & 16,43 \\
\hline TOTAL & $\mathbf{8 . 6 2 3 . 8 7 5}$ & \\
\hline
\end{tabular}

Tabla 4.9.- Número de edificios de viviendas en España, según año de construcción. Fuente: Elaboración propia a partir deCensos de población y vivienda 2001, INE

- Por último, se ha tenido en cuenta la vida útil que indica la normativa de valoración hipotecaria, Artículo 19 ECO 805/2003, según la cualla estimación de la vida útil es:

- Para edificios de uso residencial: 100 años

- Para edificios de oficinas: 75 años

- Para edificios comerciales: 50 años

- Para edificios de uso industrial e inmuebles ligados a una explotación económica: 35 años.

Teniendo en cuenta que vamos a tener en consideración las operaciones de mantenimiento recomendadas en el Libro del Edificio, así como la vida útil también de los materiales e instalaciones que forman parte del edificio, realizando las reformas, sustituciones de equipos, etc., cuando sean necesarias, se considera adecuada una vida útil para el uso residencial estudiado de 100 años. 
En lo referente a la vida útil de instalaciones y acabados, en la bibliografía consultada, dicho valor oscila en un intervalo entre 10-25 años.

Algunos autores consideran 10-15 años para instalaciones, terminaciones y acabados [Llano Elcid, 2007]; otros, especifican la vida útil según el tipo de instalación, variando desde los 10 años para calentadores de agua, hasta los 25 años para sistemas de calefacción [Liska, 2000]. El resto de fuentes consultadas se mueven en este margen, por lo que se estima finalmente como válida la vida útil de 15 años cuando estemos hablando de renovación de las instalaciones.

Así, pues se van a considerar los costes de amortización derivados de la sustitución de instalaciones, por haber agotado su vida útil, previamente al término de la vida útil del edificio. Por ejemplo para una caldera de gas, se calculará su amortización de acuerdo a 15 años de vida útil.

La amortización derivada de la sustitución o reparación de algún elemento de la construcción, que sea necesaria durante los 100 años considerados, como puede ser la reforma en baños y aseos con cambio de aparatos sanitarios, alicatados o equipamientos de cocina, se calculará considerando 25 años de vida útil, transcurridos los cuales se repondrán.

El método de amortización a utilizar va a ser siempre el lineal con valor residual 0.

La tabla 4.10 muestra los costes de amortización anuales por $\mathrm{m}^{2}$, de la construcción e instalaciones, considerando la superficie de $270,21 \mathrm{~m}^{2}$ de la vivienda estudiada y una vida útil de 100 años: 


\begin{tabular}{|l|l|c|c|c|c|c|}
\hline \multirow{2}{*}{ Coste Amortización } & \multicolumn{5}{|c|}{ CALIFICACIÓN } \\
\cline { 3 - 7 } & E & D & C & B & A \\
\hline A3 & Málaga & & 10,37 & 11,78 & 13,22 & 14,25 \\
\hline A4 & Almería & & 10,45 & 11,87 & 13,64 & 14,26 \\
\hline B3 & Castellón & & 10,52 & 11,94 & 13,82 & 14,23 \\
\hline B4 & Sevilla & 10,53 & 10,54 & 12,00 & 13,85 & 14,29 \\
\hline C1 & Santander & 10,94 & 12,16 & 12,50 & 12,81 & 14,06 \\
\hline C2 & Barcelona & 11,44 & 12,04 & 12,76 & 13,03 & 14,60 \\
\hline C3 & Granada & & 10,05 & 11,21 & & 13,39 \\
\hline C4 & Badajoz & & 9,94 & 11,12 & & 11,58 \\
\hline D1 & Pamplona & 9,22 & 9,23 & 11,98 & 12,41 & 14,11 \\
\hline D2 & Logroño & 10,23 & 10,96 & 11,96 & 12,40 & 13,70 \\
\hline D3 & Madrid & & 11,53 & 12,81 & & 14,67 \\
\hline E1 & Burgos & & 10,29 & 11,60 & 12,11 & 13,47 \\
\hline
\end{tabular}

Tabla 4.10.- Costes de amortización en $€ / \mathrm{m}^{2}$.año de la vivienda simulada. Fuente: Elaboración propia

\section{IV.3.3.- Coste de la energía ( $\left.\mathrm{C}_{\mathrm{ENER}}\right)$}

De las fuentes de energía planteadas en un principio, al estudiar las variables que influyen en la EE [Torrella, 2005], finalmente se adoptan tres:

- Electricidad

- Gas natural

- Biomasa

Para la refrigeración, resuelta mediante splits, en todos los casos se utiliza electricidad. Para la calefacción y agua caliente sanitaria (ACS) se puede utilizar cualquiera de las tres mencionadas, según se ve en la figura 4.2: 


\begin{tabular}{|c|c|c|c|}
\hline \multicolumn{2}{|c|}{ Refrigeración } & \multicolumn{2}{|c|}{ Calefacción y ACS } \\
\hline Electricidac & $\sim$ & Electricidad & \\
\hline Electricidac & $\sim$ & Gas natura & \\
\hline Electricidac & 20 & Biomasa & \\
\hline
\end{tabular}

Figura 4.2.- Esquema tipos de combustibles o fuentes de energía utilizados

Por lo tanto, el coste de la energía, teniendo en cuenta la fuente de energía utilizada, se expresa como:

$$
C_{E N E R}=C_{E L}+C_{G N}+C_{B I O}
$$

siendo,

$\mathrm{C}_{\mathrm{EL}}$ : Coste por consumo de energía eléctrica

$\mathrm{C}_{\mathrm{GN}}$ : Coste por consumo de gas natural

$\mathrm{C}_{\mathrm{BIO}}$ : Coste por consumo de biomasa

En las viviendas en que se utilicen diferentes fuentes de energía, significa que para calefacción y ACS se utiliza gas natural o biomasa, y para refrigeración electricidad.

El cálculo del coste de la energía en cada vivienda va a depender del tipo de fuente utilizada, como se desprende de la expresión [5].

Para los 50 casos simulados de viviendas, según la zona y la calificación energética, el uso de energía en calefacción y ACS, se resume esquemáticamente en la tabla 4.11: 


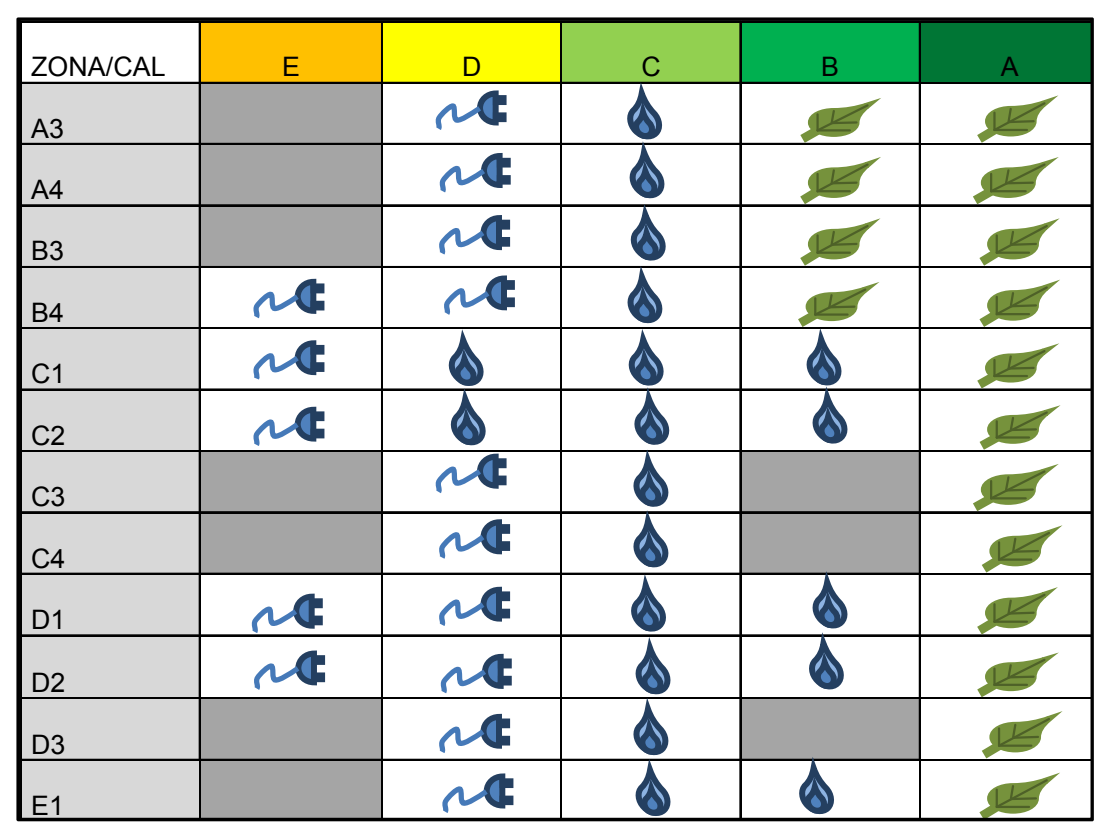

Tabla 4.11.- Fuente de energía o combustible utilizado para calefacción y ACS en las distintas configuaciones de viviendas

Se observa cómo la electricidad es la única fuente de energía utilizada en las configuraciones $E$ y en algunas D. Para el resto de calificaciones se utiliza solamente para los sistemas de refrigeración.

El gas natural se utiliza en calificaciones $C$ y en algunas $B$ para calefacción y acs. Y la biomasa es el combustible que permite alcanzar las calificaciones A y en algunos casos, es necesario para alcanzar la calificación B (ver tabla 4.8).

Los cálculos en Calener proporcionan información sobre los consumos de las distintas configuraciones de las viviendas.

Las tarifas de electricidad y gas consideradas, son las vigentes para el periodo del estudio y se obtienen del BOE 31-12-09. En ningún caso está incluido el IVA. El cálculo del precio de la biomasa se obtiene como media de los precios 
de mercado de distintas empresas suministradoras, al no existir tarifas oficiales, los cuales incluyen además los costes de portes. Cada uno de los sumandos del coste de la energía se obtiene del siguiente modo:

\section{IV.3.3.1.- Coste de electricidad, $\mathrm{C}_{\mathrm{EL}}$}

Para una vivienda tipo como la estudiada, hay que hablar de dos términos diferentes: uno fijo que depende de la potencia contratada y otro que varía en función del consumo. La expresión matemática del coste anual de la electricidad es la siguiente:

$$
\mathrm{CEL}=\alpha+\operatorname{Tp}^{*}(1+0,0486 * \mathrm{P})+T e^{*}(1+0,0486 * \beta) \quad[6]
$$

siendo,

$\alpha=$ Alquiler del contador $=6,8401 € / a n ̃ o$

$\mathrm{Tp}=$ Término de potencia, en €/año

$\mathrm{Te}=$ Término consumo, en $€ /$ año

$\beta=$ Impuesto sobre electricidad $=1,05113$

$\mathrm{P}=$ potencia contratada en $\mathrm{Kw}$

Para potencia contratada inferior a $10 \mathrm{Kw}$, el término de potencia se calcula:

$$
\mathrm{Tp}=\mathrm{P}^{*} 20,633129
$$

En el caso en que no haya discriminación horaria, el término de consumo viene dado por la expresión:

$$
\mathrm{Te}=\mathrm{C} * 0,117759
$$

donde,

$\mathrm{C}=$ consumo en $\mathrm{Kwh}$

Sustituyendo las expresiones [7] y [8] en la la expresión [6] queda del modo siguiente: 
$C_{E L}=6,8401+P$ * 20,633129 * $(1+0,0486 * P)+C * 0,117759$ * $(1+0,0486$ * 1,05113)

\section{IV.3.3.2.- Coste de gas natural, $\mathrm{C}_{\mathrm{GN}}$}

Para su cálculo se emplea la siguiente expresión:

$$
\mathrm{C}_{\mathrm{GN}}=\delta+\mathrm{Tf}+\mathrm{TV}
$$

siendo,

$\delta=$ Alquiler del contador $=2,33 € /$ mes $=27,96 € /$ año

$\mathrm{Tf}=$ Término fijo $=3,90 € /$ mes $=46,8 € /$ año

Tv= Término variable

En este caso, el término dependiente del consumo se calcula como:

$$
\mathrm{Tv}=\mathrm{C} * 0,04444219
$$

Sustituyendo la expresión [10] en la expresión [9] queda del modo siguiente:

$\mathrm{C}_{\mathrm{GN}}=74,76+\mathrm{C}^{*} 0,04444219$

\section{IV.3.3.3.- Coste de la biomasa, $\mathrm{C}_{\mathrm{BIO}}$}

Como ya se ha comentado anteriormente no hay tarifas oficiales de biomasa, ya que este tipo de combustible no es de uso común en España. Por ello, se ha realizado una búsqueda de precios de casas comerciales que se dedican a la distribución de este tipo de combustible y se adopta un valor medio de 0,24 $€ / \mathrm{Kg}$, incluyendo portes (Amatex S.A., Empasa Biocombustibles, Ökofen, Legnopel...). Por otro lado, como $1 \mathrm{Kg}$ es suficiente para generar $5 \mathrm{Kw}$, la expresión del cálculo del coste de la biomasa quedará del siguiente modo: 


$$
\begin{aligned}
& \mathrm{C}_{\mathrm{BIO}}=0,24(€ / \mathrm{Kg})^{*} 1(\mathrm{Kg} / 5 \mathrm{Kw})^{*} \mathrm{C}(\mathrm{Kwh}) \\
& \mathrm{C}_{\mathrm{BIO}}=0,24{ }^{*} \mathrm{C} / 5=0,048^{*} \mathrm{C}
\end{aligned}
$$

Los costes de consumo de energía obtenidos, según los precios vigentes, se recogen en la tabla 4.12:

\begin{tabular}{|c|l|c|c|c|c|c|}
\hline \multicolumn{1}{|c|}{$\begin{array}{c}\text { ENERG. } \\
\text { VIVIENDA }\end{array}$} & \multicolumn{5}{c|}{ S/CALIFICACIÓN } \\
\hline \multicolumn{2}{|c|}{ ZON/año) } \\
\hline A3 & Málaga & E & D & C & B & A \\
\hline A4 & Almería & -- & 628 & 531 & 485 & 431 \\
\hline B3 & Castellón & -- & 717 & 581 & 546 & 546 \\
\hline B4 & Sevilla & 730 & 721 & 592 & 545 & 684 \\
\hline C1 & Santander & 844 & 718 & 656 & 494 & 500 \\
\hline C2 & Barcelona & 820 & 712 & 663 & 492 & 647 \\
\hline C3 & Granada & -- & 898 & 724 & -- & 717 \\
\hline C4 & Badajoz & -- & 793 & 655 & -- & 513 \\
\hline D1 & Pamplona & 1.109 & 1.085 & 863 & 651 & 905 \\
\hline D2 & Logroño & 1.058 & 1.039 & 842 & 612 & 833 \\
\hline D3 & Madrid & -- & 931 & 779 & -- & 778 \\
\hline E1 & Burgos & -- & 1.232 & 947 & 777 & 986 \\
\hline
\end{tabular}

Tabla 4.12.- Coste anual de la energía en $€$ para las tarifas energéticas vigentes. Fuente: Elaboración propia

Teóricamente el coste de la energía debería ser menor según fuera mejorando la clase energética. Sin embargo, de la tabla 4.12 se observa que este patrón de comportamiento no se cumple en la mayor parte de los casos en que se pasa de una calificación B a una calificación A (cifras en cursiva).

Esto tiene su explicación en el indicador que el programa Calener v.01 utiliza para otorgar la clase energética. Si bien en la metodología [AICIA 2009a], se señala que estos indicadores deben considerar tanto el consumo energético 
( $\mathrm{Kwh} / \mathrm{m}^{2}$.año) como las emisiones de $\mathrm{CO}_{2}\left(\mathrm{Kg} \mathrm{CO}_{2} / \mathrm{m}^{2}\right.$.año), la realidad es que la herramienta Calener tiene en cuenta solamente las emisiones de $\mathrm{CO}_{2}$.

Si tenemos en cuenta el indicador consumo de energía primaria, vemos que los valores obtenidos en las simulaciones sobrepasan los límites que para esta tipología de viviendas establece la metodología (tabla 3.10). Esto se ilustra en la siguiente tabla 4.13 , donde las celdas sombreadas en gris indican que efectivamente se sobrepasan dichos límites, mientras que las cifras subrayadas indica que no se alcanzan dichos límites:

\begin{tabular}{|l|l|l|l|l|l|l|}
\cline { 5 - 8 } & \multicolumn{9}{c|}{ Nivel Eficiencia Energética } \\
\hline $\begin{array}{l}\text { Zona } \\
\text { Climática }\end{array}$ & Ciudad & A & B & C & D & E \\
\hline A3 & Málaga & 58,0 & 58,2 & 65,7 & 93,6 & - \\
\hline A4 & Almería & 71,4 & 65,3 & 62,2 & 89,9 & - \\
\hline B3 & Castellón & 80,3 & 80,3 & 76,9 & 110,4 & - \\
\hline B4 & Sevilla & 107,4 & 79,5 & 77,1 & 111,2 & $\underline{112,9}$ \\
\hline C1 & Santander & 71,9 & 60,3 & 95,6 & 109,0 & $\underline{134,4}$ \\
\hline C2 & Barcelona & 100,3 & 58,4 & 95,3 & 105,9 & $\underline{129,9}$ \\
\hline C3 & Granada & 113,6 & - & 107,1 & 144,6 & - \\
\hline C4 & Badajoz & 73,8 & - & 91,8 & 124,7 & - \\
\hline D1 & Pamplona & 151,2 & 93,9 & 139,0 & 180,0 & 184,4 \\
\hline D2 & Logroño & 136,8 & 84,9 & 133,6 & 171,1 & $\underline{174,8}$ \\
\hline D3 & Madrid & 125,7 & - & 119,5 & 150,8 & - \\
\hline E1 & Burgos & 167,2 & 121,2 & 157,5 & 207,7 & - \\
\hline
\end{tabular}

Tabla 4.13- Resultados para la vivienda adosada de consumo de energía primaria en $\mathrm{kW} \cdot \mathrm{h} / \mathrm{m}^{2} \cdot$ año

Por lo tanto, se puede concluir que el indicador $\mathrm{kg} \mathrm{CO}_{2}$ por $\mathrm{m}^{2}$ es el único implementado en la herramienta.

La principal consecuencia es que una mejor clase energética no siempre implica un coste de consumo menor, es decir, una clase mejor puede suponer 
un mayor consumo y por tanto, desde el punto de vista de la energía, no siempre es más interesante, con lo que mejor clase energética no implica mejor EE. Por lo tanto, el coste de consumo no siempre va a compensar el coste de la inversión.

\section{IV.3.4.- Coste de mantenimiento ( $\left.\mathrm{C}_{\mathrm{MAN}}\right)$ \\ IV.3.4.1.- Antecedentes}

En lo referente al mantenimiento de los edificios durante su vida útil, generalmente, sociedades menos desarrolladas utilizan un mantenimiento correctivo, mientras que a mayor nivel de desarrollo se impone un mantenimiento preventivo. En el España, y para edificios residenciales, no existe todavía una cultura del mantenimiento propiamente dicha y generalmente se realizan las reparaciones en los edificios solamente cuando son necesarias, porque exista una avería o porque el elemento considerado haya agotado su vida útil. La tendencia es a cambiar esa costumbre, abogando por labores de prevención, como es ya habitual en otros países, y en otro tipo de edificios como: hoteles, universidades escuelas, edificios públicos, etc.

El coste que supone el mantenimiento de un edificio se ve compensado por un incremento del confort, garantía del buen funcionamiento de las instalaciones y, en general, el alargamiento de la vida útil del edificio. Un plan de mantenimiento preventivo permite la detección de posibles patologías o disfunciones de los elementos que componen el edificio y, por tanto, realizar las oportunas correcciones, con un coste reducido y con una mínima afectación del edificio.

Para el cálculo de los costes de mantenimiento de edificios residenciales, se realiza una revisión de la bibliografía existente en Valoración, así como en Facility Management [Piper, 1995; Brown, 1996; Liska, 2000; Kaiser, 2001; Brathal and Langemo, 2004], donde ya existe una experiencia previa. También existen diversas publicaciones por parte de organismos reconocidos en el área 134 
de la construcción, como el Instituo Tecnológico de Cataluña [ITEC 1991a, 1991b, 1991c, 1991d, 1994, 1996, 1997, 1999].

Por otro lado, se tiene en cuenta las labores de mantenimiento que deben reflejarse en el Libro del Edificio, revisando la normativa estatal y autonómica que en este momento hay en España [0.14/02/02, Murcia; D. 35/01, Islas Baleares; D. 38/2004, La Rioja; D.158/1997, Cataluña; D.F.322/2000, Navarra; D. 349/1999, Comunidad de Madrid]. Diversas normativas inciden sobre la obligatoriedad de propietarios y/o usuarios a mantener el edificio en un adecuado estado:

\section{1.- A nivel Estatal:}

1.1.- La ley 49/60 de Propiedad Horizontal, de 23 de julio del 90 (incluyendo sus posteriores modificaciones: Ley 2/88 de 23-02-88; Ley 3/90 de 21-06-90; Ley 10/92 de 30-4-92; Ley 01/00 de 07-01-00; Ley 51/2003 de 02-12-03; reformada por la Ley 8/99 de 06-04-99), en sus artículos 9 y 10 habla acerca de la obligatoriedad por parte de propietarios y de la comunidad, de mantener un buen estado de conservación y de llevar a cabo las necesarias obras de reparación y conservación para mantener el edificio en condiciones de uso adecuadas.

1.2.- La ley $38 / 99$, de 5 de noviembre, de Ordenación de la Edificación (modificada por la Ley 24/2001, de 27 de diciembre, de Medidas Fiscales, Administrativas y del Orden Social y por la Ley 53/2002, de 30 de diciembre, de Medidas Fiscales, Administrativas y del Orden Social. Se modifica la disposición adicional segunda) en el artículo 7, habla del Libro del Edificio, del cual deberá hacerse entrega al usuario del mismo. Junto con el Acta de Recepción y relación de los agentes intervinientes en el proceso edificatorio, completa dicho documento un manual con las instrucciones de uso y mantenimiento del edificio y sus instalaciones. 
En el capítulo III de Agentes de la Edificación, el artículo 16 establece que los propietarios y/o usuarios tienen la obligación de conservar en buen estado la edificación mediante un adecuado uso y mantenimiento. Las directrices para ello estarán contenidas además en la documentación de la obra ejecutada, formando parte del Libro del Edificio, como Manual de Uso y Conservación.

2.- A nivel Autonómico: Existen varias órdenes, leyes y decretos para distintas Comunidades Autónomas, con el fin de regular el modelo a seguir en la elaboración del Libro del Edificio. También Colegios Profesionales de Arquitectos elaboran guías de redacción de este documento [Cádiz, Granada, Jaén]. Es de destacar la herramienta disponible para la elaboración del Libro del Edificio de Cataluña, así como toda la documentación relativa a mantenimiento de edificios que se generó desde comienzos de los años 90, en el Instituto Tecnológico de la Construcción de Cataluña [varios ITEC].

Uno de los puntos importantes en este estudio es la determinación de la vida útil del edificio y de sus componentes e instalaciones, que como ya se ha comentado anteriormente se parte de una vida útil de las viviendas de 100 años, basada en la normativa de valoración hipotecaria, Orden ECO 805/03, de 27 de marzo, que supone que el edificio está siendo utilizado con unas condiciones normales de uso y con un mantenimiento adecuado, que asegure un buen estado durante todo el periodo de uso. La periodicidad de la labor de mantenimiento variará en función del elemento que estemos considerando.

También se tendrá en consideración el coste derivado de las operaciones periódicas de mantenimiento, teniendo en cuenta toda la literatura consultada sobre Facility Management, así como las directrices que nos dicta la normativa española, en cuanto al contenido y estructura del Libro del Edificio.

Así pues, se considerarán los costes de las labores periódicas de mantenimiento, como podría ser la revisión preceptiva de las instalaciones de 
gas cada 4 años, o la limpieza anual de los canalones, arquetas, pinturas, etc., que no requieren un cambio del elemento revisado.

\section{IV.3.4.2.- Aplicación al caso de estudio}

Entre las diversas herramientas con las que cuenta el profesional para la redacción del Libro del Edificio, en el presente estudio se ha empleado la desarrollada por Cype Ingenieros S.A.; dicha herramienta incorpora en su generador de precios, una guía para la elaboración del Manual de Uso y Mantenimiento, que se describe por capítulos, con una estructura similar a la base de datos de precios. Esta base de datos se utilizó ya en la elaboración de los Presupuestos de Ejecución Material de las viviendas objeto de estudio, por lo que para trabajar con precios homogéneos se sigue utilizando para la estimación de los costes de mantenimiento. No obstante, también se han consultado otras fuentes diferentes para la elaboración de algunas de las partidas correspondientes a costes de mantenimiento y uso.

En cualquier caso, habrá que diferenciar entre aquellas labores que deberán ser llevadas a cabo por el usuario del inmueble, y aquellas otras para las que requerirá la intervención de un profesional especializado. En las primeras se considera que no se generan costes, y generalmente se van a ceñir a inspecciones visuales de las distintas partidas o labores de limpieza periódicas, generalmente cada 6 meses o anualmente. Cuando se requiere la intervención de un profesional sí se devengarán costes. A veces por la necesidad de intervención de empresas autorizadas, por ejemplo en el caso de instalaciones de gas; otras veces por la intervención de operarios como electricistas, pintores, carpinteros, peones y oficiales de la construcción, etc. Los factores a tener en cuenta para realizar los presupuestos de mantenimiento son:

1.- Zona y caracteristicas constructivas e instalaciones (calificación): Cada una de las configuraciones de vivienda, 50 en total, requiere adaptar su presupuesto de mantenimiento a sus soluciones constructivas e instalaciones. 
2.- Número de partidas de mantenimiento: Finalmente se cuenta con 45 posibles partidas de labores mantenimiento. Los precios utilizados en esta ocasión son 540, considerando las 12 zonas climáticas. Ejemplo de alguna de las partidas, como es el caso de la reposición de barniz en la carpintería de madera, se refleja en la tabla 4.14:

\begin{tabular}{|l|l|l|l|l|l|l|l|l|l|l|l|}
\hline \multicolumn{1}{|c|}{ Partida $\mathrm{n}^{\circ} 41 .-\mathrm{m}$ barnizado carpintería madera... } \\
\hline A3 & A4 & B3 & B4 & C1 & C2 & C3 & C4 & D1 & D2 & D3 & E1 \\
\hline 15,5 & 21,9 & 22,1 & 22,1 & 24,2 & 24,9 & 19,0 & 18,6 & 15,5 & 21,9 & 22,1 & 22,15 \\
\hline
\end{tabular}

Tabla 4.14.- Ejemplo de precio unitario $\left(€ / \mathrm{m}^{2}\right)$ en distintas zonas. Fuente: Elaboración propia a partir de Generador de precios Cype Ingenieros S.A

3.- Periodicidad de cada operación: ciertas operaciones se realizan cada año, otras cada 5 años, otras cada 15 años, etc.

4.- Posibles solapes de operaciones: algunas de las operaciones pueden estar incluidas en otras o se solapan. Por ejemplo, la revisión anual de la instalación eléctrica incluiría menos conceptos que la que se realiza a los 5 años; es decir, realizar la revisión del año 5 , implica que no es necesario realizar la del año 1 ; otro ejemplo podría ser que el cambio de la caldera implicaría que ese año no se llevara a cabo su revisión, etc.

Estos presupuestos tienen una estructura similar a los de Ejecución Material que se vieron en el apartado IV.2. Hay un estado $n^{\circ} 1$ de mediciones, unos cuadros de precios y un estado $n^{\circ} 3$ de aplicación de precios. Sin embargo, aquí el presupuestar es más complejo, ya que entra en juego el factor tiempo.

Para ello se realiza un cronograma con los 100 años considerados de vida útil, en los que se consideran los solapes mencionados y las diferentes periodicidades. El cronograma, expresado en euros constantes, contiene100 
columnas, una por año y 45 filas, una por partida. En cada casilla se aplica el montante a pagar por cada operación.

Se muestra en la tabla 4.15, a modo de ejemplo, una parte de los cronogramas (ver los cronogramas completos en anexo 2). En concreto, corresponde a la configuración A3-C y aparecen en esta tabla las 20 primeras partidas que son necesarias en los 20 primeros años. Las celdas sombradas en gris indican solapes de operaciones, por lo que no contienen ninguna cantidad asociada. Es el caso de las partidas 18 y 19, correspondientes a la revisión anual de instalaciones audiovisuales, que no proceden porque en el año 15 se renueva la instalación.

También se puede ver que las operaciones tienen distintas periodicidades, así por ejemplo, la partida 1 es anual, repitiéndose la cantidad a pagar cada año, mientras que la partida 2 tiene lugar cada 5 años, etc.

Por último, hay que indicar que no todas las partidas se aplican a todas las configuraciones. Por ejemplo, en este caso no se aplica la partida 20 , que corresponde a la revisión del termo eléctrico para ACS; esto es así ya que el combustible empleado en esta configuración es el gas natural, luego no procede aplicar esta labor de mantenimiento en este caso (en negrita, tabla 4.15). 


\begin{tabular}{|c|c|c|c|c|c|c|c|c|c|c|c|c|c|c|c|c|c|c|c|c|}
\hline 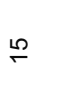 & $\infty^{\circ}$ & 今े & 8 & 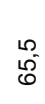 & & & & $\begin{array}{l}\stackrel{\infty}{\infty} \\
\stackrel{\infty}{\infty}\end{array}$ & $\begin{array}{l}0 \\
0 \\
\bar{m}\end{array}$ & & 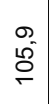 & $\begin{array}{l} \pm \\
\stackrel{0}{0} \\
\sim\end{array}$ & $\begin{array}{c}0 \\
\stackrel{0}{\rho} \\
\stackrel{2}{*}\end{array}$ & $\begin{array}{l}\stackrel{L}{\circ} \\
\stackrel{+}{\leftarrow}\end{array}$ & ז. & $\begin{array}{l}\text { M. } \\
\omega_{0}^{-1} \\
0\end{array}$ & & & & \\
\hline$\stackrel{\nabla}{\nabla}$ & $\infty^{\circ}$ & & & & & & & $\underset{\infty}{\sim}$ & & & $\begin{array}{l}0 \\
\delta^{\circ} \\
\varnothing\end{array}$ & & $\begin{array}{l}\dot{0} \\
\stackrel{\rho}{f}\end{array}$ & & & & & $\stackrel{m}{\infty_{\infty}^{\infty}}$ & $\overline{8}$ & \\
\hline$\stackrel{\simeq}{ }$ & $\begin{array}{l}0 \\
\infty^{\circ}\end{array}$ & & & & & & & $\underset{\substack{\infty \\
\infty}}{\stackrel{\infty}{\infty}}$ & & & 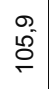 & & $\begin{array}{l}\stackrel{0}{\circ} \\
\stackrel{8}{r}\end{array}$ & & & $\begin{array}{l}m \\
\omega^{0} \\
0 \\
0 \\
0\end{array}$ & & $\stackrel{\infty}{\infty}_{\infty}^{\infty}$ & $\overline{8}$ & \\
\hline$\stackrel{m}{9}$ & $\infty^{\circ}$ & & & & & & & $\begin{array}{l}\stackrel{\widetilde{\infty}}{\infty} \\
\stackrel{\infty}{\infty}\end{array}$ & & & 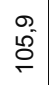 & & 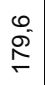 & & & & & $\begin{array}{l}m \\
\infty_{\infty}^{\infty}\end{array}$ & $\bar{s}$ & \\
\hline$F$ & $\infty^{\circ}$ & & & & & & & $\stackrel{\infty}{\infty}$ & & & 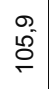 & & $\begin{array}{l}\stackrel{0}{\circ} \\
\stackrel{\circ}{\circ}\end{array}$ & & & & & $\stackrel{\infty}{\infty}_{\infty}^{\infty}$ & $\overline{8}$ & \\
\hline 우 & $\stackrel{\infty}{0}^{\circ}$ & $\stackrel{m}{m}$ & 8 & $\begin{array}{l}5 \\
08 \\
08\end{array}$ & & $\overrightarrow{5}$ & $\stackrel{\infty}{\stackrel{\infty}{\Sigma}}$ & $\stackrel{N}{\infty}$ & 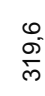 & $\underset{\widetilde{N}}{\tilde{N}}$ & 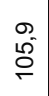 & \begin{tabular}{l}
\multirow{2}{*}{} \\
$\stackrel{0}{\sim}$
\end{tabular} & $\begin{array}{l}0 \\
\stackrel{0}{S} \\
\stackrel{2}{r}\end{array}$ & & $\stackrel{-}{\bar{d}}$ & $\begin{array}{l}\mathbb{N} \\
\text { N }\end{array}$ & & $\stackrel{m}{\infty} \infty_{\infty}^{\infty}$ & $\bar{s}$ & \\
\hline$\sigma$ & $\frac{\infty^{\circ}}{\infty^{\circ}}$ & & & & & & & $\stackrel{\infty}{\infty}$ & & & 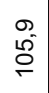 & & $\begin{array}{l}\stackrel{0}{\circ} \\
\stackrel{8}{\circ}\end{array}$ & & & $\begin{array}{l}m \\
\text { 㸃 } \\
0 \\
0\end{array}$ & & $\stackrel{\infty}{\infty}_{\infty}^{\infty}$ & $\overline{8}$ & \\
\hline$\infty$ & $\infty^{\circ}$ & & & & & & & $\stackrel{\infty}{\infty}$ & & & 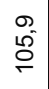 & & $\begin{array}{l}0 \\
\stackrel{0}{\circ} \\
\stackrel{5}{\circ}\end{array}$ & & & & & $\stackrel{\infty}{\infty}_{\infty}^{m}$ & $\overline{8}$ & \\
\hline$\wedge$ & $\frac{\infty^{\circ}}{\infty^{\circ}}$ & & & & & & & $\stackrel{\infty}{\sim}$ & & & 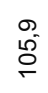 & & $\begin{array}{l}\stackrel{0}{\circ} \\
\stackrel{\circ}{\Gamma}\end{array}$ & & & & & $\stackrel{\infty}{\infty}^{m}$ & $\overline{8}$ & \\
\hline 0 & $\frac{\infty^{\circ}}{\infty^{\circ}}$ & & & & & & & $\stackrel{\infty}{\infty}$ & & & $\begin{array}{l}\stackrel{\circ}{\circ} \\
\stackrel{8}{\stackrel{8}{0}}\end{array}$ & & $\begin{array}{l}0 \\
\stackrel{0}{\circ} \\
\stackrel{5}{r}\end{array}$ & $\begin{array}{l}\stackrel{L}{\circ} \\
\stackrel{f}{\leftarrow}\end{array}$ & & 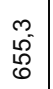 & & $\stackrel{\infty}{\infty}_{\infty}^{\infty}$ & $\overline{8}$ & \\
\hline เ & $\frac{\infty^{\circ}}{\infty^{\circ}}$ & $\stackrel{m}{m}$ & 8 & $\begin{array}{l}100 \\
\infty \\
\infty \\
\infty\end{array}$ & & & & $\underset{\infty}{\stackrel{\infty}{\infty}}$ & $\begin{array}{l}0 \\
\stackrel{0}{m} \\
\dot{m}\end{array}$ & & $\begin{array}{l}\stackrel{\circ}{\circ} \\
\stackrel{8}{\stackrel{8}{0}}\end{array}$ & $\begin{array}{l}\stackrel{+}{0} \\
\stackrel{0}{N}\end{array}$ & $\begin{array}{l}0 \\
\stackrel{0}{8} \\
\stackrel{5}{\circ}\end{array}$ & & $\underset{\dot{E}}{\stackrel{r}{d}}$ & & & $\stackrel{\infty}{\infty}^{\infty}$ & $\overline{8}$ & \\
\hline$\sigma$ & $\begin{array}{l}0 \\
\infty^{\circ} \\
1\end{array}$ & & & & & & & $\stackrel{\infty}{\infty}$ & & & 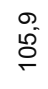 & & $\begin{array}{l}\stackrel{0}{\rho} \\
\stackrel{\rho}{\&}\end{array}$ & & & & & $\infty_{\infty}^{\infty}$ & $\overline{8}$ & \\
\hline$m$ & $\begin{array}{l}0 \\
\infty^{\circ} \\
1\end{array}$ & & & & & & & $\stackrel{\infty}{\infty}$ & & & 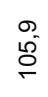 & & 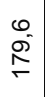 & 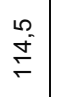 & & 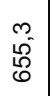 & & $\stackrel{\infty}{\infty}^{m}$ & $\overline{8}$ & \\
\hline$N$ & $\begin{array}{l}0 \\
\infty^{\circ} \\
1\end{array}$ & & & & & & & $\stackrel{\infty}{\stackrel{\infty}{\infty}}$ & & & $\begin{array}{l}\stackrel{0}{0} \\
\stackrel{0}{\circ}\end{array}$ & & $\begin{array}{l}\stackrel{0}{S} \\
\stackrel{8}{f}\end{array}$ & & & & & $\stackrel{\infty}{\infty}$ & $\overline{8}$ & \\
\hline- & $\stackrel{0}{\circ}^{\circ}$ & & & & & & & $\stackrel{\infty}{\infty}$ & & & $\begin{array}{l}\stackrel{\rho}{2} \\
\stackrel{0}{o n}\end{array}$ & & $\begin{array}{l}0 \\
\stackrel{0}{\rho} \\
\stackrel{2}{r}\end{array}$ & & & & & $\overbrace{\infty}^{\infty}$ & $\overline{8}$ & \\
\hline 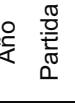 & - & $\sim$ & $m$ & $\sigma$ & ? & 0 & N & $\infty$ & $\sigma$ & $\stackrel{\circ}{\circ}$ & $F$ & $\stackrel{\simeq}{\sim}$ & $\stackrel{m}{\longrightarrow}$ & $\stackrel{+}{\leftarrow}$ & $\stackrel{\llcorner 0}{\leftarrow}$ & $\stackrel{\varphi}{\leftarrow}$ & 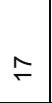 & $\stackrel{\infty}{\sim}$ & $\stackrel{\odot}{\leftarrow}$ & ลิ \\
\hline
\end{tabular}

Tabla 4.15.- Cronograma costes 20 operaciones mantenimiento, en A3-C. Años 0-15 
De la suma de costes de las 45 partidas se obtienen los costes anuales de mantenimiento por zona y calificación, teniendo en cuenta un periodo de uso del edificio de 100 años. La tabla 4.16 se divide en dos partes; las columnas a la izquierda se expresan en $€ / a n ̃ o$, mientras que las de la derecha, indican el valor de repercusión por metro cuadrado, es decir, $€ / \mathrm{m}^{2}$.año:

\begin{tabular}{|l|c|c|c|c|c|c|}
\hline \multicolumn{2}{|c|}{$\begin{array}{c}\text { MANTEN. } \\
\text { VIVIENDA }\end{array}$} & \multicolumn{5}{|c|}{ S/CALIFICACIÓN } \\
\hline \multicolumn{2}{|c|}{ ZONA } & E & D & C & B & A \\
\hline A3 & Málaga & & 2.433 & 2.669 & 2.728 & 2.652 \\
\hline A4 & Almería & & 2.450 & 2.702 & 2.890 & 2.928 \\
\hline B3 & Castellón & & 2.444 & 2.693 & 2.621 & 2.621 \\
\hline B4 & Sevilla & 2.487 & 2.601 & 2.756 & 2.673 & 2.703 \\
\hline C1 & Santander & 2.926 & 3.168 & 3.312 & 3.321 & 3.235 \\
\hline C2 & Barcelona & 2.829 & 3.056 & 3.201 & 3.210 & 3.123 \\
\hline C3 & Granada & & 3.002 & 3.161 & & 3.076 \\
\hline C4 & Badajoz & & 2.670 & 2.794 & & 2.736 \\
\hline D1 & Pamplona & 3.310 & 3.551 & 3.733 & 3.739 & 3.635 \\
\hline D2 & Logroño & 3.173 & 3.412 & 3.585 & 3.592 & 3.492 \\
\hline D3 & Madrid & & 3.012 & 3.432 & & 3.360 \\
\hline E1 & Burgos & & 2.851 & 3.195 & 3.202 & 3.114 \\
\hline
\end{tabular}

Tabla 4.16.- Costes de mantenimiento por zona y calificación. Fuente: Elaboración propia

De la tabla 4.16 se deduce que los costes de mantenimiento son mayores a mejor calificación energética, lo cual es lógico si se tiene en cuenta que mejores calificaciones requieren soluciones constructivas e instalaciones más costosas. Se invierte esta tendencia en las celdas sombreadas en gris, debido a que, en estas ocasiones, el salto de calificación supone cambiar las calderas de gas natural a calderas de biomasa (tabla 4.11). Actualmente existen unas revisiones preceptivas de las instalaciones de gas, que no lo son en el caso de 
las calderas de biomasa y por este motivo disminuye el coste de manteniento en las configuraciones con mejor calificación.

\section{IV.3.5.- Coste Social del Carbono $\left(\mathrm{C}_{\mathrm{CO} 2}\right)$}

El coste medioambiental se valora en función de la cantidad de carbono emitida durante el uso de la vivienda. Este coste se obtiene a partir de los $\mathrm{Kg}$ de $\mathrm{CO}_{2}$ que emiten anualmente las viviendas, utilizando la herramienta de simulación Calener VYP v.01. Por consiguiente, será necesario determinar el precio del Kg de $\mathrm{CO}_{2}$, para otener dicho coste.

La valoración de este tipo de coste difiere de la realizada en los apartados anteriores, debido a que no existe un consenso en cuanto al precio que podría asignarse a los $\mathrm{Kg}$ de $\mathrm{CO}_{2}$ emitidos por la vivienda.

En general, la valoración del carbono, como ocurre con otros aspectos relacionados con el medioambiente, es compleja, ya que se puede considerar como una externalidad. Se dice que existen externalidades cuando los costos privados no igualan a los costos sociales, por lo que los niveles de producción difieren de los socialmente óptimos, generándose así una ineficiencia económica [Flores, 1996].

Existe multitud de trabajos para la valoración del costo económico del carbono referidos a tierras cuyo uso pudiera ser forestal, agrícola o ganadero. En los casos en que estos terrenos se dejen de utilizar con esos fines, para destinarlos a fines medioambientales, se considera el coste de oportunidad de las tierras, es decir, los ingresos que dejan de percibir los propietarios por ese motivo [Sancho-Villalobos y Pratt, 1999]. El valor monetario del carbono fijado por los bosques, puede ser de ayuda para aplicar políticas fiscales correctoras de externalidades, o para calcular impuesto o subvenciones ambientales óptimos [Mogas y Riera, 2004]. 
En esta fase de la Tesis, es necesaria una exhaustiva revisión bibliográfica para poder establecer un valor o intervalo de valores y calcular el coste medioambiental, que la literatura científica denomina Coste Social del Carbono (SCC).

EI SCC se define como el coste marginal de emitir una tonelada extra de carbono en cualquier momento del tiempo [Yohe et al., 2007].

El problema del cálculo del SCC está relacionado con la complejidad de los procesos en los que está implicado el carbono y con las interrelaciones entre ellos. No sólo influye la cantidad emitida, sino también el tiempo de permanencia del $\mathrm{CO}_{2}$ en la atmósfera, y además los impactos generados por el $\mathrm{CO}_{2}$ en el Cambio Climático (CC). A todo ello se le une el hecho de que el problema CC es a largo plazo. En economía, la comparación de impactos en el tiempo requiere utilizar tasas de descuento y este es uno de los temas más discutidos en la literatura.

De acuerdo con la teoría económica, si la estimación del SCC fuera completa y los mercados fueran perfectos, un impuesto sobre el carbono debería ser igual al SCC. O bien, los derechos de emisión deberían tener un valor igual al SCC.

En ese caso, se podría hablar de dos posibles formas de valoración:

1. Pigou (1929): Los impuestos pigouvianos buscan corregir una externalidad negativa. En este sentido podría considerarse el $\mathrm{CO}_{2}$ antropogénico. Se podría así calcular la posible compensación del daño. Esa forma de considerar el SCC es la que se va a adoptar en la presente Tesis.

2. Coase (1937): Ante la presencia de determinadas externalidades siempre será posible la consecución de una externalidad óptima (lo cual no implica necesariamente la desaparición total de la misma) y de 
un máximo nivel de bienestar. Esto se logrará a través de la negociación. Para ello es necesario que los derechos de propiedad de las distintas partes estén bien asignados y puedan defenderse. Otra condición es que el sistema de precios funcione sin costes, y no existan efectos renta, en el marco del equilibrio general: fijación de límites máximos y de derechos de emisión (Caso actual UE ETS: Sistema Europeo de Comercio de emisiones, "Emissions Trade Escheme").

En efecto, en la Unión Europea existe un mercado con precios de $\mathrm{CO}_{2}$ : ETS Emissions Trade Scheme o Régimen de Comercio de Derechos Emisión de la UE.

El objetivo de su creación es la reducción de emisiones a un costo mínimo. Se fija un precio por tonelada de $\mathrm{CO}_{2}$, con lo que se fomenta la inversión en tecnologías bajo emisivas, induciendo a la innovación tecnológica, ahorro y eficiencia en los procesos, productos y servicios energéticos. Con ello se intenta facilitar el cumplimiento de los requisitos del protocolo de Kioto por parte de los países miembros de la UE. Como consecuencia se crea un precio de mercado de emisiones.

El precio que se pudiera obtener del análisis de este mercado, no es válido para nuestro caso de estudio, ya que de momento sólo es aplicable a empresas con elevadas emisiones, que en el caso de la UE afecta a más de 11.000 instalaciones. No obstante, es interesante hablar de los precios de $\mathrm{CO}_{2}$ en este mercado, para observar en qué orden de magnitud se está moviendo.

Este tipo de mercado tiene su origen en el año 2005 y se establecen varios periodos para la reducción de emisiones, cada vez más restrictivos: 2005-2007 y 2008-2012 [Marten et al, 2004]. 
En la primera fase se incluye sólo a los sectores energético e industrial, responsables del $45 \% \mathrm{CO}_{2}$ y $30 \% \mathrm{GEI}$. En concreto se incluye la industria de generación de electricidad y calor, plantas de combustión, refinerías de petróleo, hornos de coque, plantas producción de hierro y acero, cemento, cerámica, cal, vidrio, pasta y papel. En la segunda fase se amplía a nuevos miembros UE y a actividades que emiten $\mathrm{N}_{2} \mathrm{O}$.

En el momento actual cada Estado miembro es responsable de su reducción de emisiones por medio del Plan Nacional de Asignación de derechos de emisiones (PNA). A partir del año 2013, se prevé que además de incluir el sector de la aviación, la asignación de derechos se centralice en Bruselas En cuanto a los valores del derecho de emisión se cifró en Julio del 2005 en 18 $€ / \mathrm{tCO}$; y en Octubre del mismo año en $24 € / \mathrm{tCO}_{2}$.

La figura 4.3 recoge esquemáticamente, la evolución de los precios de la tonelada de $\mathrm{CO}_{2}$ :

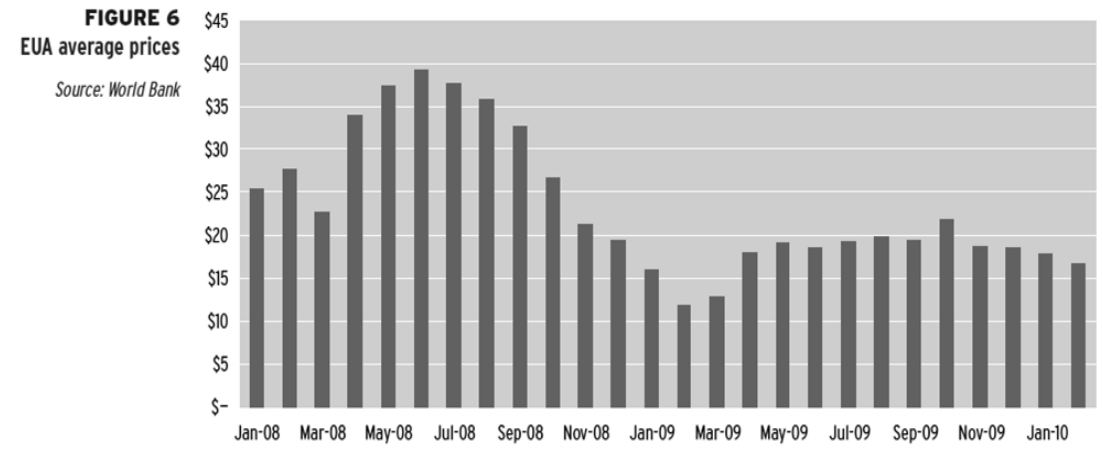

Figura 4.3.- Precios medios de tonelada $\mathrm{CO}_{2}$, según Régimen de Comercio de Derechos Emisión de la UE. Fuente: World Bank

No hay por tanto un mercado de valores de SCC que pueda ser aplicable al sector residencial. 
Para una mejor compresión del problema se realiza a continuación, en el apartado IV.3.5.1, una introducción a la problemática de la valoración del SCC, y en los apartados IV.3.5.2 y IV.3.5.3, se resume la revisión bibliográfica que se ha realizado para la valoración de este coste ambiental y los precios del SCC.

\section{IV.3.5.1- Antecedentes}

\section{Efecto invernadero}

En la atmósfera de la Tierra, para mantener las condiciones que posibilitan la vida, debe mantenerse el equilibrio entre la recepción de la radiación solar y la emisión de radiación infrarroja que se devuelve al espacio. Parte de la radiación recibida se mantiene dentro de la atmósfera, gracias a algunos de los gases que la conforman. Este balance energético permite mantener una temperatura que posibilita la vida (una temperatura media global de unos $15^{\circ} \mathrm{C}$, que sin la presencia de los gases efecto invernadero, (GEI), estaría en torno a los $-18^{\circ} \mathrm{C}$ ). Es lo que se conoce como efecto invernadero (Joseph Fourier, 1824).

La alteración del balance de radiación, ya sea por causas naturales u originadas por el hombre, es lo que se conoce como "forzamiento radiativo" y puede suponer cambios en el clima. El efecto invernadero comienza a ser un problema cuando la actividad humana supone un incremento de algunos gases, que pone en serio peligro el balance natural que se da en la atmósfera.

Aunque la atmósfera seca está compuesta en más de un 99\% por nitrógeno, oxígeno y argón, otros gases muy minoritarios en su composición, como el dióxido de carbono $\left(\mathrm{CO}_{2}\right)$, el metano $\left(\mathrm{CH}_{4}\right)$, ozono y otros, son los responsables de este efecto. Además, la atmósfera contiene vapor de agua (1\%) que es el gas natural invernadero más importante. El $\mathrm{CO}_{2}$ ocupa el segundo lugar en importancia. Ya en 1859, John Tyndalle identifica al $\mathrm{CO}_{2}, \mathrm{CH}_{4}$ y vapor de agua como bloqueadores de la radiación infrarroja. 
En resumen, los GEI más destacables, responsables del efecto descrito, son: vapor de agua $\left(\mathrm{H}_{2} \mathrm{O}\right)$, dióxido de carbono $\left(\mathrm{CO}_{2}\right)$, metano $\left(\mathrm{CH}_{4}\right)$, óxidos de nitrógeno $\left(\mathrm{NO}_{\mathrm{x}}\right)$, ozono $\left(\mathrm{O}_{3}\right)$ y clorofluorocarbonos $\left(\mathrm{CFCl}_{3}\right)$

No sólo la concentración a la que se encuentran los GEI, sino también su permanencia en la atmósfera durante largos periodos, son factores que influyen en el calentamiento global.

\section{Evolución del problema del estudio del $\mathrm{CO}_{2}$ y el $\mathrm{CC}$}

Los primeros datos del impacto del aumento del $\mathrm{CO}_{2}$ atmosférico, se deben a Svante Arrhenius, en 1896, que calculó cómo el $\mathrm{CO}_{2}$ intercepta en la atmósfera la radiación infrarroja. Según sus estimaciones, un aumento al doble de $\mathrm{CO}_{2}$ atmosférico, supondría un aumento de la temperatura de 5-6 $6^{\circ}$; por tanto aumentaría la evaporación de los océanos y con ello la cantidad de vapor de agua en la atmósfera, que incrementaría el efecto invernadero

Pero es sobre todo en el siglo XX, y principalmente desde la Revolución Industrial, cuando el efecto invernadero se incrementa, como consecuencia de la actividad humana. Poco a poco se va tomando conciencia de la amenaza que esto supone, fundamentalmente a partir de los años 80 , cuando el problema trasciende a la opinión pública.

Antes de la década de los 80 cabe destacar las siguientes fechas y acontecimientos:

- 1938, Guy Steward: existe un $10 \%$ de aumento del $\mathrm{CO}_{2}$ atmosférico entre 1890 y 1938, coincidiendo con la revolución industrial, basada en el consumo de carbón. Este estudio concluye que el aumento podría estar relacionado con la tendencia al calentamiento observado en ese periodo. 
- 1958, Charles Keeling: Realiza las primeras mediciones de forma precisa del $\mathrm{CO}_{2}$ en la atmósfera. En 1960 publica la conocida Curva de Keeling. Llama la atención mundial sobre el impacto de las emisiones de los GEI.

- 1970, Klaus Hasselmann: Formula el primer modelo estadístico de evolución del clima.

- 1979: Tiene lugar la primera Conferencia Mundial sobre el Clima por parte de la Organización Mundial de Meteorología (OMM). En esta conferencia se llama la atención sobre el CC como amenaza a nivel planetario.

Pero no es hasta los 90, cuando la Comunidad Internacional comienza a actuar frente al problema, ya que empieza a ser consciente de la amenaza real que supone el aumento de los GEl, y de la necesidad de detener su tendencia creciente. A este efecto se une la preocupación de que el aumento de la población, supondrá que las necesidades de energía se incrementarán en un futuro

Véase, por ejemplo, en la tabla 4.17, los incrementos detectados en algunos GEI, según informe del Intergovernmental Panel on Climate Change (IPCC) de 2001:

\begin{tabular}{|l|l|l|l|l|l|l|}
\hline Descripción & $\mathrm{CO}_{2}$ & $\mathrm{CH}_{4}$ & $\mathrm{~N}_{2} \mathrm{O}$ & $\mathrm{CFC}-11$ & $\mathrm{HFC}-23$ & $\mathrm{CF}_{4}$ \\
\hline $\begin{array}{l}\text { Concentración } \\
\text { pre industrial }\end{array}$ & $280 \mathrm{ppm}$ & $700 \mathrm{ppb}$ & $270 \mathrm{ppb}$ & 0 & 0 & $40 \mathrm{ppt}$ \\
\hline $\begin{array}{l}\text { Concentración } \\
1998\end{array}$ & $365 \mathrm{ppm}$ & $1.745 \mathrm{ppb}$ & $314 \mathrm{ppb}$ & $268 \mathrm{ppt}$ & $14 \mathrm{ppt}$ & $80 \mathrm{ppt}$ \\
\hline $\begin{array}{l}\text { Permanencia } \\
\text { atmósfera (años) }\end{array}$ & $5-200$ & 12 & 114 & 45 & 260 & $<50.000$ \\
\hline
\end{tabular}

Tabla 4.17.- Aumentos GEI. Fuente: Elaboración propia a partir de IPCC, Clima 2001, Resumen técnico del Informe del Grupo de Trabajo I) 
Las consecuencias del CC provocado por las emisiones de GEl se estudian en modelos de proyecciones realizados por varios institutos meteorológicos:

- Aumento de la temperatura global

- Disminución de la superficie de hielos y de nieve, que supondrán un aumento del nivel del mar

- Impactos inmediatos en ecosistemas más sensibles: tundra, bosques boreales y regiones montañosas, ecosistemas de tipo Mediterráneo y bosques tropicales por la disminución de lluvias, ecosistemas costeros como manglares y marismas.

- Disminución de los recursos hídricos de regiones secas de latitudes medias y en los trópicos secos debido a las menores precipitaciones de lluvia y la disminución de la evapotranspiración, y también en áreas surtidas por la nieve y el deshielo.

- Afectación de la agricultura en latitudes medias, debido a la disminución de agua.

- Acidificación progresiva de los océanos, que tendrá efectos negativos sobre los organismos marinos.

La creación del International Panel on Climate Change (IPCC), con el objetivo de asesorar a los gobiernos sobre los problemas climáticos, es un signo de la toma de conciencia del problema. Ya no se trata exclusivamente de un problema que concierne a los científicos, sino que la solución pasa por la aplicación de políticas adecuadas y es necesario conocer cuál será el coste de dichas medidas.

EI IPCC, a través de sus grupos de trabajo, elabora informes periódicos de evaluación, donde recopilan las investigaciones científicas conocidas en: información científica, técnica y socio-económica sobre el CC, sus causas, sus posibles efectos, y las medidas de respuesta correspondientes. Hasta el momento, se han emitido cuatro informes $(1990,1995,2001$ y 2007) y se prevé 
publicar el quinto en 2014. Paralelamente el IPCC emite unos informes Special Report Emission Scenarios (SRES), donde se crean posibles escenarios de emisión, habiéndose publicado hasta el momento 3 informes, en los que se han ido actualizando escenarios en el tiempo [Girod et al., 2009]. Estos informes revisten una gran importancia en el estudio del CC, ya que son la base de la mayor parte de estudios científicos que se van desarrollando.

Los escenarios de emisión reflejan las características económicas, de población y tecnológicas del mundo en un futuro. La imposibilidad de conocer características con un $100 \%$ de exactitud, hace que se creen diferentes escenarios sobre los que se llevarán a cabo las valoraciones.

Desde principios de la década de los 90, destacan los siguientes acontecimientos como claves en el desarrollo del estudio del Cambio Climático:

1990: Primer Informe IPCC: Confirmó los elementos científicos que suscitaban preocupación acerca del $\mathrm{CC}$. Se afirma por primera vez que se trata de un problema real. Se crean cuatro posibles escenarios de emisiones, sobre los que trabajará la mayoría de la comunidad científica (SA90-A, B, C y D). A raíz de este informe, la Asamblea General de las Naciones Unidas decidió preparar la Convención Marco sobre el Cambio Climático.

1992: Cumbre de la Tierra de Río de Janeiro: El tratado internacional Convención Marco de las Naciones Unidas sobre el Cambio Climático se firmó en 1992 y los países firmantes debían comenzar a considerar como reducir las emisiones de GEl y el calentamiento atmosférico. Los países firmantes acordaron el siguiente objetivo en el artículo 2: El objetivo último de la presente Convención... es lograr... la estabilización de las concentraciones de gases de efecto invernadero en la atmósfera a un nivel que impida interferencias antropógenas peligrosas en el sistema climático. Ese nivel debería lograrse en un plazo suficiente para permitir que los ecosistemas se adapten naturalmente al cambio climático, asegurar que la producción de alimentos no se vea 150 
amenazada y permitir que el desarrollo económico prosiga de manera sostenible.

1995: Segundo Informe IPCC: Sirvió de base para la realización del Protocolo de Kioto. Se actualizan los escenarios de emisiones con respecto a los del año 90 , de 4 a 6 escenarios, con diferentes tendencias en el tiempo en cuanto a población, desarrollo económico y fuentes de energía (IS92-a, b, c, d, e,f)

1997: Protocolo de Kioto: Primera adición al Tratado internacional Convención Marco de las Naciones Unidas sobre el Cambio Climático y compromiso de países industrializados de reducir sus emisiones de $\mathrm{GEI}\left(\mathrm{CO}_{2}, \mathrm{CH}_{4}, \mathrm{~N}_{2} \mathrm{O}, \mathrm{SF}_{6}\right.$, HFC y PFC) en los sectores energético, industrial, agricultura, cambio de uso de la tierra, silvicultura y desechos. El principal objetivo es conseguir un recorte conjunto de los GEI en un 5\% con respecto a los niveles de 1990, en el periodo de 2008-2012.

2001: Tercer Informe IPCC: Mayor comprensión de causas y consecuencias del calentamiento mundial. Se prevee que para fines del s.XXI se experimente un calentamiento mundial de entre 1,4 y $5,8^{\circ} \mathrm{C}$. Por primera vez se reconoce la influencia directa del CC en las pautas meteorológicas, recursos hídricos, ciclo de las estaciones, los ecosistemas, así como en episodios climáticos extremos. Se crean 6 escenarios de emisiones según futuro desarrollo económico, población y desarrollo de tecnologías, que son los que han estado vigentes hasta la fecha: A1F, A1T, A1B, A2, B1 y B2. (A más centrado en desarrollo económico; $\mathrm{B}$ más centrado en desarrollo sostenible; 1 mundo más globalizado; 2 mundo más regionalizado).

2004: Con la ratificación de Rusia en 2004, entra en vigor el Protocolo de Kioto. Es ratificado por los países que constan en el anexo I, que son responsables de al menos el $55 \%$ del total de emisiones de 1990. Actualmente lo han firmado 
184 partes, 183 países y la Unión Europea, y todos lo han ratificado salvo dos: Estados Unidos y Kazajistán.

2006: Se emite el Informe Stern: Respaldado por el gobierno británico y con gran repercusión internacional. Proporciona datos económicos de la repercusión de la reducción de GEl. Afirma que, el no actuar supondría una reducción del $5 \%$ del Producto Mundial Bruto (PMB), mientras que el actuar, tan solo del $1 \%$. Dicho informe es controvertido y criticado por muchos autores [Tol and Yohe, 2007; Nordhaus, 2007; Wietzman, 2007], como se verá más adelante.

2007: Emisión del cuarto Informe IPCC. Es hasta el momento, el último de los informes del IPCC. Reúne los últimos conocimientos de una amplia comunidad científica, más de 500 autores principales, 2.000 revisores expertos y es examinado por delegados de más de 100 países. Las conclusiones principales son:

1.- El cambio climático es debido a 4 factores: el aumento de los GEI en atmósfera, aumento de aerosoles, variaciones en la cubierta terrestre (cambios uso suelo) y variaciones en radiación solar (a causa de la disminución del ozono troposférico)

2.-El calentamiento del sistema climático es inequívoco: aumentos observados del promedio mundial de la temperatura del aire y del océano, deshielo generalizado de nieves y hielos, y aumento del promedio mundial del nivel del mar.

3.-Observaciones efectuadas en todos los continentes y en la mayoría de los océanos, evidencian que numerosos sistemas naturales están siendo afectados por cambios del clima regional, particularmente por un aumento de la temperatura.

4.-Las emisiones mundiales de GEI por efecto de actividades humanas han aumentado, desde la era preindustrial, en un $70 \%$ entre 1970 y 2004 . El caso del gas antropogénico de mayor concentración, el $\mathrm{CO}_{2}$, en un $80 \%$. Se habla generalmente de $\mathrm{CO}_{2}$ equivalente $\left(\mathrm{CO}_{2} \mathrm{eq}\right)$, que es la 
concentración de $\mathrm{CO}_{2}$ que generaría el mismo forzamiento radiativo, o influencia térmica positiva, y que está formado por una mezcla dada de $\mathrm{CO}_{2}$ y otros componentes de forzamiento como $\mathrm{CH}_{4}, \mathrm{~N}_{2} \mathrm{O}$ y halocarbonos. 5.-Las concentraciones atmosféricas mundiales de $\mathrm{CO}_{2}$, metano $\left(\mathrm{CH}_{4}\right)$ y óxido nitroso $\left(\mathrm{N}_{2} \mathrm{O}\right)$ han aumentado notablemente por efecto antropogénico desde 1750, y son actualmente muy superiores a los valores preindustriales. Hay un alto nivel de coincidencia y abundante evidencia respecto a que con las políticas actuales de mitigación de los efectos del cambio climático y con las prácticas de desarrollo sostenible que aquellas conllevan, las emisiones mundiales de GEI seguirán aumentando en los próximos decenios.

6.- Las consecuencias son muchas: Disminución de las superficies cubiertas de nieve y hielo, aumento del nivel del mar, alteración de las pautas eólicas, precipitaciones y temperaturas. Mayor incidencia de olas de calor, ciclones tropicales, periodos de sequía en zonas semiáridas, etc. Los ecosistemas más débiles se ven afectados: tundras, manglares, arrecifes coralinos, sistemas costeros, alteración de recursos hídricos, etc. Con mayor rapidez zonas del planeta como la zona Ártica, África, islas pequeñas. Todo ello tiene un efecto directo negativo sobre las actividades humanas, viéndose afectada tanto la agricultura como la salud de las personas.

2009: Cumbre de Copenhague: la ONU convocó a 192 países para acordar un límite a las emisiones de gases de efecto invernadero para el periodo entre 2012 y 2020. Este periodo de compromiso debía suceder al periodo 2008-2012, acordado en el protocolo de Kioto. El acuerdo final se gestó entre cuatro grandes países emergentes (China, India, Brasil y Suráfrica) y EE.UU. La delegación india propuso un tratado no vinculante que siguiera el modelo de la Organización Mundial del Comercio donde cada país declarara sus emisiones a la ONU, respetándose la soberanía nacional (aunque las reducciones de emisiones que se hicieran con dinero internacional sí estarían sujetas a un 
completo sistema de comprobación). Se mantiene el objetivo de que la temperatura global no suba más de $2^{\circ} \mathrm{C}$. Sobre cuándo las emisiones deberán alcanzar su máximo sólo se dice que "lo antes posible" y no establecen objetivos para 2050. Tampoco se ha incluido la recomendación del IPCC de que las emisiones de los países desarrollados deberían reducirse para 2020 entre un $25 \%$ y un $40 \%$ sobre el nivel que tenían en 1990 . El acuerdo lo rechazaron algunos países como Cuba, Bolivia y Nicaragua. Por ello los delegados del pleno de la Conferencia de la ONU sobre Cambio Climático renunciaron a votarlo y acordaron una fórmula de "tomar conocimiento" del documento.

2009: Informe Energy Modelling Forum EMF22: Recopila trabajos de 10 grupos internacionales, basados en IAM (Integrated Assessment Model) en lo que respecta a la valoración del coste social del carbono.

\section{IV.3.5.2.- Valoración del Coste Social del Carbono}

Los acontecimientos explicados en el apartado precedente, hacen que la valoración del carbono suponga un nuevo reto para la comunidad científica y numerosos trabajos comienzan a desarrollarse al respecto.

Del estudio que los autores hacen del SCC, puede decirse que es un problema complejo. Los mercados no son perfectos, y las estimaciones del SCC no son completas, ya que se trata de un problema que presenta una gran cantidad de incertidumbres, que hace que su valoración sea muy compleja y los valores obtenidos muy dispares. Las incertidumbres más destacables son de dos tipos:

\section{Incertidumbres Científicas:}

1.- Cómo medir las emisiones actuales de los diferentes GEI (generalmente $\mathrm{CO}_{2}$ eq)

2.- Cómo medir su permanencia en la atmósfera. Es necesario el conocimiento de los ciclos de los gases 
3.- Cómo transformar las emisiones a incremento de concentración en la atmósfera: $\mathrm{CO}_{2}$ absorbido por océanos o por vegetación; cómo influye la Deforestación/Reforestación; cómo afecta el CC sobre los fenómenos de absorción.

4.- Cómo determinar el impacto climático del aumento de concentración de GEI. Existen multitud de componentes como: incremento de temperatura, de niveles precipitación, del nivel del mar, de fenómenos climáticos extremos como inundaciones, sequías. Además, desagregación de los mismos a nivel regional. Existen posibles impactos extremos, como el cambio estructural de corrientes oceánicas, deshielo en el Antártico y efecto de los GEI más rápido de lo esperado. Como contrapartida, hay que considerar el impacto de los aerosoles de sulfato, que actúan como refrigerantes.

5.- Cómo afectará la adaptación de la sociedad a los impactos. No existe una previsión exacta de cómo influirán los avances en la tecnología. Previsiblemente las tecnologías con menos impacto ambiental se irán desarrollando en respuesta a las nuevas situaciones consecuencia de dichos impactos.

\section{Incertidumbres Económicas:}

1.- No existen mercados para negociar o valorar los impactos del cambio climático

2.- Es un problema global. Se desconoce qué factor de ponderación utilizar entre distintas regiones y si es ético o no utilizarlo. Este factor se basa en que los impactos difieren entre regiones (\$ to a poor man $\neq \$$ to a rich man) [Lange, 1942]. Además, habrá que considerar qué países son mayores emisores, cuáles lo son potencialmente (economías en desarrollo como China o India) y cuáles no lo son, así como qué países son capaces o están dispuestos a actuar para reducir sus emisiones. 
3.- Es un problema a largo plazo. Esto plantea la cuestión de cuál es la tasa o tipo de descuento adecuada a utilizar, y para ello, habrá que prever cómo se desarrollará la economía en este siglo y en el próximo. El tipo de descuento es uno de los elementos clave, al ser el mayor responsable de discusión entre distintos autores, ya que influye enormemente en el SCC. Además cómo será el mundo en un futuro desde un punto de vista económico, de evolución de población, desarrollo de tecnologías, etc. En referencia a esto último, se suele trabajar sobre escenarios de previsión predeterminados, ya mencionados anteriormente.

Los estudios desde principios de los 90 son múltiples, tanto peer-reviewed (sometidos a arbitraje por pares) como en gray literatura (no revisados). Todos ellos coinciden en cuatro puntos fundamentales:

1.- Es necesaria una intervención, con acuerdos a nivel internacional.

2.- La demora se traducirá en un aumento del coste de la intervención.

3.- Existen gran cantidad de incertidumbres conocidas "known knowns" [Tol, 2009] y hay que plantearse cómo integrar en los modelos de valoración. La mayoría de autores utilizan análisis de sensibilidad. Existen probablemente también incertidumbres desconocidas "unknown unknowns" [Tol, 2009], como por ejemplo la salinización de aguas, el aumento de las tormentas tropicales, la acidificación de los océanos, los modelos de circulación de océanos, y cómo afectará a la biodiversidad.

4.- Se precisa de una integración de conocimientos científicos y económicos para poder asesorar a los gobiernos sobre qué políticas son las más adecuadas.

Es necesario aplicar métodos de valoración adecuados. La Comunidad Científica recomienda el uso de IAM (Integrated Assessment Models, Modelos 156 
de evaluación integrada). Es el empleado en Ciencias Ambientales. Se llama integrado porque incluye conocimientos de distintas disciplinas, tanto de carácter científico como económico, con la finalidad de asesorar con respecto a las políticas a llevar a cabo. Un esquema de este tipo de modelo aparece muy bien reflejado en la siguiente figura 4.4:

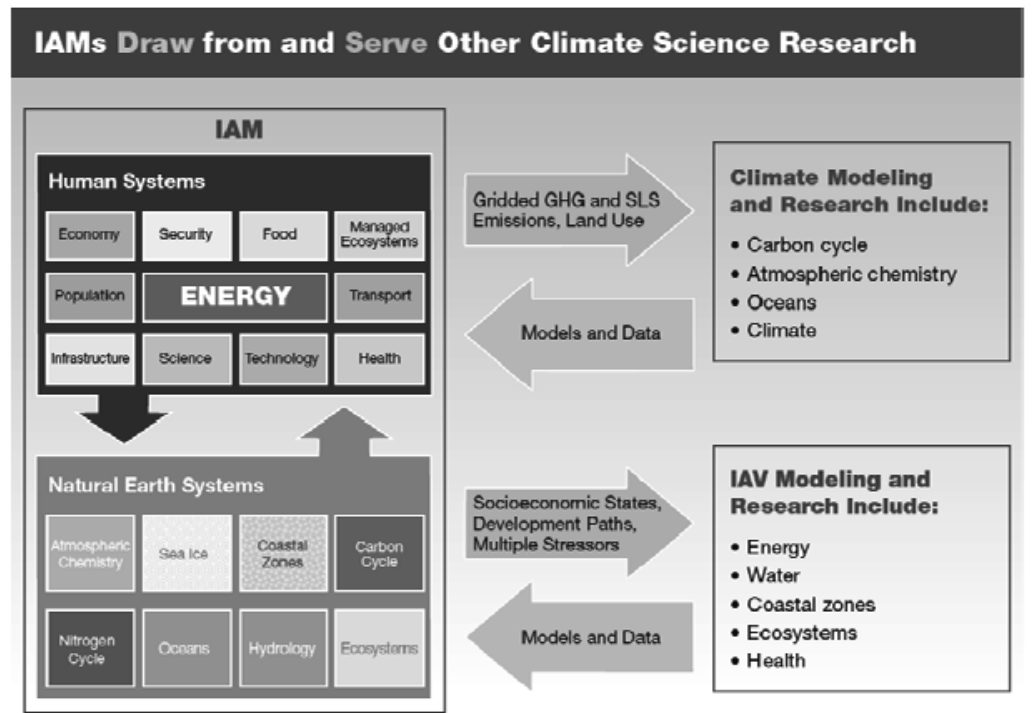

Figura 4.4.- Esquema de la complejidad de determinar el precio del SCC. Fuente: Climate Change Integrated Assessment Research. Report from the US Department of Energy. Office of Science. Office of Biological and Environmental Research. Workshop Integrated Assessment. Nov 2008

Este tipo de modelo es utilizado por muchos autores. Hay diferentes programas que simulan estos modelos: entre los más frecuentes en la literatura científica se encuentran: FUND (Tol); PAGE (Yohe) y DICE (Nordhaus). Sin embargo, el rango de valores que se encuentra en la literatura es muy amplio y son varios los autores que recopilan valores de las estimaciones realizadas hasta el momento [Clarkson and Deyes, 2002; Tol, 2005,08 y 09]. 


\section{IV.3.5.3.- Conclusiones de la revisión bibliográfica del SCC}

La reducción inmediata y radical de los niveles de $\mathrm{CO}_{2}$ atmosférico actuales, no es factible, dado que la economía actual está basada en los combustibles fósiles. Por lo tanto, la mayoría de los estudios se basan en la estabilización de los dichos niveles al doble de los niveles previos a la Revolución industrial $(2 \mathrm{x}$ 280 ppm). El informe IPCC90, indica que según los expertos en climatología, alcanzar este nivel $\left(x 2 \mathrm{CO}_{2}\right)$ supondría un aumento de la temperatura global de entre 1,5 y $4,5^{\circ} \mathrm{C}$, con un valor central de $2,5^{\circ} \mathrm{C}$ y que con la estructura económica actual (Bussiness As Usual, BAU), dicho nivel se alcanzaría antes de mitad del s. XXI.

Por tanto, el objetivo en el que se basa la mayoría de estudios, es no superar un determinado incremento de la temperatura global (en torno a $2,5^{\circ} \mathrm{C}$, variando según autores), en aproximadamente la mitad del siglo XXI (2050 en la mayoría de casos), por encima del cual los efectos serían catastróficos. Esto se debe de conseguir con la reducción de las emisiones, para lo cual es necesario aplicar un valor a la tonelada de $\mathrm{CO}_{2}$ eq emitida (en algunos estudios tonelada de $\mathrm{C}$, convertible por medio de un factor 3,66 ).

Los valores son muy diferentes según autores:

IPCC REPORT 1995: para distintos escenarios de hipótesis en el futuro (IS92a...IS92f): \$6-\$160 (precios 2000)/tC. Aumenta con el tiempo: para el período 2001-2010 estiman un intervalo de $\$ 9-\$ 197$ (precios 2000).

CLARKSON and DEYES, REPORT DEFRA 2002: Informe que contiene una revisión de la literatura existente hasta ese momento. Concluyen en un valor medio de $£ 70 / \mathrm{tC}$ (precios 2000) (con el incremento de £1/año). Las diferencias principales entre autores son de:

- Modelo: Unos están basados en el Coste Marginal (MC) y otros en el análisis Coste-Beneficio (CBA) 
- Tendencia del SCC: Unos suponen que es constante y otros, que aumenta

- Escenarios adoptados: distintas previsiones de las circunstancias socioeconómicas mundiales

- Tratamiento de las incertidumbres

- Ecuaciones que representan las emisiones de los distintos GEI, así como su permanencia en la atmósfera

- Previsión del aumento de la temperatura

- Cómo se valoran los costes y beneficios de los impactos

- Utilización o no de un factor de ponderación (Equity weighting, EW)

- Tasa o tipo de descuento empleado. (La mayoría de autores utilizan la tasa de descuento de Ramsey: SRTP = PRTP + ng; SRTP Social Rate of Time Preference, PRTP Pure Rate of Time Preference; $\mathrm{n} \%$ pérdida utilidad por \% incremento consumo; g ratio de crecimiento per cápita)

Pese a las limitaciones de los modelos utilizados en este intervalo de años, y a la variabilidad de valores estimados, asociados a diferencias en los métodos e hipótesis de partida, la Comunidad Internacional se conciencia de la problemática del CC. Es necesario llevar a cabo iniciativas encaminadas a cambiar la tendencia y a considerar los costes económicos. En la mayoría de casos, los autores, conscientes de las limitaciones de sus modelos, sugieren profundizar en el estudio en un futuro.

A continuación se muestra la revisión de los distintos trabajos referentes al estudio del SCC hasta la fecha. Los datos se recogen en varias tablas:

En la tabla 4.18 se recogen los trabajos realizados en la década de los 90 , conteniendo el autor o autores, el tipo de modelo utilizado, las hipótesis de partida como por ejemplo, la tendencia del SCC y aumento temperatura, los tipos de descuento empleados, etc. 
CAPÍTULO IV.- ESTIMACIÓN DEL VALOR DE LAS VIVIENDAS Y ANÁLISIS DE COSTES

\begin{tabular}{|c|c|c|c|c|c|c|c|c|}
\hline 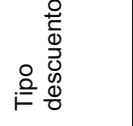 & ஓे & & 暧 & iे & \multicolumn{2}{|c|}{ 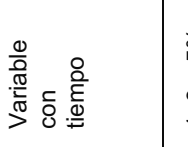 } & $\begin{array}{l}\text { 今े } \\
\text { mे } \\
\stackrel{2}{\circ}\end{array}$ & 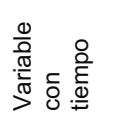 \\
\hline 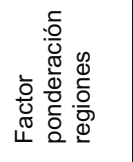 & \multicolumn{6}{|l|}{ o } & \multicolumn{2}{|c|}{$\bar{\omega}$} \\
\hline 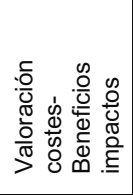 & \multicolumn{6}{|c|}{ 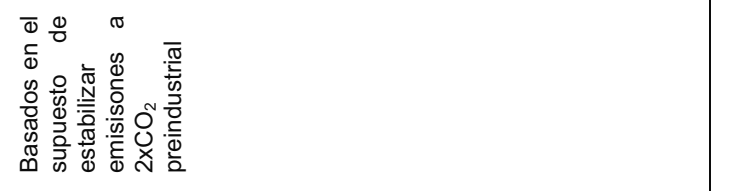 } & 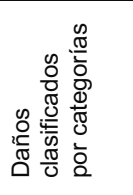 & \\
\hline 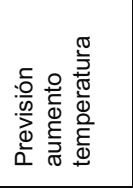 & 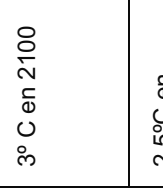 & 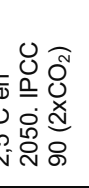 & 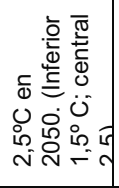 & 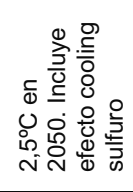 & 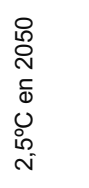 & & 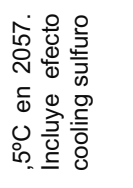 & 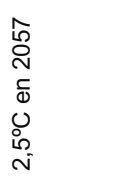 \\
\hline 崩受 & \multicolumn{2}{|l|}{ 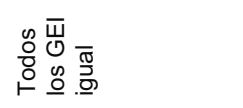 } & \multicolumn{6}{|l|}{ 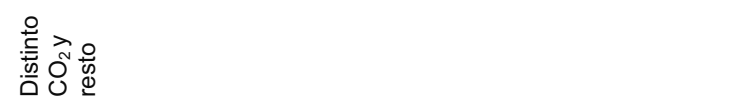 } \\
\hline 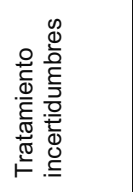 & \multicolumn{4}{|l|}{ 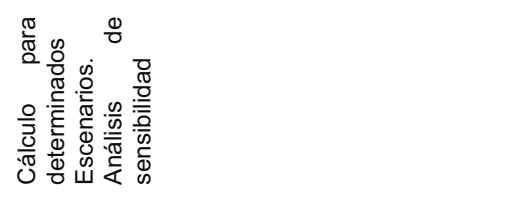 } & \multicolumn{2}{|c|}{ 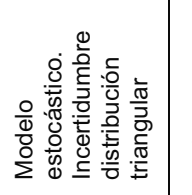 } & \multicolumn{2}{|c|}{ 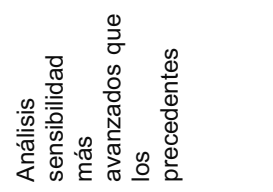 } \\
\hline 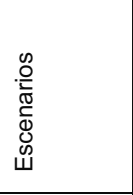 & \multicolumn{2}{|c|}{ 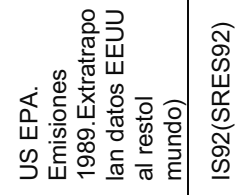 } & & & \multicolumn{4}{|c|}{ 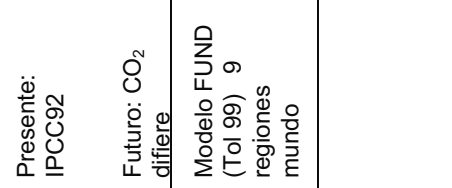 } \\
\hline 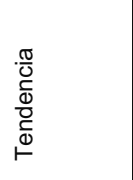 & \multicolumn{2}{|c|}{ 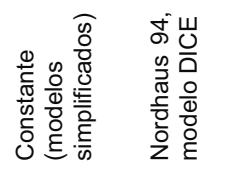 } & \multicolumn{6}{|c|}{ 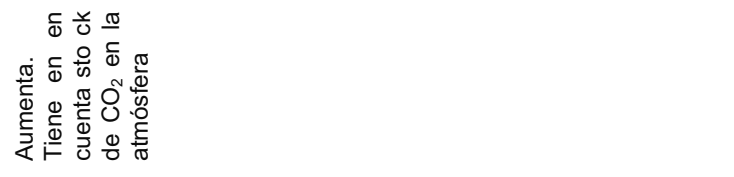 } \\
\hline$\stackrel{D}{0}^{\circ} \bar{\omega}$ & 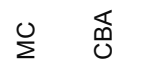 & $\sum$ & 啇 & $\sum \quad \begin{array}{c}0 \\
\Sigma\end{array}$ & $\stackrel{0}{\Sigma}$ & $\sum_{\Sigma}^{0}$ & & 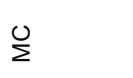 \\
\hline 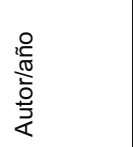 & 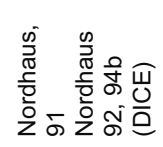 & 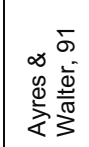 & 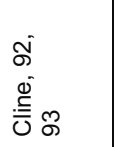 & 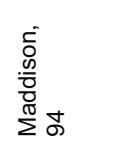 & 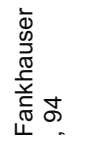 & 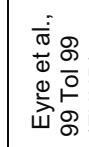 & 证 & 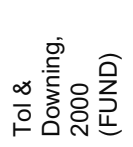 \\
\hline
\end{tabular}

Tabla4.18.- Diferencias en estudios valores SCC década 90. Fuente: elaboración propia a partir de varios autores

160 
La tabla 4.19, resume los trabajos realizados a partir del año 2001. Se distingue este periodo del anterior por la emisión del informe IPCC 2001, que tiene como consecuencia nuevos escenarios de trabajo.

\begin{tabular}{|c|c|c|c|c|}
\hline Autor - Año & $\begin{array}{l}\text { Método y datos } \\
\text { partida }\end{array}$ & \multicolumn{3}{|l|}{ Conclusiones } \\
\hline $\begin{array}{l}\text { ExternE- } \\
\text { project } \\
\text { UE+US } \\
\text { Departament } \\
\text { of Energy, } \\
\text { actualización } \\
2005\end{array}$ & $\begin{array}{l}\text { Desarrollo de } \\
\text { metodología } \\
\text { basada en FUND } \\
\text { Ratios de } \\
\text { descuento } \\
\text { utilizados: } 0 \%-3 \% \text { - } \\
6 \%\end{array}$ & \multicolumn{3}{|c|}{$\begin{array}{l}\text { Coste daño: } 9 € / \mathrm{tCO}_{2} \text { para ratio de descuento medio (sólo incluye } \\
\text { impactos con una certidumbre razonable, no incluye inundaciones, } \\
\text { huracanes, etc.). Entre } 5 \text { y } 20 € / \mathrm{tCO} \mathrm{CO}_{2} \text {. } \\
\text { Valor medio con los objetivos Kioto: } 19 € / \mathrm{tCO}_{2} \\
\text { Valor medio con los objetivos UE: } 95 € / \mathrm{tCO}_{2}\end{array}$} \\
\hline Hope, 2006 & $\begin{array}{l}\text { Basado en PAGE } \\
2002 \text { Sobre } \\
\text { escenario A2 del } \\
\text { IPCC }\end{array}$ & \multicolumn{3}{|c|}{ Resultados muy similares a los del IPCC2001: Valor medio $\$ 19 / \mathrm{tCO}_{2}$} \\
\hline $\begin{array}{l}\text { Informe Stern } \\
2006\end{array}$ & $\begin{array}{l}\text { Soluciones } \\
\text { económicamente } \\
\text { viables: } \\
\text { Estabilización } \\
\text { niveles GEI } \\
\text { atmosféricos. } \\
\text { Objetivo: no } \\
\text { superar } 500 \text { ppm } \\
\text { CO2-eq. }\end{array}$ & \multicolumn{3}{|c|}{$\begin{array}{l}\text { Implica reducir al menos } 30 \% \text { emisiones, llegando al } 50 \% \text { en } 2050 \text {. } \\
\text { Esa } 1^{\text {a }} \text { reducción del } 30 \% \text { supone una disminución del PMB del } 1 \% \\
\text { anual, y en términos monetarios unos } \$ 30 \text { por tonelada de } \mathrm{CO}_{2} \\
\text { reducida ( } 1 / 3 \text { de lo que supondría si siguiera con BAU "Bussiness as } \\
\text { Usual"). (Suponiendo políticas adecuada s). }\end{array}$} \\
\hline $\begin{array}{l}\text { Críticas al } \\
\text { Informe Stern } \\
\text { Tol and Yohe, } \\
2006, \\
\text { Nordhaus, } \\
2007, \\
\text { Wietzman } \\
2007 \text { a }\end{array}$ & & \multicolumn{3}{|c|}{$\begin{array}{l}\text { Informe encargado por el gobierno británico, parcialidad. Selección } \\
\text { parcial de los estudios precedentes, los más pesimistas y muchos de } \\
\text { ellos no sometidos a revisión por pares. Valores muy elevados. Bajo } \\
\text { ratio de descuento empleado. Aporta pocos datos para la } \\
\text { reproducibilidad de los cálculos. }\end{array}$} \\
\hline \multirow{5}{*}{ Tol, 2008} & \multirow{5}{*}{$\begin{array}{l}\text { Meta-análisis } 211 \\
\text { estimaciones, } 47 \\
\text { estudios existentes } \\
\text { Con } 5 \text { indicadores } \\
\text { calidad: } \\
\text { PR (revisados por } \\
\text { pares) } \\
\text { IE (originales) } \\
\text { ME (estiman coste } \\
\text { marginal) } \\
\text { DM (dinámico) } \\
\text { SC (escenarios } \\
\text { consistentes) }\end{array}$} & \multicolumn{3}{|c|}{$\begin{array}{l}\text { Los valores más pesimistas (mayor SCC) se dan en "gray literature" } \\
\text { Los valores de Stern están fuera de rango debido al bajo ratio de } \\
\text { descuento utilizado en su estudio } \\
\text { Los valores de SCC tienen una tendencia decreciente en los últimos } \\
\text { estudios }\end{array}$} \\
\hline & & & Mín & Máx \\
\hline & & $\mathrm{PR}=\mathrm{IE}=\mathrm{ME}=\mathrm{DM}=\mathrm{SC}=0$ & $-6,6$ & 2400 \\
\hline & & $\mathrm{PR}=\mathrm{IE}=\mathrm{ME}=\mathrm{DM}=\mathrm{SC}=1$ & 2 & 360 \\
\hline & & \multicolumn{3}{|c|}{$\begin{array}{l}\text { Que de las } 211 \text { estimaciones recogidas, } 112 \text { sean del propio Tol, será } \\
\text { después criticado en el informe de Ackermann, F. y Stanton, E.A., } 2010\end{array}$} \\
\hline
\end{tabular}




\begin{tabular}{|c|c|c|}
\hline Autor - Año & $\begin{array}{l}\text { Método y datos } \\
\text { partida }\end{array}$ & Conclusiones \\
\hline $\begin{array}{l}\text { EMF22 Energy } \\
\text { Modelling } \\
\text { Foro } \\
\text { internacional } \\
\text { expertos CC. } \\
\text { Participan } \\
\text { muchas } \\
\text { instituciones a } \\
\text { nivel } \\
\text { internacional }\end{array}$ & $\begin{array}{l}10 \text { grupos trabajo } \\
10 \text { escenarios } \\
\text { emisiones } 2100 \\
3 \text { parámetros: } \\
450-550-650 \text { ppm } \\
\text { Sin o con } \\
\text { posibilidad de } \\
\text { exceder el límite } \\
\text { antes de } 2100 \\
\text { Con participación } \\
\text { de todos los países } \\
\text { o algunos después } \\
\text { IMAGE: } \\
\text { Netherlands } \\
\text { MESSAGE, } \\
\text { POLES, SGM, } \\
\text { MiniCAM: US } \\
\text { GTEM: Australia } \\
\text { ETSAP-TIAM: } \\
\text { Canadá } \\
\text { FUND, WITCH: EU }\end{array}$ & $\begin{array}{l}\text { Supuesto más realista: } \\
\text { Retraso en medidas de algunos países (Clarke et al., 2009) } \\
550-650 \text { ppm (Se desprende de la tabla la dificultad en obtener } 450 \\
\text { ppm sin exceder temporalmente esta concentración). ( } \mathrm{x} 2 \mathrm{CO}_{2} \text { sería } 560 \\
\text { ppm) } \\
\text { Obtendríamos valores en intervalos }[7,4-64,5] \$ / \mathrm{tCO}_{2}(\mathrm{US} \$ 05)\end{array}$ \\
\hline $\begin{array}{l}\text { Stockholm } \\
\text { Environment } \\
\text { Institute, U.S. } \\
\text { Center } \\
\text { Informe } \\
\text { Ackerman- } \\
\text { Stanton } \\
2010\end{array}$ & & $\begin{array}{l}\text { Críticas al Interagency Working Group de la Administración Obama: } \\
\text { adoptan valor SCC central de } \$ 21 / \mathrm{tCO}_{2} \text { para } 2010 \text {. Ackerman-Stanton } \\
\text { indican que es un valor muy bajo, debido a una lectura parcial de la } \\
\text { literatura. } \\
\text { Sólo se basa en tres modelos FUND, PAGE y DICE. La EPA no } \\
\text { menciona ninguno de estos } 3 \text { modelos en su página web y sin embargo } \\
\text { sí otros modelos como ADAGE o MiniCAM. } \\
\text { Ratios de descuento muy altos } 2,5-5 \% \text {, con valor central } 3 \% \text {. } \\
\text { No consideran los riesgos de cambios catastróficos por el CC, como la } \\
\text { pérdida de especies, etc. } \\
\text { Defiende las cifras obtenidas por Stern }\end{array}$ \\
\hline
\end{tabular}

Tabla 4.19.- Revisión valor SCC estudios siglo XXI. Fuente: elaboración propia a partir de distintos autores

En la página siguiente se presenta la tabla 4.20 , que contiene los valores o intervalos de valores del SCC que concluyen los estudios de los distintos autores. 


\begin{tabular}{|c|c|c|c|c|}
\hline \multicolumn{5}{|c|}{ LITERATURA CIENTÍFICA } \\
\hline ESTUDIO & $1991-2000$ & $2000-2010$ & $2011-2020$ & $2021-2030$ \\
\hline $\begin{array}{l}\text { Nordhaus, } 91 \\
\text { PRTP } 4-1-0 \%\end{array}$ & $3-9,9-194,9$ & & & \\
\hline Ayres \& Walter, 1991 & $38,4-44,8$ & & & \\
\hline $\begin{array}{l}\text { Nordhaus, 92, } 94 \\
\text { PRTP 3\% } \\
\text { Best guess } \\
\text { Expected value }\end{array}$ & $\begin{array}{l}7,16 \\
16,2\end{array}$ & $\begin{array}{l}9,2 \\
24,3\end{array}$ & $\begin{array}{l}11,6 \\
24,3\end{array}$ & $\begin{array}{l}13,5 \\
--\end{array}$ \\
\hline $\begin{array}{l}\text { Cline, } 92 \\
\text { SRTP } 10-0 \%\end{array}$ & $7,8-167,5$ & $10,3-208$ & $13,2-251,2$ & $15,9-298,5$ \\
\hline $\begin{array}{l}\text { Maddison, } 94 \\
\text { SRTP 5\% }\end{array}$ & $\begin{array}{l}8 \\
8,2\end{array}$ & $\begin{array}{l}10,9 \\
11,3\end{array}$ & $\begin{array}{l}15 \\
15,5\end{array}$ & $\begin{array}{l}19,9 \\
20,5\end{array}$ \\
\hline $\begin{array}{l}\text { Fankhauser, } 94 \\
\text { PRTP } 0-3-5 \%\end{array}$ & $8,4-27,4-61$ & $10-30,8-71,4$ & $11,2-34,2-78,9$ & $\begin{array}{l}12,4-37,5- \\
86,7\end{array}$ \\
\hline IPCC 95 & & $9-197$ & & \\
\hline \multirow[t]{2}{*}{ Clarkson\&Deyes } & & $£ 70($ año 2000) & & \\
\hline & \multicolumn{2}{|l|}{ 1995-2004 } & \multicolumn{2}{|l|}{$2005-2014$} \\
\hline \multicolumn{5}{|l|}{$\begin{array}{l}\text { Eyre et al., } 99 \\
\text { Tol, } 99\end{array}$} \\
\hline $\begin{array}{l}\text { SRTP } \quad 1 \% \quad \text { Best } \\
\text { guess } \\
\text { Con EW }\end{array}$ & $255-109$ & $244-110$ & $259-119$ & \\
\hline $\begin{array}{l}\text { SRTP } \\
\text { guess }\end{array}$ & $109-42$ & $116-53$ & $117-49$ & $137-63$ \\
\hline $\begin{array}{l}\text { Con EW - Sin EW } \\
\text { SRTP } 5 \% \quad \text { Best } \\
\text { guess } \\
\text { Con EW - Sin EW }\end{array}$ & $57-20$ & $79-37$ & $65-25$ & $97-47$ \\
\hline $\begin{array}{l}\text { Tol \& Downing,00 } \\
\text { PRTP } 0-1-4 \%\end{array}$ & \multicolumn{2}{|l|}{$15,9-9,4-4$} & \multicolumn{2}{|l|}{$29-13,2-1,4$} \\
\hline Hope, 06 & \multicolumn{2}{|l|}{ US\$06 } & \multicolumn{2}{|l|}{$19 \$ / \mathrm{tCO}_{2}$} \\
\hline Stern, 06 & \multicolumn{2}{|l|}{ US\$06 } & \multicolumn{2}{|l|}{$30 \$ / \mathrm{tCO}_{2}$} \\
\hline $\begin{array}{l}\text { Tol, } 09 \text { (de estudios } \\
\text { precedentes, desde } \\
\text { 1991) }\end{array}$ & \multicolumn{2}{|l|}{ US\$95 } & \multicolumn{2}{|l|}{$\begin{array}{l}\text { Moda } 25 \$ / t C \\
\text { Moda } 50 \$ / t C\end{array}$} \\
\hline $\begin{array}{lrrr}\text { Clarke et } & \text { al., } & \text { de } \\
\text { EMF22, } 09 & & \\
\end{array}$ & \multicolumn{2}{|l|}{ US\$09 } & \multicolumn{2}{|c|}{$\begin{array}{lrr}\text { Con } & 550 & \text { ppm+overshoot } \\
\text { sería } 560 \mathrm{ppm}) & \left(\mathrm{x} 2 \mathrm{CO}_{2}\right. \\
\end{array}$} \\
\hline \multicolumn{5}{|l|}{ INFORMES } \\
\hline IPCC 95 & \multicolumn{2}{|c|}{$9-197(2000-2010)$} & & \\
\hline Clarkson\&Deyes & \multicolumn{2}{|c|}{$£ 70$ (para año 2000) } & \\
\hline ExternE & \multicolumn{2}{|l|}{ US\$05 } & \multicolumn{2}{|c|}{$\begin{array}{l}\text { Media } 9 € / \mathrm{tCO}_{2} \\
\text { Rango: } 5-20 € / \mathrm{tCO}{ }_{2} \\
\text { Proponen: (para ratio medio) } \\
\text { Lower: } 9 \\
\text { Central: } 19 \\
\text { Upper: } 50 \text { (dutch case) } \\
\text { Con objetivos Kyoto: } 19 € / \mathrm{tCO}_{2} \\
\text { Con objetivos UE: } 95 € / \mathrm{CO}_{2}\end{array}$} \\
\hline $\begin{array}{l}\text { Interagency Working } \\
\text { Group US, } 2009\end{array}$ & \multicolumn{2}{|l|}{ US $\$ 09$} & \multicolumn{2}{|l|}{$21 \$ / \mathrm{tCO}_{2}$} \\
\hline
\end{tabular}

Tabla 4.20.- Resumen revisión bibliográfica valores SCC. Fuente: elaboración propia a partir de distintos autores 
Se diferencian valores obtenidos de artículos sometidos a revisión por pares de informes que no lo están. Parte de la tabla se extrae del informe de Clarkson y Deyes, de 2002, donde se recogía una revisión de la literatura existente hasta esa fecha, ya que los datos se expresan referidos al año 2000. Los estudios posteriores a 2000 se expresan en precios de otros años, como se señala en la tabla. El caso del artículo de Tol, 2009, recoge valores de literatura revisada por pares y el resto (grey literature). El artículo de Clarke recoge datos del Energy Forum Modelling, pero sí fue publicado en revista científica.

El resto de la literatura contenida en la bibliografía, no contiene nuevos datos de valores relevantes. En muchos casos se trata de discusiones acerca de estudios precedentes o sobre la influencia de parámetros como el tipo de descuento o el factor de ponderación, etc.

\section{IV.3.5.4.- Valores adoptados del coste medioambiental}

El SCC, en definitiva, precio del $\mathrm{CO}_{2}$, tal y como se ha visto en los apartados precedentes, es variable según los autores considerados. El coste de las emisiones será función del precio adoptado y de la cantidad de emisiones de $\mathrm{CO}_{2}$, expresadas en casi todos los estudios en toneladas.

La cantidad de emisiones de $\mathrm{CO}_{2}$ se puede determinar a través de las simulaciones realizadas con el programa Calener VYP v.01, ya que éstas dan como resultado unas cifras de emisiones de $\mathrm{CO}_{2}$ en $\mathrm{Kg}$.

Una vez seleccionado el precio que se estime adecuado, se puede fácilmente obtener el coste de las emisiones de la vivienda durante su uso, simplemente con la expresión [12]:

$$
\mathrm{C}_{\mathrm{CO} 2}=\mathrm{P}_{\mathrm{CO} 2}{ }^{*} \mathrm{E}^{*} 10^{-3}
$$

donde,

$\mathrm{C}_{\mathrm{CO} 2}$ : coste medioambiental 
$\mathrm{P}_{\mathrm{CO} 2}$ : precio de $\mathrm{CO}_{2}$ en $€ /$ tonelada

$\mathrm{E}$ : emisiones de $\mathrm{CO}_{2}$ obtenidas de la simulación en Calener VYP

La tabla 4.21, recoge los valores emisiones de $\mathrm{CO}_{2}$ de la vivienda, expresados en $\mathrm{Kg} / \mathrm{m}^{2}$.año. Se puede observar la cantidad emitida para cada configuración, es decir, para cada zona climática y calificación energética simulada:

\begin{tabular}{|c|c|c|c|c|c|c|}
\hline \multirow{2}{*}{\multicolumn{2}{|c|}{$\frac{\mathrm{Kg} \mathrm{CO}_{2} / \mathrm{año} \cdot \mathrm{m}^{2}}{\text { ZONA }}$}} & \multicolumn{5}{|c|}{ CALIFICACIÓN } \\
\hline & & $E$ & D & C & $B$ & A \\
\hline A3 & Málaga & - & 23,30 & 14,60 & 7,00 & 4,30 \\
\hline A4 & Almería & -- & 22,50 & 14,00 & 7,90 & 4,30 \\
\hline B3 & Castellón & -- & 27,50 & 16,70 & 6,00 & 5,40 \\
\hline B4 & Sevilla & 28,20 & 27,70 & 17,50 & 10,00 & 6,20 \\
\hline C1 & Santander & 33,50 & 22,20 & 19,50 & 12,70 & 4,50 \\
\hline $\mathrm{C} 2$ & Barcelona & 32,30 & 21,90 & 20,10 & 12,70 & 4,50 \\
\hline C3 & Granada & -- & 36,20 & 22,90 & -- & 7,00 \\
\hline $\mathrm{C} 4$ & Badajoz & - & 31,10 & 20,00 & -- & 6,50 \\
\hline D1 & Pamplona & 46,00 & 44,90 & 28,60 & 19,40 & 3,10 \\
\hline $\mathrm{D} 2$ & Logroño & 43,60 & 42,60 & 27,70 & 17,80 & 4,50 \\
\hline D3 & Madrid & -- & 37,60 & 25,20 & -- & 5,90 \\
\hline E1 & Burgos & - & 51,80 & 32,10 & 24,70 & 2,00 \\
\hline
\end{tabular}

Tabla 4.21.- Valores de $\mathrm{Kg} \mathrm{CO} /$ año. $\mathrm{m}^{2}$ emitidas para cada una de las simulaciones Fuente: Elaboración propia

Los valores de la tabla 4.17, determinan la clasificación energética, de acuerdo a los límites establecidos en la metodología [AICIA 2009a], tal y como se muestra en la tabla 3.9. Como ya se ha mencionado anteriormente, las emisiones de $\mathrm{CO}_{2}$, son el indicador que utiliza la herramienta de simulación Calener para definir la calificación energética. En la tabla 4.16 se constata que se produce una disminución de emisiones según mejora la clase energética. La revisión bibliográfica sobre la valoración del $\mathrm{CO}_{2} \mathrm{es}$, tal y como se ha visto, un problema complejo y controvertido, coincidiendo todos los autores en que 
sus cálculos responden a unos hipotéticos escenarios, en los que existe un alto grado de incertidumbre, por lo que se habla de estimaciones. No se puede hablar de un valor de la tonelada de $\mathrm{CO}_{2}$, sino de unos intervalos de valores.

En el capítulo VI se obtienen los costes para las diferentes zonas y calificaciones bajo distintos escenarios de precio de $\mathrm{CO}_{2}$, dado que es imposible fijar un valor concreto. Asimismo, se analizarán distintos precios de energía. Se establecerá un precio umbral para el coste medioambiental, a partir del cual sea rentable obtener una calificación energéticamente más eficiente.

\section{IV.4.- COSTES TOTALES}

Una vez calculados los distintos componentes del coste, considerando el uso de la vivienda durante su vida útil, vemos en la tabla 4.22, los costes por unidad de superficie: de amortización (tabla 4.10), de energía y de mantenimiento.

En cuanto al coste del $\mathrm{CO}_{2}$, se calcula de acuerdo a las emisiones $\left(\mathrm{Kg} \mathrm{CO}_{2}\right)$ obtenidas mediante Calener VYP v.01, y será variable en función del precio que se adopte. Dado que la revisión bibliográfica del SCC, demuestra que no existe un mercado que permita establecer el precio del $\mathrm{CO}_{2}$, en la tabla 4.22, se muestra el dato del cálculo mediante el uso de Calener VYP de las emisiones en $\mathrm{Kg} \mathrm{CO}_{2} / \mathrm{m}^{2}$; también se muestra el consumo de energía primaria.

\begin{tabular}{|c|c|c|c|c|c|c|}
\hline \multirow{2}{*}{\multicolumn{2}{|c|}{ ZONA }} & \multicolumn{2}{|c|}{ Datos Calener } & \multirow{3}{*}{$\begin{array}{r}\begin{array}{c}\mathrm{C}_{\mathrm{AM}} \\
\text { (tabla 4.7) }\end{array} \\
10,37 \\
\end{array}$} & \multirow{3}{*}{\begin{tabular}{r|}
\multicolumn{1}{c|}{$\begin{array}{c}\mathrm{C}_{\text {ENER }} \\
\text { (tabla 4.9) }\end{array}$} \\
2,95 \\
\end{tabular}} & \multirow{3}{*}{$\begin{array}{r}\begin{array}{c}\mathrm{C}_{\text {MAN }} \\
\text { (tabla 4.12) }\end{array} \\
9,01\end{array}$} \\
\hline & & \multirow{2}{*}{$\begin{array}{l}\text { Consumo energía } \\
\text { KW.h/m² }\end{array}$} & \multirow{2}{*}{$\begin{array}{c}\text { Emisiones } \varphi \mathrm{KgCO}_{2} / \mathrm{m}^{2} \\
\text { (tabla 4.17) }\end{array}$} & & & \\
\hline \multirow{4}{*}{ A3 } & A3D & & & & & \\
\hline & $\mathrm{A} 3 \mathrm{C}$ & 65,70 & 14,60 & 11,78 & 2,50 & 9,88 \\
\hline & A3B & 58,20 & 7,00 & 13,22 & 2,28 & 10,10 \\
\hline & A3A & 58,00 & 4,30 & 14,25 & 2,03 & 9,82 \\
\hline \multirow{4}{*}{ A4 } & A4D & 89,90 & 22,50 & 10,45 & 2,86 & 9,07 \\
\hline & $\mathrm{A} 4 \mathrm{C}$ & 62,20 & 14,00 & 11,87 & 2,43 & 10,00 \\
\hline & A4B & 65,30 & 7,90 & 13,64 & 2,21 & 10,70 \\
\hline & $\mathrm{A} 4 \mathrm{~A}$ & 71,40 & 4,30 & 14,26 & 2,35 & 10,83 \\
\hline \multirow{4}{*}{ B3 } & B3D & 110,40 & 27,50 & 10,52 & 3,37 & 9,04 \\
\hline & B3C & 76,90 & 16,70 & 11,94 & 2,73 & 9,97 \\
\hline & B3B & 80,30 & 6,00 & 13,82 & 2,57 & 9,70 \\
\hline & B3A & 80,30 & 5,40 & 14,23 & 2,57 & 9,70 \\
\hline & & & & & & \\
\hline
\end{tabular}




\begin{tabular}{|c|c|c|c|c|c|c|}
\hline \multicolumn{2}{|c|}{ ZONA } & $\begin{array}{l}\text { Consumo energía } \\
\mathrm{KW} \cdot \mathrm{h} / \mathrm{m}^{2}\end{array}$ & $\begin{array}{c}\text { Emisiones } \varphi \mathrm{KgCO} / \mathrm{m}^{2} \\
\text { (tabla 4.17) }\end{array}$ & $\begin{array}{c}\mathrm{C}_{\mathrm{AM}} \\
\text { (tabla 4.7) } \\
\end{array}$ & \begin{tabular}{|c|}
$\mathrm{C}_{\text {ENER }}$ \\
(tabla 4.9) \\
\end{tabular} & $\begin{array}{c}\mathrm{C}_{\text {MAN }} \\
\text { (tabla 4.12) } \\
\end{array}$ \\
\hline \multirow{5}{*}{ B4 } & B4E & 112,90 & 28,20 & 10,53 & 3,43 & 9,20 \\
\hline & B4D & 111,20 & 27,70 & 10,54 & 3,39 & 9,62 \\
\hline & B4C & 77,10 & 17,50 & 12,00 & 2,78 & 10,20 \\
\hline & B4B & 79,50 & 10,00 & 13,85 & 2,56 & 9,89 \\
\hline & B4A & 107,40 & 6,20 & 14,29 & 3,22 & 10,00 \\
\hline \multirow{5}{*}{ C1 } & $\mathrm{C} 1 \mathrm{E}$ & 134,40 & 33,50 & 10,94 & 3,97 & 10,83 \\
\hline & C1D & 109,00 & 22,20 & 12,16 & 3,37 & 11,72 \\
\hline & $\mathrm{C} 1 \mathrm{C}$ & 95,60 & 19,50 & 12,50 & 3,08 & 12,26 \\
\hline & C1B & 60,30 & 12,70 & 12,81 & 2,32 & 12,29 \\
\hline & $\mathrm{C} 1 \mathrm{~A}$ & 71,90 & 2,40 & 14,06 & 2,35 & 11,97 \\
\hline \multirow{5}{*}{$\mathrm{C} 2$} & $\mathrm{C} 2 \mathrm{E}$ & 129,90 & 32,30 & 11,44 & 3,86 & 10,47 \\
\hline & C2D & 104,10 & 21,90 & 12,04 & 3,34 & 11,31 \\
\hline & $\mathrm{C} 2 \mathrm{C}$ & 95,30 & 20,10 & 12,76 & 3,12 & 11,85 \\
\hline & $\mathrm{C} 2 \mathrm{~B}$ & 58,40 & 12,70 & 13,03 & 2,31 & 11,88 \\
\hline & $\mathrm{C} 2 \mathrm{~A}$ & 100,30 & 4,50 & 14,60 & 3,04 & 11,56 \\
\hline \multirow{3}{*}{ C3 } & C3D & 144,60 & 36,20 & 10,05 & 4,22 & 11,11 \\
\hline & C3C & 107,10 & 22,90 & 11,21 & 3,40 & 11,70 \\
\hline & $\mathrm{C} 3 \mathrm{~A}$ & 113,60 & 7,00 & 13,39 & 3,37 & 11,38 \\
\hline \multirow{3}{*}{ C4 } & C4D & 124,70 & 31,10 & 9,94 & 3,73 & 9,88 \\
\hline & $\mathrm{C} 4 \mathrm{C}$ & 91,80 & 20,00 & 11,12 & 3,08 & 10,34 \\
\hline & $\mathrm{C} 4 \mathrm{~A}$ & 73,80 & 6,50 & 11,58 & 2,41 & 10,13 \\
\hline \multirow{5}{*}{ D1 } & D1E & 184,40 & 46,00 & 9,22 & 5,21 & 12,25 \\
\hline & D1D & 180,00 & 44,90 & 9,23 & 5,10 & 13,14 \\
\hline & D1C & 139,00 & 28,60 & 11,98 & 4,06 & 13,82 \\
\hline & D1B & 93,90 & 19,40 & 12,41 & 3,06 & 13,84 \\
\hline & $\mathrm{D} 1 \mathrm{~A}$ & 151,20 & 3,10 & 14,11 & 4,26 & 13,45 \\
\hline \multirow{5}{*}{ D2 } & $\mathrm{D} 2 \mathrm{E}$ & 174,80 & 43,60 & 10,23 & 4,97 & 11,74 \\
\hline & D2D & 171,10 & 42,60 & 10,96 & 4,88 & 12,63 \\
\hline & D2C & 129,60 & 27,00 & 11,96 & 3,96 & 13,27 \\
\hline & D2B & 84,90 & 17,80 & 12,40 & 2,88 & 13,29 \\
\hline & $\mathrm{D} 2 \mathrm{~A}$ & 136,80 & 4,50 & 13,70 & 3,92 & 12,92 \\
\hline \multirow{3}{*}{ D3 } & $\begin{array}{l}\text { D3D } \\
\end{array}$ & 150,80 & 37,60 & 11,53 & 4,38 & 11,15 \\
\hline & D3C & 119,50 & 25,20 & 12,81 & 3,66 & 12,70 \\
\hline & D3A & 125,70 & 5,90 & 14,67 & 3,65 & 12,43 \\
\hline \multirow{4}{*}{ E1 } & E1D & 207,70 & 51,80 & 10,29 & 5,79 & 10,55 \\
\hline & E1C & 157,50 & 32,10 & 11,60 & 4,45 & 11,82 \\
\hline & E1B & 121,20 & 24,70 & 12,11 & 3,65 & 11,85 \\
\hline & E1A & 167,20 & 2,00 & 13,47 & 4,63 & 11,52 \\
\hline
\end{tabular}

Tabla 4.22.- Resumen de costes para todas las zonas climáticas en $€ / \mathrm{m}^{2}$.año, para distintas calificaciones energéticas. Fuente: Elaboración propia 
A la vista de los resultados se extraen varias conclusiones:

1.- Los $\mathrm{Kg}$ de $\mathrm{CO}_{2}$ disminuyen al mejorar la clase energética, ya que mejores calificaciones se deben a menores emisiones, según lo visto en la tabla 4.21.

2.- Los costes de amortización aumentan a medida que mejora la calificación energética.

3.- En general, la tendencia lógica es que según mejora la clase energética, disminuyan los costes debidos al consumo de energía. Sin embargo, en las zonas A4, B4, C1, C2, D1, D2 y E1 no es así (celdas en gris con cifras en cursiva). La explicación es que el indicador que utiliza el programa Calener VYP v.01 para otorgar la clase energética depende solamente las emisiones de $\mathrm{CO}_{2}\left(\mathrm{Kg} \mathrm{CO}_{2} / \mathrm{m}^{2}\right.$.año), tal y como se vio en la tabla 4.12 .

4.- Los costes de mantenimiento aumentan conforme mejora la clase energética, excepto cuando de una calificación a la siguiente hay cambio de caldera de gas natural a caldera de biomasa, como se comentó en la tabla 4.16.

Por lo tanto, en general, amortización y mantenimiento aumentan según mejor clase energética, mientras que la tendencia del coste energía y emisiones es la contraria. En este punto, sería deseable encontrar aquellos costes de energía y $\mathrm{CO}_{2}$ que compensaran el mayor coste de amortización y mantenimietno derivado de una vivienda más eficiencte energéticamente.

Dado que el coste total se obtiene como un simple sumando de los costes considerados, según la expresión 4 , en la situación actual de tarifas energéticas, según fuera el precio adoptado de $\mathrm{CO}_{2}$, el aumento de los costes de amortización y mantenimiento al mejorar la clase energética serían o no compensados con un menor coste de energía y de las emisiones. Es decir, en las circunstancias actuales y a la vista de los resultados, de los costes que sí 168 
CAPÍTULO IV.- ESTIMACIÓN DEL VALOR DE LAS VIVIENDAS Y ANÁLISIS DE COSTES

conocemos, podría calcularse un precio umbral del $\mathrm{CO}_{2}$ que permitiera establecer cuándo es rentable un cambio a una mejor calificación. Este aspecto se tratará en el capítulo $\mathrm{V}$. 



\section{CAPÍTULO V \\ MODELOS DE COSTES Y PRECIO UMBRAL DEL $\mathrm{CO}_{2}$}



En el presente capítulo se pretende obtener unos valores hipotéticos del $\mathrm{CO}_{2}$, a partir de los cuales sería rentable mejorar la calificación energética de una vivienda tipo, situada en una zona climática determinada.

La base de datos a analizar será la recogida en la tabla 4.22.

La metodología a utilizar va a ser, en primer lugar, el análisis de costes, y en segundo lugar, el análisis de inversiones.

Previamente, se van a formular modelos de costes de construcción y de costes de uso de la vivienda tipo analizada, para cada zona climática en España y para cada una de las posibles calificaciones energéticas, con el fin de utilizarlos en el análisis de costes.

\section{V.1.- MODELOS DE COSTES}

Los modelos de costes se obtendrán utilizando el análisis de regresión múltiple, por mínimo cuadrados ordinarios, en los que el coste (C), o variable a explicar, se expresa del siguiente modo:

$$
V=a+b_{1} X_{1}+b_{2} X_{2}+\ldots \ldots+b_{n} X_{n}+\varepsilon
$$

Siendo:
a : la constante a estimar
$b_{i}:$ los coeficientes de las variables explicativas
$X_{i}$ : las variables explicativas del modelo
$\boldsymbol{\varepsilon}$ :la variable residuo o perturbación aleatoria del modelo

Para ello se van a seguir los siguientes pasos:

1. Selección de variables explicativas y a explicar

2. Definición de las variables explicativas 
3. Análisis de la normalidad de la variables cuantitativas

4. Matriz de correlaciones con las variables cuantitativas

5. Análisis de los resultados de la regresión

6. Contrastación de los supuestos para el valor teórico de: linealidad, normalidad y varianza constante.

\section{V.1.1.- Selección de variables}

Las variables utilizadas en el análisis son:

1.- Como variables dependientes o a explicar:

1.1. INVm²: Presupuesto o coste de la construcción por metro cuadrado construido

1.2. $\mathrm{C}_{\mathrm{AM}}$ : Coste anual de amortización por metro cuadrado construido

1.3. $\mathrm{C}_{\mathrm{MAN}}$ : Coste anual de mantenimiento por metro cuadrado construido

1.4. $\mathrm{C}_{\mathrm{EN}}$ : Coste anual del consumo de energía por metro cuadrado construido, teniendo en consideración las tarifas actualmente vigentes.

1.5. $\mathrm{KCO}_{2}$ : Emisiones anuales de $\mathrm{Kg}$ de $\mathrm{CO}_{2}$ por metro cuadrado construido

2.- Como variables independientes o explicativas:

2.1. La calificación energética

2.2. La zona climática

\section{V.1.2.- Definición de las variables explicativas}

Como ya se ha explicado en el capítulo IV, la calificación energética puede adoptar 5 valores, de mejor a peor calificación: A, B, C, D y E, y existen 12 zonas climáticas posibles: $\mathrm{A} 3, \mathrm{~A} 4, \mathrm{~B} 3, \mathrm{~B} 4, \mathrm{C} 1, \mathrm{C} 2, \mathrm{C} 3, \mathrm{C} 4, \mathrm{D} 1, \mathrm{D} 2, \mathrm{D} 3$ y E1, según las necesidades de calefacción y refrigeración.

La calificación energética se va a definir con 5 variables dummy, una por cada calificación (véase tabla 5.1): 


\begin{tabular}{|l|c|c|c|c|c|}
\hline Calificación & A & B & C & D & E \\
\hline Variables & & & & & \\
\hline A & 1 & 0 & 0 & 0 & 0 \\
\hline B & 0 & 1 & 0 & 0 & 0 \\
\hline C & 0 & 0 & 1 & 0 & 0 \\
\hline D & 0 & 0 & 0 & 1 & 0 \\
\hline E & 0 & 0 & 0 & 0 & 1 \\
\hline
\end{tabular}

Tabla 5.1.- Variables dummy para la calificación energética. Fuente: elaboración propia

La zona climática se va a definir a través de 4 variables métricas: la latitud, la altitud, la temperatura media y la humedad relativa media de la capital de provincia seleccionada para cada zona climática. Los valores que toman cada una de ellas figuran en la tabla 5.2:

\begin{tabular}{|l|r|r|r|r|}
\hline Zona & $\begin{array}{c}\text { Latitud } \\
\text { LAT }\end{array}$ & $\begin{array}{c}\text { Altitud }(\mathrm{m}) \\
\text { ALT }\end{array}$ & $\begin{array}{c}\text { Temperatura } \\
\text { media }\left({ }^{\circ} \mathrm{C}\right)\end{array}$ & $\begin{array}{c}\text { Humedad relativa } \\
\text { media }(\%) \\
\text { HR }\end{array}$ \\
\hline A3 & 36,67 & 7,00 & 17,96 & 66,17 \\
\hline A4 & 36,84 & 21,00 & 18,51 & 67,08 \\
\hline B3 & 39,95 & 35,00 & 16,71 & 68,00 \\
\hline B4 & 37,37 & 31,00 & 18,21 & 65,42 \\
\hline C1 & 43,46 & 65,00 & 14,18 & 74,25 \\
\hline C2 & 41,30 & 6,00 & 15,33 & 71,58 \\
\hline C3 & 37,19 & 570,00 & 15,33 & 71,58 \\
\hline C4 & 38,88 & 192,00 & 15,33 & 65,83 \\
\hline D1 & 42,76 & 461,00 & 12,18 & 65,42 \\
\hline D2 & 42,45 & 352,00 & 13,43 & 64,25 \\
\hline D3 & 40,41 & 667,00 & 14,31 & 56,42 \\
\hline E1 & 42,36 & 881,00 & 9,88 & 73,50 \\
\hline
\end{tabular}

Tabla 5.2.- Valores de variables métricas asociadas a las zonas climáticas. Fuente: elaboración propia a partir de Calener VYP, y del apéndice G del documento CTE-HE 


\section{V.1.3.- Análisis de la normalidad de las variables cuantitativas}

Para analizar la normalidad de las variables, tanto dependientes como independientes, se realiza el análisis gráfico del histograma, (anexo 3), y se visualizan la posible curtosis o "apuntamiento" (leptocurtica) o "Ilanura" (platicurtica) de la distribución comparada con la normal, así como la asimetría negativa o positiva (desplazada hacia la derecha o hacia la izquierda).

También se determinan los coeficientes de curtosis y de asimetría de las distribuciones de cada una de las variables (tabla 5.3).

\begin{tabular}{|l|r|r|r|r|}
\hline & \multicolumn{2}{|c|}{ Asimetría } & \multicolumn{2}{c|}{ Curtosis } \\
\hline & Estadístico & Error típico & Estadístico & Error típico \\
\hline INVm2 & $-0,468$ & 0,337 & $-0,438$ & 0,662 \\
\hline C $_{\text {AM }}$ & $-0,061$ & 0,337 & $-0,950$ & 0,662 \\
\hline C $_{\text {MAN }}$ & 0,212 & 0,337 & $-0,949$ & 0,662 \\
\hline C $_{\text {EN }}$ & 0,660 & 0,337 & $-0,137$ & 0,662 \\
\hline KCO2 & 0,490 & 0,337 & $-0,568$ & 0,662 \\
\hline LAT & $-0,218$ & 0,337 & $-1,571$ & 0,662 \\
\hline ALT & 0,929 & 0,337 & $-0,405$ & 0,662 \\
\hline T & $-0,338$ & 0,337 & $-0,532$ & 0,662 \\
\hline HR & $-0,240$ & 0,337 & 0,013 & 0,662 \\
\hline N & 50 & 50 & 50 & 50 \\
\hline
\end{tabular}

Tabla 5.3.- Análisis de normalidad de las variables. Fuente: elaboración propia a partir de SPSS.

Las variables relacionadas con el coste presentan una ligera asimetría positiva en el caso del coste de amortización, y negativa en el de emisiones de $\mathrm{Kg}$ de $\mathrm{CO}_{2}$ y coste de la energía. Las variables de zona se alejan un poco de la distribución normal y la que más se asemeja es la temperatura media. Se 
intenta mejorar la normalidad de las variables mediante las transformaciones logarítmicas, aunque finalmente no se han utilizado al no mejorar los modelos.

Posteriormente se obtiene el gráfico de distribución normal, que compara la distribución acumulada de los valores reales con la distribución acumulada de una distribución normal. Nuevamente se observa que de las variables de zona, es la temperatura media la que mejor se ajusta a una distribución normal (ver gráficos anexo 3).

\section{V.1.4.- Matriz de correlaciones}

En la tabla 5.4 se recoge la matriz de correlación de Pearson. Destacan los siguientes aspectos:

- De las 4 variables indicativas de zona, es la temperatura la que presenta una correlación más significativa con las variables a explicar y ha sido finalmente la adoptada en los modelos de costes para representar la zona climática. Está correlacionada de manera significativa y negativa con el coste de energía y de mantenimiento, y con los $\mathrm{kg}$ emitidos de $\mathrm{CO}_{2}$. Por el contrario, su relación con el coste de amortización y de construcción es positiva, pero no significativa.

- Los kg de emisión de $\mathrm{CO}_{2}$ están correlacionados de forma significativa y positiva con el coste de la energía.

- El coste de amortización y el coste de la construcción también están correlacionados de forma significativa y positiva.

- Los $\mathrm{Kg}$ de emisión de $\mathrm{CO}_{2}$ y el coste de energía se relacionan con los costes de construcción y de amortización de forma significativa y negativa.

- El coste de mantenimiento sólo se relaciona significativamente con el coste de la energía de forma positiva. 


\begin{tabular}{|c|c|c|c|c|c|c|c|c|c|c|}
\hline & $N=50$ & INVm2 & $\mathrm{C}_{\mathrm{AM}}$ & $\mathrm{C}_{\text {MAN }}$ & $\mathrm{C}_{\mathrm{EN}}$ & $\mathrm{KCO} 2$ & LAT & ALT & $\mathrm{T}$ & $\mathrm{HR}$ \\
\hline \multirow[t]{2}{*}{ INVm2 } & Correlación & 1,000 & $870^{* *}$ & ,219 &,$- 474^{* *}$ &,$- 637^{* *}$ & ,102 &,- 194 & ,138 & ,087 \\
\hline & Sig. (bilateral) & &, 000 & , 126 & 001 &, 000 & ,482 & , 177 & 338 & ,549 \\
\hline \multirow[t]{2}{*}{$\mathrm{C}_{\mathrm{AM}}$} & Correlación & $870^{* *}$ & 1,000 & ,134 &,$- 520^{* *}$ &,$- 863^{* *}$ &,- 035 &,- 151 & 159 & ,056 \\
\hline & Sig. (bilateral) &, 000 & & 355 & 000 &, 000 & 810 & ,295 & ,271 & ,700 \\
\hline \multirow[t]{2}{*}{$\mathrm{C}_{\text {MAN }}$} & Correlación & ,219 & , 134 & 1,000 & , 387** & 111 &, $716^{* *}$ &, $507^{* *}$ &,$- 711^{* *}$ &,- 077 \\
\hline & Sig. (bilateral) & , 126 & ,355 & & ,005 & ,444 &, 000 & ,000 &, 000 & ,594 \\
\hline \multirow[t]{2}{*}{$C_{E N}$} & Correlación &,$- 474^{* *}$ &,$- 520^{* *}$ & $387^{* *}$ & 1,000 &, $735^{* *}$ &, $490^{* *}$ & $691^{* *}$ &,$- 707^{* *}$ &,- 107 \\
\hline & Sig. (bilateral) & 001 &, 000 & ,005 & &, 000 & ,000 & ,000 & ,000 & ,461 \\
\hline \multirow[t]{2}{*}{$\mathrm{KCO} 2$} & Correlación &,$- 637^{* *}$ &,$- 863^{* *}$ &, 111 &, $735^{* *}$ & 1,000 & ,278 &, $341^{*}$ &,$- 374^{* *}$ &,- 062 \\
\hline & Sig. (bilateral) &, 000 &, 000 & , 444 & , 000 & &, 051 &, 015 &, 008 & ,669 \\
\hline \multirow[t]{2}{*}{ LAT } & Correlación & , 102 &,- 035 &, $716^{* *}$ &, $490^{* *}$ & ,278 & 1,000 &, $353^{*}$ &,$- 801^{* *}$ &, $415^{* *}$ \\
\hline & Sig. (bilateral) & , 482 & 810 &, 000 & , 000 &, 051 & & ,012 &, 000 &, 003 \\
\hline \multirow[t]{2}{*}{ ALT } & Correlación &,- 194 &,- 151 &, $507^{* *}$ & ,691* & , 341 &, $353^{*}$ & 1,000 &,$- 805^{* *}$ &,- 252 \\
\hline & Sig. (bilateral) & , 177 & ,295 &, 000 &, 000 &, 015 &, 012 & &, 000 & ,077 \\
\hline \multirow[t]{2}{*}{$\mathrm{T}$} & Correlación & , 138 & , 159 &,$- 711^{* *}$ &,$- 707^{* *}$ &,$- 374^{* *}$ &,$- 801^{* *}$ &,$- 805^{* *}$ & 1,000 &,- 199 \\
\hline & Sig. (bilateral) & ,338 & ,271 &, 000 &, 000 & ,008 &, 000 &, 000 & & , 166 \\
\hline \multirow[t]{2}{*}{ HR } & Correlación & ,087 &, 056 &,- 077 &,- 107 &,- 062 &, $415^{* *}$ &,- 252 &,- 199 & 1,000 \\
\hline & Sig. (bilateral) & ,549 & ,700 &, 594 & ,461 & ,669 & ,003 & ,077 & ,166 & \\
\hline
\end{tabular}

Tabla 5.4.- Matriz de correlación de las variables ${ }^{* *}$ La correlación es significativa al nivel 0,01 ; *La correlación es significativa al nivel 0,05). Fuente: elaboración propia a partir de SPSS. 


\section{V.1.5.- Resultados}

Se ha adoptado la temperatura como variable indicativa de zona, por tener una distribución más próxima a una normal y su mejor correlación con las variables a explicar. No obstante, se han realizado las regresiones introduciendo también el resto de variables, pero en ningún caso han resultado significativas.

Los modelos de costes, utilizando como testigo la calificación E, aparecen en la tabla 5.5:

\begin{tabular}{|c|c|c|c|c|c|}
\hline & Modelo 1 & Modelo 2 & Modelo 3 & Modelo 4 & Modelo 5 \\
\hline & \multicolumn{5}{|c|}{ Variables a explicar } \\
\hline $\begin{array}{l}\text { Variables } \\
\text { explicativas }\end{array}$ & INVm2 & $\mathrm{C}_{\mathrm{AM}}$ & $\mathrm{C}_{\text {MAN }}$ & $\mathrm{C}_{\mathrm{EN}}$ & $\mathrm{KCO} 2$ \\
\hline $\mathrm{T}$ & -- & $\begin{array}{l}0,082 \\
(0,041)^{*}\end{array}$ & $\begin{array}{l}-0,381 \\
(0,054)^{\star *}\end{array}$ & $\begin{array}{l}-0,246 \\
(0,023)^{\star *}\end{array}$ & $\begin{array}{l}-1,862 \\
(0,275)^{\star *}\end{array}$ \\
\hline$A$ & $\begin{array}{l}90,588 \\
(17,277)^{\star *}\end{array}$ & $\begin{array}{l}3,260 \\
(0,270)^{\star *}\end{array}$ & -- & $\begin{array}{l}-0,869 \\
(0,154)^{\star *}\end{array}$ & $\begin{array}{l}-28,802 \\
(1,826)^{* *}\end{array}$ \\
\hline$B$ & $\begin{array}{l}88,588 \\
(18,889)^{\star *}\end{array}$ & $\begin{array}{l}2,402 \\
(0,295)^{\star *}\end{array}$ & -- & $\begin{array}{l}-1,350 \\
(0,168)^{\star \star}\end{array}$ & $\begin{array}{l}-20,191 \\
(1,997)^{\star *}\end{array}$ \\
\hline $\mathrm{C}$ & $\begin{array}{l}50,505 \\
(1727)^{*}\end{array}$ & $\begin{array}{l}1,337 \\
(0,270)^{\star \star}\end{array}$ & -- & $\begin{array}{l}-0,748 \\
(0,154)^{\star \star}\end{array}$ & $\begin{array}{l}-11,961 \\
(1,826)^{\star *}\end{array}$ \\
\hline D & -- & -- & -- & -- & -- \\
\hline$a$ & $\begin{array}{l}685,412 \\
(11,114)^{\star *}\end{array}$ & $\begin{array}{l}9,389 \\
(0,633)^{\star *}\end{array}$ & $\begin{array}{l}16,925 \\
(0,829)^{\star \star}\end{array}$ & $\begin{array}{l}7,731 \\
(0,361)^{\star \star}\end{array}$ & $\begin{array}{l}61,55 \\
(4,279)^{\star \star}\end{array}$ \\
\hline $\mathrm{N}$ & 50 & 50 & 50 & 50 & 50 \\
\hline $\mathrm{R}^{2}$ ajustado & 0,403 & 0,769 & 0,495 & 0,793 & 0,866 \\
\hline $\mathrm{F}$ & $(12013)^{\star \star}$ & $(41,761)^{\star *}$ & $(49,059)^{\star \star}$ & $(47,926)^{\star \star}$ & $(80,301)^{\star *}$ \\
\hline
\end{tabular}

Tabla 5.5.- Modelos de costes ( ${ }^{* *}$ significativo al 0,$01 ;{ }^{*}$ significativo al 0,05$)$. Fuente: elaboración propia a partir de SPSS.

Como se puede observar en la tabla 5.5, la temperatura explica significativamente todos los costes considerados, excepto el coste de la inversión. Esto indica que no hay diferencias significativas de coste de construcción entre zonas climáticas diferentes, a pesar de que se han obtenido los presupuestos de acuerdo a precios adecuados a las diferentes provincias, o al menos, no quedan explicados al utilizar la temperatura como variable explicativa de zona. 
Por otro lado, en ningún modelo de coste resulta significativa la calificación $D$, lo cual indica que no existen diferencias entre las calificaciones $D$ y E. Esto es lógico si se observa que las emisiones de $\mathrm{CO}_{2}$ obtenidas para las calificaciones $\mathrm{E}$, en las zonas climáticas $\mathrm{B} 4, \mathrm{C} 1, \mathrm{C} 2$, D1 y D2, se encuentran todas muy cerca del valor superior del intervalo correspondiente a una calificación $D$, como se muestra en la tabla 5.6:

\begin{tabular}{|l|c|l|c|}
\hline \multicolumn{1}{|c|}{ Zona } & $\begin{array}{c}\text { Límites D } \\
\text { (tabla 3.9) }\end{array}$ & $\begin{array}{l}\text { Límites E } \\
\text { (tabla 3.9) }\end{array}$ & $\begin{array}{l}\text { Emisiones obtenidas con el Calener para } \\
\text { obtener calificación E (tabla 3.37) }\end{array}$ \\
\hline B4 & $17,9-28,1$ & $>28,1$ & 28,2 \\
\hline C1 & $19,8-30,4$ & $>30,4$ & 33,5 \\
\hline C2 & $20,2-30,1$ & $>30,1$ & 32,3 \\
\hline D1 & $30,2-45,2$ & $>45,2$ & 46,0 \\
\hline D2 & $27,8-42,6$ & $>42,6$ & 43,2 \\
\hline
\end{tabular}

Tabla 5.6.- Comparación de los valores límite de emisiones para las calificaciones E y $\mathrm{D}$, con los valores obtenidos en las simulaciones para calificación $\mathrm{E}$.

La interpretación detallada de cada uno de los 5 modelos obtenidos es la siguiente:

El coste de la inversión por metro cuadrado construido se explica en un $40 \%$ con las variables explicativas de calificación energética C, B y A. Existe un valor mínimo de partida, expresado por la constante (a), que indica que como mínimo la inversión a realizar por metro cuadrado para construir una vivienda similar a la estudiada, con una calificación $\mathrm{D} \circ \mathrm{E}$, es de unos $685 € / \mathrm{m}^{2}$, independientemente de la zona. Al mejorar la clase energética este valor se incrementa en, aproximadamente, 50,89 y $91 € / \mathrm{m}^{2}$, según sea la vivienda de la clase $\mathrm{C}, \mathrm{B}$ o $\mathrm{A}$, respectivamente.

Las variables temperatura y calificaciones $\mathrm{C}$, B y A, consiguen explicar cerca del $77 \%$ de la variabilidad del coste de amortización. En este modelo 2, el coste de partida para una vivienda $D \circ E$, sería de unos 9,4 euros $/ m 2$, que se 
incrementaría en 0,082 euros $/ \mathrm{m} 2$ por cada grado que aumente la temperatura de la zona, lo que implica que en las zonas más cálidas el coste de la amortización resulta algo mayor. Esta diferencia debida a la temperatura no es muy importante si tenemos en cuenta que las diferencias entre zonas de temperaturas medias no son excesivas y que el coeficiente que afecta a esta variable no es muy alto. Es decir, entre las zonas más fría (Burgos, E1) y la más cálida (Almería, A4), con temperaturas medias 9,88 y 18,51, respectivamente, la diferencia de incremento de la amortización será de tan sólo $0,7 € / \mathrm{m}^{2}$. Al mejorar la calificación energética de la vivienda, el coste de amortización se incrementará aproximadamente en 1,34, 2,40 ó 3,26 euros $/ \mathrm{m}^{2}$ según sea la calificación $C, B$ o $A$, respectivamente.

El modelo 3 que explica el coste de mantenimiento indica, que no existen diferencias entre las distintas calificaciones energéticas de la vivienda. Se parte de un coste inicial de 16,93 euros/m2, que disminuye en 0,381 euros/m2 por cada grado que aumente la temperatura en la zona, llegando a explicar la temperatura el $49 \%$ de la variabilidad del coste de mantenimiento. Las labores de mantenimiento son muy similares entre distintas calificaciones, ya que muchas de las operaciones se mantienen iguales, por ejemplo, en mantenimiento de pinturas, seguridad contra incendios, instalaciones de audiovisuales o de ventilación, etc., (tabla 3.36). En el cómputo global del coste de mantenimiento de todas las operaciones a realizar, estos cambios no son muy sustanciales, reduciéndose a unas pocas partidas de las 45 consideradas (anexo 2).

El modelo 4 obtenido para el coste de la energía indica que con las variables explicativas seleccionadas, de nuevo temperatura y calificaciones energéticas C, B y A, se explica el $79 \%$ del valor. En este caso, la variable temperatura tiene un coeficiente negativo, lo cual indica que el coste del consumo energético disminuye en zonas más cálidas, como es lógico asumir. Del mismo modo, al mejorar la clase energética se va disminuyendo este tipo de coste, 
excepto en la calificación A, cuyo coeficiente es menor que en la calificación B. La explicación a este hecho ya se ha mencionado anteriormente en la presente Tesis, y tiene que ver con la no utilización que hace el programa Calener-VYP v.01 del indicador consumo anual de energía primaria, como ya se viera en la tabla 4.9 del capítulo 4 .

Para finalizar, la última columna de la tabla 5.6 contiene el modelo 5 que explica las emisiones de $\mathrm{Kg}$ de $\mathrm{CO}_{2}$ en función de la temperatura, y las variables de calificación energética $\mathrm{C}, \mathrm{B}$ y $\mathrm{A}$. Todas las variables conjuntamente explican el $87 \%$ de la variabilidad de las emisiones y presentan coeficientes negativos. Es decir, las zonas más cálidas tendrán menos emisiones y las emisiones disminuirán según mejore la clase energética. En este caso, la forma en que disminuyen los coeficientes entre las calificaciones C, B y A, sí sigue el patrón lógico que cabría esperar, al ser precisamente los $\mathrm{Kg}$ de $\mathrm{CO}_{2}$ emitidos, el indicador que el programa Calener-VYP v.01 utiliza para calificar energéticamente las viviendas. Se parte de un máximo de emisiones de $61,55 \mathrm{Kg}$, para las calificaciones $\mathrm{D}$ y E, que disminuirán a razón de $1,862 \mathrm{Kg}$ por cada grado que aumente la temperatura, y de $11,96,20,19$ y $28,80 \mathrm{Kg}$ al pasar a las calificaciones C, B y A, respectivamente.

\section{V.1.6.- Análisis del modelo}

Para contrastar la linealidad del modelo y la igualdad de varianzas (homoscedasticidad) se representan los residuos tipificados frente a los valores pronostico tipificados Los gráficos (en el anexo 3), no muestran ninguna tendencia destacable. Se observa una distribución aleatoria de los puntos del gráfico de dispersión.

\section{V.2.- ANÁLISIS DE COSTES. CÁLCULO DEL PRECIO UMBRAL DEL $\mathrm{CO}_{2}$ \\ El coste medioambiental en que se incurre por el uso de la vivienda, se calcula a partir de las emisiones de $\mathrm{CO}_{2}$, multiplicadas por el precio del $\mathrm{CO}_{2}$, tal como}


se vio en el apartado IV.3.5. La revisión bibliográfica nos indica que no es posible fijar un precio único, al no existir un mercado de emisiones de $\mathrm{CO}_{2}$, ni tampoco un acuerdo entre los distintos autores. Se trata, pues, de obtener unos precios o tasas umbrales de $\mathrm{CO}_{2}$, para cada una de las diferentes situaciones en que se pueda encontrar una determinada vivienda.

De este modo, el cambio de una calificación energética dada en una vivienda a otra mejor, sería rentable siempre que se cumpliera siguiente desigualdad [14]:

$$
\mathrm{C}_{\mathrm{AMi}}+\mathrm{C}_{\mathrm{MANi}}+\mathrm{C}_{\mathrm{ENi}}+\mathrm{C}_{\mathrm{CO} 2 \mathrm{i}}>\mathrm{C}_{\mathrm{AMj}}+\mathrm{C}_{\mathrm{MANj}}+\mathrm{C}_{\mathrm{ENj}}+\mathrm{C}_{\mathrm{CO} 2 \mathrm{j}}
$$

siendo,

i= calificación energética de partida $(E, D, C, B)$

$j=$ calificación energética final $(D, C, B, A)$

$\mathrm{C}_{\mathrm{AM}}=$ coste de la amortización $\left(€ / \mathrm{m}^{2}\right.$.año)

$\mathrm{C}_{\text {MAN }}=$ coste del mantenimiento $\left(€ / \mathrm{m}^{2}\right.$.año $)$

$\mathrm{C}_{\text {ENER }}=$ coste de la energía $\left(€ / \mathrm{m}^{2}\right.$.año)

$\mathrm{C}_{\mathrm{CO} 2}=$ coste de las emisiones $\mathrm{CO}_{2}\left(€ / \mathrm{m}^{2}\right.$.año $)$

El coste de las emisiones según la expresión [15] es el producto de la cantidad de $\mathrm{CO}_{2}$ emitida en $\mathrm{Kg}$, multiplicado por el precio del $\mathrm{Kg}$ de $\mathrm{CO}_{2}$ :

$$
\mathrm{C}_{\mathrm{CO} 2}=\mathrm{KCO} 2 * \mathrm{P}
$$

donde,

$\mathrm{KCO} 2=\mathrm{Kg}$ de $\mathrm{CO}_{2}$ emitidos por $\mathrm{m}^{2}$ y año

$\mathrm{P}=$ precio umbral del $\mathrm{CO}_{2}$

Sustituyendo en la expresión [14]:

$$
\left(\mathrm{C}_{\text {AMj }}-\mathrm{C}_{\text {AMi }}\right)+\left(\mathrm{C}_{\text {MANj }}-\mathrm{C}_{\text {MANi }}\right)+\left(\mathrm{C}_{E N \mathrm{j}}-\mathrm{C}_{\text {ENi }}\right)+\left(\mathrm{KCO}_{\mathrm{j}}-\mathrm{KCO}_{\mathrm{i}}\right){ }^{*} \mathrm{P}<0
$$

y se calcula el precio umbral, a partir de la expresión [16]: 
$P>\frac{\left(\mathrm{C}_{\mathrm{AMj}}-\mathrm{C}_{\mathrm{AMi}}\right)+\left(\mathrm{C}_{\mathrm{MANj}}-\mathrm{C}_{\mathrm{MANi}}\right)+\left(\mathrm{C}_{\mathrm{ENj}}-\mathrm{C}_{\mathrm{ENi}}\right)}{\left(\mathrm{KCO}_{\mathrm{i}}-\mathrm{KCO}_{\mathrm{j}}\right)}$

Los precios umbrales de $\mathrm{CO}_{2}$ a partir de los cuales es rentable mejorar la calificación energética, se recogen en la tabla 5.7. Dichos precios han sido obtenidos para cada zona climática a partir de los valores que aparecen en la tabla 4.22, y de manera general utilizando las expresiones de los modelos de costes desarrollados en el apartado precedente. Los valores se expresan en euros por tonelada para una mejor comparación con los precios que se dan en la literatura citada:

\begin{tabular}{|l|l|l|l|l|}
\hline \multirow{2}{*}{ Zona climática } & \multicolumn{4}{|c|}{ Cambio de calificación } \\
\cline { 2 - 5 } & E-D & D-C & C-B & B-A \\
\hline A3 & & 210 & 190 & 186 \\
\hline A4 & & 226 & 370 & 247 \\
\hline B3 & & 157 & 136 & 680 \\
\hline B4 & 774 & 140 & 176 & 317 \\
\hline C1 & 135 & 216 & -61 & 93 \\
\hline C2 & 89 & 572 & -67 & 241 \\
\hline C3 & & 70 & & \\
\hline C4 & & 89 & & 154 \\
\hline D1 & 716 & 146 & -59 & 147 \\
\hline D2 & 1527 & 45 & -66 & \\
\hline D3 & & 171 & & 155 \\
\hline E1 & & 63 & -35 & \\
\hline $\begin{array}{l}\text { Según modelos de } \\
\text { costes }\end{array}$ & -- & 49 & 56 & \\
\hline
\end{tabular}

Tabla 5.7.- Precios umbral del $\mathrm{CO}_{2}$ en euros/ $\mathrm{tCO}_{2}$, para cada cambio de calificación, en cada zona climática y de forma general según los modelos de costes desarrollados 
Los valores de precios obtenidos para cada zona climática concreta, se encuentran dentro de los intervalos obtenidos en la bibliografía consultada, según se viera en el capítulo IV (tabla 4.20). No obstante, algunos valores, señalados en negrita en la tabla 5.7, son excesivamente elevados debido a que en determinadas zonas la diferencia de emisiones entre calificaciones es muy pequeña y, por tanto, el denominador de la expresión [16] muy reducido. Esto ocurre más frecuentemente en los casos en los que se pasa de una calificación $E$ a $D$, que ya se analizaron en la tabla 5.5. También ocurre de manera aislada en la zona B3, en el cambio de calificación B a A, y su explicación es la misma, ya que se alcanza la calificación $B$ con una cuantía de emisiones de $6 \mathrm{Kg} \mathrm{CO}_{2}$, mientras que la calificación energética A supone una emisión de $5,40 \mathrm{Kg} \mathrm{CO}_{2}$.

También se observan en la tabla 5.7, algunos casos en los que el precio umbral de $\mathrm{CO}_{2}$ es negativo y aparece subrayado (zonas $\mathrm{C} 1, \mathrm{C} 2, \mathrm{D} 1, \mathrm{D} 2, \mathrm{E} 1$ ). Esto indica que, en la situación actual de costes, ya es rentable el cambio de calificación, debido a que el ahorro en el coste de la energía al mejorar la clase energética, compensa el incremento de costes de amortización y mantenimiento. Nótese que coincide con las zonas más frías, donde las demandas de refrigeración son menores.

Utilizando los modelos de costes obtenidos por regresión lineal, los precios umbral de $\mathrm{CO}_{2}$ en los que es rentable mejorar la calificación se recogen en la última fila de la tabla 5.7. En este caso, al ajustar los valores a una expresión lineal, se llega a un valor único, o medio para todas las zonas climáticas. Se deduce que el cambio a clases energéticas mayores, requiere un precio umbral del $\mathrm{CO}_{2}$ mayor conforme se mejora la calificación. Así, resultaría rentable pasar de una calificación $\mathrm{C}$ a $\mathrm{D}$, siempre que existiese un precio del $\mathrm{CO}_{2}$ mayor de 49 euros/t. Igualmente si el precio fuese mayor de 56 euros/t, se adquiriría una vivienda con calificación $B$ frente a una $C$, y si fuese mayor de 155 euros/t se elegiría una vivienda con calificación $A$. 


\section{V.3.- ANÁLISIS DE INVERSIONES}

En este apartado se realiza un planteamiento dinámico del cálculo de los precios umbral del $\mathrm{CO}_{2}$, teniendo en cuenta que el uso del edificio en estudio tiene lugar a lo largo de su vida útil de 100 años y que los pagos anuales derivados del uso de la vivienda, se sitúan en distintos momentos del tiempo.

El Valor Actual neto (VAN) calcula el valor presente de un determinado número de flujos de caja futuros, originados por una inversión. La metodología consiste en descontar al momento actual (es decir, actualizar mediante una tasa) todos los flujos de caja futuros del proyecto. A este valor se le resta la inversión inicial, de tal modo que el valor obtenido es el valor actual neto del proyecto.

Para el cálculo del VAN se aplica la expresión [17]:

$$
\begin{aligned}
& \text { VAN }=-I N V+\sum_{n=1}^{100} \frac{F C_{n}}{(1+r)^{n}} \\
& F C_{n}=C_{n}-P_{n}
\end{aligned}
$$

Donde,

VAN: valor actual neto

INV: coste de la construcción o inversión en el momento cero

$F_{n}$ : flujo de caja calculado en el periodo $n$

$\mathrm{C}_{\mathrm{n}}$ : cobros en el periodo $\mathrm{n}$

$P_{n}$ : pagos en el periodo $n$

r: tasa de actualización

En este caso se plantea el análisis del VAN con la finalidad de determinar para qué precios del $\mathrm{CO}_{2}$ es rentable en una vivienda, pasar de una calificación energética a otra mejor.

Por tanto, el pasar de una promoción i a otra más eficiente energéticamente, j, sería rentable si se cumpliera la siguiente desigualdad: 


$$
\operatorname{VAN}_{\mathrm{j}}>\mathrm{VAN}_{\mathrm{i}}
$$

Y por tanto,

$$
\mathrm{VAN}_{\mathrm{j}}-\mathrm{VAN}_{\mathrm{i}}>0
$$

Desarrollando la expresión de acuerdo a la fórmula [17]:

$$
\operatorname{VAN}_{j}-\operatorname{VAN}_{i}=\left[-\mathrm{INV}_{j}+\sum_{n=1}^{100} \frac{\mathrm{FC}_{\mathrm{j}}}{(1+\mathrm{r})^{\mathrm{n}}}\right]-\left[-\mathrm{INV}_{\mathrm{i}}+\sum_{\mathrm{n}=1}^{100} \frac{\mathrm{FC}_{\mathrm{i}}}{(1+\mathrm{r})^{\mathrm{n}}}\right]>0
$$

y considerando la expresión [18]:

$$
\begin{gathered}
\operatorname{VAN}_{j}-\operatorname{VAN}_{i}=\left[-\mathrm{INV}_{j}+\sum_{n=1}^{100} \frac{\mathrm{C}_{j}-P_{j}}{(1+r)^{\mathrm{n}}}\right]-\left[-\mathrm{INV}_{\mathrm{i}}+\sum_{\mathrm{n}=1}^{100} \frac{\mathrm{C}_{\mathrm{i}}-\mathrm{P}_{\mathrm{i}}}{(1+\mathrm{r})^{\mathrm{n}}}\right]>0 \\
\mathrm{VAN}_{\mathrm{j}}-\mathrm{VAN}_{\mathrm{i}}=\mathrm{INV}_{\mathrm{i}}-\mathrm{INV}_{\mathrm{j}}+\sum_{\mathrm{n}=1}^{100} \frac{\left(\mathrm{C}_{\mathrm{j}}-\mathrm{P}_{\mathrm{j}}\right)-\left(\mathrm{C}_{\mathrm{i}}-\mathrm{P}_{\mathrm{i}}\right)}{(1+\mathrm{r})^{\mathrm{n}}}>0
\end{gathered}
$$

Para formular los flujos de caja, se van a suponer las siguientes hipótesis:

$1^{\circ}$ Que se invierte en una vivienda con destino al alquiler, por lo que los cobros anuales proceden de lospagos del alquiler por parte del arrendatario.

$2^{\circ}$ Los cobros por alquiler van a ser los mismos para cualquier calificación energética, es decir: $C_{j}=C_{i}$. Por lo tanto:

$$
\operatorname{VAN}_{j}-\operatorname{VAN}_{i}=\operatorname{INV}_{i}-I_{N V}+\sum_{n=1}^{100} \frac{P_{i}-P_{j}}{(1+r)^{n}}>0
$$


$3^{\circ}$ Los pagos anuales derivados de la inversión serán los pagos de mantenimiento, consumo de energía y emisiones de $\mathrm{CO}_{2}$, y que se supone que van a ser asumidos por el propietario de la vivienda o arrendador. Dichos pagos se corresponden con los costes de mantenimiento, energía y emisiones de $\mathrm{CO}_{2}$, calculados anteriormente. Por lo tanto:

$$
\begin{aligned}
& \mathrm{INV}_{\mathrm{j}}-\mathrm{INV}_{\mathrm{i}}=\sum_{\mathrm{n}=1}^{100} \frac{\mathrm{P}_{\mathrm{MANi}}+\mathrm{P}_{\mathrm{ENi}}-\mathrm{P}_{\mathrm{MANj}}-\mathrm{P}_{\mathrm{ENj}}+\mathrm{P} *\left(\mathrm{KCO}_{\mathrm{i}}-\mathrm{KCO} 2 \mathrm{j}\right)}{(1+\mathrm{r})^{\mathrm{n}}}>0 \\
& \frac{\mathrm{INV}_{\mathrm{j}}-\mathrm{INV}_{\mathrm{i}}+\sum_{\mathrm{n}=1}^{100} \frac{\mathrm{P}_{\mathrm{MANj}}+\mathrm{P}_{\mathrm{ENj}}-\mathrm{P}_{\mathrm{MANi}-\mathrm{P}_{\mathrm{ENi}}}}{(1+\mathrm{r})^{\mathrm{n}}}}{\sum_{\mathrm{n}=1}^{100} \frac{\left(\mathrm{KCO}_{\mathrm{i}}-\mathrm{KCO}_{\mathrm{j}}\right)}{(1+\mathrm{r})^{\mathrm{n}}}}>\mathrm{P}
\end{aligned}
$$

El precio umbral se obtendría igualando a cero la expresión anterior.

Para la obtención de la tasa de actualización r, la normativa ECO 805/03, en su artículo 32, dice que:

Se adoptará un tipo de interés nominal adecuado al riesgo del proyecto de inversión y que atienda, en particular, a su volumen y grado de liquidez, a la tipología (industrial, comercial, etc.) del inmueble, a sus características y ubicación física, al tipo de contrato de arrendamiento (existente o previsto) y al riesgo previsible en la obtención de rentas. Dicho tipo de interés se convertirá en real corrigiéndose del efecto inflacionista. Este tipo de interés nominal no podrá ser inferior a la rentabilidad media anual del tipo medio de la Deuda del Estado con vencimiento superior a dos años.

Teniendo en cuenta que la tasa de actualización se obtiene a partir de la siguiente expresión: 


$$
\begin{gathered}
(1+\mathrm{m})=\left(1+\mathrm{r}^{\prime}+\mathrm{pr}\right)(1+\mathrm{IPC}) \\
r=\mathrm{r}^{\prime}+\mathrm{pr}=\frac{(1+\mathrm{m})}{(1+\mathrm{IPC})}-1
\end{gathered}
$$

siendo,

r: tipo de actualización

$r$ : tasa real libre de riesgo

pr: prima de riesgo

$\mathrm{m}$ : tasa nominal

IPC: variación del índice de precios al consumo

\section{Tasa nominal libre de riesgo:}

Como tasa nominal sin riesgo, se adoptan los valores que aparecen en la página web del Banco de España, para la Deuda Pública de rendimiento interno del mercado secundario entre 2 y 6 años, para el periodo 2003-2010. Se calcula un valor medio de $3,18 \%$, a partir de los valores señalados en la tabla 5.8:

\begin{tabular}{|l|l|l|l|l|l|l|l|l|l|}
\hline Año & 2003 & 2004 & 2005 & 2006 & 2007 & 2008 & 2009 & 2010 & Media \\
\hline IPC & 3,10 & 2,69 & 2,68 & 3,35 & 4,08 & 4,06 & 2,83 & 2,66 & $\mathbf{3 , 1 8}$ \\
\hline
\end{tabular}

Tabla 5.8.- Tasa libre de riesgo (deuda pública rendimiento interno mercados secundarios entre 2 y 6 años). Fuente: elaboración propia a partir de Banco de España

IPC:

Por otro lado, la norma ECO 805 indica que no debe tenerse en cuenta el efecto inflacionista en el cálculo del tipo de actualización. El indicador frecuentemente adoptado es la variación del IPC, obtenido del Instituto Nacional de Estadística, tomando como valor la media entre 2003 y 2010 , ambos inclusive, obteniéndose un valor de 2,66\%, como refleja la tabla 5.9: 


\begin{tabular}{|l|l|l|l|l|l|l|l|l|l|}
\hline Año & 2003 & 2004 & 2005 & 2006 & 2007 & 2008 & 2009 & 2010 & Media \\
\hline IPC & 3,00 & 3,00 & 3,40 & 3,50 & 2,80 & 4,10 & $-0,30$ & 1,78 & $\mathbf{2 , 6 6}$ \\
\hline
\end{tabular}

Tabla 5.9.- Valor del IPC años 2003-2010. Fuente: elaboración propia a partir INE

\section{Prima de riesgo:}

Una tasa de actualización apropiada debe reflejar el riesgo asumido por la inversión. Con la prima de riesgo se aseguran tipos de actualización más elevados [Kahn and Nelling, 2010]. Esta prima de riesgo es variable, según el tipo de inversión considerado. Para viviendas de primera residencia se consultan las diversas fuentes. Una de ellas es la Asociación Nacional de Sociedades de Valoración (ATASA). Según sus recomendaciones, los valores del diferencial sobre la rentabilidad de la deuda Pública o prima de riesgo se recogen la tabla 5.10 y dependen del tipo de uso al que se destine el edificio:

\begin{tabular}{|l|l|l|l|}
\hline Uso edificio & Diferencial & Uso edificio & Diferencial \\
\hline Vivienda primera residencia & 1,00 & Plazas garaje & 2,20 \\
\hline Vivienda segunda residencia & 4,00 & Hoteles & 4,20 \\
\hline Oficinas & 2,50 & Residencias & 4,50 \\
\hline Locales comerciales & 3,20 & Otros & 4,50 \\
\hline Naves industriales & 4,50 & Rústicas & 1,00 \\
\hline
\end{tabular}

Tabla 5.10.- Valor de la prima de riesgo. Fuente: elaboración propia a partir de ATASA

Por otro lado, Tinsa Sociedad de Tasación española recoge en uno de sus informes, a partir de sus bases de datos, intervalos de valores para primas de riesgo recomendadas, según uso, para el año 2010 (tabla 5.11): 


\begin{tabular}{|l|l|l|}
\hline Uso edificio & PR máxima & PR mínima \\
\hline Vivienda primera residencia & 5,00 & 2,85 \\
\hline Vivienda segunda residencia & 8,60 & 5,40 \\
\hline VPO renta antigua & 4,50 & 2,35 \\
\hline Locales comerciales & 8,70 & 4,95 \\
\hline Oficinas & 8,25 & 4,80 \\
\hline Naves industriales & 12,00 & 6,40 \\
\hline Plazas garaje & 7,30 & 3,75 \\
\hline
\end{tabular}

Tabla 5.11.- Valor de la prima de riesgo. Fuente: elaboración propia a partir de TINSA

Por último, la normativa de valoración hipotecaria aporta unos valores de prima de riesgo, si bien son adecuados en la aplicación del método Residual Dinámico para el cálculo de valor de suelo (tabla 5.12):

\begin{tabular}{|l|l|}
\hline Uso edificio & PR mínima \\
\hline Vivienda primera residencia & 8,00 \\
\hline Vivienda segunda residencia & 12,00 \\
\hline Locales comerciales & 12,00 \\
\hline Oficinas & 10,00 \\
\hline Naves industriales & 14,00 \\
\hline Plazas garaje & 9,00 \\
\hline Otros & 12,00 \\
\hline
\end{tabular}

Tabla 5.12.- Valor de la prima de riesgo. Fuente: elaboración propia a partir de normativa de valoración hipotecaria ECO 805/03

Se obtienen por tanto valores diversos, entre 1 y $8 \%$, cuando se refiere a viviendas de primera residencia. Se estima adecuado un valor medio, de entre los recomendados, del $3 \%$.

Con todos estos datos se calcula la tasa de actualización sumándole a la tasa real libre de riesgo, la prima de riesgo de 3\%, según la expresión [20], obteniendo una tasa de actualización del 3,5\%. 


$$
r=\frac{(1+0,0318)}{(1+0,0266)}-1+0,03=0,035
$$

Aplicando los valores anteriores a la expresión [17], se obtiene la tabla 5.13, en la que se recogen los precios umbrales del $\mathrm{CO}_{2}$.

\begin{tabular}{|l|l|l|l|l|}
\hline Cambio calificación & E-D & D-C & C-B & B-A \\
\hline A3 & & 149 & 185 & 310 \\
\hline A4 & & 168 & 327 & 129 \\
\hline B3 & & 130 & 147 & 712 \\
\hline B4 & 435 & 104 & 219 & 121 \\
\hline C1 & 100 & 140 & 17 & 111 \\
\hline C2 & 95 & 179 & 14 & 179 \\
\hline C3 & & 76 & & \\
\hline C4 & & 93 & & 102 \\
\hline D1 & 178 & 51 & 24 & 122 \\
\hline D2 & 849 & 72 & 23 & \\
\hline D3 & & 112 & & 65 \\
\hline E1 & & 56 & 46 & \\
\hline
\end{tabular}

Tabla 5.13.- Precio umbral del $\mathrm{CO}_{2}$, en euros/tCO $\mathrm{CO}_{2}$, para cada cambio de calificación, en cada caso particular, mediante el análisis de inversiones

En este caso no es posible aplicar los modelos de costes para obtener un valor o precio general para cada cambio de calificación, debido a que los pagos no son constantes todos los años, como ocurría con los costes.

Los valores de precios umbrales del $\mathrm{CO}_{2}$ siguen estando dentro de los rangos estimados por los diversos autores (tabla 4.20), pero son diferentes a los obtenidos en el análisis de costes (tabla 5.7). y oscilan en un intervalo más reducido, de 14 euros/ $/ \mathrm{CO}_{2}$ a 849 euros/ $/ \mathrm{CO}_{2}$. Mientras que en el análisis de costes oscilaban entre -67 euros/tCO $\mathrm{CO}_{2}$ y 1527 euros/t $\mathrm{CO}_{2}$. 
En ningún caso se obtienen valores negativos del precio umbral del $\mathrm{CO}_{2}$, como ocurría en el análisis de costes, lo cual es lógico porque de lo contrario significaría que es rentable el cambio de calificación en las condiciones actuales de costes.

Este análisis es más realista que el análisis estático, en cuanto a que se tiene en consideración el factor tiempo. Sin embargo, presenta la desventaja de que los precios del $\mathrm{CO}_{2}$, evidentemente van a depender de la tasa de actualización adoptada. A mayor tasa de actualización, el precio del $\mathrm{CO}_{2}$ aumentará debido a que el denominador disminuye en mayor proporción que el numerador (fórmula), ya que el sumando incremento de inversiones no se ve afectado por la tasa.

\section{V.4.- COMPARACIÓN ENTRE ANÁLISIS DE COSTES Y ANÁLISIS DE INVERSIONES. CONCLUSIONES SOBRE EL PRECIO UMBRAL DEL $\mathrm{CO}_{2}$}

A continuación se realiza una comparativa sobre los valores obtenidos de precios umbrales del $\mathrm{CO}_{2}$, en el análisis de costes, y en el análisis de inversiones. Para cada uno de ellos, se aporta un histograma con la distribución de valores (figuras 5.1 y 5.2.):

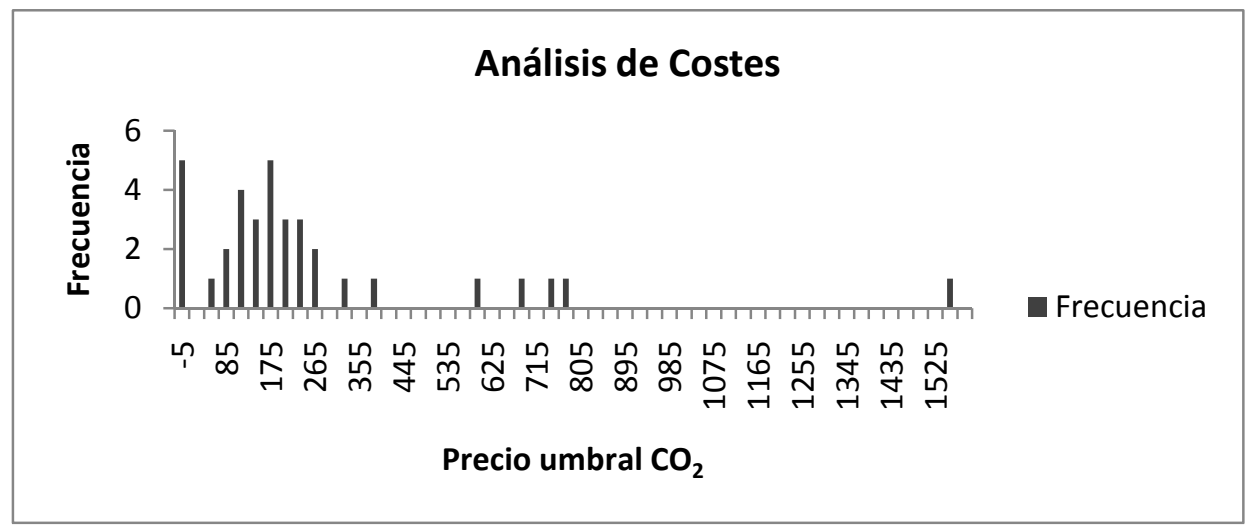

Figura 5.1.- Histograma de frecuencias, de acuerdo al análisis de costes 


\section{Análisis de Inversiones}

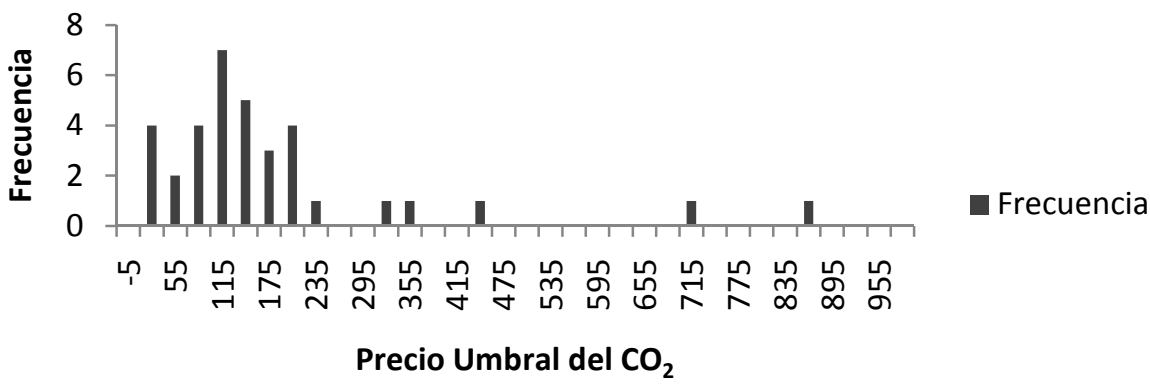

Figura 5.2.- Histograma de frecuencias, de acuerdo al análisis de inversiones

Asimismo se muestran en la tabla 5.14 los estadísticos descriptivos en cada uno de los casos considerados:

\begin{tabular}{|l|r|r|}
\hline Estadístico & Análisis Costes & Análisis Inversiones \\
\hline Media & 230,97 & 166,86 \\
\hline Error típico & 51,88 & 30,08 \\
\hline Mediana & 154,00 & 121,00 \\
\hline Moda & 89,00 & 179,00 \\
\hline Desviación estándar & 306,94 & 177,95 \\
\hline Varianza de la muestra & 94214,26 & 31664,48 \\
\hline Curtosis & 8,81 & 7,70 \\
\hline Coeficiente de asimetría & 2,62 & 2,68 \\
\hline Rango & 1594,00 & 835,00 \\
\hline Mínimo & $-67,00$ & 14,00 \\
\hline Máximo & 1527,00 & 849,00 \\
\hline Suma & 8084,00 & 5840,00 \\
\hline Cuenta & 35,00 & 35,00 \\
\hline
\end{tabular}

Tabla 5.14.- Estadísticos gráficos para el análisis de costes y el análisis de inversiones 
De las figuras 5.1 y 5.2 y del análisis de los estadísticos descriptivos se desprende que:

Los valores medios obtenidos son menores en el caso del análisis de inversiones, pero más realistas, puesto que entra en consideración el factor tiempo. Por otro lado, se estrecha el rango de valores obtenidos, al aproximarse los valores mínimo y máximo. En el caso del análisis de inversiones, no se obtiene ningún precio umbral del $\mathrm{CO}_{2}$ negativo, lo cual coincide también con la hipótesis defendida en esta Tesis, de que en las condiciones actuales, no es rentable el optar a calificaciones energéticas más eficientes; esto también puede observarse en los histogramas de frecuencias, ya que en la figura 5.2, no se observa ningún valor en la franja de valores negativos. Por último destacar, que si bien siguen existiendo casos en los que hay valores anormalmente altos, en el análisis de inversiones, se reduce bastante su valor.

Teniendo en cuenta las perspectivas consideradas para determinar el precio umbral del $\mathrm{CO}_{2}$, se puede concluir que:

- De acuerdo a los modelos de costes desarrollados, el precio umbral de $\mathrm{CO}_{2}$, es decir, aquél a partir del cual sería rentable cambiar a una mejor calificación energética, se va incrementando conforme se va mejorando en la escala de calificación, siendo de 49, 56 y 155 para el cambio de calificación energética $D$ a $C, C$ a $B$ y $B$ a A, respectivamente.

- El análisis de los datos individualizados, para cada zona climática y calificación, permite concluir que se obtienen algunos valores anormalmente altos o bajos.

- El análisis de inversiones, más realista puesto que tiene en cuenta el reparto de los gastos durante la vida útil del inmueble, obtiene precios umbral generalmente más bajos que el análisis de costes, con precios medios de 167 y $231 € / \mathrm{tCO}_{2}$, respectivamente. También el rango de 
valores es menor en el análisis de inversiones y los valores anómalos no son tan elevados como en el análisis de costes.

- En comparación con los valores obtenidos de la literatura, los precios estimados, desde todas las perspectivas analizadas, están dentro del rango de valores estimados por los distintos autores (tabla 4.20).

- Puede concluirse, que en las circunstancias actuales, no es rentable cambiar de una calificación energética dada a otra mejor. Otros estudios en el Reino Unido confirman este hecho [Dresner and Ekins, 2006]. Si se tuviera que compensar dicho cambio por medio de una tasa o impuesto que gravara las emisiones de carbono, el orden de magnitud del precio que debería pagarse la tonelada emitida de $\mathrm{CO}_{2}$, sería el que se ha estimado en el presente capítulo. 


\section{CAPÍTULO VI}

\section{ANÁLISIS MULTICRITERIO}



En el presente capítulo se pretende obtener, para una promoción de viviendas unifamiliares nuevas, de tipología igual a la empleada en los capítulos anteriores, la solución o combinación óptima de viviendas diferentes en función de su calificación energética, minimizando los costes ambientales y los costes privados derivados de su uso y el paso del tiempo. Esta búsqueda de soluciones óptimas se va a realizar para cada una de las zonas climáticas, utilizando el análisis multicriterio.

También se persigue obtener unos precios sombra para cada uno de los dos objetivos. Así, un bien o servicio puede no tener un precio de mercado; sin embargo, siempre es posible asignarle un precio sombra que permita hacer un análisis de costes. Un precio sombra es un precio teórico, interno o contable, que puede ser considerado en nuestro caso como el precio que tendría un bien en condiciones de competencia perfecta, incluyendo los costos sociales además de los privados. Representa el coste oportunidad de producir o consumir un bien o servicio.

\section{VI.1.- PROGRAMACIÓN MULTIOBJETIVO}

\section{VI.1.1.- Generalidades}

La investigación operativa y, más concretamente, la programación lineal han sido ampliamente utilizadas en las últimas décadas para la toma de decisiones en distintos ámbitos. El número de trabajos realizados es muy numeroso y sería difícil resumirlos, pero recientemente y en el sector de la construcción, podríamos citar el trabajo de Castro-Lacouture et al., 2009. En dicho estudio se propone un método para seleccionar materiales más eficientes en la construcción de viviendas desde el punto de vista medioambiental, tratando de maximizar los créditos obtenidos según el software Leadership in Energy and Environmental Design (LEED), desarrollado 
en EEUU por el Green Building Council (USGBC). El software LEED, de aplicación voluntaria, permite certificar un edificio de acuerdo a su calidad medioambiental. Se trata de una herramienta de evaluación global que puede tener en cuenta, no sólo la eficiencia energética, sino también otros aspectos como son: la ocupación del suelo, el consumo de agua o la selección de materiales, entre otros. En dicho trabajo se maximiza un único objetivo.

En general, la mayoría de las decisiones en los individuos o en las empresas se establecen en base no a un único criterio, que normalmente suele ser el beneficio económico, y en el trabajo anterior era la eficiencia medioambiental de los materiales de construcción, sino que pretenden buscar un equilibrio o compromiso entre un conjunto de criterios económicos (volumen de ventas, costes, etc.), tecnológicos, sociales o ambientales, muchas veces en conflicto, lo que ha dado lugar a la teoría de la decisión multicriterio (Multiple Criteria Decision Making o MCDM).

La optimización multicriterio se utiliza cuando la optimización simultánea de varios criterios es imposible, ya que existe un grado de conflicto entre ellos. Este tipo de análisis es muy utilizado cuando hay que tener en cuenta criterios medioambientales, que frecuentemente entran en conflicto con criterios económicos. Como ejemplos se podrían citarla planificación del territorio agroforestal [Berbel-Vecino, J., 1992], la gestión forestal [Díaz-Balteiro y Romero, 1997; DíazBalteiro y Romero, 2003; Díaz-Balteiro y Rodríguez, 2006]; y la planificación eléctrica [Linares y Romero, 2000]. Más recientemente ha sido aplicado al ámbito que nos ocupa, las construcciones, como es la valoración de las edificaciones industriales sostenibles [San José et al, 2007], o el diseño de viviendas bajo emisivas [Hamdy et al, 2011]. 
Dentro de los diferentes enfoques multicriterio, cuando el centro decisor toma sus decisiones en un contexto de objetivos múltiples, el enfoque multicriterio a considerar es la programación multiobjetivo. Si se trata de un contexto de metas múltiples, en las que se combina un objetivo y un nivel de aspiración, el enfoque multicriterio a emplear sería la programación por metas, mientras que si el contexto se caracteriza por varios atributos, el enfoque multicriterio sería la teoría de la utilidad con atributos múltiples.

En el presente trabajo se va a utilizar a la Programación Multiobjetivo (Multiobjective Programming o MOP). Se intenta encontrar un conjunto de soluciones eficientes, cuyos elementos son las soluciones alcanzables, tales que no haya ninguna otra solución que, alcanzando el mismo nivel para todos los objetivos menos uno, obtenga un mejor resultado para el objetivo restante. Hay cuatro enfoques para generar el conjunto eficiente: el método de las ponderaciones, el método de las restricciones, el NISE (Non Inferior Set Estimation) y el simplex multicriterio.

El método de las ponderaciones consiste en multiplicar cada objetivo por un peso o factor no negativo, procediéndose posteriormente a agregar todos los objetivos ponderados en una única función objetivo. El método NISE consiste en una aplicación iterativa del método de las ponderaciones, con la peculiaridad de que los pesos no se eligen arbitrariamente, sino que el cociente de sus valores w1/w2, con dos objetivos, es igual a la pendiente de la recta que conecta los puntos eficientes obtenidos en la iteración anterior. Con respecto al método de las restricciones, se optimiza uno de los $n$ objetivos, incorporándose el resto como restricciones. Tanto en el método de las restricciones como el de las ponderaciones, no se garantiza la generación de todos los puntos extremos eficientes, sino una 
aproximación al mismo. El Método Simplex Multiobjetivo se compone de tres etapas y es una extensión natural del algoritmo Simplex, ya que utiliza la misma transformación de pivote para moverse de un punto extremo eficiente a otro adyacente. Este último es el único que garantiza la obtención de todas las soluciones eficientes, sin embargo, su aplicabilidad queda limitada a problemas multiobjetivo de muy reducido tamaño [Romero y Reham, 1986; Maroto et al., 2002].

El método de las restricciones es el que se va a utilizar en la presente Tesis.

En la búsqueda del conjunto de soluciones eficientes, se puede plantear el problema de la siguiente manera:

$$
E \text { fff } Z(x)=\left[Z_{1}(x), \ldots, Z_{i}(x), \ldots, Z_{q}(x)\right]
$$

sujeto a:

$$
X \in F
$$

donde:

Eff: búsqueda de soluciones eficientes

$\mathrm{Z}_{\mathrm{i}}(\mathrm{x})$ : expresión matemática del atributo i-ésimo

$X$ : vector de variables de decisión

F: Conjunto de restricciones que definen el conjunto de soluciones posibles [Romero, C., 1993]

Un primer paso en la aplicación de la MOP consiste en la obtención de la matriz de pagos (pay-off matrix), con el fin de cuantificar el nivel de conflicto existente entre los diferentes objetivos. La mecánica de cálculo consiste en optimizar cada objetivo separadamente, 
calculando a continuación los valores alcanzados por los otros objetivos restantes en la solución óptima.

De esta manera se obtienen un conjunto de soluciones Pareto óptimas o conjunto eficiente, formada por soluciones factibles (satisfacen las restricciones), tales que no existe otra solución factible que proporcione una mejora en un objetivo sin producir un empeoramiento en al menos otro de los objetivos. De esta manera se consigue particionar el conjunto factible en dos subconjuntos: el subconjunto de soluciones eficientes y el subconjunto de soluciones dominadas o inferiores, lo cual se ha realizado sin tener en cuenta las preferencias del centro decisor.

Los valores que optimizan cada uno de los objetivos se denominan valores ancla o ideales, de tal manera que el conjunto de estos valores anclas componen las coordenadas del punto o alternativa ideal, o ancla, y se representan por el vector:

$\left(Z^{*}{ }_{1}\right.$ $Z^{*}$ $\left.Z^{*}{ }_{n}\right)$

Siendo:

$Z^{*} \mathrm{j}$ = óptimo Zj $(x)$

Sujeto a:

$X \in F$

Obviamente, este punto ideal es inalcanzable, ya que lo contrario indicaría que no existe conflicto entre los n objetivos y, por tanto, no existe ningún problema de elección multicriterio, ya que la alternativa ideal sería la solución óptima.

Los peores valores de cada uno de los objetivos, se denominan valores anti-ideales, cuyo conjunto de valores componen las 
coordenadas del punto o alternativa no ideales, representados por el vector:

$$
\left(Z_{1^{*}}, Z_{2^{*}, \ldots . . .} Z_{n^{*}}\right)
$$

Esta frontera de producción posible o conjunto eficiente, o relación de trueque marginal, que separa los puntos accesibles de los inaccesibles, formada por las restricciones en el modelo de programación lineal, se expresa de la siguiente manera:

$$
T\left(z_{1}, z_{2}, \ldots, z_{n}\right)=K
$$

Sin pérdida de generalidad, en la presente Tesis todos los criterios están definidos en sentido minimizador. De este modo, la representación gráfica de la curva de soluciones eficientes, así como la posible situación de los puntos ideal y anti-ideal, para el caso de dos objetivos únicamente, y con valores ancla menores a los valores anti-ideales, se recoge en la figura 1 :

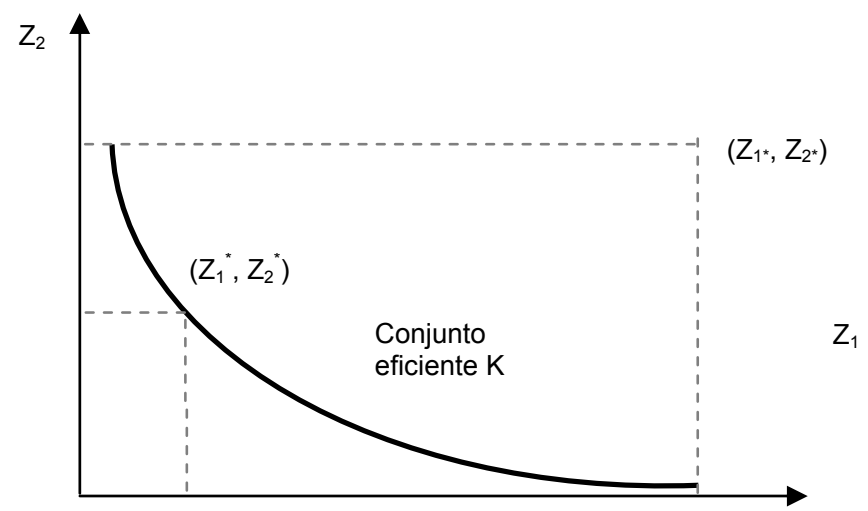

Figura 6.1.- Curva de soluciones eficientes y puntos anti-ideal y ancla 


\section{VI.2.- PROGRAMACIÓN COMPROMISO}

\section{VI.2.1- Generalidades}

Una vez obtenido el conjunto eficiente y eliminadas las soluciones inferiores, el siguiente paso en el proceso decisional sería introducir las preferencias del centro decisor, para obtener la solución óptima.

El punto de tangencia o intersección entre esta curva de posibilidades o conjunto eficiente y la función de utilidad social nos daría la solución óptima. El problema reside en que esta función de utilidad social es desconocida y para obtenerla habría que recurrir a encuestas a la población, lo cual resultaría muy costoso.

Este problema se puede obviar con la aplicación de la utilidad compromiso propuesta por Yu (1973) y Zeleny (1973 y 1974). Dicha técnica ha sido utilizada en diversos ámbitos y países, como es la planificación del uso de la tierra en Australia [Baja et al., 2007] o la gestión del uso del agua potable en ciudades de Irán [Fattahi and Fayyaz, 2010], o incluso en conflictos no ambientales, como es el crecimiento económico y la tasa de inflación en España [André et al, 2008]. Más concretamente y muy recientemente, en el sector de la construcción que es nuestro caso de estudio, se ha aplicado en Grecia para la elección de materiales de ventanas y cerramientos, en el que previamente se han utilizado dos objetivos, minimizar el coste de los materiales y minimizar la transmitancia de los mismos [Diakaki et al., 2010].

La programación compromiso se basa en que, si el centro decisor actúa racionalmente, la solución óptima será aquella que se encuentre más próxima al punto ideal. Esta proximidad se mide por medio del concepto matemático de distancia, representado gráficamente en la figura 6.2 : 


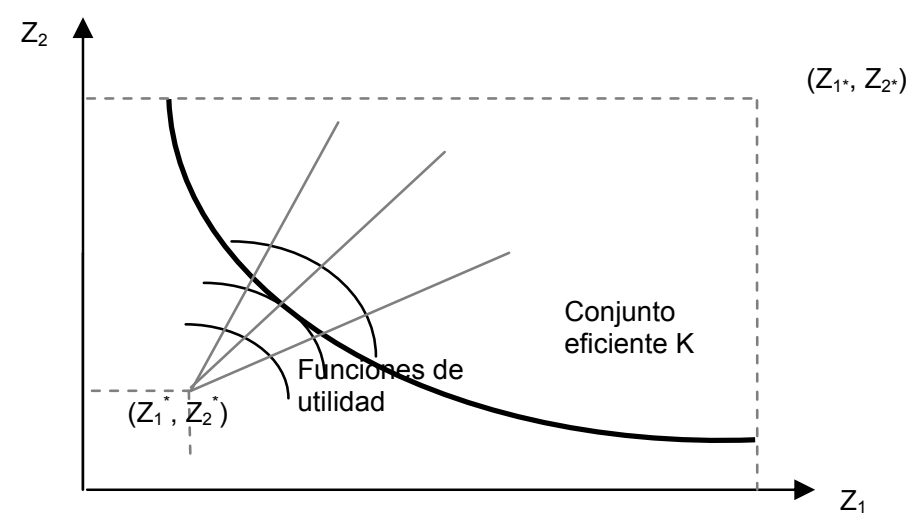

Figura 6.2.- Funciones de utilidad y distancia del punto ideal a la curva de soluciones eficientes

El axioma de Zeleny (1973) dice que: la solución óptima o mejor solución compromiso viene dada por la solución eficiente más próxima al punto ideal. Dependiendo de la métrica ${ }^{1}$ que se elija, existirán distintas funciones de distancia, lo que permitirá establecer diferentes conjuntos compromiso.

El concepto general de distancia viene se representa por la expresión:

$$
L_{\pi}=\left[\sum_{j=1}^{n}\left|x_{j}^{1}-x_{j}^{2}\right|^{\pi}\right]^{1 / \pi}
$$

Según el valor de $\pi$ se obtienen distintas distancias, de las cuales las más comunes son:

$\pi=1$ : Distancia Manhattan o Norma $L_{1}$ $\pi=2$ : Distancia Euclidiana o Norma $\mathrm{L}_{2}$ $\pi=\infty$ : Distancia Chevysev o Norma $L_{\infty}$

\footnotetext{
${ }^{1}$ Como es conocido, existen distintas métricas o métodos para medir distancias. La que se utiliza de manera universal es la métrica euclidiana, la cual define la distancia entre dos puntos como la recta que pasa por ellos.
} 
La distancia, o grado de proximidad entre el objetivo j-ésimo y su ideal $Z_{\mathrm{j}}(\mathrm{x})-\mathrm{Z}_{\mathrm{j}}^{*}$, normalizada $\mathrm{u}$ homogeneizada, ya que probablemente los objetivos vengan definidos en unidades distintas, se define como:

$$
d_{j}=\frac{\left|Z_{j}^{*}-Z_{j}(x)\right|}{\left|Z_{j}^{*}-Z_{*_{j}}\right|}
$$

siendo $Z_{*_{j}}$ el anti-ideal o peor valor del objetivo j-ésimo.

De esta forma, las distancias o grado de proximidad normalizado están acotadas entre 0 y 1 , de manera que cuando el objetivo alcanza su valor óptimo (mínimo o máximo, según el caso) vale 0 y, por el contrario, cuando alcanza su peor valor la distancia es 1 .

Si denominamos por $\mathrm{W}_{\mathrm{j}}$ las preferencias o pesos del centro decisor por cada objetivo, la búsqueda de soluciones eficientes en la programación compromiso se convierte en el siguiente problema de minimización, dado por la expresión [23]:

$$
\operatorname{Min} L_{\pi}=\left[\sum_{j=1}^{n} W_{j}^{\pi}\left|\frac{Z_{j}^{*}-Z_{j}(x)}{Z_{j}^{*}-Z_{* j}}\right|^{\pi}\right]^{1 / \pi}
$$

sujeto a $X € F$

a) Para la métrica $\pi=1$, la ecuación anterior se reduce a:

$$
\operatorname{MinL}_{1}=\sum_{j=1}^{n} W_{j} \frac{Z_{j}^{*}-Z_{j}(x)}{Z_{j}^{*}-Z_{*_{j}}}=\sum_{j=1}^{n} W_{j} \frac{Z_{j}(x)-Z_{j}^{*}}{Z_{*_{j}}-Z_{j}^{*}}
$$

equivalente a su vez a, en el caso de valores ancla mayores que los valores anti-ideales. 
$\operatorname{Max}_{1}=\sum_{j=1}^{n} W_{j} \frac{Z_{j}(x)}{Z_{j}^{*}-Z_{* j}}=\sum_{j=1}^{n} \alpha_{j} Z_{j}(x)$

y en el caso de unos valores ancla menores que los valores antiideales:

$\operatorname{MinL}_{1}=\sum_{j=1}^{n} W_{j} \frac{Z_{j}(x)}{Z_{j}^{*}-Z_{*_{j}}}=\sum_{j=1}^{n} \alpha_{j} Z_{j}(x)$

b) Para la métrica $\pi=\infty$, por definición, se minimiza la máxima desviación de entre todas las desviaciones individuales, ya que sólo la desviación mayor influye en el proceso de minimización. El problema de minimización se resuelve, en este caso:

$\operatorname{Min} \mathrm{L}=\mathrm{d}$

sujeto a $X € F$

$\alpha_{1}\left[Z_{1}^{*}-Z_{1}(x)\right] \leq d$.

$\alpha_{n}\left[Z_{n}^{*}-Z_{n}(x)\right] \leq d$

Para problemas con dos objetivos únicamente, Yu (1973) demostró que, las mejores soluciones compromiso, o conjunto-compromiso, pertenecen al conjunto acotado por los puntos $L_{1}$ y $L_{\infty}$.

Como se desprende de la ecuación anterior [21], la solución $L_{1}$ corresponde a una situación en que se maximiza la suma ponderada de los logros de cada objetivo, lo cual puede ser equivalente a un punto de máxima eficiencia. 
Por su parte, la solución $L_{\infty}$, según demostraron Ballestero y Romero (1991) satisface las siguientes relaciones entre los objetivos:

$$
\begin{aligned}
& \alpha_{1}\left[Z_{1}^{*}-Z_{1}(x)\right]=\ldots \ldots \ldots . .=\alpha_{j}\left[Z_{j}^{*}-Z_{j}(x)\right]=\ldots \ldots . .= \\
& \alpha_{n}\left[Z_{n}^{*}-Z_{n}(x)\right]
\end{aligned}
$$

o lo que es lo mismo:

$$
\begin{aligned}
& W_{1} \frac{Z_{1}^{*}-Z_{1}(x)}{Z_{1}^{*}-Z_{*_{1}}}=\ldots \ldots \ldots=W_{j} \frac{Z_{j}^{*}-Z_{j}(x)}{Z_{j}^{*}-Z_{*_{j}}}=\ldots \ldots \ldots . . . \\
& W_{n} \frac{Z_{n}^{*}-Z_{n}(x)}{Z_{n}^{*}-Z_{*_{n}}}
\end{aligned}
$$

esto es, las distancias ponderadas y normalizadas entre el valor alcanzado por cada objetivo y sus respectivos ideales son iguales. Lo que indica que se trata de una elección equilibrada entre los distintos objetivos, cosa que no ocurre con la solución $L_{1}$.

Además, en el caso de una función de utilidad bicriterio (dos criterios únicamente), la condición necesaria y suficiente para que el máximo de la función de utilidad pertenezca al conjunto eficiente para cualquier curva de transformación es que la relación marginal de sustitución $K$ entre $Z_{1}(x)$ y $Z_{2}(x)$ sea igual al cociente $\alpha_{1} / \alpha_{2}$, sobre el camino de asignaciones equilibradas:

$$
\left.\alpha_{1}\left[Z_{1}^{*}-Z_{1}(x)\right]=\ldots \ldots \ldots . .=\alpha_{j} \mid Z_{j}^{*}-Z_{j}(x)\right]=\ldots \ldots . .=\alpha_{n}\left[Z_{n}^{*}-Z_{n}(x)\right]
$$

$$
\frac{Z_{1}^{*}-Z_{1}(x)}{Z_{2}^{*}-Z_{2}(x)}=\frac{\alpha_{1}}{\alpha_{2}}=K
$$




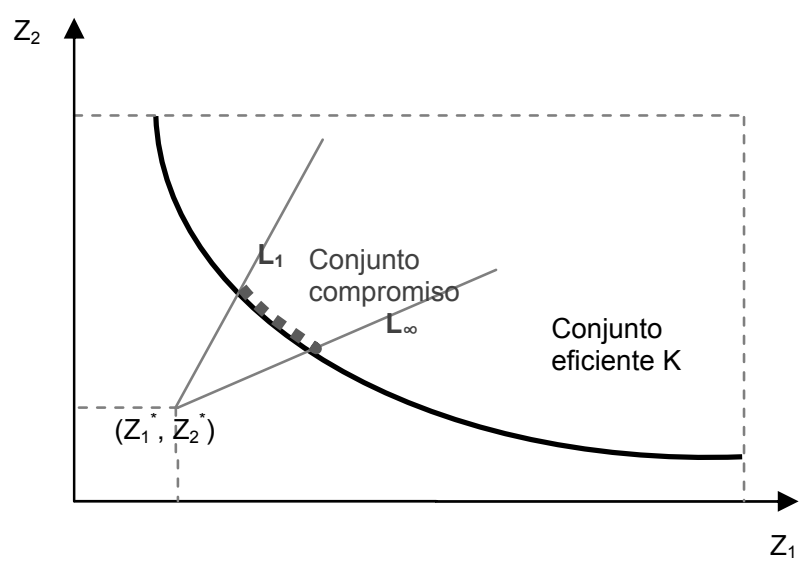

Figura 6.3.- Representación del conjunto compromiso

\section{VI.2.2- Determinación de los pesos como precios sombra}

El análisis compromiso ha sido utilizado para definir unos precios sombra en la producción múltiple, como es el caso de la producción de productos o servicios intermedios para obtener los productos finales hospitalarios [Guadalajara y Ballestero, 2000]. En la contabilidad de costes, existen ciertas secciones, llamadas intermedias las cuales contribuyen al proceso de producción que se llevan a cabo en las secciones finales de la misma empresa. Las secciones intermedias producen servicios o bienes intermedios que se ponen a disposición de las secciones finales como insumos, pero el precio interno a asignar a estos bienes intermedios no está claramente determinado, sino que resulta de una distribución de costos entre las secciones que reciben los insumos intermedios. Se trata, pues de llegar a una solución suficientemente precisa al problema de imputar costos internos en ambos casos, y, en general, en todos aquellos en los que el precio de los productos se desconoce, como puede ser los bienes ambientales. 
Dentro del esquema compromiso, la asignación de precios sombra que servirán para definir los pesos del centro decisor se desarrolla como sigue. Estos precios-sombra o pesos no son preferenciales, sino que obedecen a leyes de producción.

Supongamos una cesta de productos, definida a través del siguiente vector $\left(x_{1}, x_{2}, . ., x_{i}, . ., x_{n}\right)$, obtenida en un proceso de producción múltiple o conjunta, con un nivel de recursos $B$. Los precios de los inputs o recursos $B$ utilizados en la producción conjunta son conocidos, a partir de los cuales se puede obtener el coste en que se incurre para producir la cesta de productos, dentro de la frontera de producción posible o conjunto eficiente. Este coste total o agregado lo llamaremos R. Surge el problema de imputar los costes a los recursos $\mathrm{B}$, los cuales contribuyen al proceso productivo en mayor o menor medida, sin que existan relaciones de proporcionalidad ni funcionales directas aplicables a la imputación. Para estos costes $\mathrm{R}$ el analista necesita establecer unos precios sombra $\mathrm{W}_{\mathrm{i}}$.

Un sistema de precios-sombra perfecto y consistente debe cumplir dos condiciones [Ballestero y Romero, 1993; Ballestero, 1994]:

\section{Primera condición}

El valor-sombra agregado de los productos con tales precios (valorsombra de la cesta de productos) debe cubrir el coste total de los recursos $\mathrm{R}$.

De la misma manera, el valor-sombra $Q$ correspondiente a los precios sombra $W_{i}$, de la cesta de productos debe ser mayor o igual que el coste $R$ en que se incurre para producir esos productos, pues de lo contrario la empresa incurriría en pérdidas. Esto es: 


$$
Q=\sum_{i=1}^{n} w_{i}^{*} X_{i} \geq R
$$

Siendo $\mathrm{W}_{\mathrm{i}}=$ precio sombra

\section{Segunda condición}

El margen de producción $Q-R$, entre el valor-sombra de la cesta de productos y el coste de los recursos consumidos en su producción, debe ser estimado de forma prudencial evitando sobreestimaciones.

Ambas condiciones se pueden unir de la siguiente manera en el siguiente modelo de optimización:

$$
\begin{aligned}
& \operatorname{Min}(Q-R) \equiv \operatorname{Min} \sum_{i=1}^{n} w_{i} * x_{i} \\
& \text { Sujeto a: } Q=\sum_{i=1}^{n} w_{i} * x_{i} \geq R
\end{aligned}
$$

donde la minimización restringida se extiende a cualquier cesta de productos dentro de la frontera de producción posible o conjunto eficiente. De esta manera, los precios sombra minimizarán cualquier diferencia entre un valor sombra de la cesta y el coste de los inputs conjuntos utilizados, al mismo tiempo que se aumenta la riqueza de la empresa.

En los teoremas que se enuncian a continuación [Ballestero y Romero, 1993], se obtienen los precios-sombra que cumplen las dos condiciones [30].

\section{Teorema 1:}

Sea una frontera de producción eficiente, interceptando cada eje xi en un punto $\left(0, \ldots \ldots . . . \mathrm{X}^{*}, \ldots \ldots . . .0\right)$, todos los anti-ideal $\left(\mathrm{x}^{*}{ }_{\mathrm{i}}\right)$ son nulos $\mathrm{y}$ el valor de $\mathrm{R}$ es real y positivo, los pesos tales como: 


$$
\mathrm{W}^{*}{ }_{1} \mathrm{X}^{*}{ }_{1}=\ldots \ldots=\mathrm{w}^{*}{ }_{\mathrm{i}} \mathrm{X}_{\mathrm{i}}{ }_{\mathrm{i}}=\ldots \ldots \ldots \ldots=\mathrm{w}^{*}{ }_{\mathrm{n}} \mathrm{X}_{\mathrm{n}}{ }_{\mathrm{n}}=\mathrm{R}
$$

se demuestra que son los únicos que satisfacen [26], y son, por tanto, precios-sombra perfectos y consistentes.

\section{Teorema 2:}

Sea una frontera de producción eficiente, interceptando cada eje xi en un punto $\left(0, \ldots \ldots x^{*} i, \ldots \ldots . .0\right)$, los valores anti-ideal $\left(x^{*} i\right)$ no son todos nulos, sino que hay alguno distinto de cero y el valor de $R$ es real $y$ positivo, los pesos tales como:

$$
w_{i}=\frac{R}{\left(x_{i}^{*}-x_{i^{*}}\right)\left(1+\sum_{i=1}^{n} \frac{x_{i^{*}}}{x_{i}^{*}-x_{i^{*}}}\right)}
$$

se demuestra que son los únicos que satisfacen [25-26], y son, por tanto, precios-sombra perfectos y consistentes.

En nuestro caso, los valores anti-ideales son distintos de cero, de manera que corresponde la aplicación del teorema 2.

\section{VI.2.3- Determinación de la solución compromiso}

Una vez obtenidos los pesos o precios sombra en el apartado anterior, o bien han sido fijados a criterio propio del centro decisor, se van a utilizar para obtener los límites $L_{1}$ y $L_{\infty}$ del conjunto compromiso.

Para obtener el límite $L_{1}$ del conjunto compromiso se resolverá el siguiente problema de optimización: 


$$
\begin{gathered}
\operatorname{Min} L_{1}=\sum_{j=1}^{n} W_{j} \frac{Z_{j}^{*}-Z_{j}(x)}{Z_{j}^{*}-Z_{*_{j}}} \\
\text { Sujeto a: } \quad \mathrm{T}\left(\mathrm{x}_{1}, \mathrm{x}_{2}, \ldots ., \mathrm{x}_{\mathrm{n}}\right)=\mathrm{K}
\end{gathered}
$$

Y para obtener el límite $L_{\infty}$ del conjunto compromiso

\section{VI.3.APLICACIÓN}

De los capítulos anteriores se pone de manifiesto que la mejora de la calificación energética implica, por un lado, el aumento de los costes de inversión y mantenimiento y, por otro lado, la disminución de los costes de energía y de las emisiones de $\mathrm{Kg}$ de $\mathrm{CO}_{2}$. Por tanto, no es posible alcanzar una solución óptima o combinación de viviendas con distinta calificación dentro de una promoción de viviendas, que minimice los costes de energía, amortización y mantenimiento, y a la vez la contaminación ambiental.

Existen, por tanto, dos objetivos enfrentados: uno económico o privado y otro ambiental o público, reflejando cada uno de ellos los intereses de los dos agentes implicados: el que genera la contaminación (usuario de la vivienda) y el que la sufre (la sociedad en general).

Si llamamos, para todo i / i=A, B, C, D:

$\mathrm{X}_{\mathrm{i}}$ : porcentaje de vivienda tipo $\mathrm{i}$

se busca el conjunto de soluciones eficientes, que cumplan los dos objetivos: 
Eff $Z(x)=\left[Z_{1}(x), Z_{2}(x)\right]$

$Z_{1}(x)$ : objetivo minimizar costes de amortización, mantenimiento y energía

$\mathrm{Z}_{2}(\mathrm{x})$ : objetivo minimizar las emisiones de $\mathrm{CO}_{2}$

Para ello se puede plantear un modelo, para cada zona climática, en los que se establezca que las dos funciones objetivo están sujetas a unas restricciones de porcentaje de participación de viviendas de cada calificación energética, de manera que los compradores potenciales puedan elegir viviendas con distintas calificaciones. Se parte de la hipótesis de que no existen restricciones de limitación de presupuesto, ni de emisiones de $\mathrm{CO}_{2}$, aunque pudiera plantearse un caso concreto con restricciones de este tipo.

La resolución del problema se resuelve con la optimización de cada objetivo por separado. La minimización de $Z_{1}(x)$ dará como resultado un alto porcentaje de viviendas más baratas en cuanto a amortización, consumo energético y mantenimiento, pero por otro lado peores desde el punto de vista medioambiental. Por el contrario, la minimización de $Z_{2}(x)$ dará como resultado un alto porcentaje de viviendas más caras en cuanto a inversión y mantenimiento, pero mejores desde el punto de vista medioambiental. De esta manera se encuentran el punto ideal, que es el de menores costes para $Z_{1}(x)$ y $Z_{2}(x)$, obviamente no alcanzable, y el punto anti-ideal, que es el de mayores costes.

Por ejemplo, para la zona A3, dichas funciones serán:

$$
\begin{gathered}
Z_{1}(x)=26,10^{\star} X_{A}+25,59^{*} X_{B}+24,15^{*} X_{C}+22,32^{*} X_{D} \\
Z_{2}(x)=4,30^{*} X_{A}+7,00^{*} X_{B}+14,60^{*} X_{C}+23,30^{*} X_{D}
\end{gathered}
$$


s.a.

$X_{i} \geq 0.1$, indica que al menos debe haber un $10 \%$ de viviendas de cada calificación

$X_{i} \leq 0.5$, indica que como máximo habrá un $50 \%$ de viviendas de cada calificación

$\sum x i=1$

Resolviendo el modelo con el programa Lingo, software para optimización, se siguen los pasos descritos a continuación:

$1^{\circ}$.- Minimizar $Z_{1}(x)$ :

$\operatorname{MINZ}_{1}(x)=26,10^{*} X_{A}+25,59^{*} X_{B}+24,15^{*} X_{C}+22,32^{*} X_{D}$

s.a:

$X_{A}+X_{B}+X_{C}+X_{D}=1$

$X_{A}>=0.1$

$X_{B}>=0.1$;

$X_{C}>=0.1$

$X_{D}>=0.1$

$\mathrm{X}_{\mathrm{A}}<=0.5$;

$X_{B}<=0.5$;

$\mathrm{X}_{\mathrm{C}}<=0.5$;

$X_{D}<=0.5$;

$2^{\circ}$.- $\quad$ Minimizar $Z_{2} \quad(x): \quad M I N Z_{2}(x)=4,30^{*} X_{A}+7,00^{*} X_{B}+14,60^{*} X_{C}+$ $23,30^{*} X_{D}$

s.a:

$X_{A}+X_{B}+X_{C}+X_{D}=1$;

$X_{A}>=0.1$;

$X_{B}>=0.1$

$X_{C}>=0.1$;

$X_{D}>=0.1$;

$X_{A}<=0.5$; 
$\mathrm{X}_{\mathrm{B}}<=0.5$

$\mathrm{X}_{\mathrm{C}}<=0.5$;

$X_{D}<=0.5$;

Las soluciones se recogen a continuación en la tabla 6.1. Aparecen más oscuros los valores del punto ideal y en gris claro, los del punto anti-ideal:

\begin{tabular}{|l|l|l|l|l|l|l|l|}
\hline & & $Z_{1}(x)$ & $Z_{2}(x)$ & $X_{A}$ & $X_{B}$ & $X_{C}$ & $X_{D}$ \\
\hline $\min Z_{1}(x)$ & $\begin{array}{l}\text { Óptimo económico } \\
\text { o privado }\end{array}$ & 23,57 & 17,16 & 0.1 & 0.1 & 0.3 & 0.5 \\
\hline $\min Z_{2}(x)$ & $\begin{array}{l}\text { Óptimo ambiental } \\
\text { o público }\end{array}$ & 25,37 & 8,04 & 0.5 & 0.3 & 0.1 & 0.1 \\
\hline
\end{tabular}

Tabla 6.1.- Matriz de pagos: puntos ideal (ancla) y anti-ideal para la zona A3

A continuación se busca un conjunto de soluciones eficientes, entre los valores de costes de los puntos ideal y anti-ideal, recogidos en la tabla 6.2:

\begin{tabular}{|l|l|l|l|l|l|l|}
\hline & $Z_{1}(x)$ & $Z_{2}(x)$ & $X_{A}$ & $X_{B}$ & $X_{C}$ & $X_{D}$ \\
\hline $\min Z_{1}(x)$ & 23,57 & 17,16 & 0,10 & 0,10 & 0,30 & 0,50 \\
\hline & 23,77 & 16,12 & 0,20 & 0,10 & 0,20 & 0,50 \\
\hline & 23,97 & 15,07 & 0,30 & 0,10 & 0,10 & 0,50 \\
\hline & 24,17 & 14,06 & 0,35 & 0,10 & 0,10 & 0,45 \\
\hline & 24,37 & 13,06 & 0,41 & 0,10 & 0,10 & 0,39 \\
\hline & 24,57 & 12,05 & 0,46 & 0,10 & 0,10 & 0,34 \\
\hline & 24,77 & 11,05 & 0,50 & 0,12 & 0,10 & 0,28 \\
\hline & 24,97 & 10,05 & 0,50 & 0,18 & 0,10 & 0,22 \\
\hline & 25,17 & 9,06 & 0,50 & 0,24 & 0,10 & 0,16 \\
\hline $\min Z_{2}(x)$ & 25,37 & 8,04 & 0,50 & 0,30 & 0,10 & 0,10 \\
\hline
\end{tabular}

Tabla 6.2.- Soluciones eficientes para la zona A3 
Se observa como a medida que se reducen las emisiones y aumenta el coste total, la participación en la promoción de viviendas más eficientes va a aumentando hasta alcanzar el límite impuesto en la restricción, al contrario de lo que ocurre con la participación de viviendas menos eficientes energéticamente.

Los puntos ideal y anti-ideal vienen dados por los pares de valores:

$P$. ideal $(23,57 ; 8,04)$ : Mínimo coste en amortización-mantenimientoenergía $\left(€ / \mathrm{m}^{2}\right.$.año) y en emisiones $\mathrm{CO}_{2}\left(\mathrm{Kg} / \mathrm{m}^{2}\right.$.año).

P. anti-ideal $(25,37 ; 17,16)$ : Máximo coste en amortizaciónmantenimiento-energía ( $€ / \mathrm{m}^{2}$.año) y en emisiones $\mathrm{CO}_{2}\left(\mathrm{Kg} / \mathrm{m}^{2}\right.$.año).

La representación gráfica de los pares de puntos posibles aparece en la figura 6.4 a continuación:

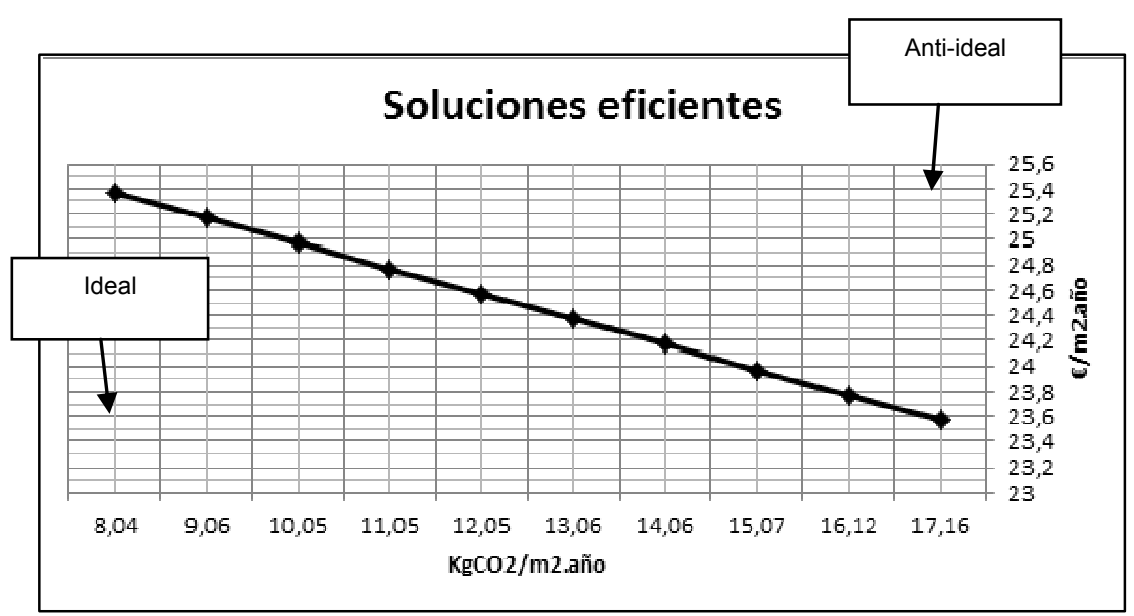

Figura 6.4.- Representación puntos ideal y anti-ideal. Curva eficiente para la zona $\mathrm{A} 3$

En la figura 6.4 aparece representado en el eje de ordenadas la calidad (euros $/ \mathrm{m}^{2}$ ) de la combinación de viviendas y en el eje de abscisas la cantidad de liberación de $\mathrm{CO}_{2}\left(\mathrm{Kg} / \mathrm{m}^{2}\right)$ para cada 
combinación de viviendas. Un mayor coste de la combinación de distintas clases de viviendas es equivalente a una mayor calidad constructiva de la combinación de viviendas, la cual vienen medida en euros $/ \mathrm{m}^{2}$. Y por otro lado, a medida que disminuye la calidad aumenta el nivel de contaminación, de forma que calidad constructiva y contaminación están en conflicto.

Próximos al origen de coordenadas se recogen los valores ideales $u$ óptimos $(23,57 ; 8,04)$, y en los extremos de cada eje los anti-ideales o valores anti-ideales $(25,37 ; 17,16)$. A partir del conjunto de soluciones eficientes o curva eficiente es posible obtener la curva de transformación o relación técnica de sustitución: $\mathrm{T}\left(\mathrm{C}, \mathrm{CO}_{2}\right)=\mathrm{K}$, por medio de un ajuste mínimo cuadrático, tal como:

$$
\mathrm{C}=27,034-0,21 * \mathrm{CO}_{2}+0,000493 * \mathrm{CO}_{2}{ }^{2}
$$

Se trata prácticamente de una línea recta debido a que el coeficiente de la variable $\mathrm{CO}_{2}$ al cuadrado tiene un valor muy próximo a cero, aunque sí se considera al ser significativo, como se observa en la tabla 6.3.

\begin{tabular}{|l|l|}
\hline Variables explicativas & \multicolumn{1}{|c|}{$\mathrm{C}$} \\
\hline $\mathrm{A}$ & 27,034 \\
& $(0,018)^{\star}$ \\
\hline $\mathrm{CO}_{2}$ & $-0,210$ \\
& $(0,003)^{\star}$ \\
\hline $\mathrm{CO}_{2}{ }^{2}$ & 0,0000493 \\
& $(0,000117)^{\star *}$ \\
\hline $\mathrm{R}^{2}$ ajustado & 1,000 \\
\hline $\mathrm{F}$ & $(216957,571)^{*}$ \\
\hline
\end{tabular}

Tabla 6.3.- Curva de transformación (** significativo al 0,01 ; ${ }^{*}$ significativo al 0,05). Fuente: elaboración propia a partir de SPSS. 
El paso siguiente sería determinar los pesos de cada objetivo. Según se valore más obtener los menores de costes de amortización, energía y mantenimiento (peor calidad de viviendas) o la mínima emisión de $\mathrm{CO}_{2}$, el punto óptimo se desplazará a lo largo de la curva de transformación, a la derecha o a la izquierda, respectivamente.

El valor de $\mathrm{R}$ (coste total de los recursos) tal que resulte inferior al valor sombra, según la expresión [30], se ha obtenido dando posibles valores a $\mathrm{R}$, y comprobando que los valores obtenidos satisfacen dicha expresión, siendo el mayor valor posible de 22,5.

A continuación se obtienen los pesos de acuerdo a la expresión [31], ya que en este caso los valores anti-ideales no son nulos:

$$
\begin{aligned}
& w_{1}=\frac{22,5}{(23,57-25,37) *\left(1+\frac{25,37}{23,57-25,37}+\frac{17,16}{8,04-17,16}\right)}=0,835 ; \\
& w_{2}=\frac{22,5}{(8,04-17,16) *\left(1+\frac{25,37}{23,57-25,37}+\frac{17,16}{8,04-17,16}\right)}=0,165 ;
\end{aligned}
$$

Por tanto, se obtienen unos pesos de $83,5 \%$ y $16,5 \%$, para la calidad y para la emisión de $\mathrm{CO}_{2}$, respectivamente.

De acuerdo a esos valores se minimizan las distancias respecto a los valores ideales, para las métricas $L_{1}$ y $L_{\infty}$ :

Para la métrica $\pi=1$, sustituyendo en la expresión [26]: 
$\operatorname{MinL}_{1}=0,835 * C+0,165 * C O 2$

s.a.: $C=27,034-0,21 * C O 2+0,000493 *(C O 2)^{\wedge} 2$

Se obtiene el punto (C, CO2): $(24,38 ; 13,01)$

Para la métrica $\pi=\infty$, sustituyendo en la expresión [27]:

$0,835 *[23,57-C]=0,165 *[8,04-C O 2]$

s.a. : $C=027,034-0,21 * C O 2+0,000493 *(C O 2)^{\wedge} 2$

Se obtiene el punto (C; CO2): $(25,26 ; 8,62)$

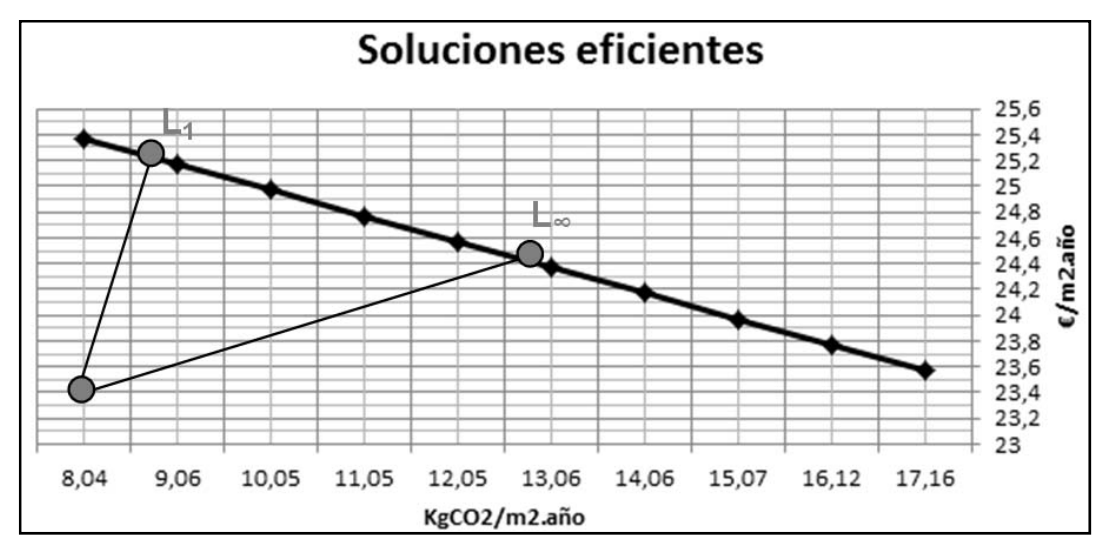

Figura 6.5.- Representación soluciones eficientes de la curva de transformación, comprendidas entre las soluciones de las métricas $L_{1}$ y $L_{\infty}$

De esta manera, el promotor podría tomar su decisión entre un rango de valores más estrecho que el planteado en la matriz de pagos original y decidir finalmente la parte del presupuesto que destinaría a la construcción de viviendas de cada calificación energética.

De acuerdo a la matriz de pagos, el rango de valores sería el que se recoge en la tabla 6.4 : 


\begin{tabular}{|l|l|l|l|l|l|l|}
\hline & $\mathrm{Z}_{1}(\mathrm{x})$ & $\mathrm{Z}_{2}(\mathrm{x})$ & $\mathrm{X}_{\mathrm{A}}$ & $\mathrm{X}_{\mathrm{B}}$ & $\mathrm{X}_{\mathrm{C}}$ & $\mathrm{X}_{\mathrm{D}}$ \\
\hline $\mathrm{L}_{\infty}$ & 24,38 & 13,01 & 0,41 & 0,10 & 0,10 & 0,39 \\
\hline & 24,57 & 12,05 & 0,46 & 0,10 & 0,10 & 0,34 \\
\hline & 24,77 & 11,05 & 0,50 & 0,12 & 0,10 & 0,28 \\
\hline & 24,97 & 10,05 & 0,50 & 0,18 & 0,10 & 0,22 \\
\hline $\mathrm{L}_{1}$ & 25,26 & 8,62 & 0,50 & 0,27 & 0,10 & 0,13 \\
\hline
\end{tabular}

Tabla 6.4.- Soluciones eficientes acotadas por medio de las distancias

El proceso se realiza para cada una de las zonas climáticas, siguiendo los mismos pasos que los realizados para la zona A3. En la tabla 6.5 , se recogen los resultados. Las dos primeras columnas muestran los puntos ideal y anti-ideal en cada zona, referidos a los costes económicos o privados. Las columnas 3 y 4 recogen los valores ancla y anti-ideal para los costes ambientales o sociales, referidos a las emisiones de $\mathrm{CO}_{2}$ anuales por metro cuadrado construido.

\begin{tabular}{|l|l|l|l|l|}
\hline & \multicolumn{2}{|l|}{ Coste económico } & \multicolumn{2}{l|}{ Coste ambiental } \\
\hline zona & $Z_{1}^{*}(x)$ & $Z_{1^{*}}(x)$ & $Z_{2}^{*}(x)$ & $Z_{2^{*}}(x)$ \\
\hline A3 & 23,57 & 25,37 & 8,04 & 17,16 \\
\hline A4 & 23,87 & 26,35 & 8,17 & 16,67 \\
\hline B3 & 24,11 & 25,87 & 8,92 & 19,90 \\
\hline B4 & 24,17 & 26,18 & 12,44 & 23,01 \\
\hline C1 & 26,69 & 27,79 & 11,26 & 24,26 \\
\hline C2 & 26,64 & 28,06 & 12,22 & 24,26 \\
\hline C3 & 26,03 & 27,13 & 16,28 & 27,96 \\
\hline C4 & 23,88 & 24,23 & 14,37 & 20,02 \\
\hline D1 & 27,93 & 30,23 & 17,38 & 37,09 \\
\hline D2 & 28,00 & 29,51 & 17,13 & 35,25 \\
\hline D3 & 28,27 & 29,75 & 16,79 & 29,47 \\
\hline E1 & 28,10 & 28,60 & 19,59 & 27,22 \\
\hline
\end{tabular}

Tabla 6.5.- Valores ideal y anti-ideal por cada zona climática 
Se comprueba cómo las zonas más cálidas tienen, en general, unos menores costes económicos y ambientales que las zonas más frías.

A continuación, con los pares de valores intermedios entre los ancla y anti-ideal obtenidos $\left(Z_{2^{*}}, Z_{1}{ }^{*}\right)$ y $\left(Z_{1^{*}}, Z_{2}{ }^{*}\right)$, se calcula las curva de transformación en cada zona climática, aplicando regresión lineal por mínimos cuadrados. Los modelos son los mostrados en la tabla 6.6:

\begin{tabular}{|c|c|}
\hline zona & Curva de transformación $\mathrm{T}\left(\mathrm{C}, \mathrm{CO}_{2}\right)=\mathrm{K}$ \\
\hline A3 & $\mathrm{C}=27,034-0,21{ }^{*} \mathrm{CO}_{2}+0,000493{ }^{*} \mathrm{CO}_{2}{ }^{2}$ \\
\hline A4 & $\mathrm{C}=29,811-0,49{ }^{*} \mathrm{CO}_{2}+0,008048{ }^{*} \mathrm{CO}_{2}{ }^{2}$ \\
\hline B3 & $\mathrm{C}=27,664-0,23{ }^{*} \mathrm{CO}_{2}+0,002713^{*} \mathrm{CO}_{2}{ }^{2}$ \\
\hline B4 & $\mathrm{C}=29,803-0,36{ }^{*} \mathrm{CO}_{2}+0,004886^{*} \mathrm{CO}_{2}{ }^{2}$ \\
\hline C1 & $\mathrm{C}=28,882-0,1063{ }^{*} \mathrm{CO}_{2}+0,00064{ }^{*} \mathrm{CO}_{2}{ }^{2}$ \\
\hline C2 & $\mathrm{C}=31,455-0,38{ }^{*} \mathrm{CO}_{2}+0,007383^{*} \mathrm{CO}_{2}{ }^{2}$ \\
\hline C3 & $\mathrm{C}=29,083-0,14{ }^{*} \mathrm{CO}_{2}+0,000919^{*} \mathrm{CO}_{2}{ }^{2}$ \\
\hline C4 & $\mathrm{C}=27,455-0,34{ }^{*} \mathrm{CO}_{2}+0,008031^{*} \mathrm{CO}_{2}{ }^{2}$ \\
\hline D1 & $\mathrm{C}=33,736-0,25{ }^{*} \mathrm{CO}_{2}+0,002432{ }^{*} \mathrm{CO}_{2}{ }^{2}$ \\
\hline D2 & $\mathrm{C}=33,293-0,29{ }^{*} \mathrm{CO}_{2}+0,004124{ }^{*} \mathrm{CO}_{2}{ }^{2}$ \\
\hline D3 & $\mathrm{C}=34,138-0,35{ }^{*} \mathrm{CO}_{2}+0,004995^{*} \mathrm{CO}_{2}{ }^{2}$ \\
\hline E1 & $\mathrm{C}=30,892-0,16{ }^{*} \mathrm{CO}_{2}+0,001991{ }^{*} \mathrm{CO}_{2}{ }^{2}$ \\
\hline
\end{tabular}

Tabla 6.6.- Curvas de transformación en cada zona climática

El valor de $\mathrm{R}$ (coste total de los recursos) tal que resulte inferior al valor sombra, según la expresión [27]. A continuación se obtienen los 
pesos de acuerdo a la expresión [28], ya que en este caso los valores anti-ideales no son nulos.

Los valores por zonas climáticas se muestran en la tabla 6.7. Se observa cómo los mayores pesos medioambientales se dan, generalmente, en las zonas más cálidas, y los menores en las zonas más frías:

\begin{tabular}{|l|c|c|c|}
\hline zona & $\mathrm{R}$ & $\mathrm{W}_{1}$ & $\mathrm{~W}_{2}$ \\
\hline A3 & 22,5 & 0,835 & 0,165 \\
\hline A4 & 22,2 & 0,782 & 0,219 \\
\hline B3 & 23,5 & 0,870 & 0,130 \\
\hline B4 & 24,0 & 0,855 & 0,145 \\
\hline C1 & 26,5 & 0,920 & 0,080 \\
\hline C2 & 26,4 & 0,923 & 0,077 \\
\hline C3 & 26,2 & 0,914 & 0,086 \\
\hline C4 & 23,7 & 0,965 & 0,035 \\
\hline D1 & 28,7 & 0,895 & 0,105 \\
\hline D2 & 28,5 & 0,940 & 0,06 \\
\hline D3 & 28,2 & 0,895 & 0,105 \\
\hline E1 & 28,0 & 0,940 & 0,06 \\
\hline
\end{tabular}

Tabla 6.7.- Valor de $\mathrm{R}$ y pesos asignados a cada criterio

De acuerdo a los pesos obtenidos se minimizan las distancias, para las métricas $L_{1}$ y $L_{\infty}$, como ya se viera en las expresiones [23] y [24].

Estos valores se recogen en la tabla 6.8:

La primera columna indica la zona climática. Para cada zona se muestran, en la tercera columna, los puntos $(\mathrm{C}, \mathrm{CO} 2)$, para la métrica $\pi=1$ y para la métrica $\pi=\infty$, separadas en filas diferentes dentro de la misma zona climática. En el resto de columnas, a la derecha de la 
tabla, se recogen los porcentajes de viviendas de cada calificación energética que correspondería a los valores obtenidos para las métricas aplicadas:

\begin{tabular}{|c|c|c|c|c|c|c|c|}
\hline Zonas & Métrica & $(\mathrm{C}, \mathrm{CO} 2)$ & $\mathrm{X}_{\mathrm{A}}$ & $X_{B}$ & $\mathrm{X}_{\mathrm{C}}$ & $X_{D}$ & $X_{E}$ \\
\hline \multirow{2}{*}{ A3 } & $\mathrm{L}_{1}$ & $(24,38 ; 13,01)$ & 41 & 10 & 10 & 39 & \\
\hline & $\mathrm{L}_{\infty}$ & $(25,26 ; 8,62)$ & 50 & 27 & 10 & 13 & \\
\hline \multirow{2}{*}{ A4 } & $\overline{L_{1}}$ & $\overline{(24,78 ; 13,07)}$ & 20 & 10 & 50 & 20 & \\
\hline & $\mathrm{L}_{\infty}$ & $(26,08 ; 8,93)$ & 50 & 18 & 22 & 10 & \\
\hline \multirow{2}{*}{ B3 } & $\overline{L_{1}}$ & $(24,85 ; 14,85)$ & 10 & $\overline{444}$ & 10 & 36 & \\
\hline & $\mathrm{L}_{\infty}$ & $(25,72 ; 9,52)$ & 29 & 50 & 11 & 10 & \\
\hline \multirow{2}{*}{ B4 } & $\overline{\mathrm{L}_{1}}$ & $(24,64 ; 19,49)$ & 10 & 10 & 38 & 10 & 32 \\
\hline & $\mathrm{L}_{\infty}$ & $(25,88 ; 13,32)$ & 25 & 45 & 10 & 10 & 10 \\
\hline \multirow{2}{*}{ C1 } & $\mathrm{L}_{1}$ & $(27,44 ; 14,84)$ & 19 & 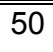 & 10 & 10 & 11 \\
\hline & $\mathrm{L}_{\infty}$ & $(27,73 ; 11,70)$ & 46 & 24 & 10 & 10 & 10 \\
\hline \multirow{2}{*}{ C2 } & $\overline{\mathrm{L}_{1}}$ & 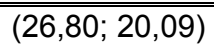 & 10 & 28 & 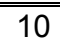 & 10 & 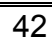 \\
\hline & $\mathrm{L}_{\infty}$ & $(27,81 ; 12,76)$ & 37 & 33 & 10 & 10 & 10 \\
\hline \multirow{2}{*}{ C3 } & $\mathrm{L}_{1}$ & $(26,16 ; 24,98)$ & 111 & & 50 & 39 & \\
\hline & $\mathrm{L}_{\infty}$ & $(26,81 ; 16,88)$ & 35 & & 50 & 15 & \\
\hline \multirow{2}{*}{ C4 } & $\mathrm{L}_{1}$ & $\overline{(23,90 ; 18,91)}$ & 444 & & 10 & 446 & \\
\hline & $\mathrm{L}_{\infty}$ & $(24,21 ; 14,57)$ & 50 & & 38 & 12 & \\
\hline \multirow{2}{*}{ D1 } & $\overline{\mathrm{L}_{1}}$ & $(28,73 ; 27,28)$ & 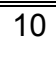 & $\overline{433}$ & $\overline{c 10}$ & $\overline{110}$ & 27 \\
\hline & $\mathrm{L}_{\infty}$ & $(29,92 ; 18,62)$ & 40 & 30 & 10 & 10 & 10 \\
\hline \multirow{2}{*}{ D2 } & $\overline{\mathrm{L}_{1}}$ & $\overline{(28,00 ; 27,42)}$ & 10 & 12 & 10 & 18 & 50 \\
\hline & $\mathrm{L}_{\infty}$ & $(29,41 ; 17,99)$ & 48 & 22 & 10 & 10 & 10 \\
\hline \multirow{2}{*}{ D3 } & $\overline{\mathrm{L}_{1}}$ & $\overline{(28,70 ; 23,26)}$ & 37 & & 13 & 50 & \\
\hline & $L_{\infty}$ & $(29,54 ; 17,54)$ & 50 & & 30 & 20 & \\
\hline \multirow{2}{*}{ E1 } & $\overline{\mathrm{L}_{1}}$ & $(28,19 ; 24,15)$ & $\overline{c 16}$ & 50 & 24 & $\overline{c 10}$ & \\
\hline & $\mathrm{L}_{\infty}$ & $(28,50 ; 19,86)$ & 33 & 47 & 10 & 10 & \\
\hline
\end{tabular}


Tabla 6.8.- Valor de los puntos (C, CO2) para las métricas $L_{1}$ y $L_{\infty}$ y porcentajes correspondientes para cada tipo de vivienda de acuerdo a su calificación energética

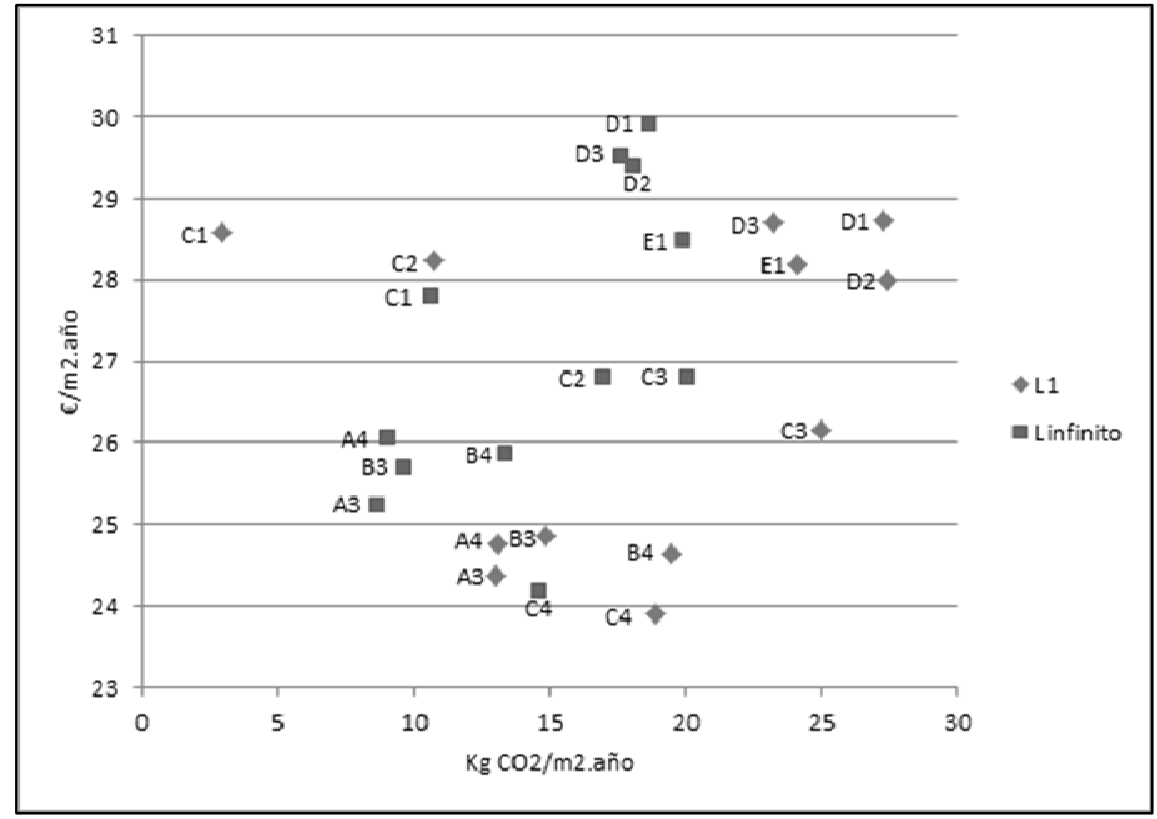

Figura 6.6.- Valor de los puntos $(C, C O 2)$ para las métricas $L_{1}$ y $L_{\infty}$

De la tabla 6.8 y de la figura 6.6 se puede concluir:

Los resultados obtenidos de la aplicación de la métrica $\pi=1$, da resultados más favorables hacia el punto de vista económico. Por el contrario, los resultados de aplicar la métrica $\pi=\infty$ son más favorables desde el punto de vista medioambiental.

Como se ha comentado anteriormente, $L_{1}$ corresponde a una situación en que se maximiza la suma ponderada de los logros de cada objetivo, lo cual puede ser equivalente a un punto de máxima 
eficiencia. Por otro lado, en $L_{\infty}$, se trata de una elección equilibrada entre los distintos objetivos, motivo por el cual el objetivo medioambiental se ve favorecido.

Cabe destacar el hecho de que la diferencia entre el componente $\mathrm{C}$ obtenido por ambas métricas es muy pequeña, mientras que se pueden obtener reducciones importantes en emisiones con ese incremento de los costes de la calidad. Esto también queda de manifiesto en la figura 6.6, donde comparando calificaciones energéticas iguales, vemos que las diferencias son mayores en el eje de abscisas que en el de ordenadas.

En los casos $L_{\infty}$, se aumenta el porcentaje de las viviendas con mejores calificaciones, lo cual puede ser interesante, dada la tendencia que previsiblemente tendrá el mercado, a la vista de lo que ya se indica en la directiva 2010/31/UE, (modificación de la directiva 2002/91/UE), donde se indica que los Estados miembros se asegurarán de que a más tardar el 31 de Diciembre de 2020, todos los edificios nuevos sean edificios de consumo de energía casi nulo.

La transposición de esta Directiva por parte de los Estados Miembros, debe ser efectiva en un periodo de tiempo corto, para algunos artículos en 2012 y para otros en 2013 y en algún caso 2015. Por tanto, desde el punto de vista del promotor, cada vez más será interesante optar por calificaciones más eficientes desde el punto de vista energético. 



\section{CAPÍTULO VII CONCLUSIONESY DISCUSIÓN}



En este capítulo final de la Tesis se resumen las conclusiones más importantes y su discusión, resaltando sus principales aportaciones originales y las posibles líneas de investigación futuras

\section{VII.1.- CONCLUSIONES Y DISCUSIÓN}

Se pueden extraer varias conclusiones como las más relevantes a partir de la realización de esta Tesis. Al tratarse de un estudio multidisciplinar en el que se han tenido en cuenta consideraciones arquitectónicas, medioambientales y económicas y la relación entre ellas, se divide el presente apartado en varios subapartados, en los que se resumen las conclusiones y se realiza una discusión crítica de las mismas.

A modo de resumen los contenidos de los subapartados son:

1.- Análisis de las medidas para mejorar la EE del edificio, y del coste de implementar dichas medidas para determinar su costo-eficiencia.

2.- Análisis de los software Lider v.01 y Calener VYP v.01, únicas herramientas oficiales en España en estos momentos, para poder certificar energéticamente viviendas de nueva construcción por la opción general. De este análisis, se proponen una serie de recomendaciones para que estas herramientas sean más útiles y ayuden de una manera más efectiva al diseño de edificios energéticamente eficientes.

3.- Discusión de los resultados de costes obtenidos en función de las calificaciones energéticas. Con ello se consigue relacionar el valor de la vivienda con su calificación energética.

4.- Propuesta de utilización de técnicas multicriterio aplicadas a edificación. Esto responde a la necesidad de obtener soluciones compromiso entre criterios económicos y criterios medioambientales, como consecuencia de la 
importancia que va adquiriendo el factor medioambiental, hasta ahora prácticamente olvidado en este sector

\section{VII.1.1.- Análisis de las medidas de mejora de la EE y su costo-eficiencia} En el apartado III.3 de esta Tesis, previamente a la obtención de las calificaciones energéticas por zona climática, se estudiaron aisladamente distintas variables que influían en la EE. Si se analiza la eficiencia de dichas variables en la reducción de emisiones, de acuerdo a su coste económico, se puede concluir su costo-eficiencia, que es de mayor a menor:

1.- Material aislante

2.- Uso de radiadores y calderas de gas natural (frente al uso de energía eléctrica)

3.- Aumento de espesor de acristalamientos

4.- Distintos tipos de calderas de gas natural: de baja temperatura, seguida de caldera condensación y por último caldera estándar.

5.- Carpinterías de madera

6.- Calderas de biomasa

El aumento de espesor de los aislamientos, lo cual implica actuar a nivel de la envolvente térmica, es significativamente más costo-eficiente que el resto de medidas, es decir, con un bajo coste de inversión, se consiguen reducciones importantes de emisiones de $\mathrm{CO}_{2}$. El único inconveniente a considerar cuando se implemente esta medida es si dicho aumento de espesor influye en la disminución de superficie útil de la vivienda.

Por el contrario, la menor costo-eficiencia, con diferencia se obtiene con el uso de la caldera de biomasa, debido a su elevado coste de inversión, no sólo de la caldera en sí, sino también porque su utilización requiere un silo de almacenamiento de combustible. La medida caldera de biomasa es la única que permite alcanzar las mejores calificaciones energéticas, es decir, clase $\mathrm{A}$. 
La efectividad de esta medida es muy alta en zonas frías, con bajos requerimientos de refrigeración, pero generalmente no es suficiente y requiere de medidas adicionales en zonas cálidas.

Esta solución tiene varios inconvenientes, independientemente de su coste, que pueden dificultar su uso. En primer lugar un requerimiento de espacio para construcción del silo de almacenamiento de pellets. No todas las viviendas disponen de suficiente superficie para ello. Habría además que replantearse la medida cuando se trate de edificios plurifamiliares. Por otro lado, habría que tener en cuenta al elegir un combustible, la seguridad en el suministro. Al realizar el estudio de costes, se constató la poca información existente en España, con sólo unas pocas empresas comercializadoras de combustible. Habría que plantearse qué ocurriría en el caso de generalizarse el uso de este tipo de calderas. Quizás sería necesario la importación de combustible de otros países, lo cual, si incrementamos las emisiones derivadas del transporte del material, haría desaconsejable la medida

El uso de biomasa no es, por tanto, la panacea para la obtención de altas calificaciones energéticas. El programa Calener VYP considera que el uso de biomasa emite cero $\mathrm{Kg}$ de $\mathrm{CO}_{2}$, al considerarlo combustible neutral, es decir, que emite la cantidad de $\mathrm{CO}_{2}$ que absorbió durante su vida como árbol. Sin embargo, supone generalmente un aumento del consumo de energía.

Por otro lado, la implementación de medidas varía en función de la zona climática considerada. En general, en la mejora de la EE, existe mayor cantidad de medidas efectivas a implementar en zonas frías, con altas demandas de calefacción, que en zonas cálidas, donde el problema es la alta demanda de refrigeración. Esto es probablemente debido al mayor desarrollo de tecnologías y materiales para aumentar la EE en países fríos.

Cuando las medidas que ofrece el mercado no son suficientes o bien suponen un aumento del coste económico, se pone de manifiesto la importancia de la 
fase de diseño en la EE del edificio. Algunas medidas, como son la orientación del edificio, o el diseño de los huecos en función de dicha orientación, posibilitan mejoras importantes a costo cero, que hay que tener en cuenta antes que otras medidas.

\section{VII.1.2.- Análisis de las herramientas de certificación energética en España}

Se ha visto que la opción general, por medio del uso de Lider y Calener es la única forma de alcanzar las mejores calificaciones energéticas $A, B$ y $C$; y desde un punto de vista medioambiental, lo deseable es optar a mejores calificaciones. Debe tenerse además en cuenta que la última directiva europea EPBD de 2010, ya indica que los edificios para 2020 deben tener un consumo casi nulo, lo cual debería corresponderse con viviendas muy eficientes energéticamente.

Las herramientas actualmente disponibles, presentan un elevado grado de complejidad en su manejo que no facilita su uso. Entre otras cosas, cabe destacar:

1.- Calener requiere el uso previo de la herramienta Lider. Esta herramienta no dispone de funciones tan básicas como es el comando "deshacer", lo cual obliga a definir un sistema tan complejo como es un edificio, sin admitir la posibilidad de cometer algún error en el proceso. En la práctica, se traduce en muchos casos, en tener que repetir varias veces el proceso de introducción de datos hasta conseguir realizarlo sin errores, lo cual resulta tedioso y "desesperante" para el proyectista.

2.- La herramienta Lider no permite modelizar distintas soluciones constructivas, como las fachadas ventiladas o muros Trombé, aconsejables desde el punto de vista medioambiental en muchos casos. 
3.- El manejo del programa Calener exige introducir al inicio del programa una serie de datos, de difícil comprensión para el usuario medio, no especializado en instalaciones, probablemente debido a que ha sido desarrollado por ingenieros industriales. Esto favorece el uso de la opción simplificada para evitar la complejidad en el uso de la opción general, lo cual implica que no se puedan conseguir calificaciones mejores que la $\mathrm{D}$.

4.- En Calener VYP, deberían mejorarse los algoritmos de cálculo para algunas soluciones: por ejemplo, no simula bien el comportamiento de suelos radiantes. El manual de uso de Calener permite introducir un suelo radiante, exactamente igual que una calefacción por radiadores, simplemente disminuyendo la temperatura de impulsión del agua. El método no parece muy adecuado y de hecho los resultados obtenidos no son muy distintos a los obtenidos con emisores térmicos tipo radiadores. Consultas realizadas a Miyabi, consultora energética, desaconsejan el cálculo de suelos radiantes por medio de Calener, y proponen programas alternativos como Energy Plus. El programa no tiene en consideración aspectos como la mayor superficie de radiación o la inercia térmica del pavimento frente a la de los radiadores.

5.-Favorece excesivamente algunas medidas, como el uso de calderas de biomasa, sin tener en cuenta los inconvenientes de este sistema ni el hecho de que su uso implique un aumento en el consumo energético. Por contra, no considera la introducción de medidas pasivas de refrigeración basadas en la circulación del aire. Además no permite diferenciar regímenes distintos de renovación de aire, para periodos de invierno y de verano, cuando lógicamente el uso normal de la vivienda, conlleva un distinto régimen de apertura de ventanas en esos dos periodos. Esto sería válido en países fríos, pero no es adecuado para el caso de España.

6.- Por último, hay que destacar una característica que sería ampliamente recomendable en próximas versiones del programa. Se trata de la no implementación en el programa del indicador energía primaria anual, en el 
proceso de certificación energética. Este factor es vital para realizar un buen análisis de costes que implique ahorros del consumo energético en viviendas de mejor clase energética.

Tal y como se ha comentado en el apartado III.2.2, la metodología que figura en el documento "Escala de calificación energética. Edificios de nueva construcción" del Instituto para la Diversificación y Ahorro de la energía, Ministerio de Industria, Turismo y Comercio [AICIA 2009a], indica que hay dos indicadores para otorgar la calificación. Por un lado, las emisiones de $\mathrm{CO}_{2}$ en Kg/año y, por otro, el consumo de energía primaria, en kWh/año.

El programa Calener VYP calcula ambos indicadores, pero solamente tiene en cuenta en la calificación las emisiones de $\mathrm{Kg}$ de $\mathrm{CO}_{2}$, como queda de manifiesto en el presente trabajo. Es decir, al otorgar la calificación se atiende solamente a los límites de la tabla 3.9 , lo cual se comprueba en las simulaciones realizadas en la tabla 4.18. Sin embargo, no se tiene en cuenta el indicador consumo de energía, de acuerdo a la tabla 3.10, como queda de manifiesto en la tabla 4.13 .

Por lo tanto, se puede concluir que el indicador $\mathrm{kg} \mathrm{CO}_{2}$ por $\mathrm{m}^{2}$ es el único implementado en la herramienta.

La principal consecuencia de este aspecto es que una mejor clase energética no siempre implica un coste de consumo de energía menor; es decir, una clase mejor puede suponer un mayor consumo y, por tanto, desde el punto de vista energético, no siempre es más interesante.

Se puede concluir que Calener VYP v1.0 no es una herramienta apropiada para alcanzar mejoras de eficiencia energética, que consideren el consumo de energía de la vivienda, máxime si se tiene en cuenta su larga vida útil. En cualquier caso, el programa debería incluir el consumo de energía primaria anual como indicador. 


\section{VII.1.3.- Análisis de costes en relación a la calificación energética}

En la situación actual vemos que una vivienda mejor desde el punto de vista de su EE, supone el empleo de mejores materiales de construcción, y por tanto, un mayor coste de inversión inicial.

En el modelo de costes de construcción o inversión, las variables de calificación energética C, B y A explican alrededor de un $40 \%$ del coste, pero la zona no resulta significativa en el modelo. Como mínimo la inversión a realizar por metro cuadrado para construir una vivienda similar a la estudiada, con una calificación $\mathrm{D}$ ○ $\mathrm{E}$, es de unos $685 € / \mathrm{m}^{2}$. Al mejorar la clase energética este valor se incrementa en, aproximadamente, 50,89 y $91 € / \mathrm{m}^{2}$, según sea la vivienda de la clase $\mathrm{C}, \mathrm{B}$ o $\mathrm{A}$, respectivamente.

También se han obtenido modelos de costes de amortización, mantenimiento y energía por el uso de la vivienda, con los cuales se explica cerca del $77 \%, 49 \%$ y $79 \%$ del coste, respectivamente La variable temperatura, relacionada con la zona climática, resulta ser significativa en todos los casos, y las calificaciones C, B y A sólo en los modelos de costes de amortización y de costes de energía.

Del modelo de costes de amortización se deduce que el coste de partida para una vivienda $D$ o $E$, sería de unos 9,4 euros $/ \mathrm{m}^{2}$, que se incrementaría en 0,082 euros $/ \mathrm{m}^{2}$ por cada grado que aumente la temperatura de la zona. Al mejorar la calificación energética de la vivienda, dicho coste aumenta aproximadamente en $1,34,2,40$ ó 3,26 euros $/ \mathrm{m}^{2}$ según sea la calificación $\mathrm{C}, \mathrm{B}$ ○ $\mathrm{A}$ respectivamente.

En el modelo de costes de mantenimiento, se parte de un coste inicial de 16,93 euros $/ \mathrm{m}^{2}$, que disminuye en 0,381 euros $/ \mathrm{m}^{2}$ por cada grado que aumente la temperatura en la zona. 
En el modelo de coste de la energía, todas las variables presentan un coeficiente negativo, lo cual indica que, en general, el coste del consumo energético disminuye en zonas más cálidas y con mejores calificaciones.

Con los datos obtenidos, se observa cómo la disminución de los costes de energía al mejorar la clase energética, no se compensan con el aumento de los costes de construcción, y en consecuencia, amortización; con lo cual, el ahorro de energía no es un motivo suficiente para promover viviendas más eficientes desde un punto de vista medioambiental, y que en algunos casos puede llegar a suponer un incremento de los costes.

Por lo tanto, para promover viviendas más eficientes o sostenibles, hay que considerar no solo los costes privados, sino también los costes públicos en los que se incurre al emitir $\mathrm{CO}_{2}$, de más difícil cuantificación. Este último coste claramente disminuye al aumentar la clase energética, al ser los $\mathrm{Kg}$ de $\mathrm{CO}_{2}$ el indicador que Calener VYP utiliza al otorgar la clase energética. Este coste podría implementarse en forma de tasa para promover la EE, como se vio en el capítulo IV. Esta medida ya ha sido utilizada en otros países como Finlandia, Noruega, Dinamarca y Suecia que introdujeron unas tasas de carbono en los años 1990, 1991, 1992 y 1996, respectivamente. Distintos estudios revelan una reducción en las emisiones del $3 \%$ y $7 \%$ en Noruega y Suecia, respectivamente, y un $10 \%$ de reducción del consumo energético en Dinamarca [Dresner and Ekins, 2006].

Al analizar el conjunto de todos los costes privados considerados durante los 100 años de vida útil del edificio, el orden de magnitud del coste de la energia es muy bajo respecto a aquellos a los que deberían compensar (amortización y mantenimiento). No existen por tanto criterios que permitan defender la promoción de viviendas eficientes energéticamente en las condiciones actuales.

El estudio calcula el precio umbral de $\mathrm{CO}_{2}$, en forma de tasa medioambiental, que haría rentable el cambio a calificaciones energéticas mejores. Para ello, se 
ha realizado el estudio económico mediante el análisis de costes, tomando los valores de costes individuales de todas las configuraciones y los valores medios obtenidos con los modelos de costes. También se ha realizado el estudio económico mediante el anàlisis de inversiones para una vida útil del edificio de 100 años.. Las conclusiones han sido:

1.- El análisis de inversiones, más realista que el análisis de costes puesto que tiene en cuenta la localización de los pagos durante la vida útil del inmueble y el interés del dinero, obtiene precios umbral generalmente más bajos que el análisis de costes, con precios medios de 167 y $231 € / \mathrm{tCO}_{2}$, respectivamente. También, el rango de valores es menor en el análisis de inversiones y los valores anómalos no son tan elevados como en el análisis de costes.

2.- De acuerdo a los modelos de costes desarrollados, el precio umbral de $\mathrm{CO}_{2}$, es decir, aquél a partir del cual sería rentable cambiar a una mejor calificación energética, se va incrementando conforme se va mejorando en la escala de calificación, siendo de 49, 56 y 155 Euros/tCO ${ }_{2}$, para el cambio de calificación energética $D$ a $C, C$ a $B$ y $B$ a $A$, respectivamente. Lo cual, para una vivienda de tipología similar a la simulada, de $270 \mathrm{~m}^{2}$ supone un coste anual de 158 , 124 y 360 euros respectivamente, de media en España. Los modelos de costes se recogen en la tabla 5.5 .

3.- En comparación con los valores obtenidos de la literatura, los precios umbral de $\mathrm{CO}_{2}$ estimados, desde todas las perspectivas analizadas, están dentro del rango de valores estimados por los distintos autores (tabla 4.20).

Puede concluirse, que en las circunstancias actuales, con los precios de la construcción y de la energía, no es rentable cambiar de una calificación energética dada a otra mejor. 


\section{VII.1.4.- Aplicación de técnicas multicriterio a edificación}

El sector de la construcción ha tenido tradicionalmente una fuerte impacto en el medioambiente. No sólo por el proceso de la construcción en sí, sino también por la extracción de materiasy su transformación como elementos constructivos y por el largo periodo de uso de los edificios. La inclusión del factor medioambiental en todos los sectores productivos, implica la necesidad de cambios profundos en la industria de la construcción. Las normativas ya se orientan en esa dirección y además se van endureciendo progresivamente para conseguir las mejoras medioambientales requeridas. Como se ha visto, en las condiciones actuales, los objetivos medioambientales y económicos están claramente contrapuestos.

En este sentido, se propone la aplicación de las técnicas multicriterio con el fin de obtener una solución compromiso que permita optimizar ambos objetivos.

En el capítulo VI se hizo una propuesta que permitía dar respuesta a un posible promotor medio que quisiera diversificar su oferta de viviendas de distintas calificaciones energéticas de manera que, no incurriera en gastos muy elevados y pudiera tener en cuenta el criterio medioambiental, al emitir sus viviendas la menor cantidad de $\mathrm{Kg}$ de $\mathrm{CO}_{2}$ posible.

Los resultados obtenidos de la aplicación de la métrica $\pi=1$, dieron resultados económicamente más favorables, mientras que la métrica $\pi=\infty$ era más conveniente medioambientalmente. El abanico de valores entre ambas métricas, sería el conjunto de soluciones eficientes y sería decisión del promotor qué valores adoptar.

De acuerdo a la tendencia que previsiblemente tendrá el mercado, a la vista de lo que ya se indica en la directiva 2010/31/UE, (modificación de la directiva 2002/91/UE), donde se propone que en el año 2020 todos los edificios nuevos sean edificios de consumo de energía casi nulo, se debe orientar al promotor hacia la construcción de mayores porcentajes de viviendas con altas 240 
calificaciones energéticas. En ese caso, resulta más recomendable la solución obtenida con la métrica $\pi=\infty$. En este caso, los aumentos de costes requeridos no son muy elevados, y sí se obtienen importantes reducciones de emisiones.

\section{VII.2.- APORTACIONES}

El objeto de estudio de la presente Tesis Doctoral es muy novedoso en cuanto a que introduce algunos aspectos no considerados hasta el momento en la literatura científica.

En primer lugar, el análisis se realiza para todas las zonas climáticas que existen en España. Para ello se tienen en cuenta las particularidades de cada zona y los requerimientos específicos en cuanto a soluciones constructivas.

En segundo lugar, el análisis de costes se realiza considerando todas las componentes de costes, al contrario de lo que ocurre en otros estudios analizados en la bibliografía. Así, hay estudios en Europa que consideran únicamente los costes inversión/ahorro energía [Entrop et al., 2010]. Utilizando también Calener y en España, el estudio PRECOST\&E llevado a cabo por la UPM, (Europa Press 07/07/10) en la zona climática D3 (en Madrid) incluye sólo los costes de construcción y consumo de energía, según calificación energética.

En el presente estudio se tienen en cuenta además los costes de mantenimiento, de considerable importancia dada la larga vida útil de los edificios residenciales [Alavedra et al., 1997]. Las labores de mantenimiento planteadas durante la vida útil del edificio se establecen de acuerdo a la documentación existente hasta la fecha del Libro del Edificio, documento que estimamos deberá adquirir gran importacia en un futuro. Se considera que las labores de mantenimiento, se normalizarán en el parque edificatorio español en 
un futuro y que por tanto, es importante su consideración, ya que las labores de prevención son más propias de sociedades desarrolladas.

Se tiene en cuenta además los costes sociales derivados de las emisiones de carbono, como consecuencia del uso de la vivienda, ya que dichas emisiones son las que determinan cuál es la clase energética del edificio. Se realiza una revisión bibliográfica que permita establecer, al menos, un orden de magnitud de este tipo de coste.

Al integrar todos los costes se analiza los valores que deberían tener los costes de, carbono y energía, para que según las condiciones actuales, fuera rentable construir con una mayor clase energética. A este respecto se obtiene, por primera vez en España, un precio umbral del $\mathrm{CO}_{2}$, en forma de tasa medioambiental, que hiciera rentable la inversión en la mejora de la eficiència energética.

Por último, esta Tesis aplica por primera vez en España el análisis multicriterio en el sector de la construcción, para buscar soluciones compromiso entre objetivos contrapuestos, por un lado la disminución de emisiones de $\mathrm{CO}_{2}$ y por otro, la reducción de costes económicos, tratando de optimizar simultáneamente objetivos sociales o públicos, con objetivos económicos o privados. Se obtienen una solución compromiso para cada zona climática.

\section{VII.3.- LÍNEAS DE INVESTIGACIÓN FUTURAS}

En esta Tesis se ha analizado una tipología edificatoria concreta, que es una vivienda unifamiliar tipo adosado. Podría ampliarse el estudio a otras tipologías edificatorias. Sería interesante ampliar el estudio a viviendas en bloque en usos residenciales.

Respecto a las medidas de EE utilizadas, podría emplearse soluciones energéticamente eficientes como el suelo radiante, si bien, debido a las carencias de Calener, habría que utilizar otros programas más adecuados 242 
como el Energy Plus. No resulta aconsejable el uso de la biomasa, tal y como lo considera actualmente la herramienta de simulación. Por lo tanto, para poder alcanzar calificaciones altas, sería necesario profundizar en las medidas de mejora implementadas en la fase de diseño. Por ejemplo, orientación y dimensión de huecos. Más aún, si nos encontráramos en un edificio plurifamiliar, podría ser conveniente, introducir mejoras distintas en función de la situación y orientación de la vivienda en el edificio, lo cual supone una mayor complicación a nivel del diseño.

El estudio realizado se ha ceñido a edificios residenciales. Podría realizarse análogamente para edificios comerciales, mediante la herramienta Calener GT, si bien en este caso tendría una mayor complejidad a nivel de instalaciones.

Por otro lado, sólo se han analizado edificios de nueva construcción, dado que actualmente, la normativa y procedimientos para edificios existentes no está totalmente desarrollada. Sin embargo, dado el parque edificatorio español, y dada la situación actual del sector de la construcción, la rehabilitación energética de edificios parece constituir una vía de negocio importante en un futuro próximo. Es por tanto, un línea de investigación a considerar muy importante.

Este trabajo se ha centrado en el periodo operacional o de uso del edificio, abarcando desde la finalización de su construcción hasta el final de su vida útil. La fase considerada es la de mayor impacto ambiental y la única que es necesario tener en cuenta de acuerdo al objetivo de la Tesis. Sin embargo, otra posible línea de investigación se basaría en la evaluación de impactos ambientales, teniendo en cuenta el Análisis del Ciclo de Vida (ACV). Este método es el más adecuado, por consenso de la comunidad científica, para evaluar el impacto ambiental. Incluye los impactos en las fases de:

- Extracción, transporte y procesado de materias primas para obtener productos para la construcción 
CAPÍTULO VII.- CONCLUSIONES Y DISCUSIÓN

- Construcción del edificio, incluyendo el transporte a obra de los materiales y consumo de energía necesaria

- Fase de ocupación y mantenimiento, con el consumo energético necesario para el uso del edificio

- Demolición con la energía y recursos necesarios para llevarla a cabo. 


\section{BIBLIOGRAFÍA}

Ackermann, F.; Stanton, E.A., (2010), The social cost of carbon. A Report for the Economics for Equity and the Environmental Network.

AICIA (2009a), Escala de calificación energética. Edificios de nueva construcción. Madrid: Instituto para la Diversificación y Ahorro de la energía, Ministerio de Industria, Turismo y Comercio.

AICIA (2009b), Condiciones de aceptación de procedimientos alternativos a Lider y Calener. Madrid: Instituto para la Diversificación y Ahorro de la energía, Ministerio de Industria, Turismo y Comercio.

Alavedra, P.; Domínguez, J.; Engràcia, G.; SerRa, J. (1997), La construcción sostenible. El estado de la cuestión. Informes de la Construcción, Vol. 49 (451), pp. 41-45.

AlCÁZAR MolinA, M. (2003), Valoración inmobiliaria. Editorial Montecorvo S.A.

AmARILLA, B.C., (1989), Los costes de mantenimiento de edificios en países en vías de desarrollo. Informes de la Construcción, Vol. 41, pp. 73-80.

Andaloro, A.P.; Salomone, R.; Ioppolo, G.; Andaloro, L., (2010), Energy certification of buildings: A comparative analysis of progress towards implantation in European countries. Energy Policy, Vol.38, pp. 5840-5866.

André, F.J.; Cardenete, M.A.; Romero, C., (2008), Using compromise programming for macroeconomic policy making in a general equilibrium framework: theory and application to the Spanish economy. Journal of the Operational Research Society. Vol.59, pp. 875-883. 
ANTHOFF, D.; TOL, R.S.J.; YOHE, G.W., (2009), Risk aversion, time preference and the social cost of carbon. Environmental Research Letters, Vol.4, 024002 (7pp). doi: 10.1088/1748-9326/4/2/024002

AnthofF, D, Hepburn, C.; Tol, R.S.J., (2009), Equity weighting and the marginal damage costs of climate change. Ecological Economics, Vol. 68, pp. 836-849. doi: 10.1016/j.ecolecon.2008.06.017

AYRES, R..; WALTER, J., (1991), The greenhouse effect: damags, costs and abatement. Environmental and Resources Economics, Vol. 1. Mc Millan.

Baja, S., Chapman,D.M.; Dragovich, D., (2007), Spatial based compromise programming for multiple criteria decision making in land use planning, Environmetal Modeling and Assessment, Vol.12, pp. 171-184.

Balaras, C.A., DroutSa, K.; Dascalaki, E.; KontuyianNidis, S., (2005), Deterioration of European apartment buildings. Energy and Buildings, Vol. 37, pp. 515-527.

Ballestero, E.; Romero C., (1991), A theorem connecting utility function optimization and compromise programming. Operations Research Letters, Vol. 10, pp. 421-427.

Ballestero, E.; Romero, C., (1993), Weighting in compromise programming. A theorem on shadow prices, Operations Research Letters, Vol. 13, pp. 325-329.

BALlestero, E.; Romero C., (1994), Utility optimization when the utility function is virtually unknown, Theory and Decision, Vol. 37, pp. 233-243. 
Ballestero, E., (1994), Joint Production Model: A Note on a Connection between Market Prices and CP Anchor Values, Journal of Multi-Criteria Decision Analysis, Vol. 3, pp. 119-121.

Barker, T.; Bashmakov, I.; Bernstein, J.L.; Borgner, E.; Bosch, P.R.; Dave, R.; Davidson, O.R.; Fisher, B.S.; Gupta, S.; Halsnaes, K.; HeiJ, G.J.; Kahn Ribeiro, S.; Kobayashi, S. LeVIne, M.D.; Martino, D.L.; MASera, O.; MetZ, B.; MeYer, L.A.; MABuURS, G.J.; NAJAm, A.; NAKICEnOVIC, N.; ROgneR, H.H.; ROY, J.; Sathaye, J.; Schock, R.; Shukla, P.; Urge-Vorsetz, D.; Zhou, D., (2007), Resumen Técnico. Contribución del Grupo de Trabajo III al Cuarto Informe de Evaluación del Grupo Intergubernamental de Expertos sobre Cambio Climático 2007. Pp. 27-96. Cambridge University Press, Cambridge, Reino Unido y Nueva York, NY, EEUU.

Berbel-Vecino, J., (1992), Planificación del uso del territorio y programación matemática multicriterio, Revista de Estudios Agrosociales, Vol. 159, pp. 171188.

Bertrán Moreno, A., (2009), Las mediciones en las obras adaptadas al CTE. 2009. $4^{a}$ Edición. Editorial Jorge Loring S.I.

Betelu, A.; Anta, J.M.; Aldabe, L.; Lumbreras, M.; Velasco, J.; Alzueta, J.; CABASÉs, F., (2003), Aproximación metodológica de los costos sociales del transporte de viajeros en la comarca de Pamplona, Quinto Congreso de Economía de Navarra.

BiCKel, P., Friedich, R. (eds), (2005), Institut fur Energiewirtschaft und Rationelle Energieundwendung IER. Universitat Stutgart. Germany. ExternE. Externalities for Energy. Methodology 2005 update. 
Bohringer, C.; RUtherford, T.F.; TOL, R.S.J., (2009), The EU 20/20/2020 targets: An overview of EMF22 assessment, Energy Economics, Vol.31, pp. S268-S273. doi 10.1016/j.eneco.2009.10.010

Bosello, F.; Roson, R.; Tol, R.S.J., (2006), Economy-wide estimates of the implications of climate change: Human Health, Ecological Economics, Vol. 58, pp. 579-591.

Bradley, P.E., Kohler, N., (2007), Methodology for the survival analysis of urban building stocks, Building Research and Information, Vol. 35, pp. 529-542.

Brathal, D.; Langemo, M., (2004), Facilities Management: A guide for total workplace design and Management. Knight Printing. Grand Forks, North Dakota.

BRown, D.W., (1996), Facility Maintenance: The manager's practical guide and handbook. AMACOM American Management Association.

CARTER, E., (2006), Making money from sustainable homes: a developer's guide. Ascot UK: CIOB Publications.

CASANOVAS, X., (2009), La construcción sostenible. Una mirada estratégica. Ponencia Marco Sostenibilidad y Medioambiente. $V$ Convención Técnica y Tecnológica de la Arquitectura Técnica, Contart 09, Albacete, 25, 26 y 27 de marzo.

Castro-lacouture, D.; Sefair, J. A.; Florez, L.; Medaglia, A. L., (2009), Optimization model for the selection of materials using a LEED-based green building rating system in Colombia, Building and Environment, Vol. 44, pp. 1162-1170. 
Clarckson, R.; Deyes, K., (2002), Estimating the Social Cost of Carbon Emissions. Government Economic Service Workingpaper 140. Climate Change and Energy Policy Branch Environment Protection Economics. Department of Environment, Food and Rural Affairs, U.K.

Clarke, L.; Edmons, J.; Krey, V.; Richels, R.; Rose, S.; Tavoni, M, (2009), International climate policy architectures: Overview of the EMF22 International Scenarios, Energy Economics, Vol.31, S64-S81.

CLINE, W.R., (1992), The economics of global warming. Institute for International Economics. Washington D.C.

Concerted Action EPBD, (2008), Implementation of the Energy Performance of Buildings Directive, Country reports 2008. Brussels: Directorate General for Energy and Transport, European Commission.

CHANG, M.Y., (2005), La Economia Ambiental. En: Foladori, G. y Pierri, N (coordinadores) Sustentabilidad? Desacuerdos sobre el desarrollo sustentable. Mexico. Universidad autónoma de Zacatecas, pp. 175-188.

Davies, H., WyatT, D., (2004), Appropiate use or method for durability and service life prediction, Building Research and Information, Vol. 32, pp. 552-553. doi: 10 1080/0961321042000291938

Decreto 158/1997, de 8 de julio, por el que se regula el Libro del Edificio de las viviendas existentes y se crea el programa para la revisión del estado de conservación de los edificios de viviendas. Cataluña.

Decreto 349/1999, de 30 de diciembre, por el que se regula el Libro del Edificio.

Decreto 35/01, de 9 de marzo, por el que se establecen medidas reguladoras del uso y mantenimiento del edificio, Islas Baleares. 
Decreto Foral 322/2000, de 2 de octubre, del Gobierno de Navarra, por el que se regula el Libro del Edificio.

Decreto 38/2004, de 2 de julio, por el que se regula el Libro del Edificio en La Rioja.

Decreto 26/2009, de 3 de marzo, por el que se regula el procedimiento de visado del Certificado de Eficiencia Energética de Edificios y se crea el correspondiente Registro en el ámbito de la Comunidad Autónoma de Canarias

Decreto 136/2009, de 12 de junio, por el que se regula la certificación de eficiencia energética de edificios en la Comunidad Autónoma de Extremadura.

Decreto 42/2009, de 21 de enero, por el que se regula la certificación energética de edificios de nueva construcción en la Comunidad Autónoma de Galicia.

Decreto 112/2009, de 31 de julio, del Consell, por el que regula las actuaciones en materia de certificación de eficiencia energética de edificios. Valencia.

DiakAKI, C.; Grigoroudis, E.;KolokotSA, D., (2008), Towards a multi-objective optimization approach for improving energy efficiency in buildings, Energy and Buildings, Vol. 40, pp. 1747-1754. doi: 10.1016/j.enbuild.2008.03.002

Diakaki, C.; Grigoroudis, E.;Kabelis, N.;Kolokotsa, D.; KalaitZakis, K.; STAVRAKAKIS, G., (2010), A multi-objective decision model for the improvement of energy efficiency in buildings, Energy, Vol. 35, pp. 5483-5496. doi: 10.1016/j.energy.2010.05.012

Diaz-BAlteiro, L.; Romero, C., (1997), Modelling timber harvest scheduling problems with multiple criteria: an application in Spain, Forest Science, Vol. 44, pp. 47-57. 
Diaz-Balteiro, L.; Romero, C., (2003), Forest management optimization models when carbon captured is considered: a goal programming approach, Forest Ecology and Management, Vol. 174, pp. 447-457.

Diaz-Balteiro, L.; Rodríguez, L.C.E., (2006), Optimal rotations on Eucalyptus plantations including carbon sequestration. A comparison of results in Brazil and Spain, Forest Ecology and Management, Vol. 229, pp. 247-258.

Directiva 2010/31/UE del Parlamento Europeo y del Consejo, de 19 de mayo, relativa a la eficiencia energética de los edificios

Dobbelsteen AAJF van den, ARets M, Nunes R., (2007), Sustainable design of supporting structures - Optimal structural spans and component combinations for effective improvement of environmental performance, Construction Innovation: Information, Process, Management, Vol. 7, pp. 54-71.

Dobson, A., (2007), Environmental citizenship: towards sustainable development, Sustainable development, Vol. 15, pp. 276-285.

Durán Redondo, A., (2009), Vida útil de los edificios ¿Qué es?¿Cómo se mide? ¿De qué depende? Colegio Oficial de Aparejadores y Arquitectos Técnicos de Madrid. Comunicación Convención Técnica y Tecnológica de la Arquitectura Técnica, Contart 09.

EscrivÁ-Escrivá, G.; Álvarez-Bel, C.; Peñalvo-LóPez, E., (2010), New índices to assess building energy efficicency at the use stage, Energy and Buildings, Vol. 43, pp. 476-484. doi: 10.1016/j.enbuild.2010.10.012.

EntroP, A.G.; Brouwers, H.J.H.; Reinders, A.H.M.E., (2010), Evaluation of energy performance indicators and finantial aspects of energy saving techniques in residential real estate, Energy and Buildings, Vol. 42, pp. 618629. 
Eyre, N.; Downing,T.; Hoekstra, R.; Rennings, (1999), Global Warming Damages. Final Report of a ExternE Global Warming Subtax (sep 98) DGXII, European Comission. Brussels.

FANKHAUSER, S., (1994a), Evaluating the social cost of GHG emissions. Centre for Economic Research into the Global Environment (CSERGE), University College London and University of East Anglia. Working Paper GEC 94-01.

FANKHAUSER, S., (1994b), The social cost of greenhouse gas emissions: an expected value approach, Energy journal, Vol. 15, pp.157-185.

FANKHAuser, S., (1994c), The Economic Cost of Global Warming Damage. A survey. Global Environmental Change. Vol. 4, pp. 301-309.

FATTAHI, P.; FAYYAZ, S., (2010), A Compromise Programming Model to Integrated Urban Water Management. Water Resources Management. Vol. 24, pp. 1211-1227.

Fawcett, A.A.; Calvin, K.V.; De La Chesnaye, F.C.; Reilly, J.M.; Weyant, J.P., (2009), Overview of the EMF22 US transition scenarios, Energy economics, Vol. 31, pp. S198-S211.

FloRES, A., (1996), Microeconomía y Medioambiente. Boletín de Lecturas Sociales y Económicas, UCA, FCSE. Año 3, nº 14, pp. 83-89.

GaRcía Casals, X., (2006), Analysis of building energy regulation and certification in Europe: their role, limitations and differences, Energy and Buildings, Vol. 38, pp. 381-392. 
García Olmos, F., (1997), Mantenimiento y vida útil de los edificios. Comunicación Convención Técnica y Tecnológica de la Arquitectura Técnica, Contart 97.

GARCíA PALACIOS, A., (1998), Valoración Inmobiliaria Pericial. Editorial Agrícola Española.

GhafghazI, S.; SoWlati, T.; Sokhansanu, S.; Melin, S. (2010). A multicriteria approach to evaluate district heating options. Applied Energy, Vol. 87, pp. 11341140.

GIROD , B.; WIEK, A.; MIEG, H.; Hulme, M., (2008), The evolution of the IPCC'S emissions scenarios, Environmental Sciences and Policy. doi: 10.1016/j.envsci.2008.12.006

GodWY, J.; JULIA, R., (2010), Global Warming Economics in the long run: A conceptual framework, Land Economics, Vol.86, pp. 117-130.

GonZÁLEZ, A.B.R.; DíAZ, J.J.V.; WILBY, M.R., (2010), Towards a universal energy efficiency for buildings, Energy and Buildings, Vol. 43, pp.980-987. doi:10.1016/j.enbuild.2010.12.023

Grupo Interministerial de Cambio Climatico (GICC). Plan Nacional de Asignacion de Derechos de Emision 2008-2012. (Propuesta de 12 de Julio de 2006).

Guadalajara, N.; Ballestero, E., (2000), Precios-sombra para imputar costes indirectos en la producción múltiple. I Encuentro Iberoamericano de contabilidad de gestión. VII Jornadas AECA de Contabilidad de Gestión Universidad de Valencia. 
HAMDY, M., HASAN, A.; SIREN, K., (2011), Applying a multi-objective optimization approach for design of low-emission cost-effective dwellings, Building and Environment, Vol. 46, pp.109-123.

Hanley, N., McGregor, P.G., Swales, J.K.; Turner, K., (2009), Do increases in energy efficiency improve environmental quality and sustainability?, Ecological Economics, Vol. 68, pp. 692-709.

HepbuRn, C., (2006), Regulating by prices, quantities or both: an update and an overview, Oxford Review of Economic Policy, Vol. 22, pp. 226-247. doi: 10.1093/oxrep/grj014

HOPE, C, (2006a), The marginal impact of CO2 from PAGE2002: An Integrated Assessment Model incorporating the IPCC's five reasons for concern, The Integrated Assessment Journal, Vol. 6, pp. 19-56.

HOPE, C., (2006b), The social cost of carbon. What does actually it depends on?, Climate policy, Vol.6, pp. 565-572.

HoPE, C., (2008), Discount rates, equity weights and the social cost of carbon, Energy Economics, Vol. 30, pp. 1011-1019d.

INSTITUTO DE LA DIVERSIFICACIÓN Y AHORRO ENERGÉtICO (IDAE), (2009), Escala de Calificación Energética para edificios de nueva construcción.

INSTITUTO DE LA DIVERSIFICACIÓN Y AHORRO ENERGÉtICO (IDAE), (2008a), Soluciones de aislamiento con poliestireno extruido.

INSTITUTO DE LA DIVERSIFICACIÓN Y AHORRO ENERGÉTICO (IDAE), (2008b), Soluciones de aislamiento con lana mineral. 
INSTITUTO DE LA DIVERSIFICACIÓN Y AHORRO ENERGÉtICO (IDAE), (2008c), Soluciones de aislamiento con poliuretano.

InStituto EduARdo ToRroja de CIenCIAS de LA Construcción (ITTCC), (2010), Catálogo de Elementos Constructivos del Código Técnico. Versión CAT-ECv06.3_MARZO10

Institut de TeCnologia de la Construcció de Catalunya (ITEC), (1991a), Manual de uso y conservación de la vivienda. COAAT Principado de Asturias. Simancas Edicionas S.A. Valladolid.

Institut de TeCnologia de la Construcció de Catalunya (ITEC), (Març 1991b), Manteniment de l'edifici. Fitxes. 1ª Edición. Gràfiques Pacífic.

Institut de TeCnologia de la Construcció de Catalunya (ITEC), (Juny 1991c), Manteniment instal.lacions. Fitxes. $1^{\text {a }}$ Edición. Gràfiques Pacífic.

Institut de TeCnologia de la Construcció de Catalunya (ITEC), (Setembre 1991d), Manteniment urbanització. Fitxes.1ª Edición. Gràfiques Pacífic.

InStitut de TeCnologia de la Construcció de Catalunya (ITEC), (Abril 1994), $L^{\prime}$ 'actualitat $i$ el cost del manteniment en edificis d'habitatge. Guia pràctica. $1^{a}$ Edición. Gama S.L. Servicios editoriales.

Institut de TeCNOlogia de LA Construcció de CATAlunya (ITEC), (1996), Ús i manteniment de l'habitatge. Quadern de l'usuari. $1^{\text {a }}$ Edición, Gràfiques Cometa. Institut de TeCnologia de la Construcció de Catalunya (ITEC), (Diciembre 1997), La vivienda: manual de uso y mantenimiento. COAAT de Cantabria. $1^{a}$ Edición.

Institut de TeCnologia de la Construcció de Catalunya (ITEC), (Mayo 1999), La vivienda: manual de uso y mantenimiento. COAAT Principado de

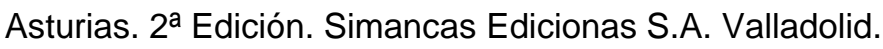


Instituto Tecnológico de Cataluña. $1^{a}$ ed. (ITEC), (2000a), Manual de minimización y gestión de residuos en las obras de construcción y demolición.

Instituto Tecnológico de Cataluña. $1^{a}$ ed. (ITEC), (2000b), Plan de gestión de residuos en las obras de construcción y demolición.

instituto Tecnológico de Cataluña. (ITEC), (2000c), Situación actual y perspectivas de futuro de los residuos de construcción. $1^{\text {a }}$ ed.

Instituto Nacional de Estadística (INE), (2009), Índice de Precios de Consumo. Medias anuales. Base 2006 España.

Intergovernmental Panel on Climate Change, (1994), Special Report on Emission Scenarios.

Intergovernmental Panel on Climate Change, (2001), Special Report on Emission Scenarios.

Intergovernmental Panel on Climate Change, (2007), Cambio Climático 2007: Informe de Síntesis. Contribución de los grupos de trabajo I, II, y III al Cuarto Informe de Evaluación del Grupo Intergubernamental de Expertos sobre Cambio Climático [Equipo de redacción principal: Pachauri, R.K. y Reisinger, A. (directores de la publicación)] IPCC, Ginebra, Suiza, 104 pags.

ISO 15686-1 Buildings and constructed assets - Service life planning: Part 1: General principles

ISO 15686-2 Buildings and constructed assets - Service life planning: Part 2, Service life prediction procedures 
JАKOB, M., (2006), Maginal costs and co-benefits of energy efficiency investments, The case of the Swiss residential secto, Energy policy, Vol.34, pp. 172-187.

JACCARD, M.; BAILIE, M., (1996), $\mathrm{CO}_{2}$ emission reduction cost in the residential sector: Behavioural parameters in a bottom-up simulation model, Energy journal, Vol.17, pp. 107.

JENKINS, D.P., (2010), The value of retrofitting carbon-saving measures into fuel poor social housing, Energy Policy, Vol. 38, pp. 832-839.

JOHNSTONE, I.M., (2001a), Energy and mass flows of housing: a model and example, Building and Environment, Vol. 36, pp. 27-41.

JOHNSTONE, I.M., (2001a), Energy and mass flows of housing: estimating mortality, Building and Environment, Vol.36, pp. 43-51.

KAISER, H.H., (2001), The Facilities Audit. A process for improving facilities conditions. Kirby Lithographic. APPA. The Association of Higher Education Facilities Officers.

KaHN, M.J.; NeLLING, E.F, (2010), Estimating the value of medical education: A Net present Value Approach, Teaching and Learning in Medicine, Vol. 22, pp. 205-208.

KeEPING, M.; SHIERS, D.E., (2004), Sustainable property development: a real guide to real estate and the environment. Oxford: Blackwell Publishing.

Kelly, D.L.; Kolstad, C.D., (1998), Integrated Assessment Models for Climate Change Control, Current version November (forthcoming: Henk Folmer and Tom Tietenberg (eds), International Yearbook of Environmental and Resource Economics 1999/2000: A survey of Current Issues (Chentelham, UK: Edward Elgar, 1999). 
KIM, G.H.; AN, S.H.; KANG, K.I., (2004), Neural network model incorporating a genetic algorithm in estimating construction cost, Building and Environment, Vol. 39, pp. 1333-1340.

KUCKShinRichs, W.; KRONenberg, T.; HANSEN, P., (2010), The Social return on investment in the energy efficiency of buildings in Germany, Energy Policy, Vol. 38, pp. 4317-4329.

LANGE, O., (1942), The foundations of welfare economics, Econometrica, Vol. 10, pp. 215-228.

Lecuona neumann, A.; IzQuierdo Millán, M.; Rodríguez Aumente, P.A., (2005), Investigación e impacto ambiental de los edificios. La energía, Informes de la Construcción, Vol. 57, pp.47-61.

LEE, W. L., YIK, F.W.H., (2004), Regulatory and voluntary approaches for enhacing building energy efficiency, Progress in Energy and Combustion Science, Vol. 30, pp. 477-499.

Ley 2/99 de medidas para la Calidad de la Edificación, de 17 de marzo, de la Comunidad de Madrid

Ley 3/04 de Ordenación y Fomento de la Calidad de la Edificación, de 30 de junio, de la Comunidad Valenciana

Ley 8/04 de la Vivienda, de 20 de octubre, de la Comunidad Valenciana

Ley 10/1998 de Residuos, de 21 de Abril. Instituto Nacional de Seguridad e Higiene en el Trabajo

Ley 10/2000, de 12 de diciembre, de residuos de la Comunidad Valenciana. 
Ley 38/99 de Ordenación de la Edificación, de 5 de noviembre de 1999

Ley 49/60 de Propiedad Horizontal, 23 de julio de 1960

Ley 30/2007, de 30 de octubre, de Contratos del Sector Público

Libro del Edificio COA Cádiz

Libro del Edificio COA Granada

Libro del Edificio COA Jaén

Lider v1.0. Manual de usuario. Madrid: Ministerio de Vivienda e Instituto para la Diversificación y Ahorro de la Energía (IDAE), 2007.

LINARES P., (1997), Una aplicación de la programación multiobjetivo a la planificación eléctrica, Ingeniería energética y medioambiental, año $23, n^{\circ} 2$, pp. 71-76.

LINARES, P.; ROMERO, C., (2000), A multiple criteria decisión making approach for electricity planning in Spain: economic versus environmental objectives. Journal of the Operational Research Society, Vol. 51, pp. 736-743.

LINDO SYSTEMS INC., (2010) Lingo User's Guide.

LISKA, R. W., (2000), Means Facilities Maintenance Standards. R.S. Means Company, Inc. Construction Publishers \& Consultants.

López-Mesa, B.; Pitarch, A.; Tomás, A.; Gallego, T., (2009), Comparison of environmental impacts of building structures with in situ cast floors and with precast concrete floors, Building and Environment, Vol. 44, pp. 699-712.

LUCUIK, M.; SEguin, P.; ReID, A., (2006), Material and Operational Environmental Impacts of Building Insulation: How much is enough? IEEE EIC Climate Change 
Conference, May 09-12. Ottawa, Canada. Athena Institute, Canada. http://www.athenasmi.ca/about/lcaModel.html

LLANO ELCID A., (2007), Valoraciones Inmobiliarias: fundamentos teóricos y manual práctico, Llano Realtors S.L. Vizcaya.

MADDISON, D.J., (1994), Economics and the environment. The shadow price of GHG and Aerosols. Centre for Economic Research into the Global Environment (CSERGE), University College London and University of East Anglia

MAHLIA, TMI; IQBAL, A ., (2010), Cost benefits analysis and emission reductions of optimum thickness and air gaps for selected insulation materials for buildings walls in Maldives, Energy, Vol 35, pp. 2242-2250.

MALIN, N., (2005), Life cycle assessment for whole buildings: seeking the holy grail, Building Design and Construction, November 2005, pp. 6-11.

Maroto Álvarez, C.; Alcaraz Soria, J.; Ruiz García, Rubén, (2002). Universidad Politécnica de Valencia. Servicio de Publicaciones

MARTEINSSON, B., (2003), Durability and the factor method of ISO 15686-1, Building Research \& Information, Vol. 31 (6), pp. 416-426.

MARtÉn, I.; Molleda FernándeZ-LlamaZARes, J.A.; LóPEZ, D.; BAEZA, R., (2004), El reto de Kioto: mitos y realidades. Universia Business Review, Vol. 2, pp. 118-135.

Martínez de Alegría, I.; Díaz de Basurto Uraga, P.; Ruiz de Arbulo López, P., (2009), European Union's renewable energy sources and energy efficiency policy review: The Spanish perspective, Renewable and Sustainable Energy Reviews, Vol. 13, pp. 100-114. 
Meler Burillo, J; López Esteve, A., (1998). Ejercicios resueltos mediciones, presupuestos y valoraciones. Ed. Torres Gosálvez, Ramón.

MendizÁbal ZubeldiA, A; Miera ZabalzA, L.M.; Zubia ZubiaurRe, M., (2002), El modelo de Markowitz en la selección de carteras, Cuadernos de Gestión, Vol. 2, pp. 33-46.

MINISTERIO DE VIVIENDA E INSTITUTO PARA LA DIVERSIFICACIÓN Y AHORRO DE LA ENERGÍA (IDAE), (2007). Calener VYP v1.0. Manual de usuario.

Minguez, J.L.; PorteiroA, J.; LóPez-GonzÁlez, L.M.; VicuñA, J.E.; MuRILlo, S.; MoránA, J.C.; GranadA., E., (2006), Review of the energy rating of dwellings in the European Union as a mechanism for sustainable energy, Renewable and Sustainable Energy Reviews, Vol. 10, pp. 24-45.

MINISTERIO DE INDUSTRIA, TURISMO Y COMERCIO. La Energía en España 2007.

MogAS, J.; RierA, P., (2004), El valor de la fijación de carbono en los programas de forestación. Segundo Simposio Iberoamericano de Gestión y Economía Forestal.

NORDHAUS, W.D., (1991), To slow or not to slow: the economics of the greenhouse effect, Economic Journal, Vol. 101, pp. 920-937.

NORDHAUS, W.D., (1992), An optimal transition path for controlling greenhouse gases, Science, Vol. 25, pp. 1315-1319.

Nordhaus, W.D. (1993), Optimal Greenhouse- Gas Reduction and Tax Policy in the DICE Model, The American Economic Review, Vol. 83, pp. 313-317. Papers and Proceedings of the Hundred and Fifth Annual Meeting of the American Economic Association. 
Nordhaus, W. D., (2007), A review of the Stern Review on the Economics of Climate Change, Journal of Economic Literature, Vol. 45, pp. 686-702.

Orden del 14/02/02 por el que se aprueba el modelo del Libro del Edificio en Murcia

Orden MAM/304/2002, de 8 de febrero, por la que se publican las operaciones de valorización y eliminación de residuos y la lista europea de residuos. .

Orden ECO/805/2003, de 27 de marzo, sobre normas de valoración de bienes inmuebles y de determinados derechos para ciertas finalidades financieras.

ORDEN ITC/3801/2008, de 26 de diciembre, por la que se revisan las tarifas eléctricas a partir de 1 de enero de 2009.

ORDEN ITC/3802/2008, de 26 de diciembre, por la que se establecen los peajes y cánones asociados al acceso de terceros a las instalaciones gasistas, la tarifa de último recurso, y determinados aspectos relativos a las actividades reguladas del sector gasista.

Comunidad de Madrid

Orden foral 7/2010, de 21 de enero, del Consejero de Innovación, Empresa y Empleo, por la que regula el Registro administrativo de certificados de eficiencia energética de edificios de nueva construcción. Navarra

Orden de 25 de junio de 2008, por la que se crea el Registro Electrónico de Certificados de eficiencia energética de edificios de nueva construcción y se regula su organización y funcionamiento. Andalucía 
Orden de 3 de septiembre de 2009 por la que se desarrolla el procedimiento, la organización y el funcionamiento del Registro de Certificados de Eficiencia Energética de Edificios en la Comunidad Autónoma de Galicia.

Ortiz, O.; Bonnet, C.; Bruno, J.C.; CAstells, F., (2009), Sustainability based on LCM of residential dwellings: A case study in Catalonia, Spain, Building and Environment, Vol. 44, pp. 584-594.

Osmani, M.; O'Reilly, A., (2009), Feasibility of zero carbon homes in England by 2016: A house builder's perspective, Building and Environment, Vol. 44, pp. 1917-1924.

Patlitzianas, K.; Doukasa, H.; Kagiannasa, A.G.; Psarrasa, J., (2008), Sustainable energy policy indicators: Review and recommendations, Renewable Energy, Vol. 33, pp. 966-973.

Pérez-Lombard, L. Ortiz, J.; GonzÁlez, R., (2008), A review of benmarching, rating and llabelling concepts within the framework of building energy certification schemes, Energy and Buildings, Vol. 41, pp. 272-278, doi: 10.1016/j.enbuild.2008.10.004.

Pérez-LoPEZ, C., (2005), Métodos estadísticos avanzados con SPSS. Thomson Editores Spain Paraninfo S.A.

I Plan Nacional de Residuos de Construcción y Demolición (PNRCD) 20012006

II Plan Nacional de Residuos de Construcción y Demolición (II PNRCD) 20072015 
PIPER, J. E., (1995), Handbook of Facility Management: Tools and Techniques, formulas and tables. Prentice Hall Inc.

Popescu, D., Mladin, A.C.; Boazu, R.; Bienert, S., (2009), Methodology for Real Estate Appraisal of Green Value, Environmental Engineering and Management Journal, Vol. 8, pp.601-606.

RADHI, H., (2008), A systematic methodology for optimizing the energy performance of buildings in Bahrain, Energy and Buildings, Vol. 40, pp. 12971303. doi: 10.1016/j.enbuild.2007.11.007

Ramírez de Arellano AGudo, A., (2004), Presupuestación de obras. $3^{\mathrm{a}}$ ed. Universidad de Sevilla. Secretariado de Publicaciones. Colección Manuales Universitarios, 37.

Ramos MARTIN, J., (1998), Modelos de estimación del coste de reducción de emisiones de $\mathrm{CO}_{2}$. Fundamentos de Economía Ecológica.

RD. 47/2007, de 19 de enero, por el que se aprueba el Procedimiento básico para la certificación de eficiencia energética de edificios de nueva construcción.

RD 105/2008, de 1 de febrero, por el que se regula la producción y gestión de residuos de la construcción y demolición

R. D. 314/2006, de 19 de octubre, por el que se aprueba el Código Técnico de la Edificación

RD 604/2006 que modifica al RD 39/1997 reglamento de los servicios de prevención y al RD 1627/1997 disposiciones de seguridad y salud en las obras de construcción 
R.D. 1027/2007, de 20 de julio, por el que se aprueba el Reglamento de Instalaciones Térmicas en los Edificios.

RD 1777/2003 de 30 de julio, por el que se aprueba el Reglamento del Impuesto sobre Sociedades.

Resolución $N^{\circ} 43$, de 26-12-2002, según la tabla de vida útil fijada por el Servicio de Impuestos Internos para bienes físicos del activo inmovilizado

REPoRt of the US Department of Energy. Office of Science. Office of Biological and Environmental Research. Workshop on Integrated Assessment, November 2008. Science Challenge and future directions: Climate Change Integrated Assessment Research.

Rey, F.J.; Velasco, E.; Varela, F., (2007),Building Energy Analysis (BEA): A methodology to assess building energy labeling, Energy and Buildings, Vol. 39, pp. 709-716.

Roca Cladera, J., (1989), Manual de Valoraciones Inmobiliarias. $2^{\text {a }}$ Edición. Editorial Ariel S.A. Barcelona.

RocA, X., (2005), Estudio de la aplicabilidad de materiales compuestos avanzados en la construcción de edificios avanzados. PhD dissertation. Universitat Politècnica de Catalunya, Barcelona.

Rodriguez Gonzalez, A.B., Díaz, J.J.V.; Camaño, A.J., (2011), Towards a universal energy efficiency index for buildings, Energy and Buildings, Vol. 43, pp. 980-987.

Rodrigo Morant, F.; Collado López, M.L.; Amselem Moryoussef, R., (2001), Técnicas de Gestión Presupuestaria. Editorial Universidad Politécnica de Valencia. 
ROMERO, C.; ReHMAN, T. (1986). La programación multiobjetivo y la planificación agraria: algunas consideraciones teóricas, Agricultura y Sociedad, Vol. 40, pp. 9-35.

ROMERo, C., (1993), Teoría de la decisión multicriterio: Conceptos, Técnicas y Aplicaciones . Ed. Alianza Editorial.

Romero, C., (1996), Multicriteria decisión analysis and environmental economics: An approximatio, European Journal of Operational Research, Vol. 96, pp. 81-89.

Romero, C., (1997), Economía de los recursos ambientales y naturales. Ed. Alianza Economía. $2^{\mathrm{a}}$ edición.

Romero, C.; Ríos, V. and Díaz Balteiro, L., (1998), Optimal forest rotation age when carbon captured is considered: theory and applications. Journal of the Operational Research Society, Vol. 49, pp. 121-131.

RuÁ, M.J., Vives, L., Civera, V., LóPez-MesA. B., (2010), Approximation to the calculation of the energy efficiency of ventilated façades and their environmental impact Papers B, Qualicer'10. XI World Congress on Ceramic Tile Quality. Castellón de la Plana. Spain.

RUDBECK, C., (2002), Service life of building envelope components: making it operational in economical assessment, Construction and Building Materials, Vol. 16, pp. 83-89.

SÁnchez-Chóliz, J., DuARTe, R., (2004), $\mathrm{CO}_{2}$ emissions embodied in international trade: evidence for Spain, Energy Policy, Vol. 32, pp. 1999-2005. 
SANCHO-VILlalobos, F., PRATt, L., (1999), Estimación del costo marginal de los servicios de fijación del carbono en Costa Rica.

SANDler, M. ANd DeShazo, J.R., (Draft December 10, 2008), Carbon Cost: How a \$15/ton CO2 cost could raise household electricity bills.

SAn José, J.T.; Losada, R.; CuAdRAdo, J.; GARRuCho, I., (2007), Approach to the quantification of the sustainable value in industrial building, Building and Environment, Vol. 42, pp. 3916-3929.

Shimoda, Y., NagotaA, T.; IsayamaA, N.; Mizunoa, M., (2008), Verification of energy efficiency of district heating and cooling system by simulation considering design and operation parameters, Building and Environment, Vol. 43, pp. 569-577.

SILVÁN MARTíneZ, L.J., (2006), Tasaciones mercantiles, hipotecarias, catastrales y de mercado. Dykinson S.L.

Sole, J., (2007), Aislamiento térmico en la edificación. Limitación de la demanda energética $D B$ HE1 e iniciación a la calificación energética. Tarragona: Col-legi d'Aparelladors i Arquitectes Tècnics de Tarragona,

Stern, N., (2006), The Stern Review: The Economics of Climate Change. Cambridge University Press.

Theodosiou, T.G.; Papadopoulos, A.M., (2008), The impact of thermal bridges on the energy demand of buildings with double brick wall constructions, Energy and Buildings, Vol. 40, pp. 2083-2089.

ToL, R.S.J., (1999), The marginal cost of greenhouse gas emissions, The Energy Journal, Vol. 20, pp. 61-82. 
TOL, R.S.J.; DownIng, T.E., (2000), The Marginal Cost of Climate Changing Emissions, Draft Paper to be published by European Commission as part for the work of ExternE.

ToL, R.S.J., (2002), Welfare specifications and optimal control of climate change: an application of FUND, Energy Economics, Vol.24, pp. 367-376.

TOL, R.S.J.; YOHE, G.W., (2006), A Review of the Stern Review. World Economics, Vol. 7, pp. 233-250.

ToL, R.S.J., (2008), The social cost of carbon: Trends, Outliers and Catastrophes, Economics, The Open-Access, Open-Assessment E-journal., Vol.2, pp. 2008-2025.

ToL, R.S.J., (2009), The Economic Effect of Climate-Change. Journal of Economic Perspectives, Vol. 23, pp. 29-51.

TORRelLA, E., (2005), Manual de Climatización. Ed: A.M.V Ediciones, España.

TraineR, T., (2010), A critical discussion of the Stern and IPCC analyses of carbon emissions mitigation possibilities and costs, Energy and Environment, Vol. 21, pp. 49-73.

Uihlein, A.; Eden, P., (2010), Policy options towards an energy efficient residential building stock in the UE-27, Energy and Buildings, Vol. 42, pp.791798.

UNE-EN ISO 6946:1997/A1:2005 - Building components and building elements - Thermal resistance and thermal transmittance - Calculation method (ISO/DIS 6946:2005). 
UNE-EN 1026: Ventanas y puertas. Permeabilidad al aire

UNE-EN 12207: Ventanas y puertas. Permeabilidad al aire. Clasificación

Universidad Politécnica de Madrid. Departamento de Construcción y Vías RURALES (2009). Evaluación de los costes constructivos y consumos energéticos derivados de la calificación energética de viviendas. Precost\&E. Fase1

Urge-Vorsatz, D.; Koeppe, S.; Mirasgedis, S., (2007), Appraisal of Policy instruments for reducing buildings' $\mathrm{CO}_{2}$ emissions, Building Research and Information, Vol. 35, pp. 458-477.

UzSILAITYTE, L.; MARTINAITIS, V., (2010), Search for optimal solution of public building renovation in terms of life cycle,Journal of Environmental Engineering and Landscape Management, Vol. 18, pp. 102-110.

WANG, W.; ZMeUReAnu, R.; RIVARD, H., (2005), Applying multi-objective genetic algorithms in green building design optimization, Building and Environment, Vol 40, pp.1512-1525.

Wietzman, M.L., (2007a), A review of the Stern Review on the Economics of Climate Change. Journal of Economic Literature, Vol. 45, pp. 703-724.

Wietzman, M.L., (2007b), Subjective expectations and Asset-Return Puzzles. American Economic Review, Vol. 97, pp. 1102-1130.

WIETZMAN, M.L., (2008), On modeling and interpreting the economics of catastrophic climate change. REStat Version 6/5/08. $38 \mathrm{p}$ 
WILliAMS, K.; DAIR, C., (2005), What is stopping sustainable building in England? Barriers experienced by stakeholders in delivering sustainable development. Sustainable Development, Vol. 15, pp. 135-147.

Yohe, G.W.; Lasco, R.D.; Ahmad, Q.K.; ARnell, N.W.; Cohen, S.J.; Hope, C.; Janetos, A.C.; Perez, R.T., (2007), Perspectives on climate change and sustainability. Chapter 20. Climate Change 2007: Impacts, Adaptation and Vulnerability. Contribution of Working Group II to the Fourth Assessment Report of the Intergovernmental Panel on Climate Change [M.L. Parry et al., Eds]. Cambridge University Press, Cambridge, UK, 811-841.

YU, P. L., (1973), A Class of Solutions for Group Decision Problems, Management Science, Vol. 19, pp. 936-946.

Zeleny, M., (1973), Compromise Programming, en Multiple Criteria Decision Making (Cochrane, J.L.; Zeleny, M. editors). University of South Carolina Press, Columbia, pp. 262-301.

ZeLENY, M., (1974), A Concept of Compromise Solutions and the Method of the Displaced Ideal, Computers and Operations Research, Vol. 1, pp. 479-496.

\section{PÁGINAS WEBS CONSULTADAS}

www.idae.es

www.mityc.es

www.energypriorities.es

www.construction.ecnext.com

www.builup.eu

wWw.sii.cl

www.ine.es 
http://epp.eurostat.ec.europa.eu

www.ecobusinesslinks.com

www.e3network.org 



\section{ANEXO 1}

1.1.- DATOS ACRISTALAMIENTOS

1.2.- DATOS CARPINTERÍAS

1.3.- DATOS AISLAMIENTOS

1.4.- DATOS EQUIPOS CALEFACCIÓN Y ACS

1.5.- DATOS EQUIPOS AIRE ACONDICIONADO 



\section{1.- DATOS ACRISTALAMIENTOS}

\begin{tabular}{|l|l|l|}
\hline Acristalamiento & $\begin{array}{l}\text { Factor solar g } \\
\text { Normativa EN 410 }\end{array}$ & $\begin{array}{l}\text { Transmisión térmica }\left(\mathrm{W} / \mathrm{m}^{2} \mathrm{~K}\right) \\
\text { Normativa EN 673 }\end{array}$ \\
\hline $4+4 / 12 / 6$ & 0,66 & 2,8 \\
\hline $4+4$ & 0,77 & 5,7 \\
\hline $10+10 / 12 / 4+4$ & 0,73 & 2,7 \\
\hline $6 / 12 / 4 ; 6 / 12 / 8$ & 0,73 & 2,8 \\
\hline $4+4 / 12 / 4+4$ & 0,61 & 2,8 \\
\hline $4 / 6 / 6 ; 4 / 6 / 4$ & 0,75 & 3,3 \\
\hline
\end{tabular}

Cálculos en Calumen para introducir a la base de datos de Lider

Otros acristalamientos especiales:

Factor solar en vidrio control solar: 0,42

Factor solar en vidrio baja emisividad: 0,5

Información de:

Catálogo comercial: Isolar solarlux. Vitro. Fecha 01/02/2008

(www.vitrocristalglass.com)

Catálogo comercial: SGG Climalit doble acristalamiento. Saint Gobain Glass. Fecha versión 07/04/2009 (www.saint-gobain-glass.com)

Catálogo comercial: SGG Planitherm. Vidrios con baja emisividad. Saint Gobain Glass. Fecha versión 07/04/2009 (www.saint-gobain-glass.com)

Catálogo comercial: SGG Climalit control solar. Saint Gobain Glass. Fecha versión 07/04/2009 (www.saint-gobain-glass.com)

\section{2.- DATOS CARPINTERÍAS}

Catálogo informativo casa comercial: Carpintería y ahorro de energía. Kommerling. Fecha versión 10/05/2007 (www.kommerling.es)

Catálogo informativo casa comercial: Guía para profesionales de la construcción sobre ventanas en el Código Técnico de la Edificación. Kommerling. Fecha versión 10/05/2007 (www.kommerling.es) 


\section{3.- DATOS AISLAMIENTOS}

Se introducen en la base de datos de Lider:

\begin{tabular}{|l|l|}
\hline & Resistencia térmica $\left(\mathrm{m}^{2} \mathrm{~K} / \mathrm{W}\right)$ \\
\hline Pladur Foc & 0,06 \\
\hline Pladur Trillaje & 0,2 \\
\hline XPS $3 \mathrm{~cm}$ & 0,9 \\
\hline XPS $4 \mathrm{~cm}$ & 1,2 \\
\hline XPS $5 \mathrm{~cm}$ & 1,5 \\
\hline
\end{tabular}

Fuentes diversas: catálogos informativo comercial: "Manual básico Pladur Uralita". Fecha versión 05/02/20078; "Rendimientos de los materiales y características térmicas de los sistemas pladur". versión 02/04/20078 (www.pladur.com.es)

\section{4.- DATOS EQUIPOS CALEFACCIÓN Y ACS}

\begin{tabular}{|l|l|l|l|}
\hline & & Marca & $\begin{array}{l}\text { Características } \\
\text { técnicas }\end{array}$ \\
\hline Equipo & Termo eléctrico & Junkers HS200 & $\begin{array}{l}\text { Capacidad total 2,6 } \\
\text { KW }\end{array}$ \\
\hline & $\begin{array}{l}\text { Caldera GN } \\
\text { estándar }\end{array}$ & $\begin{array}{l}\text { Immergas Hercules } \\
27\end{array}$ & $\begin{array}{l}\text { Capacidad total 31,4 } \\
\text { KW } \\
\text { Rendimiento 91,5\% }\end{array}$ \\
\hline & $\begin{array}{l}\text { Caldera GN baja } \\
\text { temperatura }\end{array}$ & $\begin{array}{l}\text { Hermann Master } \\
\text { Inox 30 SE }\end{array}$ & $\begin{array}{l}\text { Capacidad total 32 } \\
\text { KW } \\
\text { Rendimiento 93,7\% }\end{array}$ \\
\hline & $\begin{array}{l}\text { Caldera GN } \\
\text { condensación }\end{array}$ & $\begin{array}{l}\text { Immergas Hercules } \\
\text { Condensing }\end{array}$ & $\begin{array}{l}\text { Capacidad total 31,4 } \\
\text { KW } \\
\text { Rendimiento 98\% }\end{array}$ \\
\hline & $\begin{array}{l}\text { Caldera } \\
\text { biomasa y silo }\end{array}$ & Okofen & $\begin{array}{l}\text { Capacidad total 29 } \\
\text { KW } \\
\text { Rendimiento 91\% }\end{array}$ \\
\hline $\begin{array}{l}\text { Unidades } \\
\text { terminales }\end{array}$ & Radiadores & Ferroli "Xian" & Varias dimensiones \\
\hline
\end{tabular}

Fuentes diversas: Datos termo: Manual comercial "Calentadores y termos eléctricos Junkers". Junkers grupo Bosch (www.junkers.es). Datos calderas GN: Catálogo de productos Immergas 09. Fecha versión 09/01/2009. Datos base datos calderas IDEA. Datos radiadores: Catálogo radiadores "xian". Fecha versión 21/05/08 (www.ferroli.es). Caldera de biomasa y silo: www.okofen.es 
ANEXO 1

1.5.- DATOS EQUIPOS AIRE ACONDICIONADO

\begin{tabular}{|l|l|l|}
\hline & Marca & Características técnicas \\
\hline Unidades exteriores & Daikin 2MXS40D & Capacidad total 3,9 KW \\
\cline { 2 - 3 } & Daikin 4MXS80E & Capacidad total 8 KW \\
\hline \multirow{4}{*}{ Unidades interiores } & Daikin PBFTX 20W & Sólo frío \\
\cline { 2 - 2 } & & \\
\cline { 2 - 3 } & Daikin PBFTX 50W & \\
\cline { 2 - 3 } & Daikin PDXS 25E & Frío-calor \\
\cline { 2 - 3 } & Daikin PDXS 25E & \\
\hline
\end{tabular}

Fuente: Daikin aire acondicionado. Catálogo 2009 (www.daikin.es) 



\section{ANEXO 2}

2.1.- ESTADO 1. OPERACIONES MANTENIMIENTO

2.2.- CRONOGRAMA OPERACIONES MANTENIMIENTO ZONA A3-CALIFICACIÓN C

2.3.- PRECIOS MANTENIMIENTO POR ZONAS CLIMÁTICAS 



\section{1.- ESTADO 1. OPERACIONES MANTENIMIENTO}

\begin{tabular}{|c|c|c|c|c|c|c|c|c|c|}
\hline \multicolumn{4}{|r|}{ ESTADO No 1} & \multicolumn{6}{|c|}{ MEDICIONES } \\
\hline \multirow[b]{3}{*}{$\begin{array}{l}\mathrm{N}^{\circ} \\
\text { Ord }\end{array}$} & \multirow[b]{3}{*}{ Códig } & & & & & & & \multirow{2}{*}{\multicolumn{2}{|c|}{\begin{tabular}{|c|} 
Hoja: 1 \\
CANTIDADES \\
\end{tabular}}} \\
\hline & & \multirow[b]{2}{*}{ Uds. } & \multirow[b]{2}{*}{ DESCRIPCION } & \multicolumn{4}{|c|}{ DIMENSIONES } & & \\
\hline & & & & \begin{tabular}{|c|} 
P. \\
Igual \\
\end{tabular} & $\mathrm{x}$ & $\mathrm{y}$ & $z$ & Parc & TOTAL \\
\hline \multicolumn{10}{|c|}{ CAPITULO 1- RED HORIZONTAL DE SANEAMIENTO } \\
\hline 1.1 & RHS.1 & Ud & $\begin{array}{l}\text { realizando si fuera necesario: limpieza y revisión de } \\
\text { acometidas, drenajes y arquetas; comprobación de la } \\
\text { estanqueidad general de la red y de la ausencia de olores, }\end{array}$ & 13 & 1 & & & & 13 \\
\hline 1.2 & RHS.2 & Ud & $\begin{array}{l}\text { Reparación de los desperfectos que pudieran aparecer en } \\
\text { las arquetas a pie de bajante, de paso, sifónicas o sumidero. } \\
\text { Cada } 5 \text { años }\end{array}$ & 13 & 1 & & & & 13 \\
\hline \multicolumn{10}{|c|}{ CAPITULO 2- MUROS Y SOLERAS } \\
\hline 2.1 & MS.1 & Ud & $\begin{array}{l}\text { fisuras, roturas o humedades, así como la reparación en } \\
\text { juntas de retracción si fuera necesario. A realizar cada } 5 \\
\text { años }\end{array}$ & 13 & 1 & & & & 13 \\
\hline 2.1 & MS.2 & Ud & $\begin{array}{l}\text { Reparación y sustitución del sellado de las juntas, en muros } \\
\text { no expuestos a la intemperie. Comprobación del estado del } \\
\text { enmasillado de las juntas, renovándolo cuando sea }\end{array}$ & 13 & 1 & & & & 13 \\
\hline \multicolumn{10}{|c|}{ CAPITULO 3- FACHADAS } \\
\hline 3.1 & F.1 & $\mathrm{m} 2$ & $\begin{array}{l}\text { de la impermeabilización en fachadas. Visita de inspección } \\
\text { y mantenimiento, comprobando el buen estado de los } \\
\text { elementos de albañilería relacionados con el sistema de }\end{array}$ & 13 & 63,66 & & & & 827,58 \\
\hline 3.2 & F.2 & $\mathrm{m} 2$ & $\begin{array}{l}\text { años para detectar: Posible aparición y desarrollo de grietas } \\
\text { y fisuras, así como desplomes u otras deformaciones. } \\
\text { Erosión anormal o excesiva de paños o piezas aisladas, }\end{array}$ & 13 & 63,66 & & & & 827,58 \\
\hline 3.3 & F.3 & $\mathrm{m} 2$ & $\begin{array}{l}\text { Limpieza hoja exterior fachada mediante los procedimientos } \\
\text { usuales tales como lavado con agua, limpieza química o } \\
\text { proyección de abrasivos, a realizar cada } 10 \text { años. }\end{array}$ & 13 & 63,66 & & & & 827,58 \\
\hline \multicolumn{10}{|c|}{ CAPÍTULO 4- CARPINTERÍA EXTERIOR } \\
\hline 4.1 & FC.1 & Ud & $\begin{array}{l}\text { Comprobación anual en carpintería exterior del } \\
\text { funcionamiento de cierres automáticos, retenedores } \\
\text { magnéticos, mecanismos inclinados, motores hidráulicos, } \\
\text { etc. Reparación anual sobre carpintería exterior de aluminio, } \\
\text { de los elementos de cierre y sujeción, en caso necesario. }\end{array}$ & 13 & 1 & & & & 13 \\
\hline 4.2 & FC. 2 & Ud & $\begin{array}{l}\text { Revisión cada } 5 \text { años sobre la carpintería exterior, para } \\
\text { verificar el buen estado de la masilla, burletes y perfiles de } \\
\text { sellado. }\end{array}$ & 13 & 1 & & & & 13 \\
\hline 4.3 & FC. 3 & Ud & $\begin{array}{l}\text { En carpintería exterior cada } 10 \text { años: Inspección del anclaje } \\
\text { de los marcos de las puertas a las paredes y renovación del } \\
\text { sellado de los marcos con la fachada }\end{array}$ & 13 & 1 & & & & 13 \\
\hline \multicolumn{10}{|c|}{ CAPITULO 5- PUERTA GARAJE } \\
\hline 5.1 & PG.1 & Ud & $\begin{array}{l}\text { Revisión anual en puertas de garaje, consistente en: } \\
\text { revisión de los herrajes de colgar (engrasándolos con aceite } \\
\text { ligero si fuera necesario), del estado de los mecanismos y } \\
\text { del líquido de freno retenedor, en su caso, y del estado de } \\
\text { los elementos del equipo automático. Engrase de las guías } \\
\text { de los cierres y los elementos de articulación, con pincel y } \\
\text { aceite multigrado o grasa termoestable. Revisión y engrase } \\
\text { con aceite ligero de los herrajes de cierre y de seguridad. }\end{array}$ & 13 & 1 & & & & 13 \\
\hline 5.2 & PG.2 & Ud & $\begin{array}{l}\text { Cada } 5 \text { años, renovación de la pintura de las puertas, en } \\
\text { ambientes no agresivos. }\end{array}$ & 13 & 1 & & & & 13 \\
\hline
\end{tabular}




\begin{tabular}{|c|c|c|c|c|c|c|c|c|}
\hline \multicolumn{4}{|r|}{ ESTADO Nº 1} & \multicolumn{5}{|c|}{ MEDICIONES } \\
\hline \multirow{3}{*}{$\begin{array}{c}\mathrm{N}^{\circ} \\
\text { Ord }\end{array}$} & \multirow{3}{*}{ Códig } & & & & & & & oja: 2 \\
\hline & & \multirow[b]{2}{*}{ Uds. } & \multirow{2}{*}{ DESCRIPCION } & \multicolumn{3}{|c|}{ DIMENSIONES } & \multicolumn{2}{|c|}{ CANTIDADES } \\
\hline & & & & \begin{tabular}{|c|} 
P. \\
Igual \\
\end{tabular} & $\mathrm{x}$ & $\mathrm{y}$ & \begin{tabular}{|l|l|l|}
$z$ & Parc \\
\end{tabular} & TOTAL \\
\hline \multicolumn{9}{|c|}{ CAPÍTULO 6- PERSIANAS } \\
\hline 6.1 & P.1 & Ud & $\begin{array}{l}\text { Inspección del buen funcionamiento de los elementos } \\
\text { móviles de las persianas enrollables. Inspección del estado } \\
\text { de las lamas para detectar roturas, desencajados y } \\
\text { desplazamientos horizontales y comprobación del buen } \\
\text { estado de conservación de las cintas, cables o manivelas de } \\
\text { elevación. Engrase de los cojinetes de los tornos o de los } \\
\text { elementos móviles correspondientes (en el caso de } \\
\text { persianas con manivela o accionadas eléctricamente). } \\
\text { Operación a realizar anualmente. }\end{array}$ & 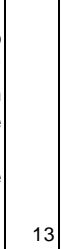 & 1 & & & 13 \\
\hline 6.2 & P.2 & Ud & $\begin{array}{l}\text { Cada } 3 \text { años, inspección de la persiana reparando los } \\
\text { defectos que hayan aparecido y pintado o engrase de los } \\
\text { elementos que lo precisen. Reposición de las cintas de las } \\
\text { persianas enrollables. }\end{array}$ & 13 & 1 & & & 13 \\
\hline \multicolumn{9}{|c|}{ CAPÍTULO 7- VIDRIOS } \\
\hline 7.1 & V.1 & $\mathrm{m}$ & $\begin{array}{l}\text { Cada } 5 \text { años, revisión de las juntas de estanqueidad de } \\
\text { vidrios, reponiéndolas si existen filtraciones (se estima un } \\
25 \% \text { de reposición de un total de } 93,76 \mathrm{~m} \text { ) }\end{array}$ & 13 & 23,44 & & & 304,72 \\
\hline \multicolumn{9}{|c|}{ CAPÍTULO 8- CEOSÍAS } \\
\hline 8.1 & C.1 & $\mathrm{m} 2$ & $\begin{array}{l}\text { Cada } 3 \text { años, repintado de las celosías, en ambientes no } \\
\text { agresivos. }\end{array}$ & 13 & 29,59 & & & 384,67 \\
\hline 8.2 & C.2 & $\mathrm{m} 2$ & $\begin{array}{l}\text { Cada } 5 \text { años, inspección visual de la celosía y, si hubiese } \\
\text { alguna pieza deteriorada, sustitución de la misma (se } \\
\text { supone sustitución del } 20 \% \text { ) }\end{array}$ & 13 & 5,92 & & & 76,934 \\
\hline \multicolumn{9}{|c|}{ CAPITULO 9- INSTALACIÓN AUDIOVISUALES } \\
\hline 9.1 & IAA.1 & Ud & $\begin{array}{l}\text { Revisión anual de instalación audiovisuales de radio y } \\
\text { televisión, consistente en: Revisión del sistema de captación } \\
\text { terrestre, reorientando las antenas y parábolas que se hayan } \\
\text { desviado. Reparación de los preamplificadores de antenas } \\
\text { terrestres y los conversores de parábolas. Revisión de los } \\
\text { cables de distribución, conjuntamente con las tomas y los } \\
\text { conectores de los equipos de Radio-TV, reparándose los } \\
\text { defectos encontrados. Sustitución de las antenas u otro } \\
\text { material dañado, como cables. Ajuste de la tensión de los } \\
\text { ventos y de la presión de las tuercas y tornillos, } \\
\text { revestimiento con imprimación de pintura antioxidante en los } \\
\text { elementos metálicos expuestos a la intemperie y reparación } \\
\text { de la impermeabilización de los anclajes del sistema. } \\
\text { Comprobación de la ganancia de señal en el amplificador, } \\
\text { midiendo la señal a la entrada y salida del mismo. }\end{array}$ & 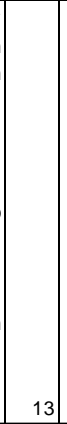 & 1 & & & 13 \\
\hline 9.2 & IAA.3 & Ud & $\begin{array}{l}\text { Revisión anual de instalación audiovisuales de telefonía } \\
\text { básica, consistente en: Revisión tanto de las redes comunes } \\
\text { como de la red interior. Revisión de las líneas de } \\
\text { distribución, conjuntamente con la toma y los conectores de } \\
\text { los equipos telefónicos, reparándose los defectos } \\
\text { encontrados. Revisión del estado de fijación, aparición de } \\
\text { corrosiones o humedades en las cajas de conexión, } \\
\text { instalación y armarios de enlace, base y registro. } \\
\text { Comprobación de la buena recepción y del buen estado de } \\
\text { las tomas de señal. }\end{array}$ & 13 & 1 & & & 13 \\
\hline 9.3 & ICAL.1 & Ud & $\begin{array}{l}\text { Cada } 4 \text { años: Revisión de aparatos exclusivos para la } \\
\text { producción de agua caliente sanitaria de potencia térmica } \\
\text { nominal }<=24,4 \mathrm{~kW} \text {. }\end{array}$ & 13 & 1 & & & 13 \\
\hline 9.4 & ICAL.4 & Ud & $\begin{array}{l}\text { Cada año, en calderas y grupos térmicos de menos de } 70 \\
\text { KW: Comprobación y limpieza, si procede, de circuitos de } \\
\text { humos de calderas. Limpieza del quemador de la caldera. } \\
\text { Comprobación de estanqueidad de cierre entre quemador y } \\
\text { caldera. Revisión general de calderas. Revisión del sistema } \\
\text { de control automático. }\end{array}$ & 13 & 1 & & & 13 \\
\hline
\end{tabular}




\begin{tabular}{|c|c|c|c|c|c|c|c|c|c|}
\hline \multicolumn{4}{|r|}{ ESTADO No 1} & \multicolumn{6}{|c|}{ MEDICIONES } \\
\hline \multirow[b]{3}{*}{$\begin{array}{l}\mathrm{N}^{\mathrm{o}} \\
\text { Ord }\end{array}$} & \multirow[b]{3}{*}{ Códig } & \multirow[b]{3}{*}{ Uds. } & \multirow[b]{3}{*}{ DESCRIPCION } & \multirow{2}{*}{\multicolumn{4}{|c|}{ DIMENSIONES }} & \multirow{2}{*}{\multicolumn{2}{|c|}{\begin{tabular}{|c|} 
Hoja: 3 \\
CANTIDADES \\
\end{tabular}}} \\
\hline & & & & & & & & & \\
\hline & & & & \begin{tabular}{|c|}
$P$. \\
Igual \\
\end{tabular} & $\mathrm{x}$ & $\mathrm{y}$ & $z$ & Parc & TOTAL \\
\hline \multicolumn{10}{|c|}{ CAPÍTULO 11- INSTALACIÓN SOLAR } \\
\hline 11.1 & SOL.1 & Ud & $\begin{array}{l}\text { Revisión anual del sistema de energía solar, consistente en: } \\
\text { Revisión de la instalación para instalaciones con superficie } \\
\text { de captación inferior a } 20 \mathrm{~m}^{2} \text {. Comprobación de la presencia } \\
\text { de lodos en el fondo del depósito del sistema de } \\
\text { acumulación. Comprobación del nivel de desgaste y del } \\
\text { buen funcionamiento de los ánodos del sistema de } \\
\text { acumulación. Comprobación de la presencia de humedad en } \\
\text { el aislamiento. Control de funcionamiento y limpieza del } \\
\text { intercambiador de placas y del serpentín. Inspección visual y } \\
\text { control de funcionamiento en el fluido refrigerante, } \\
\text { aislamiento, purgador, bomba, vaso de expansión, sistema } \\
\text { de llenado y válulas. Control de funcionamiento del cuadro } \\
\text { eléctrico, del control diferencial, del termostato y del sistema } \\
\text { de medida. }\end{array}$ & 13 & 1 & & & & 13 \\
\hline \multicolumn{10}{|c|}{ CAPÍTULO 12- INSTALACIÓN ELÉCTRICA } \\
\hline 12.1 & IE.1 & Ud & $\begin{array}{l}\text { Cada año revisión en instalación eléctrica de vivienda, } \\
\text { consistente en: Comprobación del funcionamiento de todos } \\
\text { los interruptores del cuadro de mando y protección, } \\
\text { verificando que son estables en sus posiciones de abierto y } \\
\text { cerrado. Revisión de las instalaciones de garajes por } \\
\text { instaladores autorizados libremente elegidos por los } \\
\text { propietarios o usuarios de la instalación. El instalador } \\
\text { extenderá un boletín de reconocimiento de la indicada } \\
\text { revisión, que será entregado al propietario de la instalación. }\end{array}$ & 13 & 1 & & & & 13 \\
\hline 12.2 & IE. 2 & Ud & $\begin{array}{l}\text { Cada } 2 \text { años, revisión sobre la instalación eléctrica, } \\
\text { consistente en: Revisión general, comprobando el estado del } \\
\text { cuadro de mando y protección, los mecanismos alojados y } \\
\text { conexiones. Comprobación mediante inspección visual del } \\
\text { estado del interruptor de corte y de los fusibles de } \\
\text { protección, el estado frente a la corrosión de la puerta del } \\
\text { armario y la continuidad del conductor de puesta a tierra del } \\
\text { marco metálico de la misma. Verificación del estado de } \\
\text { conservación de las cubiertas aislantes de los interruptores } \\
\text { y bases de enchufe de la instalación, reparándose los } \\
\text { defectos encontrados. }\end{array}$ & 13 & 1 & & & & 13 \\
\hline 12.3 & 19.3 & Ud & $\begin{array}{l}\text { Cada } 5 \text { años, revisión sobre la instalación eléctrica, } \\
\text { consistente en: Comprobación de los dispositivos de } \\
\text { protección contra cortocircuitos, contactos directos e e } \\
\text { indirectos, así como sus intensidades nominales en relación } \\
\text { a la sección de los conductores que protegen, reparándose } \\
\text { los defectos encontrados. Revisión de la rigidez dieléctrica } \\
\text { entre los conductores. }\end{array}$ & 13 & 1 & & & & 13 \\
\hline 12.4 & $1 \boxminus .4$ & Ud & $\begin{array}{l}\text { Cada } 10 \text { años, revisión sobre la instalación eléctrica, } \\
\text { consistente en: Revisión general de la instalación. Todos los } \\
\text { temas de cableado son exclusivos de la empresa } \\
\text { autorizada. }\end{array}$ & 13 & 1 & & & & 13 \\
\hline \multicolumn{10}{|c|}{ CAPITULO 13- INSTALACIÓN FONTANERÍA } \\
\hline 13.1 & IF.1 & Ud & $\begin{array}{l}\text { Cada } 2 \text { años: Revisión de la instalación de fontanería en } \\
\text { general y, si existieran indicios de alguna manifestación } \\
\text { patológica tales como corrosión o incrustación, se efectuaría } \\
\text { una prueba de estanqueidad y presión de funcionamiento, } \\
\text { bajo la supervisión de un técnico competente. }\end{array}$ & 13 & 1 & & & & 13 \\
\hline 13.2 & IF.4 & Ud & $\begin{array}{l}\text { Limpieza de los canalones y comprobación de su correcto } \\
\text { funcionamiento, al final del verano. }\end{array}$ & 13 & 1 & & & & 13 \\
\hline 13.3 & IF.5 & Ud & $\begin{array}{l}\text { Cada } 2 \text { años, revisión de toda la red de pluviales, } \\
\text { comprobando su estanqueidad o sujeción y reparando los } \\
\text { desperfectos que se observen. }\end{array}$ & 13 & 1 & & & & 13 \\
\hline
\end{tabular}




\begin{tabular}{|c|c|c|c|c|c|c|c|c|}
\hline \multicolumn{4}{|r|}{ ESTADO No 1} & \multicolumn{5}{|c|}{ MEDICIONES } \\
\hline \multirow{3}{*}{$\begin{array}{c}\mathrm{N}^{\circ} \\
\text { Ord }\end{array}$} & \multirow[b]{3}{*}{ Códig } & \multirow[b]{3}{*}{ Uds. } & \multirow[b]{3}{*}{ DESCRIPCION } & & & & & oja: 4 \\
\hline & & & & \multicolumn{3}{|c|}{ DIMENSIONES } & \multicolumn{2}{|c|}{ CANTIDADES } \\
\hline & & & & \begin{tabular}{|c|}
$P$. \\
Igual
\end{tabular} & $\mathrm{x}$ & $y$ & \begin{tabular}{|l|l|l|}
$z$ & Parc \\
\end{tabular} & TOTAL \\
\hline \multicolumn{9}{|c|}{ CAPITULOO 14- INSTALACIÓN GAS } \\
\hline 14.1 & IGI.1 & Ud & $\begin{array}{l}\text { Cada año revisión de la instalación de gas, consistente en: } \\
\text { Comprobación del adecuado aspecto de las canalizaciones } \\
\text { y válvulas. Verificación del estado de la canalización con } \\
\text { agua jabonosa, nunca con llama, para detectar posibles } \\
\text { fugas. }\end{array}$ & 13 & 1 & & & 13 \\
\hline 14.2 & $1 \mathrm{GI} .2$ & Ud & $\begin{array}{l}\text { Cada } 5 \text { años: Revisión de la instalación de gas, emitiendo un } \\
\text { certificado acreditativo de dicha revisión que quedará en } \\
\text { poder del usuario. }\end{array}$ & 13 & 1 & & & 13 \\
\hline \multicolumn{9}{|c|}{ CAPÍTULO 15- INSTALACIÓN VENTILACIÓN } \\
\hline 15.1 & IV.1 & Ud & $\begin{array}{l}\text { Cada año, revisión del sistema de ventilación de la vivienda, } \\
\text { consistente en: Comprobación de que no existen problemas } \\
\text { de funcionamiento en los conductos de extracción y de que } \\
\text { los aparatos que evacúan en ellas no sufren anomalías en la } \\
\text { evacuación (falta o exceso de tiro). Comprobación del } \\
\text { funcionamiento adecuado de la aspiración. Inspección visual } \\
\text { del estado del aspirador. Verificación de los elementos } \\
\text { antivibratorios de los ventiladores y extractores, así como los } \\
\text { conductos elásticos de unión con los conductos de } \\
\text { ventilación. }\end{array}$ & 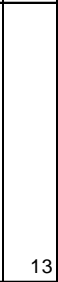 & 1 & & & 13 \\
\hline 15.2 & IV.2 & Ud & $\begin{array}{l}\text { Cada } 5 \text { años, revisión del sistema de ventilación de la } \\
\text { vivienda, consistente en: Comprobación de la estanqueidad } \\
\text { de los conductos de extracción. Limpieza de los conductos } \\
\text { de extracción. Limpieza del aspirador, eliminando aquellos } \\
\text { elementos que se hayan podido fijar sobre él, con cuidado } \\
\text { de que no caigan restos al interior de los conductos. } \\
\text { Limpieza de las aberturas. }\end{array}$ & 13 & 1 & & & 13 \\
\hline 15.3 & IV.4 & Ud & $\begin{array}{l}\text { Cada año, revisión del sistema de ventilación del garaje, } \\
\text { consistente en: Realización de labores de limpieza y } \\
\text { verificación del estado del ventilador, además de la } \\
\text { sustitución o limpieza de filtros, si los posee. Comprobación } \\
\text { del funcionamiento adecuado del ventilador. Inspección } \\
\text { visual del estado del ventilador. Comprobación de que no } \\
\text { existen problemas de funcionamiento en los conductos de } \\
\text { ventilación y de que los aparatos que evacúan en ellas no } \\
\text { sufren anomalías en la evacuación de los productos } \\
\text { procedentes de la combustión (falta o exceso de tiro). } \\
\text { Verificación de los elementos antivibratorios del ventilador, } \\
\text { así como los conductos elásticos de unión con los } \\
\text { conductos de ventilación. }\end{array}$ & 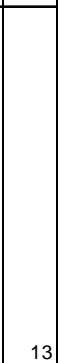 & 1 & & & 13 \\
\hline 15.4 & N.5 & Ud & $\begin{array}{l}\text { Cada } 5 \text { años, revisión del sistema de ventilación del garaje, } \\
\text { consistente en: Limpieza de las rejillas. Comprobación de } \\
\text { las conexiones eléctricas y reparación de los defectos } \\
\text { encontrados. Limpieza del ventilador, eliminando aquellos } \\
\text { elementos que se hayan podido fijar sobre él, con cuidado } \\
\text { de que no caigan restos al interior de los conductos. } \\
\text { Comprobación de la estanqueidad de los conductos de } \\
\text { ventilación. Limpieza de los conductos de ventilación. }\end{array}$ & 13 & 1 & & & 13 \\
\hline 15.5 & QAC.1 & Ud & $\begin{array}{l}\text { Anualmente revisión canalización recogida aguas pluviales y } \\
\text { reparación posibles desperfectos }\end{array}$ & 13 & 1 & & & 13 \\
\hline 15.6 & QAC.2 & Ud & $\begin{array}{l}\text { Cada } 3 \text { años, revisión sobre cubiertas planas ventiladas, } \\
\text { consistente en: Conservación en buen estado de los } \\
\text { elementos de albañilería relacionados con el sistema de } \\
\text { estanqueidad, tales como petos. Comprobación de la fijación } \\
\text { de la impermeabilización al soporte y reparación de los } \\
\text { defectos observados. Comprobación del estado de } \\
\text { conservación de la protección, verificando que se mantiene } \\
\text { en las condiciones iniciales. }\end{array}$ & 13 & 1 & & & 13 \\
\hline
\end{tabular}




\begin{tabular}{|c|c|c|c|c|c|c|c|c|}
\hline \multicolumn{4}{|r|}{ ESTADO No 1} & \multicolumn{5}{|c|}{ MEDICIONES } \\
\hline \multirow[b]{3}{*}{$\begin{array}{l}\mathrm{N}^{\circ} \\
\text { Ord }\end{array}$} & \multirow[b]{3}{*}{ Códig } & & & & & & & oja: 5 \\
\hline & & \multirow[b]{2}{*}{ Uds. } & \multirow[b]{2}{*}{ DESCRIPCION } & \multicolumn{3}{|c|}{ DIMENSIONES } & \multicolumn{2}{|c|}{ CANTIDADES } \\
\hline & & & & \begin{tabular}{|c|} 
P. \\
Igual \\
\end{tabular} & $\mathrm{x}$ & $y$ & $z$ Parc & TOTAL \\
\hline \multicolumn{9}{|c|}{ CAPÍTULO 16- REVESTIMIENTOS } \\
\hline 16.1 & RAG.1 & Ud & $\begin{array}{l}\text { Cada } 3 \text { años, revisión revestimientos cerámicos o de gres, } \\
\text { mediante la comprobación de la ausencia de procesos } \\
\text { patológicos tales como erosión mecánica, erosión química, } \\
\text { grietas y fisuras, desprendimientos, humedades capilares y } \\
\text { humedades accidentales. Revisión revestimientos cerámicos } \\
\text { o de gres, mediante la inspección del estado de las juntas } \\
\text { entre piezas y de las juntas de dilatación, comprobando su } \\
\text { estanqueidad al agua y reponiendo, cuando sea necesario, } \\
\text { los correspondientes sellados. Revisión de los distintos } \\
\text { revestimientos, con reposición cuando sea necesario. } \\
\text { Comprobación del estado de los cubrejuntas, rodapiés y } \\
\text { cantoneras con material de relleno y sellado. }\end{array}$ & \multicolumn{3}{|c|}{$\begin{array}{l}1 \\
5 \\
\\
5 \\
\\
\\
\\
\\
\\
\end{array}$} & & 13 \\
\hline 16.2 & RIP.1 & $\mathrm{m} 2$ & $\begin{array}{l}\text { Cada } 5 \text { años, reposición pinturas en interiores, } \\
\text { humedeciendo el paramento con abundante agua mediante } \\
\text { brocha, rascando a continuación el revestimiento con } \\
\text { espátula, cepillos de púas, rasqueta o lijadores mecánicos } \\
\text { hasta su total eliminación. Pintura plástica con textura lisa, } \\
\text { color blanco, acabado mate, sobre paramentos horizontales } \\
\text { y verticales interiores de yeso o escayola, preparación del } \\
\text { soporte con plaste de interior, mano de fondo y dos manos } \\
\text { de acabado (rendimiento: } 0,125 \mathrm{l} / \mathrm{m}^{2} \text { cada mano). }\end{array}$ & \multicolumn{3}{|c|}{ 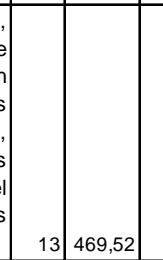 } & & 6103,8 \\
\hline 16.3 & RMB.1 & $\mathrm{m} 2$ & $\begin{array}{l}\text { Cada } 5 \text { años: Reposición del barniz sobre soporte exterior, } \\
\text { en carpintería de madera, eliminando previamente la pintura } \\
\text { existente mediante procedimientos tales como mecánicos, } \\
\text { quemado con llama, ataque químico o decapantes técnicos, } \\
\text { en ambientes agresivos. Barniz sintético, incoloro, acabado } \\
\text { brillante, sobre superficie de carpintería exterior de madera, } \\
\text { preparación del soporte, mano de fondo protector, } \\
\text { insecticida, fungicida y termicida (rendimiento: } 0,2 \mathrm{l} / \mathrm{m}^{2} \text { ) y } \\
\text { dos manos de acabado con barniz sintético a poro cerrado } \\
\text { (rendimiento: } 0,083 \mathrm{l} / \mathrm{m}^{2} \text { cada mano). }\end{array}$ & \multicolumn{3}{|c|}{ 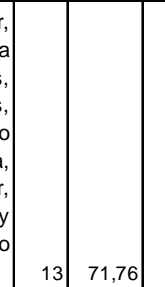 } & & 932,88 \\
\hline 16.4 & RNE1 & $\mathrm{m} 2$ & $\begin{array}{l}\text { Cada } 5 \text { años: Reposición del barniz sobre soporte exterior, } \\
\text { en elementos metálicos, eliminando previamente la pintura } \\
\text { existente mediante procedimientos tales como mecánicos, } \\
\text { quemado con llama, ataque químico o decapantes técnicos, } \\
\text { en ambientes agresivos. }\end{array}$ & \multicolumn{3}{|c|}{, } & & 156 \\
\hline 16.5 & RSM.1 & $\mathrm{m} 2$ & $\begin{array}{l}\text { Cada } 5 \text { años, inspección general del pavimento de parquet, } \\
\text { procediéndose a las reparaciones necesarias bajo dirección } \\
\text { de técnico competente, si fuera necesario, consistentes en } \\
\text { acuchillado, lijado y barnizado. }\end{array}$ & \multicolumn{2}{|c|}{$13 \quad 48,84$} & & & 634,92 \\
\hline \multicolumn{9}{|c|}{ CAPÍTULO 17-SEGURIDAD CONTRA INCENDIOS } \\
\hline 17.1 & SI.1 & Ud & $\begin{array}{l}\text { Inspección ocular extintor portátil de polvo químico ABC } \\
\text { polivalente antibrasa, con presión incorporada, de eficacia } \\
21 \mathrm{~A}-113 \mathrm{~B}-\mathrm{C}, \text { con } 6 \mathrm{~kg} \text { de agente extintor: seguros, } \\
\text { precintos, peso, presión, mangueras, etc }\end{array}$ & 13 & 1 & & & 13 \\
\hline 17.2 & SI.2 & Ud & $\begin{array}{l}\text { Inspección ocular extintor con carro, de polvo químico ABC } \\
\text { polivalente antibrasa, con presión incorporada, de eficacia } \\
\text { ABC, con } 50 \mathrm{~kg} \text { de agente extintor: seguros, precintos, } \\
\text { peso, presión, mangueras, etc }\end{array}$ & 1 & 1 & & & \\
\hline
\end{tabular}




\section{2.- CRONOGRAMA OPERACIONES MANTENIMIENTO}

El ejemplo aportado corresponde a la zona A3 y calificación C. En total se realizan 50 cronogramas, uno por configuración. En las siguientes 4 páginas aparecen las tablas para cada periodo de 25 años, a saber: años 1-25, años 26-50, años 51-75 y años 76-100. En cada casilla se muestra la cantidad a abonar por operación de mantenimiento. Existen solapes de operaciones que se muestran en las celdas oscurecidas.

Leyenda:

Indica el año en que se realiza la operación de mantenimiento

Indica el año en que no se realiza por estar incluida en otra operación 


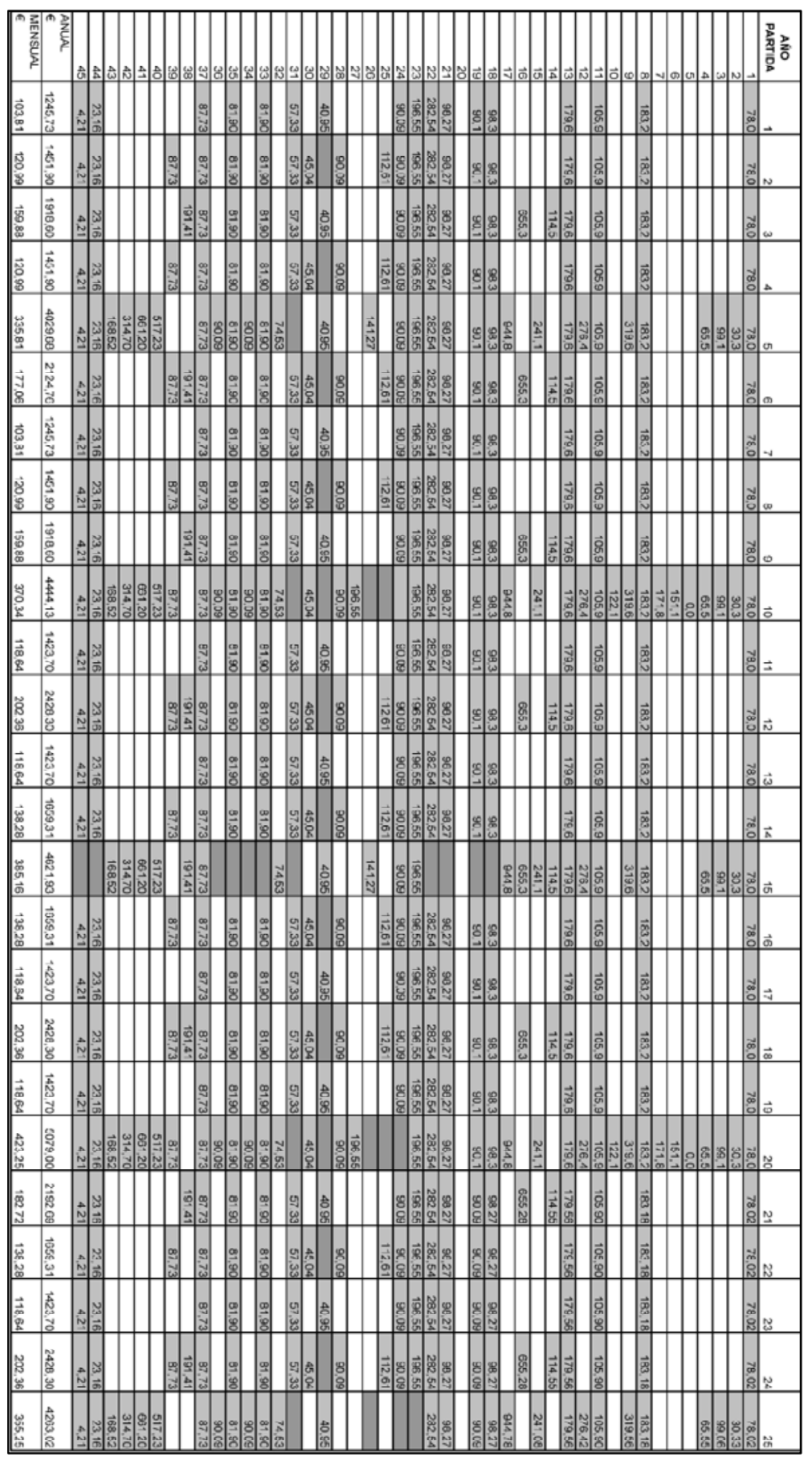




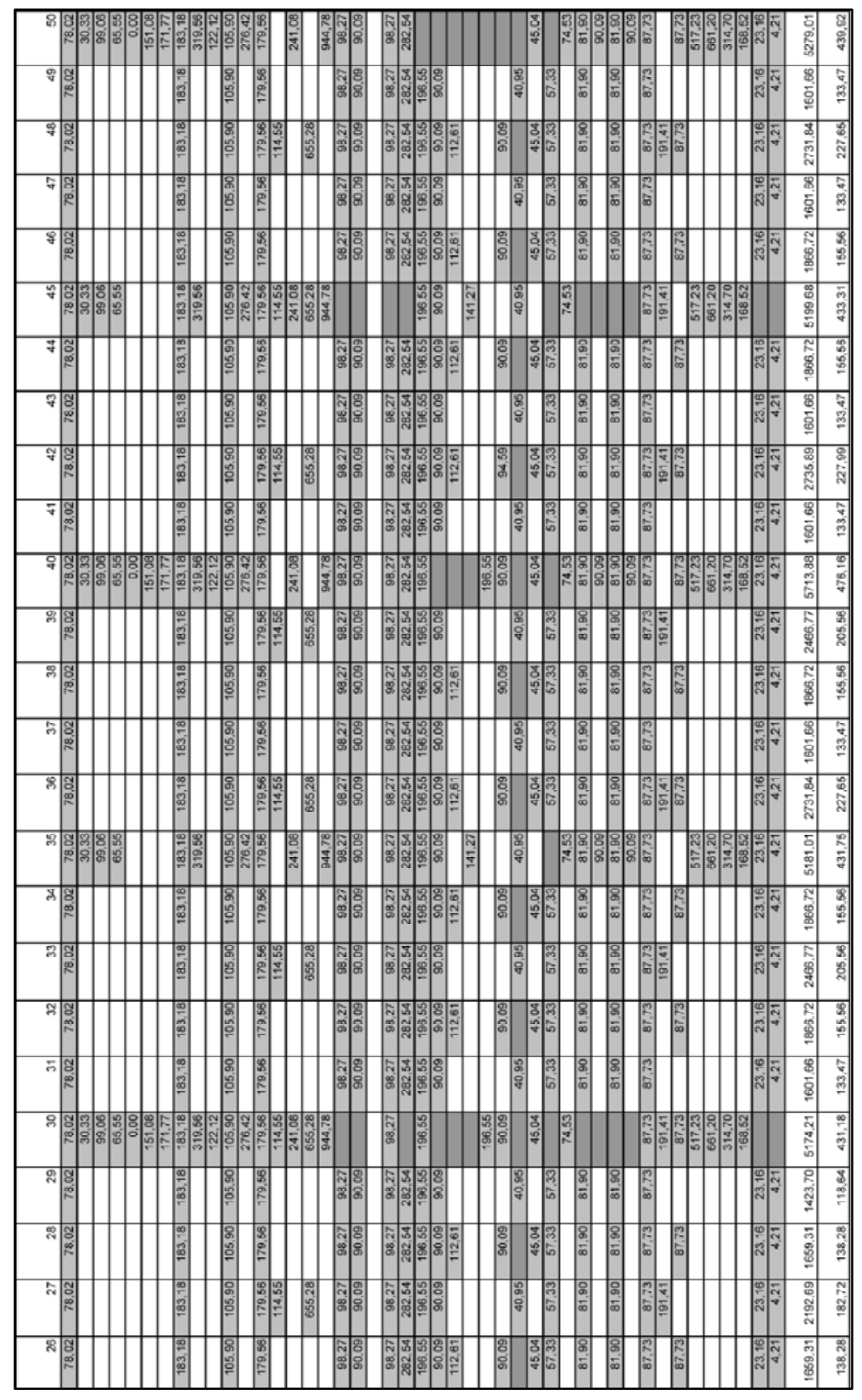




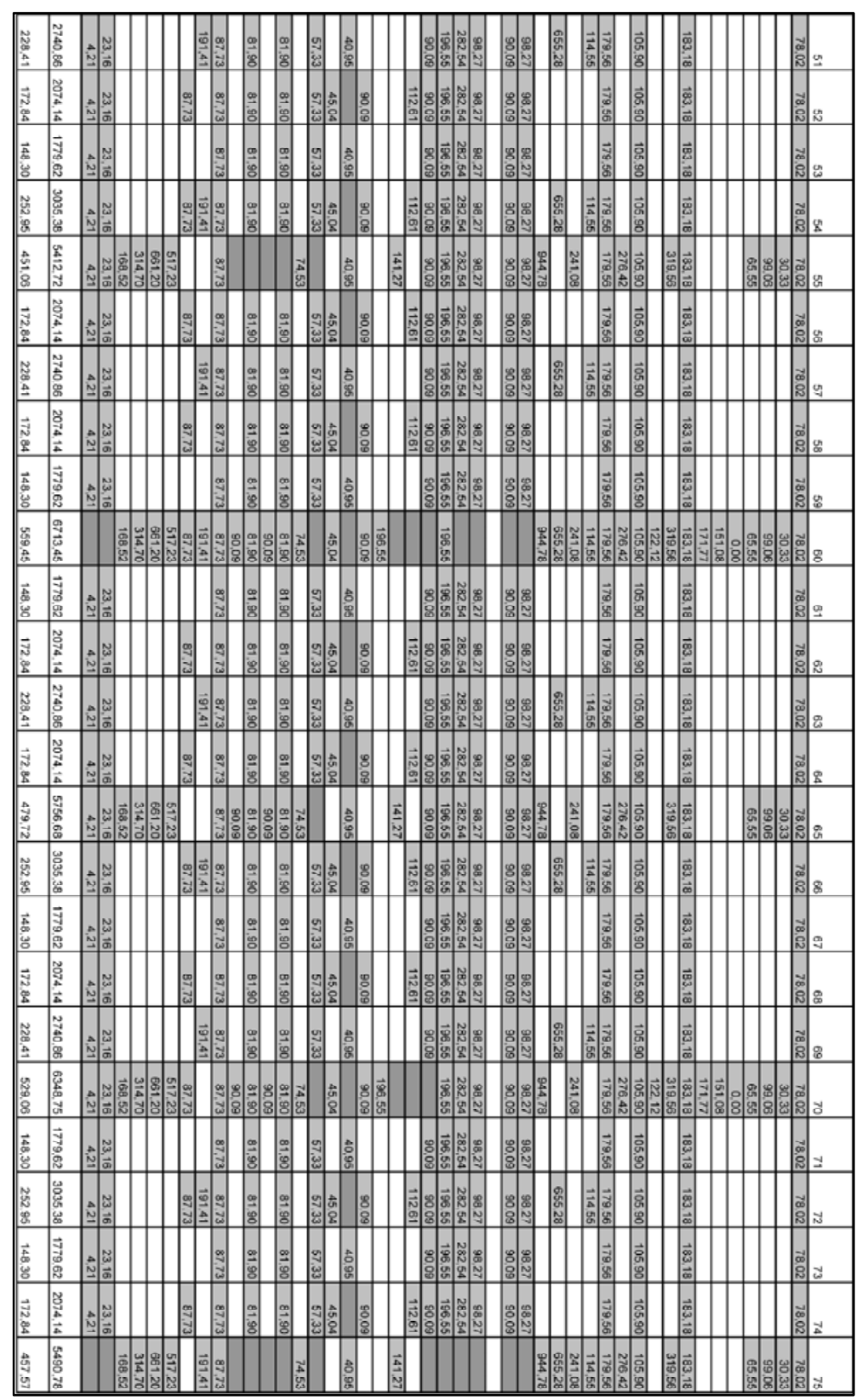




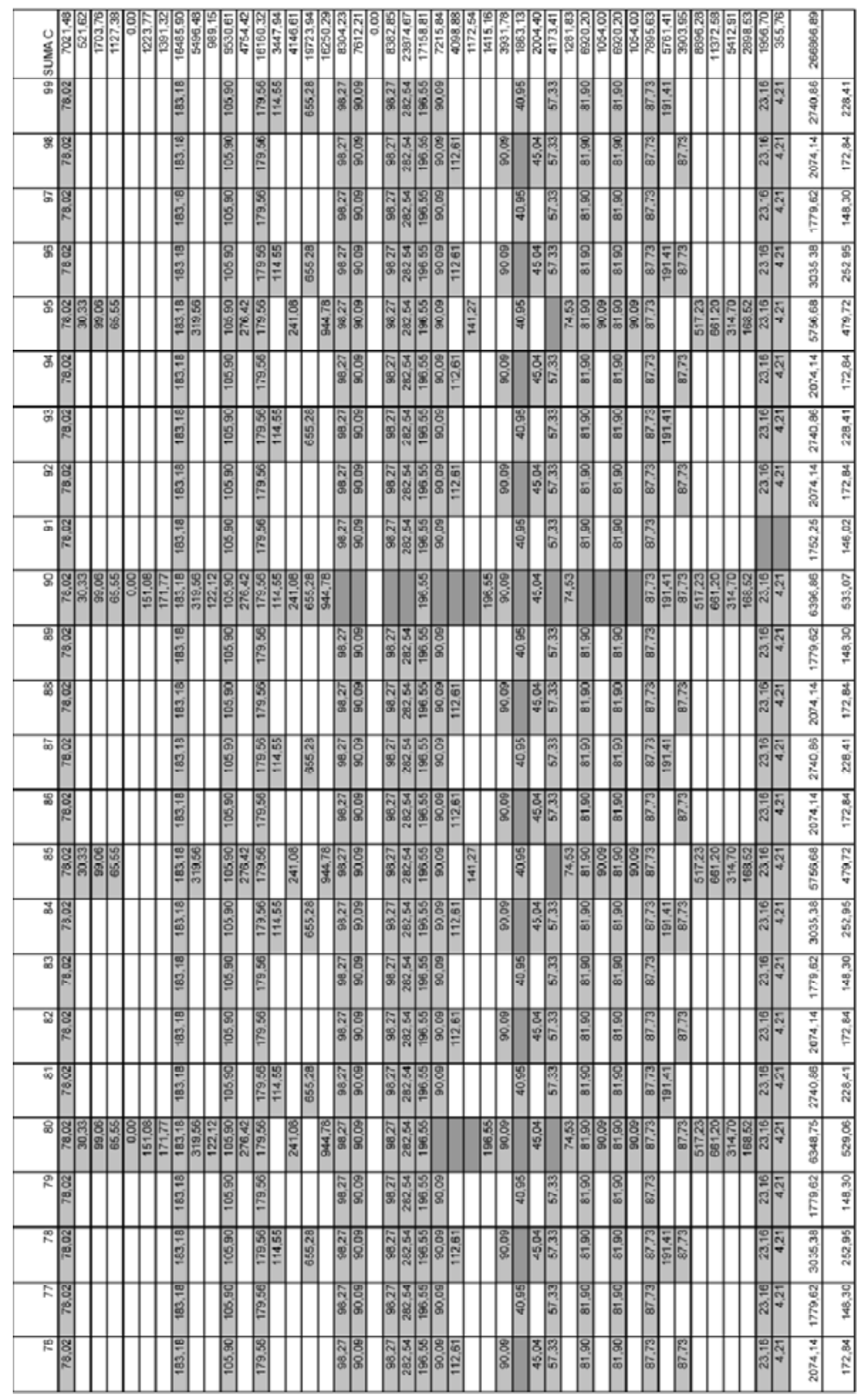




\section{3.- PRECIOS MANTENIMIENTO POR ZONAS CLIMÁTICAS}

\begin{tabular}{|c|c|c|c|c|c|c|c|c|c|c|c|c|}
\hline \multicolumn{5}{|c|}{ ESTADO N ${ }^{\circ}$ 2- CUADRO 1} & \multicolumn{8}{|c|}{ PRECIOS UNITARIOS-COMPLEJOS. HOJA No 1} \\
\hline n & A3 & A4 & B3 & B4 & C1 & C2 & C3 & $\mathrm{C4}$ & D1 & $\mathrm{D} 2$ & D3 & E1 \\
\hline \multicolumn{13}{|c|}{ APÍTULO 1-RED HORIZONTAL DE SANEAMIENTO } \\
\hline 1.1 & 65,56 & 63,68 & 57,00 & 69,16 & 63,32 & 79,48 & 70,80 & 56,04 & 73,52 & 67,48 & 63,80 & 67,76 \\
\hline 1.2 & 25,48 & 24,78 & 22,27 & 6,83 & 4,64 & 30,70 & 27,45 & 21,91 & 28,47 & 26,20 & 24,82 & 26,31 \\
\hline \multicolumn{13}{|c|}{ CAPITULO 2-MUROS Y SOLERAS } \\
\hline 2.1 & 83,24 & 80,03 & 81,39 & 85,99 & 86,51 & 106,07 & 79,31 & 68,06 & 96,87 & 93,60 & 94,30 & 78,61 \\
\hline 2.2 & 55,08 & 53,06 & 53,73 & 57,14 & 57,06 & 70,77 & 53,25 & 45,20 & 65,00 & 62,48 & 61,86 & 52,52 \\
\hline \multicolumn{13}{|c|}{ CAPITULO 3-FACHADAS } \\
\hline 3.1 & 18,67 & 18,60 & 17,93 & 18,01 & 19,06 & 18,89 & 17,26 & 17,26 & 17,25 & 18,19 & 18,76 & 17,17 \\
\hline 3.2 & 58 & 10,97 & 11,03 & 11,20 & 11,48 & 13,72 & 9,71 & 9,71 & 12,22 & 12,16 & 13,18 & 10,58 \\
\hline 3.3 & 12,03 & 10,62 & 11,24 & 11,30 & 12,20 & 14,11 & 9,22 & 8,50 & 12,10 & 11,96 & 14,08 & 9,60 \\
\hline \multicolumn{13}{|c|}{ CAPITULO 4-CARPINTERIA EXTERIOR } \\
\hline 4.1 & 153,93 & 152,31 & 146,52 & 161,07 & 152,91 & 187,08 & 152,94 & 149,43 & 179,70 & 168,54 & 154,32 & 158,01 \\
\hline 4.2 & 268,54 & 266,38 & 258,66 & 278,06 & 267,18 & 312,74 & 267,22 & 262,54 & 302,90 & 288,02 & 269,06 & 273,98 \\
\hline 4.3 & 102,62 & 101,54 & 97,68 & 107,38 & 101,94 & 124,72 & 101,96 & 99,62 & 119,80 & 112,36 & 102,88 & 105,34 \\
\hline \multicolumn{13}{|c|}{ CAPITIULO 5-PUERTA GARAJE } \\
\hline 5.1 & 88,99 & 87,91 & 84,05 & 93,75 & 88,31 & 111,09 & 88,33 & 85,99 & 106,17 & 98,73 & 89,25 & 91,71 \\
\hline 5.2 & 232,29 & 222,57 & 233,71 & 232,43 & 247,57 & 280,14 & 198,71 & 187,14 & 246,29 & 243,57 & 279,14 & 196,43 \\
\hline \multicolumn{13}{|c|}{ CAPITULO 6-PERSIANAS } \\
\hline 6.1 & 150,89 & 149,27 & 143,48 & 158,03 & 149,87 & 184,04 & 149,90 & 146,39 & 176,66 & 165,50 & 151,28 & 154,97 \\
\hline 6.2 & 96,26 & 95,18 & 91,32 & 101,02 & 95,58 & 118,36 & 95,60 & 93,26 & 113,44 & 106,00 & 96,52 & 98,98 \\
\hline \multicolumn{13}{|c|}{ CAPITULO 7-VIDRIOS } \\
\hline 7.1 & 202,59 & 200,97 & 195,18 & 209,73 & 201,57 & 235,74 & 201,60 & 198,09 & 228,36 & 217,20 & 202,98 & 206,67 \\
\hline \multicolumn{13}{|c|}{ CAPITULO 8-CELOSIA S Y CERRAJERRA } \\
\hline 8.1 & 18,61 & 14,84 & 15,58 & 15,50 & 16,50 & 18,68 & 13,25 & 12,48 & 16,42 & 16,24 & 18,61 & 13,10 \\
\hline 8.2 & 134,16 & 133,58 & 134,22 & 134,17 & 135,03 & 136,93 & 132,21 & 131,53 & 134,96 & 134,82 & 136,86 & 132,58 \\
\hline \multicolumn{13}{|c|}{ CAPITULO 9- INSTALACIÓN AUDIOVISUALES } \\
\hline 9.1 & 82,58 & 81,43 & 76,66 & 88,51 & 81,96 & 109,49 & 90,48 & 70,61 & 103,58 & 98,40 & 83,06 & 86,04 \\
\hline 9.2 & 75,70 & 74,65 & 70,27 & 81,14 & 75,13 & 100,36 & 82,94 & 64,72 & 94,95 & 90,20 & 76,14 & 78,87 \\
\hline \multicolumn{13}{|c|}{ CAPITULO 10- CLIMA TIZACIÓN } \\
\hline 10.1 & 67,10 & 66,16 & 62,28 & 71,92 & 66,59 & 88,96 & 73,52 & 57,37 & 84,16 & 79,95 & 67,49 & 69,91 \\
\hline 10.2 & 82,58 & 81,43 & 76,66 & 88,51 & 81,96 & 109,49 & 90,48 & 70,61 & 103,58 & 98,40 & 83,06 & 86,04 \\
\hline \multicolumn{13}{|c|}{ CAPITULO 11- INSTALACIÓN SOLAR } \\
\hline 11.1 & 165,17 & 171,01 & 160,98 & 185,88 & 172,12 & 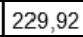 & 190,01 & 148, & 217 & 206,64 & 174,4 &, 00 \\
\hline \multicolumn{13}{|c|}{ CAPITULO 12- INS TALACIÓN EEÉCTRICA } \\
\hline 12.1 & 75,70 & 74,65 & 70,27 & 81,14 & 75,13 & 100,36 & 82,94 & 64,72 & 94,95 & 90,20 & 76,14 & 78,87 \\
\hline 12.2 & 94,63 & 93,31 & 87,84 & \begin{tabular}{|l|}
101,42 \\
\end{tabular} & 93,91 & 125,46 & 103,68 & 80,91 & 118,69 & 112,75 & 95,18 & 98,59 \\
\hline 12.3 & 118,71 & 117,06 & 110,19 & 127,24 & $\begin{array}{l}117,82 \\
\end{array}$ & 157,39 & 130,07 & 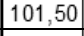 & 148,90 & 141,45 & 119,40 & 123,68 \\
\hline 12.4 & 165,17 & 162,86 & 153,31 & \begin{tabular}{|l|}
177,02 \\
\end{tabular} & 163,92 & 218,98 & 180,96 & 141,22 & 207,17 & 196,80 & 166,13 & 172,08 \\
\hline
\end{tabular}




\begin{tabular}{|c|c|c|c|c|c|c|c|c|c|c|c|c|}
\hline \multicolumn{6}{|c|}{ ESTADO N ${ }^{0} 2$ - CUADRO 1} & \multicolumn{7}{|c|}{ PRECIOS UNITARIOS-COMPLEJOS. HOJA N 2} \\
\hline NOrden & A3 & A4 & B3 & B4 & c1 & c2 2 & c3 & C4 & D1 & D2 & D3 & E1 \\
\hline \multicolumn{13}{|c|}{ CAPITULO 13- INSTALACIÓN FONTANERÍA } \\
\hline 13.1 & 75,70 & 74,65 & 70,27 & 81,14 & 75,13 & 100,36 & 82,94 & 64,72 & 94,95 & 90,20 & 76,14 & 78,87 \\
\hline 13.2 & 34,41 & 33,93 & 31,94 & 36,88 & 34,15 & 45,62 & 37,70 & 29,42 & 43,16 & 41,00 & 34,61 & 35,85 \\
\hline 13.3 & 37,85 & 37,32 & 35,13 & 40,57 & 37,57 & 50,18 & 41,47 & 32,36 & 47,48 & 45,10 & 38,07 & 39,44 \\
\hline \multicolumn{13}{|c|}{ CAPITULO 14-INSTALACIÓN GAS } \\
\hline 14.1 & 48,17 & 47,50 & 44,72 & 51,63 & 47,81 & 63,87 & 52,78 & 41,19 & 60,42 & 57,40 & 48,45 & 50,19 \\
\hline 14.2 & 62,63 & 61,75 & 58,13 & 67,12 & 62,15 & 83,03 & 68,61 & 53,54 & 78,55 & 74,62 & 62,99 & 65, \\
\hline \multicolumn{13}{|c|}{ CAPITULO 15- INSTALACIÓN VENTILACIÓN } \\
\hline 15.1 & 68,82 & 67,86 & 63,88 & 73,76 & 68,30 & 91,24 & 75,40 & 58,84 & 86,32 & 82,00 & 69,22 & 71,70 \\
\hline 15.2 & 75,70 & 74,65 & 70.27 & 81,14 & 75.13 & 100,36 & 82,94 & 64,72 & 94,95 & 90,20 & 76,14 & 78,87 \\
\hline 15.3 & 68,82 & 67,86 & 63,88 & 73,76 & 68,30 & 91,24 & 75,40 & 58,84 & 86,32 & 82,00 & 69,22 & 71,70 \\
\hline 15.4 & 75,70 & 74,65 & 70,27 & 81,14 & 75,13 & 100,36 & 82,94 & 64,72 & 94,95 & 90,20 & 76,14 & 78,87 \\
\hline \multicolumn{13}{|c|}{ CAPITULO 16- CUBAERTAS } \\
\hline 16.1 & 73,72 & 71,96 & 67,25 & 78,67 & 72,62 & 95,99 & 80,48 & 62,79 & 90,84 & 83,42 & 73,81 & 76,49 \\
\hline 16.2 & 160,85 & 157,01 & 146,74 & 171,65 & 158,45 & 209,42 & 175,58 & 136,99 & 198,19 & 182,02 & 161,04 & 166,9 \\
\hline \multicolumn{13}{|c|}{ CAPITULO 17-REVESTIMIENTOS } \\
\hline 17.1 & 73,72 & 71,96 & 67,25 & 78,67 & 72,62 & 95,99 & 80,48 & 62,79 & 90,84 & 83,42 & 73,81 & 76,49 \\
\hline 17.2 & 0,93 & 0,89 & 0,93 & 0,93 & 0,98 & 1,10 & 0,80 & 0,76 & 0,97 & 0,96 & 1,09 & 0,83 \\
\hline 17.3 & 7,74 & 21,89 & 22,14 & 22,15 & 24,22 & 24,88 & 19,02 & 18,29 & 23,91 & 23,45 & 24,74 & 18,63 \\
\hline 17.4 & 22,04 & 2,90 & 2,94 & 2,94 & 2,99 & 3,11 & 2,81 & 2,77 & 2,99 & 2,98 & 3,11 & 2,84 \\
\hline 17.5 & 2,90 & 6,09 & 6,18 & 6,17 & 6,28 & 6,53 & 5,91 & 5,82 & 6,27 & 6,25 & 6,53 & 5,96 \\
\hline \multicolumn{13}{|c|}{ CAPITULO 18-SEGURIDAD CONTRA INCENDIOS } \\
\hline 18.1 & 19,46 & 20,03 & 19,47 & 22,05 & 20,50 & 28,36 & 22,53 & 17,34 & 27,35 & 25,12 & 21,00 & 21,28 \\
\hline 18.2 & 45,99 & 47,34 & 46,03 & 52,12 & 48,46 & 67,02 & 53,26 & 40,98 & 64,65 & 59,38 & 49,63 & 50,29 \\
\hline
\end{tabular}




\section{ANEXO 3}

3.1.- NORMALIDAD DE LAS VARIABLES

3.2.- ANÁLISIS DE LOS RESIDUOS 

3.1. NORMALIDAD DE LAS VARIABLES

$\mathrm{KgCO}_{2}$
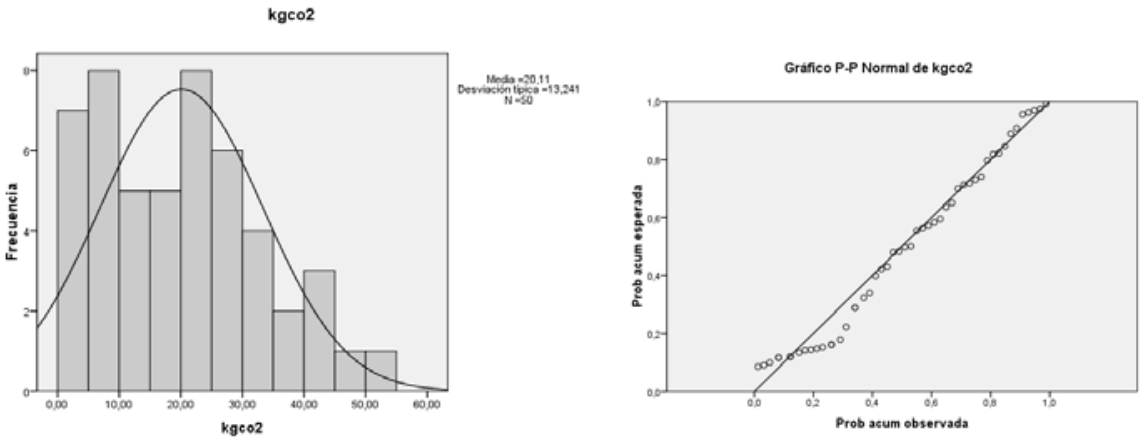

Amortización
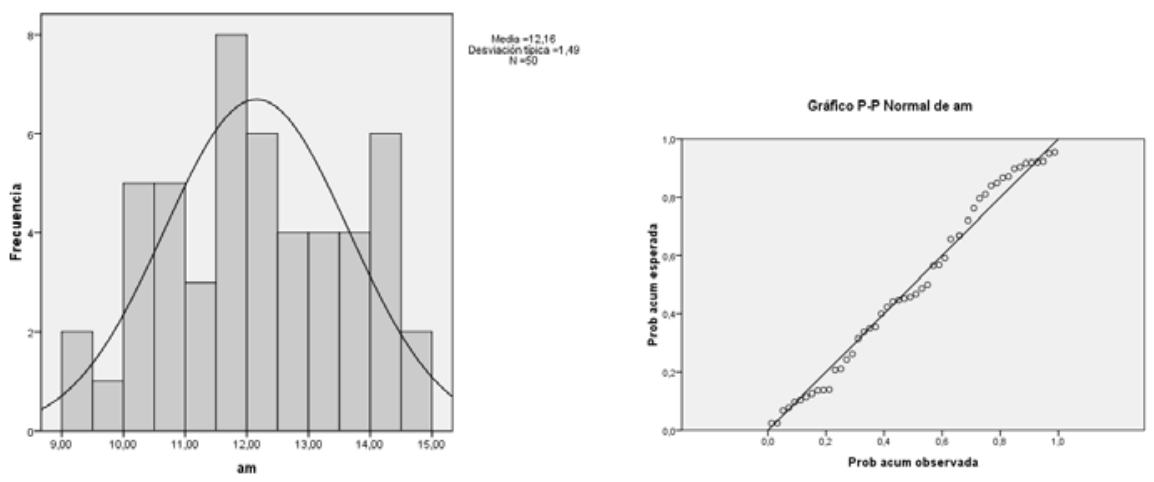

Energía
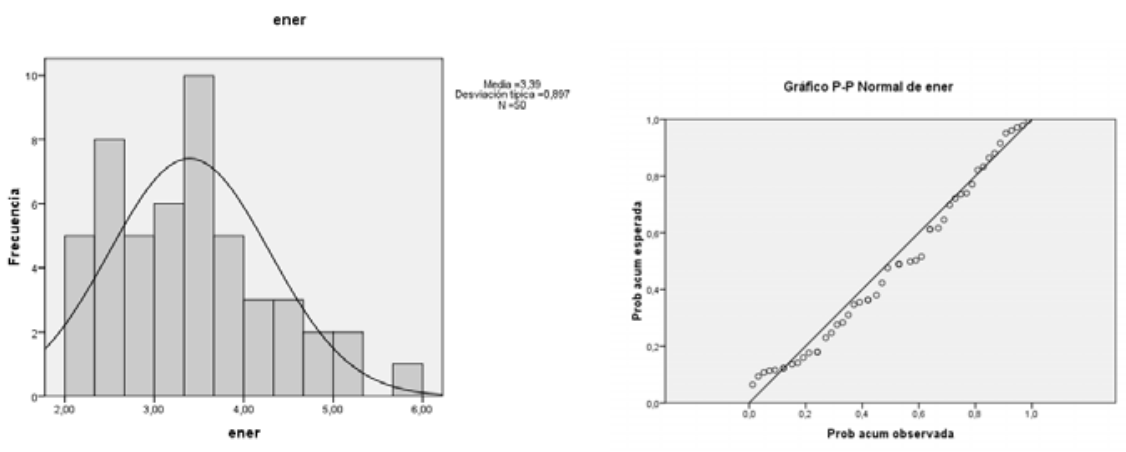

295 

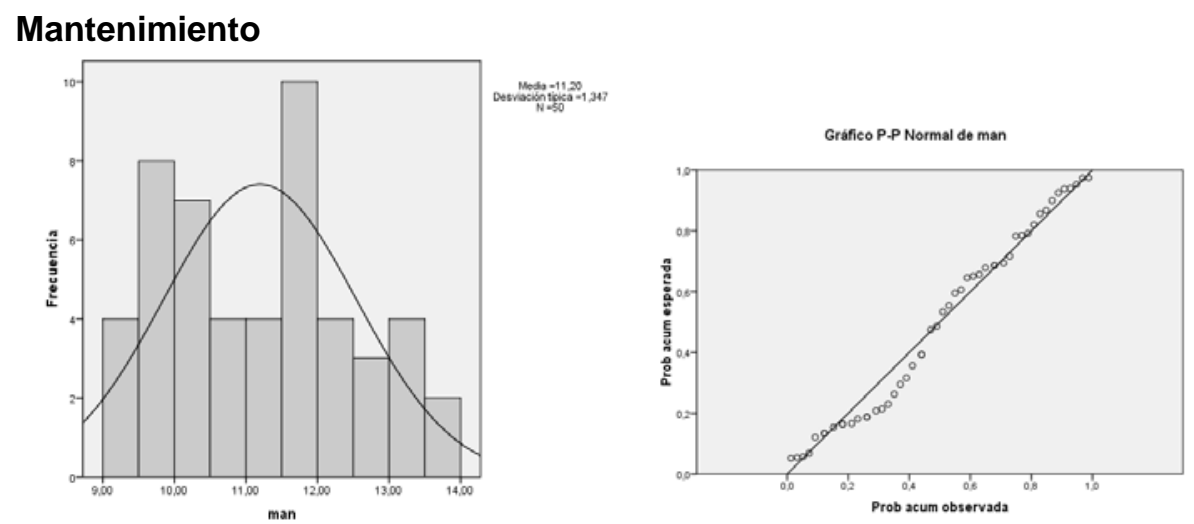

Amortización + Mantenimiento
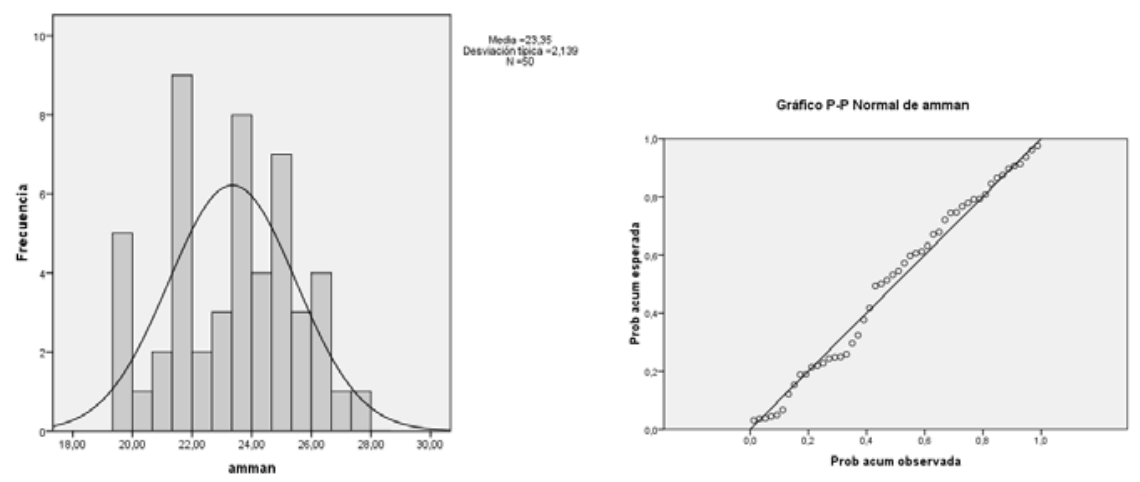

VARIABLES DE ZONA Latitud
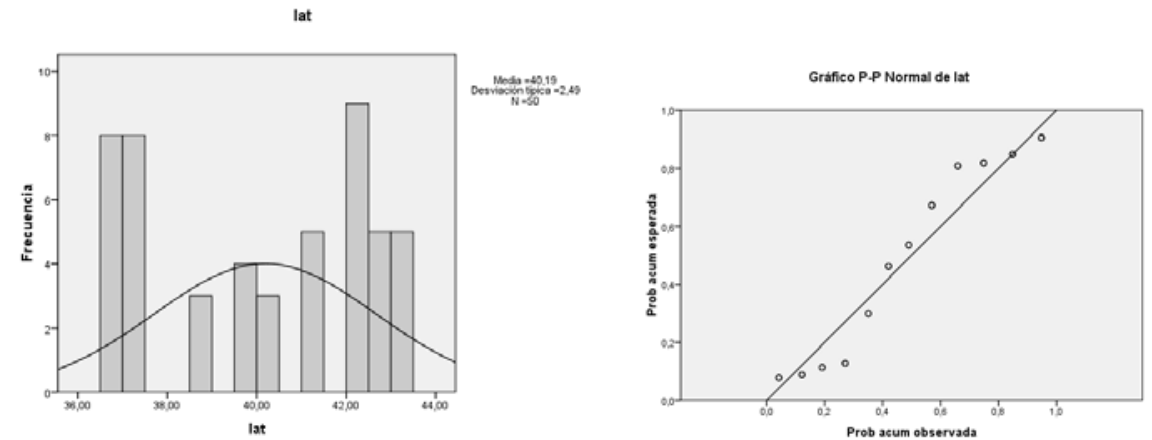


\section{Altitud}
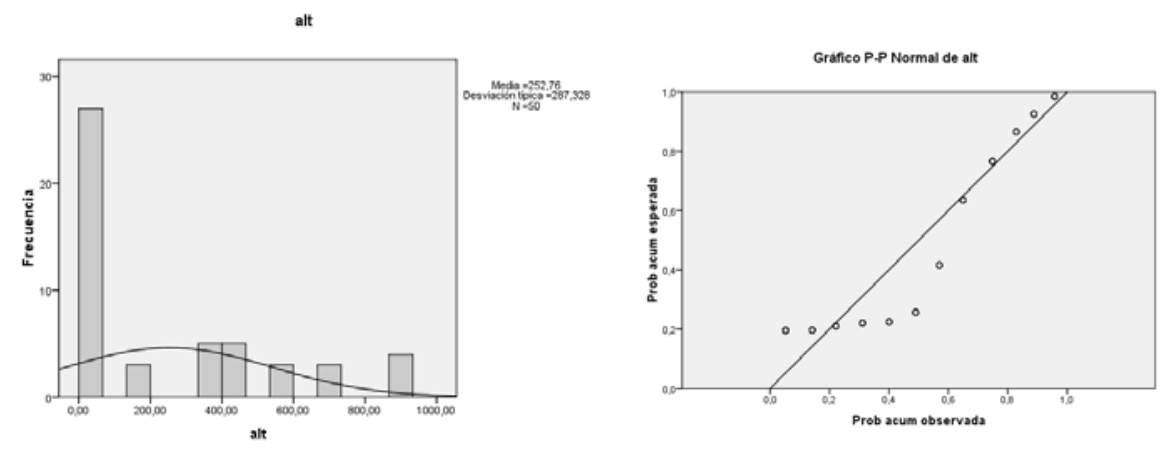

\section{Temperatura}
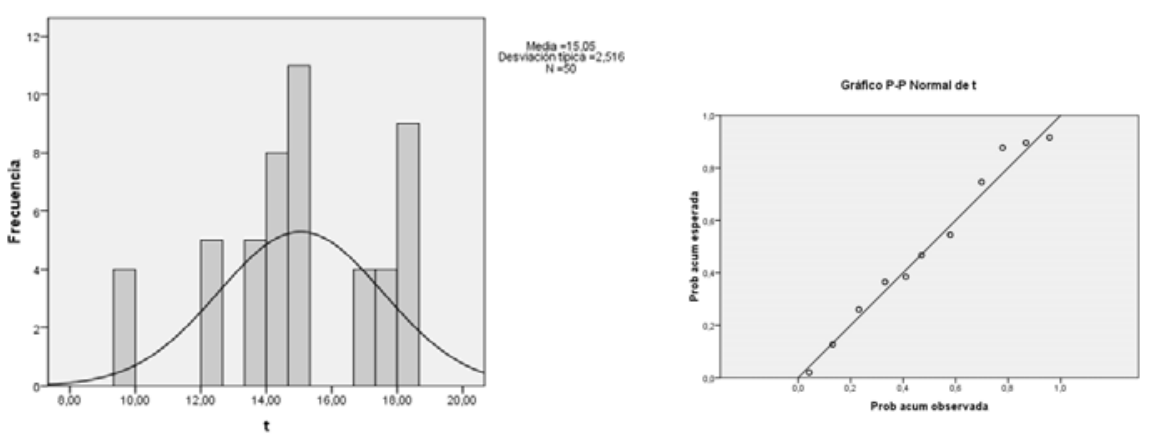

Humedad relativa media
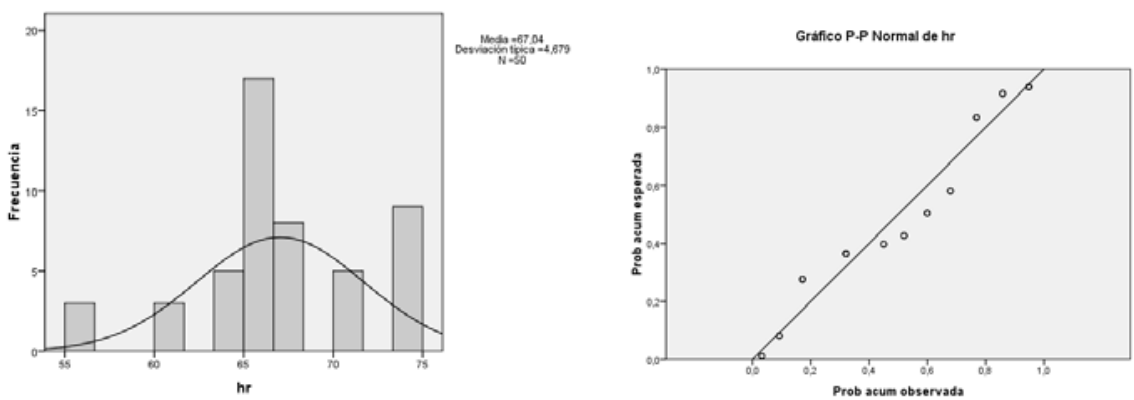
ANEXO 3

Inversión euros $/ \mathrm{m}^{2}$
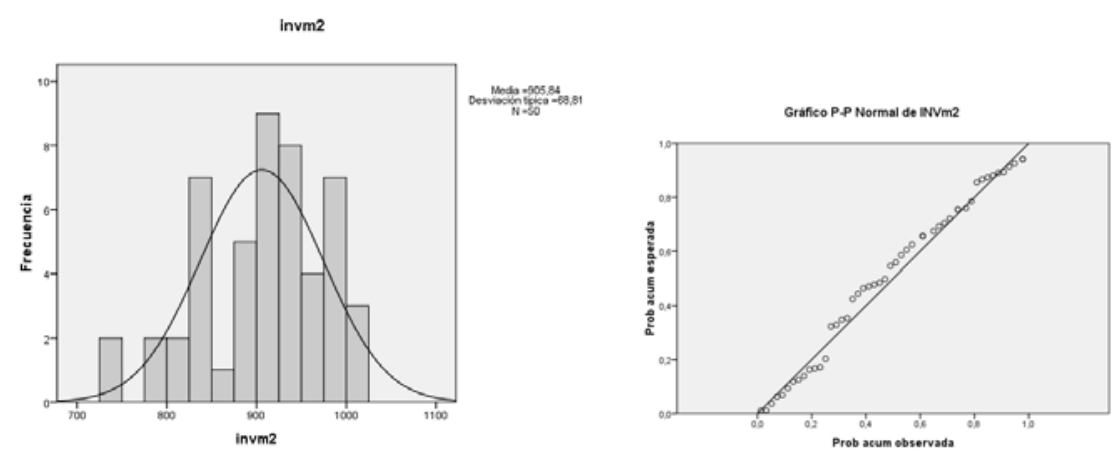

\section{2.- ANÁLISIS DE LOS RESIDUOS}

$\mathrm{KgCO}_{2}$
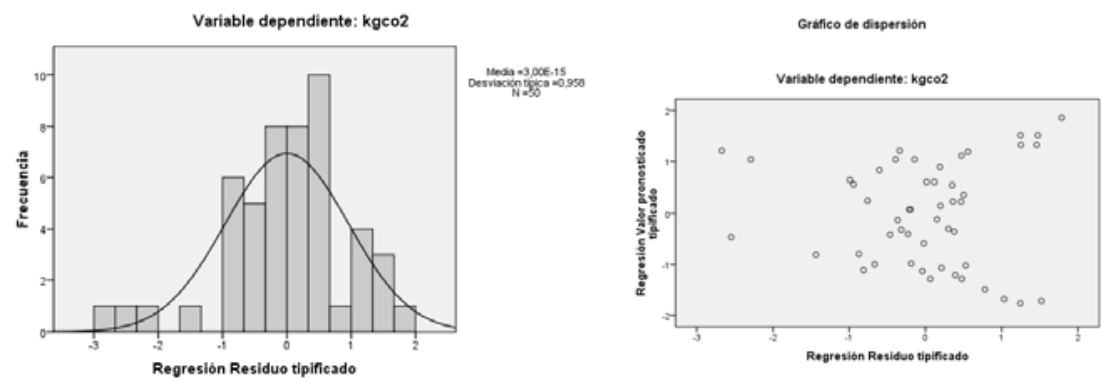

Amortización

Histograma
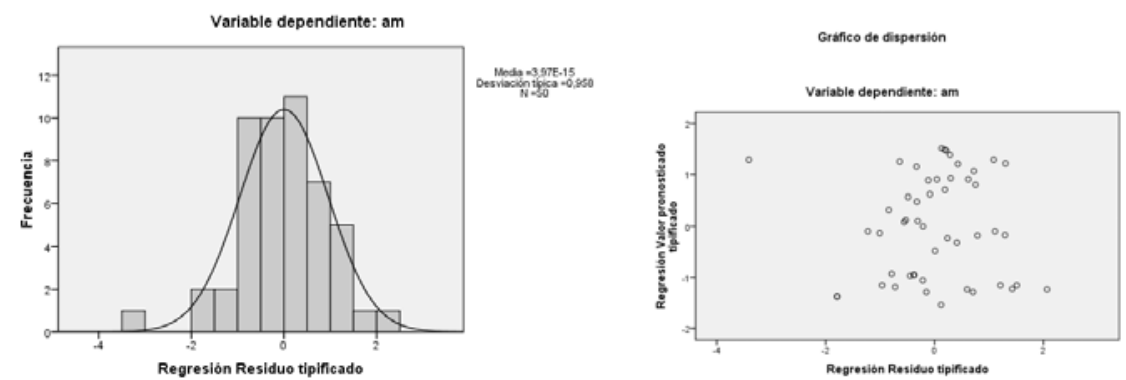

298 


\section{Energía}
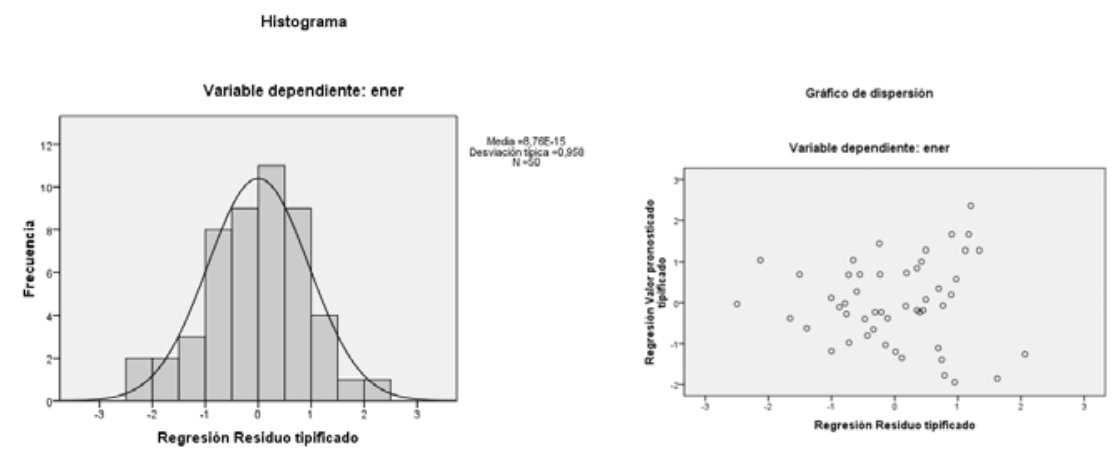

\section{Mantenimiento}

Histograma
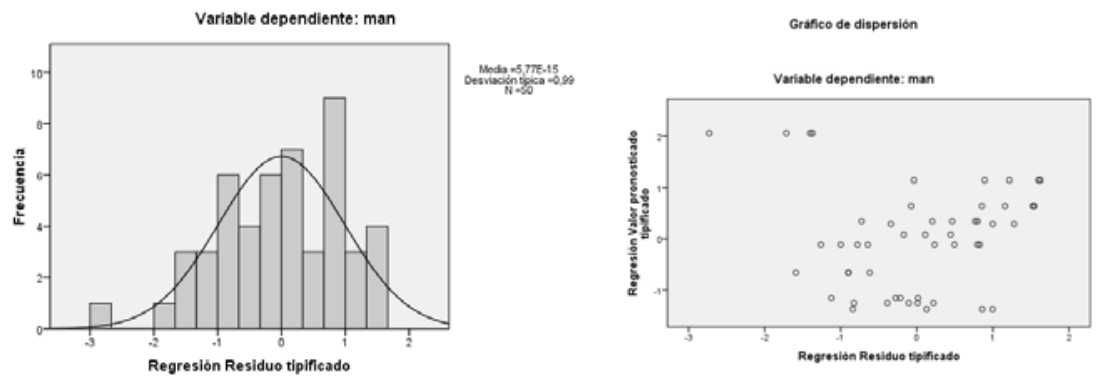

Invm $^{2}$

Histograma
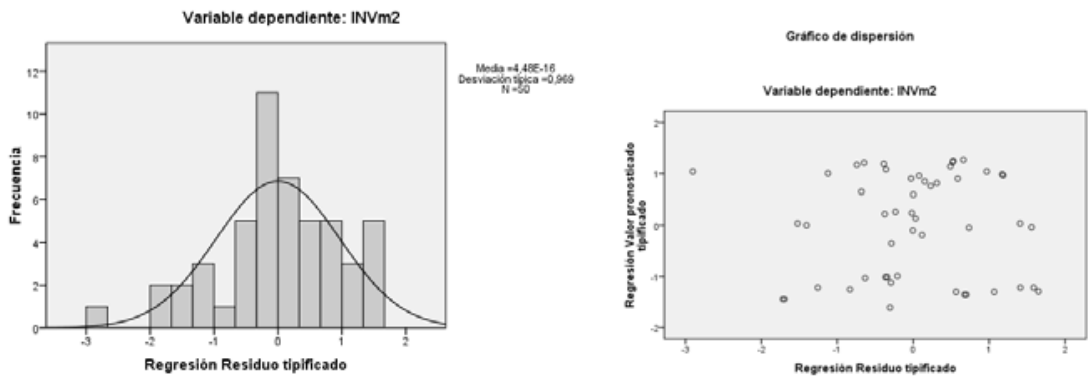
